PAULA MARIA NOGUEIRA AMBROGI

POLIMERIZAÇÃO DE ESTIRENO EM MINIEMULSÃO:

MONITORAMENTO EM LINHA USANDO ESPECTROSCOPIA DE INFRAVERMELHO PRÓXIMO E RAMAN E MODELAGEM MATEMÁTICA DO PROCESSO 
PAULA MARIA NOGUEIRA AMBROGI

\section{POLIMERIZAÇÃO DE ESTIRENO EM MINIEMULSÃO: MONITORAMENTO EM LINHA USANDO ESPECTROSCOPIA DE INFRAVERMELHO PRÓXIMO E RAMAN E MODELAGEM MATEMÁTICA DO PROCESSO}

Tese apresentada à Escola Politécnica da Universidade de São Paulo para obtenção do título de Doutora em Engenharia

Área de Concentração:

Engenharia Química

Orientador:

Prof. Dr. Reinaldo Giudici

São Paulo

2015 
PAULA MARIA NOGUEIRA AMBROGI

POLIMERIZAÇÃO DE ESTIRENO EM MINIEMULSÃO: MONITORAMENTO EM LINHA USANDO ESPECTROSCOPIA DE INFRAVERMELHO PRÓXIMO E RAMAN E MODELAGEM MATEMÁTICA DO PROCESSO

Tese apresentada à Escola Politécnica da Universidade de São Paulo para obtenção do título de Doutora em Engenharia

Área de Concentração:

Engenharia Química

Orientador:

Prof. Dr. Reinaldo Giudici 
Este exemplar foi revisado e alterado em relação à versão original, sob responsabilidade única do autor e com a anuência de seu orientador.

São Paulo, 01 de Julho de 2015.

Paula Maria Nogueira Ambrogi

Prof. Dr. Reinaldo Giudici

CATALOGAÇÃO-NA-PUBLICAÇÃO

Ambrogi, Paula Maria Nogueira

Polimerização de estireno em miniemulsão: monitoramento em linha usando espectroscopia de infravermelho próximo e Raman e modelagem matemática do processo/ P.M.N.

Ambrogi. -- São Paulo, 2015. 163p.

Tese (Doutorado) - Escola Politécnica da Universidade de São Paulo. Departamento de Engenharia Química.

1.Polímeros (Química orgânica) 2.Espectroscopia Raman 3.Espectroscopia NIR 4.Modelos matemáticos 5.Calibração multivariada I.Universidade de São Paulo. Escola Politécnica. Departamento de Engenharia Química Il.t. 


\section{DEDICATÓRIA}

Dedico este trabalho ao meu marido por todo incentivo e paciência durante essa longa fase da minha vida em que me dividi entre as diversas responsabilidades que assumi simultaneamente: filha, mãe, esposa, aluna e professora. Tenho certeza que muitas vezes a parte esposa ficou com a menor parte do meu tempo e nem por isso você me desestimulou a continuar. 


\section{AGRADECIMENTOS}

Ao professor Dro $^{\circ}$ Reinaldo Giudici pela confiança depositada em meu trabalho. Agradeço por ver hoje que muitas portas se abriram à minha frente porque algumas vezes o senhor me ajudou a caminhar até elas; outras vezes, me mostrou os caminhos e; outras vezes, me contou que os caminhos existiam e eu pude caminhar sozinha até elas. Isso foi consequência de todo o amadurecimento profissional que tive durante essa longa etapa da minha vida em que contei com sua orientação e me espelhei em seu exemplo de profissional competente.

Aos meus filhos, Mateus e Júlia, que pensam que vou virar médica quando terminar o doutorado!

À minha mãe que não se contém e sempre demonstra ter tanto orgulho de mim, mas que não reconhece o tamanho de sua responsabilidade e de sua contribuição desde o início de minha vida até aqui, seja com palavras de encorajamento ou com o seu exemplo de mãe, mulher e profissional que até hoje continua estudando e se especializando.

Ao meu pai, por me mostrar que responsabilidade, respeito e caráter não configuram a forma mais simples de viver e sim a mais gratificante e integra.

A minha amiga Maria Magdalena Cólman, por sua amizade e por todas as discussões poliméricas que tivemos ao longo desses longos e árduos anos que trabalhamos juntas e que sempre me vendo com inúmeras tarefas, nunca deixou de me dizer que tem horas que ter foco é a chave do sucesso.

À aluna de mestrado Cristiane Serra Serrano por sua contribuição em etapas específicas desse trabalho, executadas com qualidade e com responsabilidade. 
Ao "Santo" Paulo Firmino que está sempre pronto para ajudar a todos que o pedem auxilio. E como pedem! Tenho certeza que se não fosse pela sua boa vontade, pela sua paixão pelo trabalho e por seu empenho, muitos de nós alunos e professores, não conseguiríamos concluir nossos experimentos.

Aos queridos professores Adriano Rodrigues Azzoni, Ardson dos Santos Vianna Júnior, Cláudio Augusto Oller do Nascimento, Galo Antonio Carrillo Le Roux, Marcelo Martins Seckler, Maria Elena Santos Taqueda, Rita Maria de Brito Alves, Roberto Guardani e Song Won Park que me acompanharam mais de perto ao longo de toda minha história na POLI que começou em $1998 \mathrm{com}$ a graduação em Engenharia Química, seguida de mestrado (concluído em 2009) e doutorado (concluído em 2015). Se tudo der certo minha história aqui ainda não terminou!

Aos colegas do LSCP pela companhia e pela troca de informações.

Ao CNPq, pelo auxílio financeiro que possibilitou a execução desse trabalho.

E a todos aqueles que colaboraram direta ou indiretamente, na execução deste trabalho. 


\section{EPÍGRAFE}

"Por vezes sentimos que aquilo que fazemos não é senão uma gota de água no mar. Mas o mar seria menor se lhe faltasse uma gota".

Madre Teresa de Calcutá 


\section{RESUMO}

Neste trabalho estudou-se o processo de polimerização de estireno em miniemulsão, através do monitoramento in-line da conversão do monômero e do tamanho das partículas geradas durante o processo de polimerização, através das técnicas espectroscópicas de Infravermelho Próximo (Near Infra Red - NIR) e Raman. As medições off-line de conversão foram feitas através de gravimetria e do tamanho das partículas através de Espalhamento Dinâmico de Luz (Dynamic Light Scattering - DLS). Também foi objeto deste estudo a modelagem matemática do process de polimerização em miniemulsão, assim como sua simulação utilizando o programa Matlab. A metodologia adotada para a obtenção dos resultados envolveu o trabalho experimental de monitoramento da síntese de poliestireno em miniemulsão utilizando iniciador hidrossolúvel (persulfato de potássio), tensoativo (lauril sulfato de sódio) e co-estabilizantes (hexadecano e poliestireno) e equipamento rotor-estator, Ultra Turrax T25, para obtenção da miniemulsão. O modelo matemático envolveu a determinação de equações fenomenológicas representativas do sistema em questão, prevendo as possíveis variações na cinética e fenômenos físico-químicos, decorrentes de variações na formulação prevendo inclusive os mecanismos de nucleação existentes em função da concentração de tensoativo utilizado. Como resultado, este trabalho validou as metodologias avaliadas para monitoramento da conversão e diâmetro das partículas poliméricas e também, ao comparar as metodologias avaliadas, identificou a espectroscopia NIR como metodologia preferencial por não exigir preparação da amostra, fornecer respostas em tempo real, sem defasagem de tempo e também por permitir coletar espectros com pequenos intervalos de tempo, garante melhor precisão e evita a perda de informações do processo.

Palavras-chave: polimerização em miniemulsão, modelagem matemática, monitoramento em linha, monitoramento off-line, espectroscopia Raman, espectroscopia NIR. 


\section{ABSTRACT}

In this work, is the development of a detailed study of the miniemulsion polymerization process monitoring monomer conversion and particle size along process. Near Infrared Spectroscopy (Near Infra Red - NIR) and Raman Spectroscopy were used to conversion and diameter determination. Gravimetric analyses were used to conversion determination. Dynamic Light Scattering (Dynamic Light Scattering - DLS) to particle size determination. It was also object of this study the Mathematical Modeling of Miniemulsion Polymerization Reaction Kinetic, as well as it simulation using Matlab software.

The methodology used to obtain the results involved experimental work to synthesize and monitor miniemulsion polystyrene using water-soluble initiator (potassium persulfate), stabilizer (sodium lauryl sulfate) and co-stabilizers (hexadecane and polystyrene) and rotor-stator equipment Ultra Turrax T25 for miniemulsion obtaining. The mathematical model involved the determination of representative phenomenological equations this system, anticipating the possible variations in kinetics and physical-chemical phenomena, resulting from formulation variations mainly by verifying the surfactant concentration [S] to determine the existing nucleation mechanism when compared with the same surfactant critical micelle concentration [CMC]. The provided mechanisms are: micellar nucleation to $[\mathrm{S}] \geq[\mathrm{CMC}]$, droplets nucleation and homogeneous nucleation to $[\mathrm{S}]<[\mathrm{CMC}]$. As a result, this study validated the proposed methods for monitoring conversion and polymer particles diameter and also compare the evaluated methodologies, identifying NIR spectroscopy as a differential method among others for not to require sample preparation, supply answers in real time, no time delay and also to perform in shorter intervals, preventing the loss of process information.

Keywords: miniemulsion polymerization, mathematical modeling, in-line monitoring, off-line monitoring, Raman spectroscopy, NIR spectroscopy 


\section{LISTA DE TABELAS}

Tabela 1 - Comparação entre diferentes processos heterogêneos de polimerização...... 28

Tabela 2 - Diferenças entre polimerizações realizadas em meios heterogêneos............ 29 Tabela 3 - Diferenciação entre as três regiões da Espectroscopia do Infravermelho e

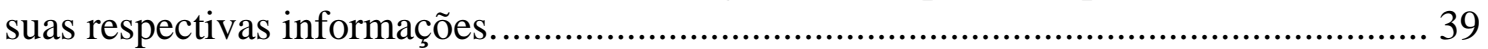

Tabela 4 - Aplicações possíveis da técnica de Espectroscopia de Infravermelho

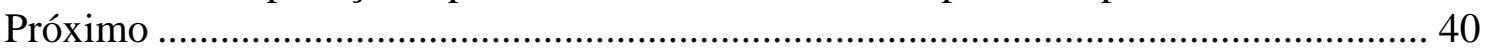

Tabela 5 - Comparação entre Espectroscopia NIR e Raman........................................ 40

Tabela 6 - Informações presentes nos espectros de NIR e Raman em reações de polimerização em meio heterogêneo. ....................................................................... 41

Tabela 7 - Picos característicos do estireno e poliestireno identificados através de

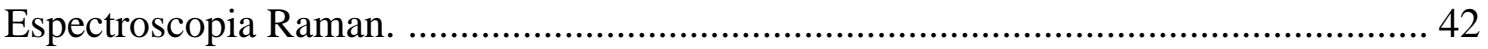

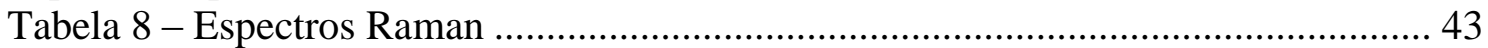

Tabela 9- Cinética de polimerização via radicais livres.............................................. 46

Tabela 10 - Tipo de nucleação em função da concentração de tensoativo ..................... 49

Tabela 11 - Definição das equações de concentração mássica de radicais poliméricos de

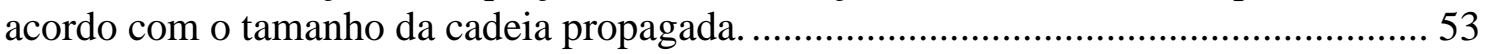

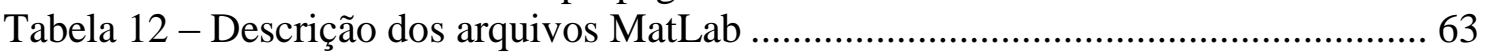

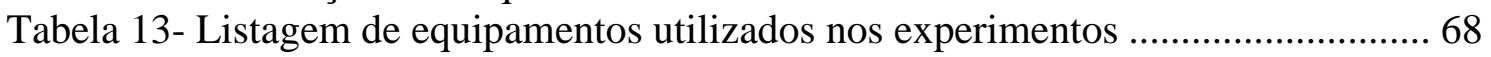

Tabela 14- Reagentes utilizados para polimerização em miniemulsão de estireno....... 70

Tabela 15 - Estrutura molecular dos principais reagentes ........................................... 70

Tabela 16 - Composição dos reagentes utilizados em cada experimento de miniemulsão

Tabela 17 - Planejamento Experimental: $2^{2}+$ duplicata do ponto central dos experimentos de preparação da miniemulsão........................................................... 75

Tabela 18 - Níveis mínimo, médio e máximo das variáveis, ......................................... 75

Tabela 19 - Condições operacionais das análises realizadas no Turbiscan .................... 76

Tabela 20 - Condições operacionais das análises realizadas no Equipamento de

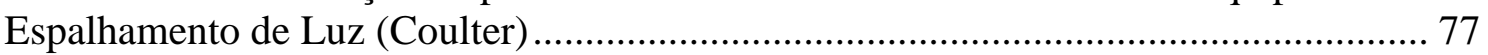

Tabela 21 - Set-up OPUS para NIR e Raman ............................................................ 79

Tabela 22 - Resumo das técnicas de monitoramento in-line ......................................... 82

Tabela 23 - Resumo das técnicas de monitoramento off-line........................................ 82

Tabela 24 - Composição da formulação da reação de polimerização em emulsão (em porcentagem mássica de cada componente) usada para produzir amostras com diferentes

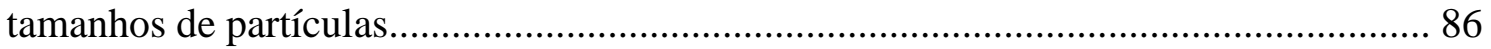

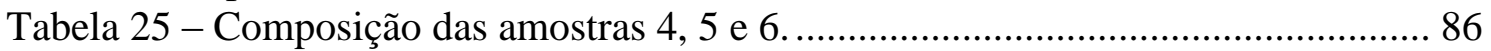

Tabela 26 - Composição das amostras preparadas com as amostras 1, 2 e 3................ 86

Tabela 27 - Teor de sólidos das amostras determinados por gravimetria......................8 87

Tabela 28 - Diluição das amostras 1E, 2E e 3E e teor de sólidos resultante. .................. 88

Tabela 29 - Variações no perfil de retroespalhamento de luz (BS) para cada tipo de

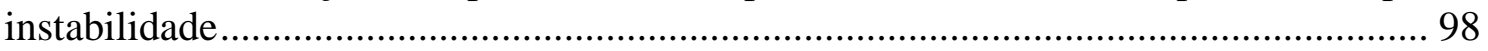

Tabela 30 - identificação entre tratamentos espectrais utilizados para calibração de modelo multivariado para determinação da conversão da reação.............................. 109

Tabela 31 - Identificação dos tratamentos realizados nos espectros Raman ................ 120

Tabela 32 - Valores de constantes e parâmetros utilizados na simulação ..................... 124 


\section{LISTA DE FIGURAS}

Figura 1 - Número de publicações em polimerização em miniemulsão desde 1996 até

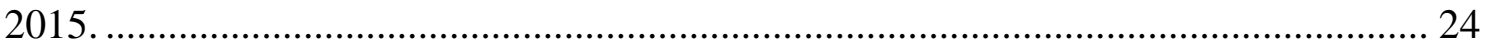

Figura 2- Esquema de classificação dos diferentes mecanismos de polimerização ...... 26

Figura 3 - Esquema de classificação dos diferentes meios de polimerização ................. 26 Figura 4 - Taxa de polimerização em função da conversão para polimerização em

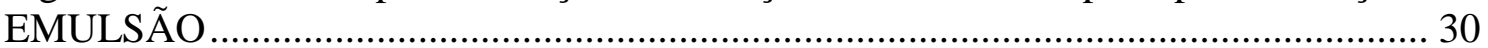

Figura 5 - Taxa de polimerização em função da conversão para polimerização em

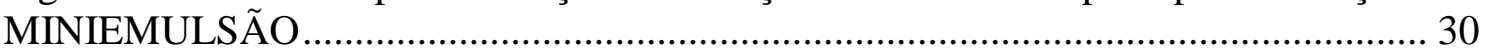

Figura 6 - Taxa de polimerização em função da conversão para polimerização em

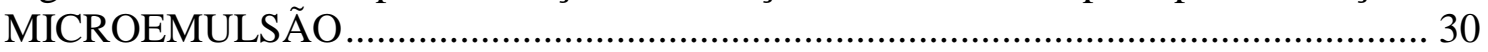

Figura 7 - Mecanismos utilizados para preparação da miniemulsão monomérica. (a)Ultrassom, (b) Rotor-estator e (c) Homogenizador de alta pressão. .......................... 31

Figura 8 - Principais fenômenos que geram instabilidade nas miniemulsões ................ 32 Figura 9 - Variação do potencial químico para monômero puro em função do raio da

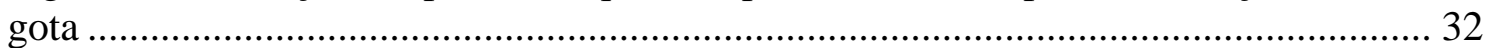

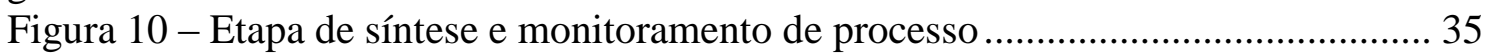

Figura 11 - Processos de desestabilização que uma emulsão pode sofrer....................... 38

Figura 12 - Esquema ilustrativo do Turbiscan com sua fonte de luz e seus dois sensores

Figura 13 - Espectro NIR com indicação da região de espalhamento para determinação de propriedades físicas e região de absorbância, para determinação de propriedades da

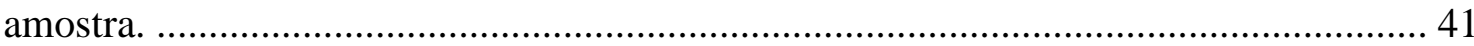

Figura 14 - Sequência para determinação do mecanismo de nucleação ........................ 57

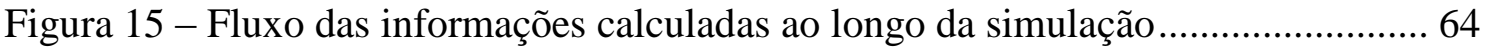

Figura 16- Esquema ilustrativo da $1^{\text {a }}$ Abordagem - Monitoramento e Síntese ............... 65

Figura 17 - Esquema ilustrativo da 2a Abordagem - Modelagem e Simulação ............. 66

Figura 18 - Unidade Experimental para Polimerização em Miniemulsão...................... 67

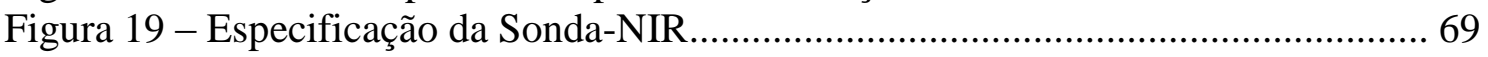

Figura 20 - Preparação da Miniemulsão de Estireno com Ultra Turrax.......................... 71

Figura 21 - Esquema da Etapa 1 para preparação da miniemulsão monomérica............ 74

Figura 22 - Esquema da Etapa 2 para preparação da miniemulsão monomérica........... 74

Figura 23 - Avaliação da estabilidade da miniemulsão monomérica ........................... 76

Figura 24 - Frasco de Amostra utilizado no Turbiscan Lab ........................................... 76

Figura 25 - Esquema da Etapa 3 para polimerização da miniemulsão monomérica...... 78

Figura 26 - Esquema de aplicação de análise de componentes principais..................... 79

Figura 27 - Esquema representativo da análise gravimétrica .................................... 83

Figura 28 - Distribuição de diâmetros das amostras 1E, amostra $2 \mathrm{E}$ e amostra $4 \mathrm{E}$ que é composta por $50 \%$ vol amostra $1 \mathrm{E}+50 \%$ vol amostra $2 \mathrm{E}$......................................... 90

Figura 29 - Distribuição de diâmetros das amostras $1 \mathrm{E}$, amostra $3 \mathrm{E}$ e amostra $5 \mathrm{E}$ que é

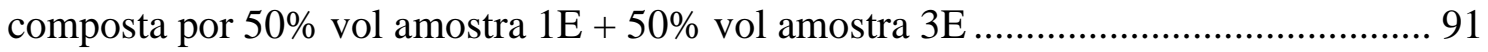
Figura 30 - Distribuição de diâmetros das amostras 2E, amostra $3 \mathrm{E}$ e amostra $6 \mathrm{E}$ que é

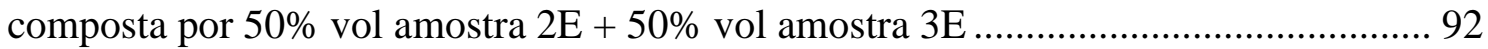
Figura 31 - comparação entre os diâmetros calculados e medidos para as amostras 4E,

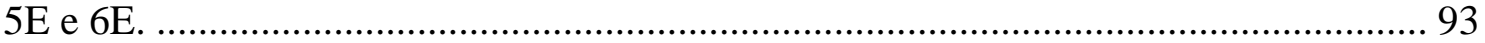
Figura 32- Desvio entre os diâmetros calculados e os diâmetros medidos para as

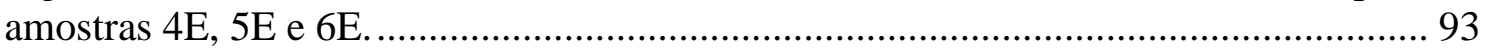
Figura 33 - Relação entre teor de tensoativo da formulação e diâmetro médio de

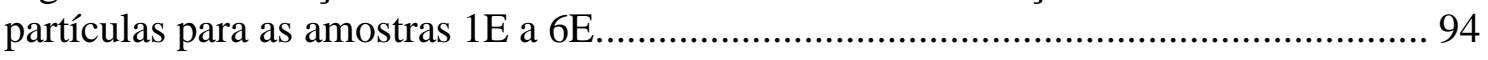


Figura 34 - Variação da polidispersidade em função da velocidade de agitação .......... 95

Figura 35 - Variação da polidispersidade em função do tempo de agitação ................... 95 Figura 36 - Variação do diâmetro médio das gotas em função da velocidade de agitação

Figura 37 - Variação do diâmetro médio das gotas em função do tempo de agitação .. 95 Figura 38 - Variação no índice de estabilidade da miniemulsão monomérica em função da velocidade de agitação

Figura 39 - Variação no índice de estabilidade da miniemulsão monomérica em função do tempo de agitação

Figura 40 - Variação no diâmetro médio das partículas durante teste de estabilidade.. 97 Figura 41 - Diagrama para interpretação do retroespalhamento de luz (BS) e

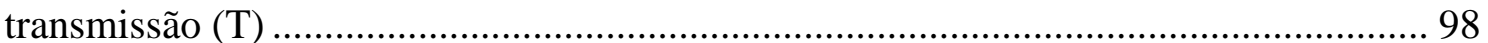

Figura 42 - Variação do Backscattering da Amostra Mini_06 ao longo do tempo. .... 100 Figura 43 - Variação do Backscattering da Amostra Mini_07 ao longo do tempo. .... 100 Figura 44 - Variação do Backscattering da Amostra Mini_08 ao longo do tempo. .... 100 Figura 45 - Variação do Backscattering da Amostra Mini_09 ao longo do tempo. .... 100 Figura 46 - Variação do Backscattering da Amostra Mini_10 ao longo do tempo. .... 100 Figura 47 - Variação do Backscattering da Amostra Mini_11 ao longo do tempo. .... 100 Figura 48 - Variação de Backscattering no TOPO das amostras ao longo do tempo.. 101 Figura 49 - Variação de Backscattering no FUNDO das amostras ao longo do tempo.

Figura 50 - Variação de Backscattering GLOBAL ao longo do tempo...................... 101 Figura 51 - Comparação entre a variação de Backscattering para todas as amostras do DOE após 120 minutos em estabilidade................................................................. 101 Figura 52 - Espectro NIR Mini_03 em 3 dimensões: (x) número de onda, (y) intensidade e (z) ordem cronológica das amostras. ................................................... 102 Figura 53 - Ilustração do volume iluminado pelo laser em (a) meio heterogêneo e (b) em meio homogêneo.

Figura 54 - Comparação entre conversão calculada pelo modelo com conversão

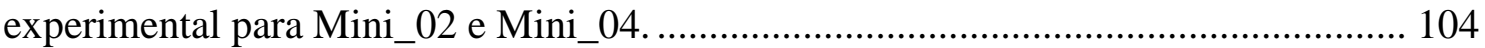
Figura 55 - Análise dos componentes principais para o modelo de calibração obtido

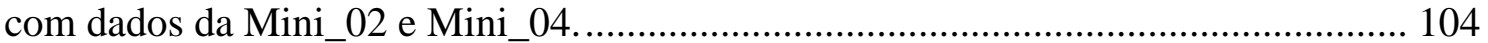
Figura 56 - Validação interna da conversão com dados da Mini_02 e Mini_04......... 104 Figura 57 - Análise dos componentes principais para a validação interna do modelo de calibração obtido com dados da Mini_02 e Mini_04.................................................... 104 Figura 58 - Validação externa do modelo de calibração com dados da Mini_01 ........ 104 Figura 59 - Validação externa do modelo de calibração com dados da Mini_03 ........ 104 Figura 60 - Comparação entre diâmetro calculada pelo modelo com diâmetro

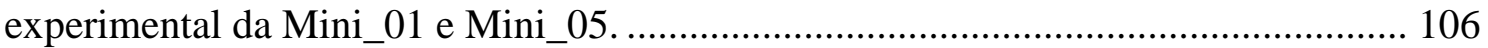
Figura 61 - Análise dos componentes principais para o modelo de calibração obtido com

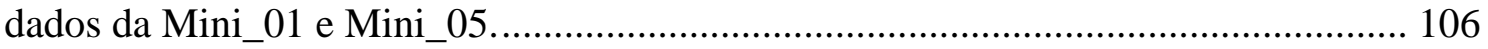
Figura 62 - Validação interna do modelo de diâmetro com dados da Mini_01 e Mini_05. 106

Figura 63 - Análise dos componentes principais para a validação interna do modelo de calibração obtido com dados da Mini_01 e Mini_05. .................................................. 106 Figura 64 - Validação externa do modelo de calibração com dados da Mini_02........ 106 Figura 65 - Validação externa do modelo de calibração com dados da Mini_04........ 106 Figura 66 - Monitoramento da temperatura de reação em função do tempo................ 107 Figura 67 - Monitoramento da temperatura de reação em função da conversão. ......... 107 Figura 68 - Evolução da conversão da reação medida por gravimetria ........................ 108 
Figura 69 - Conversão determinada por Espectroscopia Raman através do método

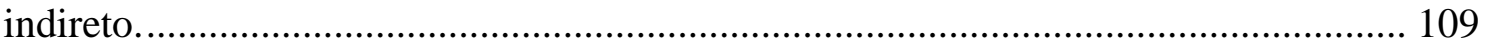

Figura 70 - Intensidade Raman da amostra Mini_02 em 3D................................... 110

Figura 71 - Intensidade Raman da amostra Mini_02 em 2D........................................ 110

Figura 72 - Intensidade Raman da amostra Mini_03 em 3D........................................ 111

Figura 73 - Intensidade Raman da amostra Mini_03 em 2D...................................... 111

Figura 74 - Conversão da reação determinada por Raman através do método direto. 112

Figura 75 - Comparação entre as conversões determinadas através de Gravimetria, área dos espectros de Raman e Modelos de Calibração obtidos dos espectros de Raman para

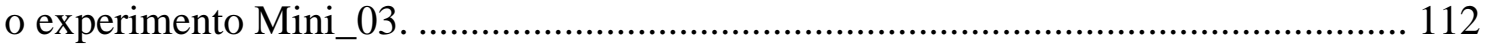

Figura 76 - Comparação entre a conversão obtida por gravimetria e por Raman, pelo método direto para o experimento Mini_03 ........................................................ 112

Figura 77 - Evolução do diâmetro médio de partículas ao longo das reações .............. 113

Figura 78- Taxa de variação do diâmetro médio de partículas ao longo das reações.. 113

Figura 79 - Distribuição de diâmetro de partículas para Mini_01 em t=zero ............... 115

Figura 80 - Distribuição de diâmetro de partículas para Mini_01 em t=final ............... 115

Figura 81 - Distribuição de diâmetro de partículas para Mini_02 em t=zero ............... 116

Figura 82 - Distribuição de diâmetro de partículas para Mini_02 em t=106 min........ 116

Figura 83 - Distribuição de diâmetro de partículas para Mini_03 em t=zero ............... 117

Figura 84 - Distribuição de diâmetro de partículas para Mini_03 em t=final ............... 117

Figura 85- Variação do número de partículas $(\mathrm{Np})$ em função do tempo ..................... 118

Figura 86 - Variação do número de partículas $(\mathrm{Np})$ em função da conversão .............. 118

Figura 87 - Diâmetro versus conversão global ......................................................... 119

Figura 88 - Diâmetro versus conversão Mini_01 ........................................................ 119

Figura 89 - Diâmetro versus conversão Mini_02 ......................................................... 119

Figura 90 - Diâmetro versus conversão Mini_03 ......................................................... 119

Figura 91 - Diâmetro versus conversão Mini_04 ......................................................... 119

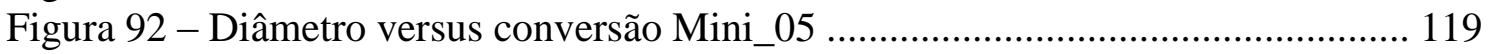

Figura 93 - Variação da razão Np/Ng para Mini_02 em função do tempo................... 120

Figura 94 - Variação da razão Np/Ng para Mini_03 em função do tempo.................... 120

Figura 95 - Variação da razão Np/Ng em função do tempo........................................ 120

Figura 96 - Variação da razão Np/Ng em função da conversão.................................... 120

Figura 97 - Comparação entre os diâmetros de partículas avaliados através do Espalhamento de Luz e calculados através de Modelos de Calibração obtidos dos espectros de Raman para o experimento Mini_3 .......................................................... 121

Figura 98 - Taxa de polimerização em função da conversão para polimerização em

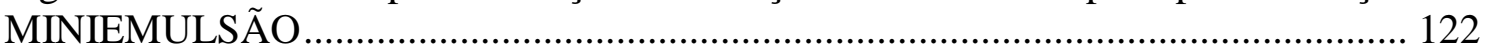

Figura 99 - Taxa de polimerização versus conversão Mini_03 ................................. 122

Figura 100 - Taxa de polimerização referência para polimerização em EMULSÃO.. 122

Figura 101 - Taxa de polimerização versus conversão Mini_04 …............................. 122

Figura 102 - Taxa de polimerização versus conversão global ................................... 123

Figura 103 - Taxa de polimerização versus conversão Mini_01 ................................. 123

Figura 104 - Taxa de polimerização versus conversão Mini_02 …............................. 123

Figura 105 - Taxa de polimerização versus conversão Mini_05 …............................. 123

Figura 106 - Conversão em função do tempo, calculada pelo modelo matemático

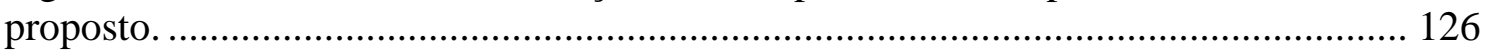

Figura 107 - Conversão em função do tempo, obtida por experimentalmente por Gravimetria para os experimentos Mini 2 e 3 e, por Raman para os experimentos Mini 1,4 e 5 . 
Figura 108 - Comparação entre conversão experimental e calculada em função do tempo para a Mini_01.

Figura 109 - Comparação entre conversão experimental e calculada em função do tempo

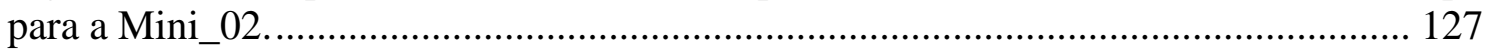

Figura 110 - Comparação entre conversão experimental e calculada em função do tempo

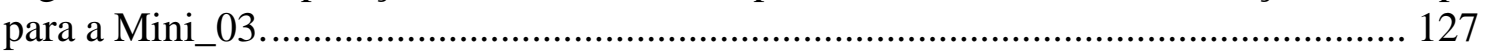
Figura 111 - Comparação entre conversão experimental e calculada em função do tempo para a Mini_04.

Figura 112 - Comparação entre conversão experimental e calculada em função do tempo para a Mini_05......

Figura 113 - Diâmetro em função do tempo, calculada pelo modelo matemático

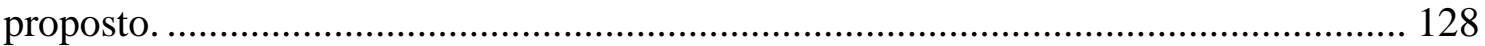

Figura 114 - Diâmetro em função do tempo, obtida por experimentalmente por

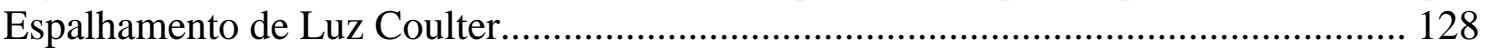

Figura 115 - Comparação entre diâmetro experimental e calculado em função do tempo

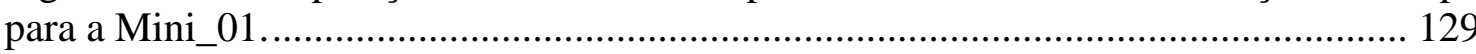

Figura 116 - Comparação entre diâmetro experimental e calculado em função do tempo para a Mini_02.

Figura 117 - Comparação entre diâmetro experimental e calculado em função do tempo para a Mini_03....

Figura 118 - Comparação entre diâmetro experimental e calculado em função do tempo para a Mini_04....

Figura 119 - Comparação entre diâmetro experimental e calculado em função do tempo

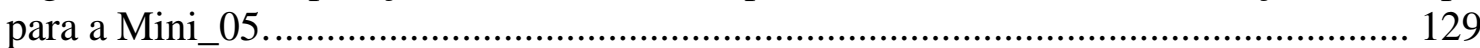

Figura 120 - Número médio de radicais por partícula em função do tempo ................ 130

Figura 121- Número médio de radicais por partícula em função da conversão ............ 130

Figura 122 - Concentração de monômero na fase contínua em função do tempo........ 131

Figura 123 - Concentração de radicais poliméricos que podem entrar nas partículas ou micelas em função do tempo ................................................................................. 131

Figura 124 - Concentração de monômero na fase dispersa em função do tempo......... 131

Figura 125 - Concentração de polímero na fase dispersa em função do tempo ........... 131

Figura 126 - Fator para o efeito gel em função do tempo............................................ 132

Figura 127 - Fator para o efeito gel em função da conversão..................................... 132

Figura 128- Fator para o efeito vítreo em função do tempo ...................................... 132

Figura 129- Fator para o efeito vítreo em função da conversão .................................. 132

Figura 130 - Número de partículas que sofreram nucleação homogênea em função do

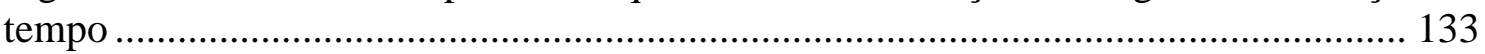

Figura 131 - Número de partículas que sofreram nucleação micelar em função do tempo

Figura 132 - Comparação entre os métodos para determinação da conversão da Mini_03

Figura 133 - Comparação entre os métodos para determinação do diâmetro da Mini_03 


\section{LISTA DE ABREVIATURAS E SIGLAS LATINAS}

\begin{tabular}{|c|c|}
\hline$A^{i}$ & Concentração molar de monômero na fase aquosa \\
\hline$A_{p t}$ & Área superficial total de todas as partículas poliméricas \\
\hline$D_{p}$ & Diâmetro médio das partículas poliméricas obtidas ao final da polimerização \\
\hline$D_{w}$ & Difusividade do monômero em água \\
\hline$E_{C M C}$ & Concentração micelar crítica \\
\hline$E_{\text {ads }}$ & Concentração de tensoativo adsorvido nas partículas \\
\hline$E_{a d s}^{s a t}$ & Concentração de saturação \\
\hline$E^{i}$ & Concentração mássica de tensoativo na fase contínua \\
\hline$E^{\text {total }}$ & Concentração mássica de tensoativo no reator \\
\hline$K^{p}$ & Coeficiente de partição \\
\hline$M W_{o}$ & Concentração mássica do monômero no reator no instante inicial \\
\hline$M W_{t}$ & Concentração mássica do monômero no reator no instante tempo t \\
\hline$M^{\text {alimentado }}$ & Concentração Mássica de Monômero alimentado no reator \\
\hline$M^{i}$ & Concentração mássica de monômero na fase contínua \\
\hline$M^{i i}$ & Concentração Mássica de Monômero na fase dispersa \\
\hline$N_{a}$ & Número de Avogadro \\
\hline$N_{m i c}$ & Número total de micelas no reator \\
\hline$N_{p}$ & Número de partículas \\
\hline$P M_{E}$ & Peso molecular do tensoativo \\
\hline$P^{i i}$ & Concentração mássica de polímero na fase dispersa \\
\hline$R_{1}$ & Concentração mássica de radicais com um único mero \\
\hline$R_{m}$ & Raio das micelas \\
\hline$R_{\text {pinch }}$ & Raio da partícula inchada \\
\hline$R_{\text {podem entrar }}=R_{T}^{e n t}$ & $\begin{array}{l}\text { Concentração mássica de radicais que podem entrar em uma partícula ou } \\
\text { micela }\end{array}$ \\
\hline$R_{\text {tot }}$ & Concentração mássica total de radicais \\
\hline$T_{g m}$ & Temperatura de transição vítrea do monômero \\
\hline$T_{g p}$ & Temperatura de transição vítrea do polímero \\
\hline$V^{i}$ & Volume da fase contínua \\
\hline$V^{i i}$ & Volume da fase dispersa \\
\hline$V_{r}$ & Volume do reator \\
\hline
\end{tabular}




\begin{tabular}{|c|c|}
\hline$W^{i}$ & Concentração Mássica de Água na fase contínua \\
\hline$a_{s}$ & Área superficial coberta por uma molécula de tensoativo \\
\hline$f_{a m}$ & Fator de ajuste da equação $k_{a m}$ \\
\hline$f_{k e}$ & Fator de ajuste da equação $k_{e}$ \\
\hline$f_{m i c}$ & Número de moléculas de tensoativo por micela \\
\hline$g_{p}$ & Fator para o efeito vítreo \\
\hline$g_{t}$ & Fator para o efeito gel \\
\hline$k^{\prime}$ & Coeficiente de adsorção de tensoativo pelas partículas \\
\hline$k_{a m}$ & Coeficiente de absorção de radicais pela micela \\
\hline$k_{d}$ & Constante cinética de decomposição do iniciador \\
\hline$k_{e}$ & Coeficiente de entrada de radicais pela micela \\
\hline$k_{f}$ & Constante cinética de transferência de cadeia \\
\hline$k_{p}^{0}$ & Constante cinética de propagação inicial \\
\hline$k_{p}^{i}$ & Constante cinética de propagação na fase contínua \\
\hline$k_{p}^{i i}$ & Constante cinética de propagação do monômero na fase dispersa \\
\hline$k_{t}$ & Constante cinética de terminação \\
\hline$k_{t}^{0}$ & Constante cinética de terminação inicial \\
\hline$k_{t}^{i}$ & Constante cinética de terminação na fase contínua \\
\hline$m_{I}$ & Massa de iniciador \\
\hline$\tilde{n}$ & Número médio de radicais por partícula \\
\hline$v_{f}$ & Volume livre \\
\hline$v_{f c r 2}$ & Fração de volume livre crítica \\
\hline$v_{m}$ & Volume de monômero \\
\hline$v_{p}$ & Volume de polímero \\
\hline$v_{r}$ & Volume do reator \\
\hline B & Constante \\
\hline $\mathrm{E}$ & Concentração Mássica de Tensoativo \\
\hline $\mathrm{f}$ & Fator de eficiência da decomposição térmica do iniciador \\
\hline$h$ & Identifica o tamanho do radical \\
\hline $\mathrm{i}$ & Identifica dados referentes à fase contínua \\
\hline I & Concentração Mássica de Iniciador \\
\hline ii & Identifica dados referentes à fase dispersa \\
\hline
\end{tabular}


Concentração Mássica de Monômero

$\mathrm{R}$

Concentração de radicais nas partículas.

$\mathrm{T}$

Temperatura do reator

W

Concentração Mássica de Água

W

Concentração mássica de água no reator

$\mathrm{X}$

Conversão de monômero

$\mathrm{NucHo}$

Número de partículas que sofreram nucleação homogênea

NucMi

Número de partículas que sofreram nucleação micelar

NucTot

Número total de partículas que sofreram nucleação

jcrit

Tamanho do maior radical presente na fase aquosa

$Z$

Tamanho do menor radical que pode entrar em uma micela ou partícula 


\section{LISTA DE ABREVIATURAS E SIGLAS GREGAS}

$\Phi_{p}$

$\alpha$

$\alpha_{P}$

$\alpha_{g}$

$\alpha_{l}$

$\alpha_{m}$

$\beta_{E}$

$\rho_{P}$

$\rho_{a n}$

$\rho_{c o}$

$\rho_{w}$
Fração de área recoberta pelo tensoativo

Densidade do monômero

Fração volumétrica de polímeros nas partículas

$\alpha_{l}-\alpha_{g}$

Coeficiente de expansão do polímero

Coeficiente de expansão para o estado vítreo

Coeficiente de expansão para o estado líquido

Coeficiente de expansão do monômero

Massa de tensoativo por micela

Densidade do polímero

Densidade do agente nuclear

Densidade do co-etabilizante

Densidade da água 


\section{SUMÁRIO}

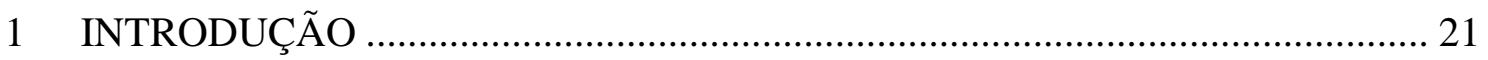

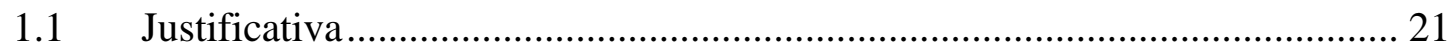

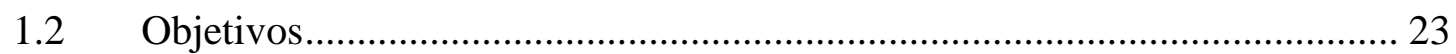

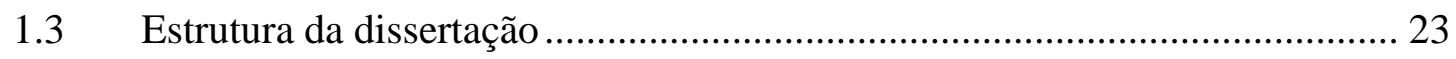

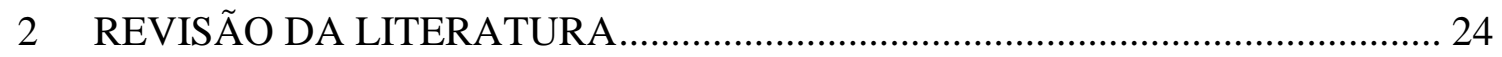

2.1 Polimerização em Miniemulsão via Radicais Livres ................................... 25

2.2 Miniemulsões Monoméricas ....................................................................... 30

2.3 Monitoramento in-line, on-line e off-line................................................... 33

2.3.1 Espalhamento de Luz........................................................................... 35

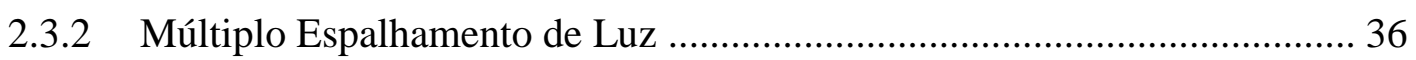

2.3.3 Espectroscopia de Infravermelho Próximo............................................... 39

2.3.4 Espectroscopia Raman........................................................................... 41

2.4 Modelagem da Cinética de polimerização em miniemulsão .......................... 44

3 MODELO MATEMÁTICO DO PROCESSO DE POLIMERIZAÇÃO EM

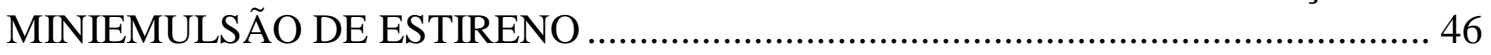

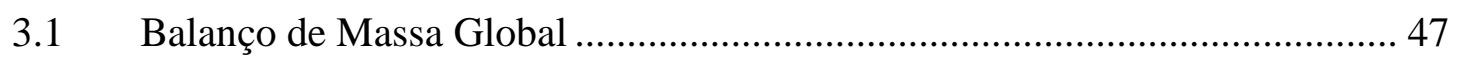

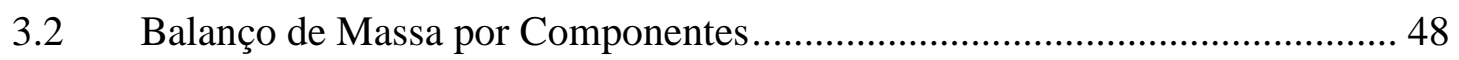

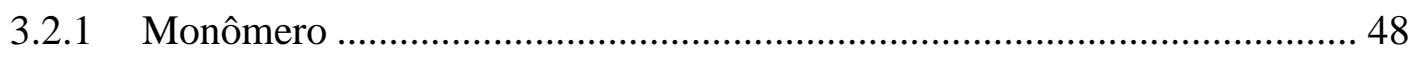

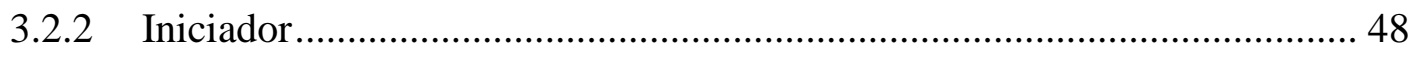

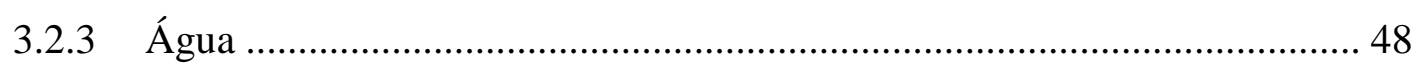

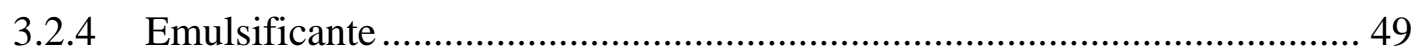

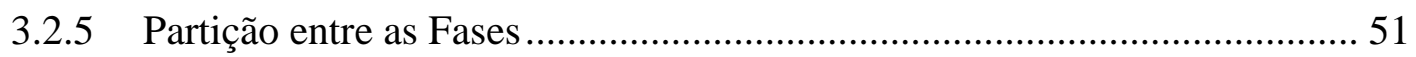

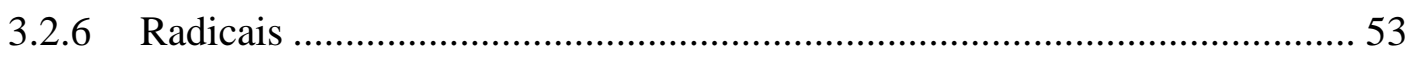

3.2.7 Balanço dos radicais no meio contínuo ................................................ 54

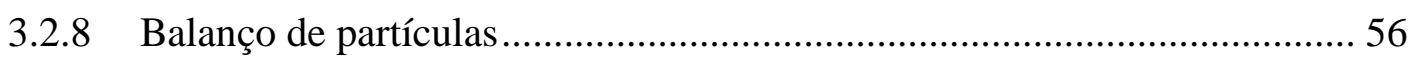

3.2.9 Número médio de radicais por partícula................................................... 59

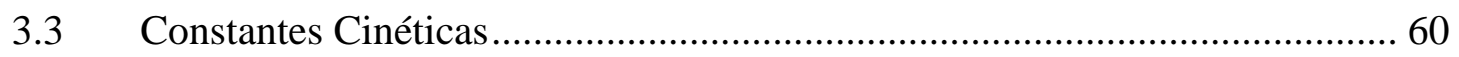

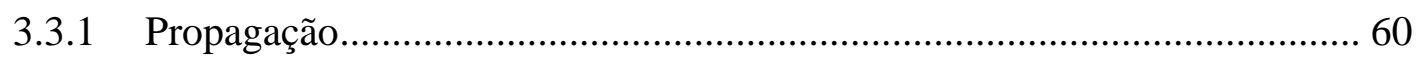

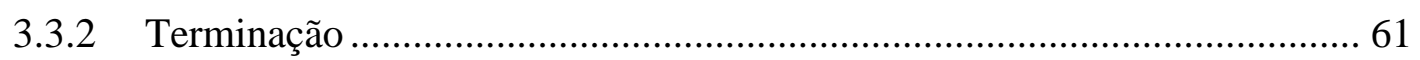

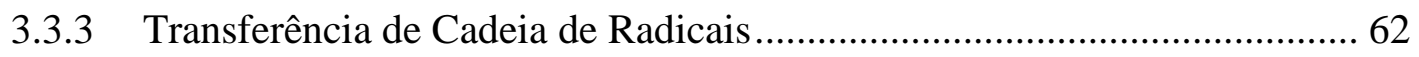

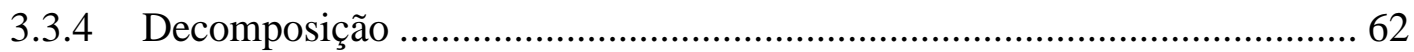




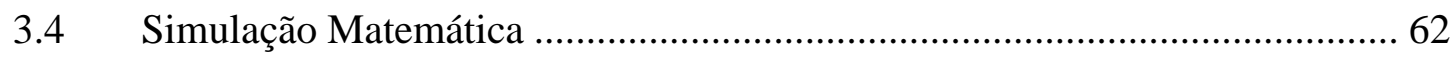

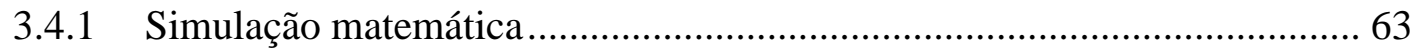

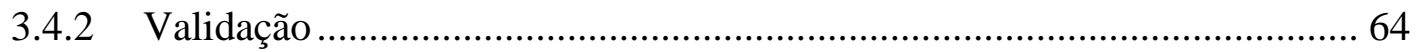

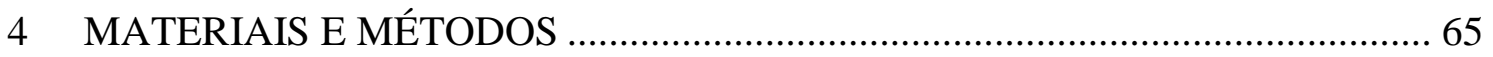

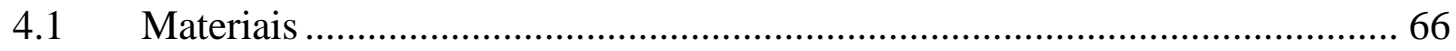

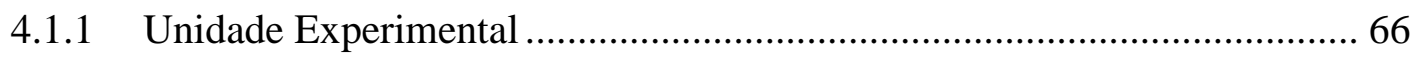

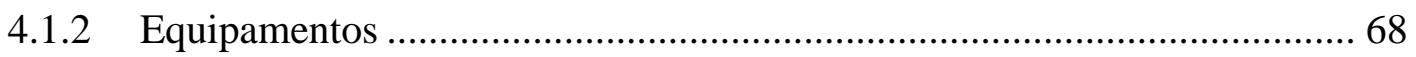

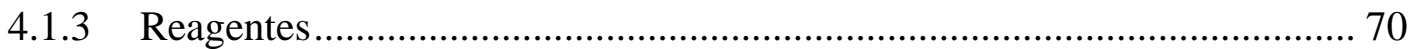

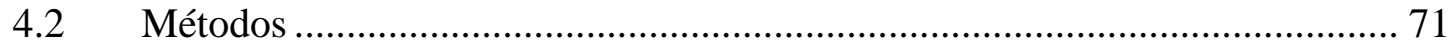

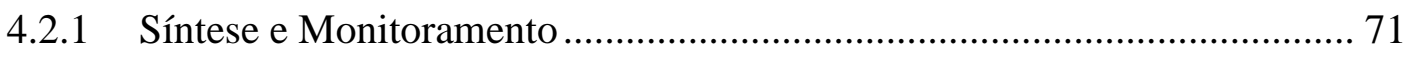

4.2.1.1 Definição de Condições Operacionais .......................................... 71

4.2.1.1.1 Condições Operacionais - Miniemulsão ...................................... 71

4.2.1.1.2 Condições Operacionais - Polimerização ................................... 72

4.2.1.2 Definição da Formulação ............................................................. 72

4.2.1.3 Preparo da Miniemulsão............................................................... 73

4.2.1.4 Delineamento dos experimentos ................................................ 74

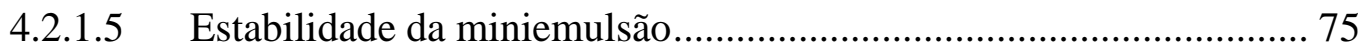

4.2.1.6 Síntese - Polimerização .............................................................. 77

4.2.1.7 Monitoramento do processo - in line.......................................... 78

4.2.1.7.1 Espectroscopia NIR ....................................................... 78

4.2.1.8 Monitoramento do processo - off-line. ........................................ 82

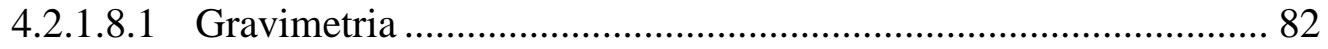

4.2.1.8.2 Espectroscopia Raman .......................................................... 84

4.2.1.8.3 Espalhamento de Luz ......................................................... 85

4.2.2 Avaliação preliminar das técnicas ......................................................... 85

4.2.2.1 Multimodalidade x Espalhamento de Luz...................................... 86

4.2.2.2 Teor de Polímero x Espectroscopia NIR e Raman............................ 87

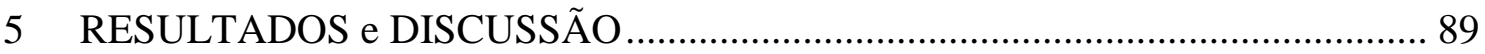

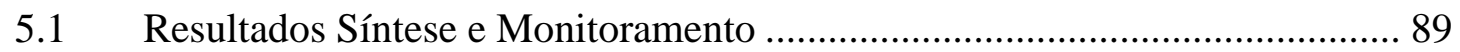


5.1.1 Avaliação Preliminar da Bimodalidade da Distribuição de Tamanhos das

Partículas 89

5.1.2 Resultados - Miniemulsão 96

5.1.2.1 Influência das Condições de Processo na Miniemulsão Monomérica 96

5.1.3 Estabilidade das Miniemulsões Monoméricas 96

5.1.3.1 Avaliação da Estabilidade pela Variação do Diâmetro Médio das Gotas 96

5.1.3.2 Estabilidade por Retro espalhamento de Luz. 97

5.1.4 Resultados - Polimerização .............................................................. 101

5.1.4.1 Monitoramento do processo - in line........................................... 101

5.1.4.1.1 Conversão (Espectroscopia NIR) ............................................ 102

5.1.4.1.2 Diâmetro de partículas (Espectroscopia NIR) ........................... 105

5.1.4.1.3 Temperatura de Reação (Termopar) ........................................ 105

5.1.4.2 Monitoramento do processo - off line ....................................... 107

5.1.4.2.1 Conversão (Gravimetria) ......................................................... 107

5.1.4.2.2 Conversão (Espectroscopia Raman) ........................................ 108

5.1.4.2.2.1 Método Indireto - Calibração Multivariada ............................ 108

5.1.4.2.2.2 Método Direto - Áreas dos Espectros .................................... 109

5.1.4.2.3 Diâmetro de partículas ............................................................... 113

5.1.4.2.4 Diâmetro de partículas (Espectroscopia Raman) ....................... 120

5.1.4.3 Avaliação da Taxa de Polimerização ............................................. 121

5.2 Resultados Modelagem e Simulação ........................................................ 123

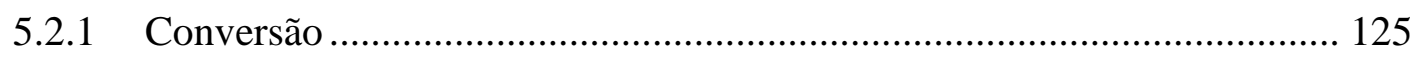

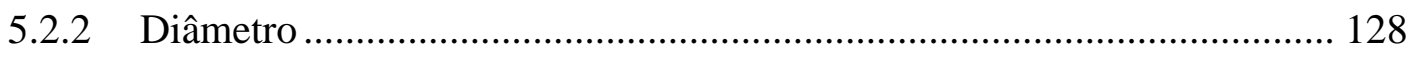

5.2.3 Numero médio de radicais por partícula................................................ 130

5.2.4 Concentração de Monômero nas fases contínua e dispersa....................... 130

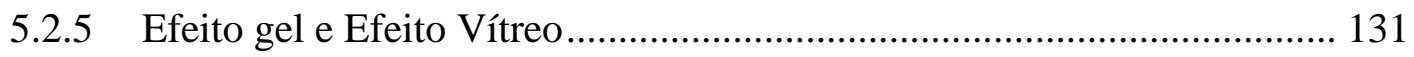

5.2.6 Nucleação Homogênea e Nucleação Micelar .......................................... 133

5.3 Comparação entre os Métodos de Monitoramento \& Modelagem e Simulação 133 
6 CONCLUSÕES.

135

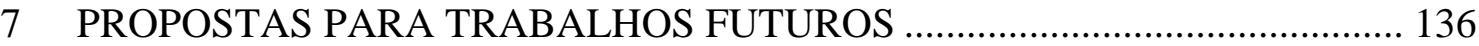

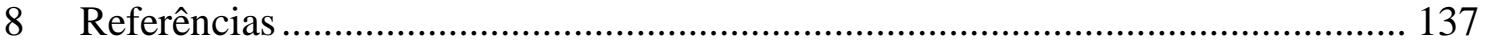

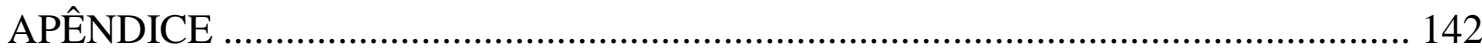




\section{INTRODUÇÃO}

\subsection{Justificativa}

O processo de polimerização pode ser realizado através de diferentes mecanismos, divididos em duas classes: polimerização por crescimento em cadeia e polimerização por crescimento em etapas. Pode ainda ser realizado em diferentes misturas reacionais, homogêneas ou heterogêneas, e em diferentes reatores, batelada, semi-batelada e contínuo.

A escolha do polímero determina o mecanismo cinético de polimerização, mas a escolha do meio reacional e do reator é realizada juntamente com a identificação da demanda de desenvolvimento, da tecnologia disponível e da aplicação fim. Cada situação terá suas vantagens e desvantagens.

Quando comparados com processos realizados em meios homogêneos, os processos realizados em meios heterogêneos, em geral, apresentam menor viscosidade no meio reacional, e melhor controle de temperatura, exigindo menores investimentos em equipamentos para agitação, bombeamento e controle de temperatura.

O presente trabalho envolve o processo de polimerização via radicais livres, realizado em miniemulsão, que é um meio heterogêneo, e em reator batelada.

Entre os processos em meio heterogêneo existentes, o processo de polimerização em emulsão é um processo amplamente estudado e utilizado. Pode ser utilizado para produzir diferentes produtos com diferentes aplicações, a depender do monômero e condições de processos adotados. Possui entre suas aplicações, algumas que exigem severo controle de qualidade, como aplicações na área biomédica, em que os polímeros são utilizados em transplantes de medula óssea como mecanismo de transporte de fármacos e também como fase sólida para imunoensaios. São utilizados também em tintas, adesivos, polímeros condutores, materiais com grande resistência ao impacto, materiais de recobrimento de superfície de tapetes, cartões e papéis (SIESLER et al., 2006). 
Temperatura de transição vítrea, dureza, peso molecular, distribuição de tamanhos de partículas, diâmetro de partícula são algumas das propriedades dos polímeros que podem ser manipuladas através de modificações no processo. Essas modificações no processo podem ser desejadas, mas também podem ocorrer por desvios de processos, resultando em modificações indesejadas.

Apesar das diferenças de performances entre os polímeros produzidos em meios heterogêneos e homogêneos, o apelo ambiental dos polímeros produzidos em meios que utilizam menos componentes orgânicos em suas formulações, é muito forte. Por serem ambientalmente mais amigáveis, os processos heterogêneos que usam água como meio dispersante, tais como os processos em emulsão e em miniemulsão, apresentam grande demanda de desenvolvimento. Aliado a isso, as legislações ambientais caminham na substituição de polímeros com base em solventes orgânicos por látex em base aquosa, elevando a importância da polimerização em emulsão convencional e em miniemulsão.

Uma das grandes vantagens da polimerização em miniemulsão é permitir a utilização de monômeros e outros componentes altamente hidrofóbicos em sua formulação, pois como a polimerização acontece nas gotas, esses componentes insolúveis não precisam ser transportados pelo meio aquoso.

O processo de polimerização em miniemulsão é mais recente do que em emulsão e por isso apresenta muitas oportunidades de desenvolvimento técnico e aplicado. $\mathrm{O}$ número de publicações em polimerização em miniemulsão mostrou forte crescimento apenas nos últimos quinze anos. É um processo complexo, pois a síntese via radicais livres tem forte influência dos fenômenos coloidais, ou seja, as etapas de nucleação, crescimento e estabilização são controladas por mecanismos de polimerização via radicais livres combinados com vários fenômenos coloidais.

Assim, o grande desafio no desenvolvimento das tecnologias de polimerização em miniemulsão está no conhecimento, controle e monitoramento da nucleação das partículas.

Por essas razões, o conhecimento do processo de polimerização em miniemulsão, tanto em termos de modelos matemáticos que representem a cinética do processo de polimerização, assim como a medição das variáveis do processo in-line e em tempo real, variáveis tais como conversão e tamanho de partículas, pode trazer grandes benefícios para quem produz e para quem desenvolve processos de produção de materiais poliméricos. 


\subsection{Objetivos}

Dentro do contexto apresentado, o presente trabalho tem como objetivo o desenvolvimento de um estudo detalhado do processo de polimerização em miniemulsão:

(a) na parte experimental, objetiva-se testar e aplicar técnicas de monitoramento in-line para acompanhar as variações da conversão do monômero e do tamanho das partículas durante o processo de polimerização em miniemulsão, utilizando Espectroscopia de Infravermelho Próximo (Near Infra Red - NIR) e Espectroscopia Raman. Para o desenvolvimento de modelos de calibração adequados relacionando os espectros às variáveis de interesse, e para verificação, avaliação e validação das técnicas espectroscópicas, são necessárias medições das mesmas variáveis com o uso de técnicas de referência; no caso, a conversão foi medida através de gravimetria e o tamanho das partículas através de Espalhamento Dinâmico de Luz (Dynamic Light Scattering- DLS).

(b) na parte teórica-computacional, objetiva-se testar modelo matemático do processo de polimerização em miniemulsão, avaliando a capacidade preditiva do modelo frente aos dados experimentais.

\subsection{Estrutura da dissertação}

A presente dissertação é composta por cinco capítulos, incluindo este capítulo de Introdução.

No Capítulo 2 são apresentadas as informações relevantes obtidas na literatura sobre o processo em estudo, bem como uma revisão dos principais trabalhos que estudaram síntese, monitoramento e simulação de processo de polimerização em miniemulsão. No Capítulo 3 é apresentada a modelagem matemática do processo. No Capítulo 4 são apresentados os materiais e métodos utilizados ao longo do trabalho. No Capítulo 5 são apresentados os resultados e suas discussões. No Capítulo 6 são apresentadas as conclusões do trabalho. Por fim, no Capítulo 7 são apresentadas recomendações para trabalhos futuros. 


\section{REVISÃO DA LITERATURA}

O processo de polimerização em miniemulsão apresenta publicações recentes, com forte expressão a partir do ano 2000, como mostra a Figura 1. É um processo complexo, pois a síntese via radicais livres tem forte influência dos fenômenos coloidais, ou seja, as etapas de nucleação, crescimento e estabilização são controladas por mecanismos de polimerização via radicais livres combinados com vários fenômenos coloidais (THICKETT; GILBERT, 2007).

Figura 1 - Número de publicações em polimerização em miniemulsão desde 1996 até 2015.

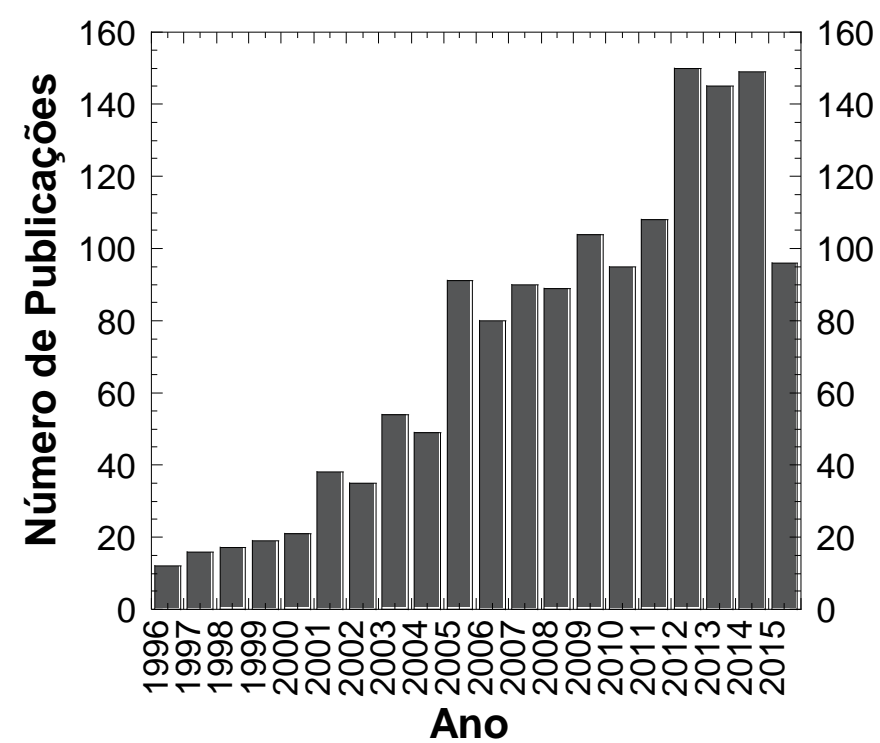

Fonte: http://www.sciencedirect.com/, busca realizada com palavraschaves, miniemulsion polymerization em 16-06-2015.

O presente Capítulo traz algumas definições básicas necessárias para a contextualização do processo e para um melhor aproveitamento e entendimento do conteúdo deste trabalho. 


\subsection{Polimerização em Miniemulsão via Radicais Livres}

O processo de polimerização pode ser realizado através de diferentes mecanismos de polimerização, divididos em duas classes: polimerização por crescimento em cadeia e polimerização por crescimento em etapas. Os dois mecanismos se diferenciam basicamente pela forma como a cadeia polimérica é formada, sendo que o crescimento em cadeia se dá através da geração de centros ativos, que são mais reativos que os monômeros e que garantem um rápido crescimento da cadeia polimérica, enquanto que o crescimento em etapas resulta de reações entre grupos funcionais reativos presentes nos monômeros por meio de etapas sucessivas idênticas (OLIVEIRA; COUTINHO, 2006).

O mesmo mecanismo de polimerização pode ser realizado ainda em diferentes misturas reacionais, homogêneas ou heterogêneas, conforme apresentado na Figura 3 considerando apenas reações realizadas em meio líquido.

$\mathrm{Na}$ polimerização em EMULSÃO, a formulação é composta por água, monômero, tensoativo e iniciador solúvel em água. O tensoativo é utilizado acima de sua concentração micelar crítica, por isso, há formação de micelas e no início do processo o monômero presente encontra-se disperso em gotas de tamanho muito maior que o das micelas. Os radicais gerados na fase aquosa pela decomposição do iniciador crescem até tamanhos que os tornam hidrofóbicos e então estes radicais oligoméricos migram para as micelas, convertendo-as em partículas de polímero, que crescem até tamanhos na faixa submicrométrica. Ao longo da polimerização o monômero migra das gotas para as partículas poliméricas. Para as emulsões, o lócus da polimerização são as partículas geradas a partir das micelas e não as gotas de monômeros.

Na polimerização em MINIEMULSÃO, a formulação é composta por água, monômero, tensoativo, co-estabilizante e iniciador. O monômero é disperso na forma de gotas muito pequenas (na faixa submicrométrica) através do uso de dispositivos de alta energia. O tensoativo é utilizado abaixo de sua concentração micelar crítica, por isso, não há formação de micelas. Assim, o monômero presente encontra-se disperso nas gotas e lá continuará ao longo do processo ao ser iniciado e propagado. Para as miniemulsões, o lócus da polimerização são as gotas de monômeros. 
Figura 2- Esquema de classificação dos diferentes mecanismos de polimerização

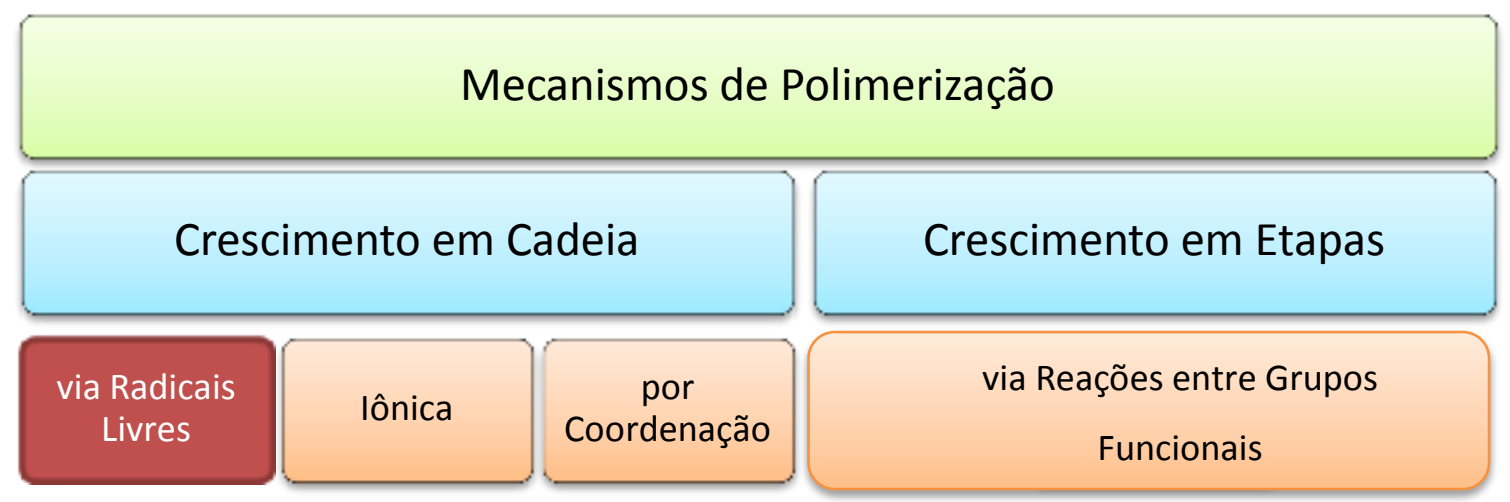

Fonte: adaptado de Oliveira; Coutinho (2006).

Na polimerização em MICROEMULSÃO, a formulação é composta por água, monômero, tensoativo e, usualmente, um co-monômero em que é adicionado um iniciador hidrossolúvel.

Miniemulsão, microemulsão e emulsão se mostram diferentes devido à cinética de nucleação e crescimento das partículas, de acordo com o representado na Tabela 1.

Na polimerização por PRECIPITAÇÃO, o monômero é solúvel na fase contínua e não incha o polímero. A polimerização ocorre na interface partícula-água.

Figura 3 - Esquema de classificação dos diferentes meios de polimerização

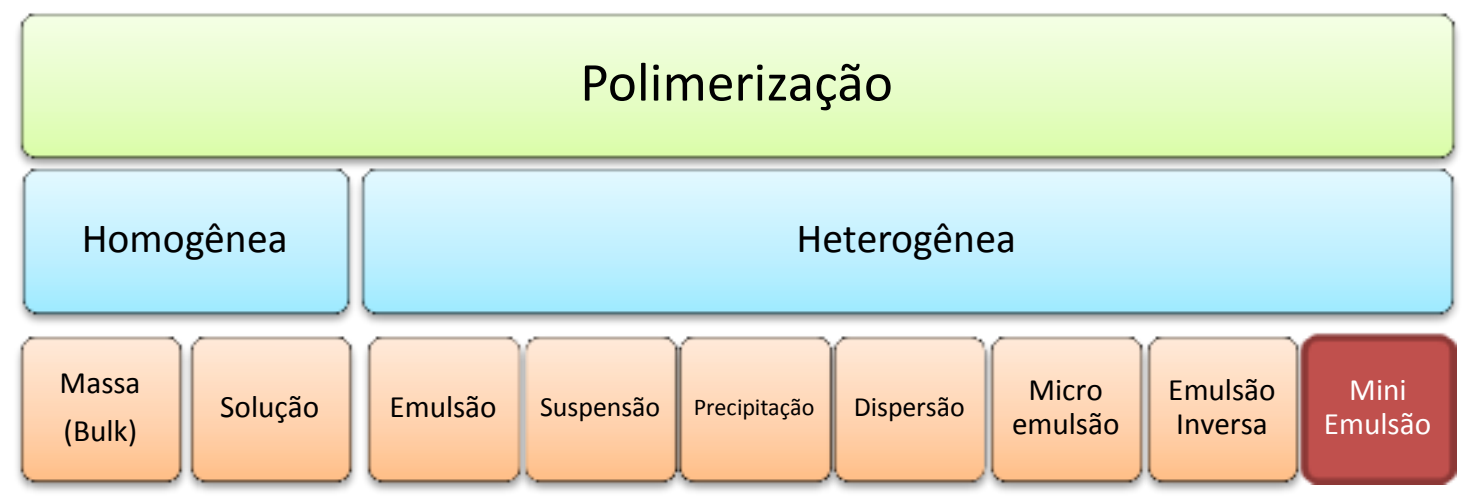

Na polimerização em SUSPENSÃO, o processo inicia-se com água, monômero, surfactante e um iniciador solúvel em óleo. O lócus da polimerização são as gotas de monômeros que se tornam a fase polimérica ao longo do processo. As partículas de polímero geradas terão tipicamente a mesma faixa de tamanhos das gotas de monômero (10 $\mu \mathrm{m}$ a $1 \mathrm{~mm})$. Quando o polímero e monômero são completamente miscíveis, as 
partículas formadas a partir da polimerização nas gotas serão como pérolas; quando o polímero formado é insolúvel no monômero, o produto final é granulado (cada gota dará origem a um aglomerado de pequenos grãos).

$\mathrm{Na}$ polimerização em DISPERSÃO, o processo inicia-se com monômero, iniciador solúvel na fase orgânica, um solvente orgânico, no qual o polímero formado será insolúvel assim como o estabilizante polimérico. Nesse caso, a fase contínua será o solvente no qual o monômero é solúvel, mas o polímero é insolúvel. O polímero será formado na fase contínua e se precipitará formando as partículas que formarão uma nova fase estabilizada por surfactantes. Assim, serão geradas pequenas partículas orgânicas formadas pela agregação das cadeias poliméricas crescentes que se precipitaram à medida que as cadeias poliméricas atinjam um tamanho limite crítico. A coalescência das partículas precursoras entre elas e com as que sofreram agregação formarão partículas coloidais estáveis quando houver surfactante o suficiente para recobrir a superfície das partículas.

As principais diferenças entre as polimerizações em meio heterogêneo estão representadas nas Tabela 1 e Tabela 2.

Uma dispersão estável de gotas submicrométricas é chamada de miniemulsão. Elas não são formadas espontaneamente, requerem equipamentos de alto cisalhamento para serem formadas (DANIELS et al, 2001). A dispersão resultante é formada de pequenas gotas, com tamanhos na faixa de 50 a $500 \mathrm{~nm}$, cujas áreas somadas resultam em grandes áreas superficiais. Todo tensoativo utilizado na formulação das miniemulsões é utilizado para estabilizar as gotas e, portanto, não há formação de micelas no sistema. Como resultado, as gotas tornam-se os núcleos predominantes para nucleação e polimerização.

Em miniemulsões ideais, a razão entre as gotas monoméricas iniciais e as partículas poliméricas finais deve ser 1:1, mas nem sempre essa razão é obtida.

A polimerização realizada em emulsão apresenta três intervalos distintos e bem definidos: Intervalo I, Intervalo II e Intervalo III, de acordo com a Teoria de HarkinsSmith-Ewart, enquanto a polimerização em miniemulsão apresenta quatro intervalos distintos.

Já para a polimerização em miniemulsão, a cinética pode ser dividida em quatro intervalos. No primeiro intervalo, há um rápido aumento na taxa de polimerização devido à formação das partículas de látex que ocorre até um primeiro máximo (Intervalo I) seguido de uma diminuição na taxa de polimerização à medida que aumenta a 
conversão do monômero (Intervalo II). Na sequência, há um segundo aumento na taxa de polimerização até que um segundo máximo é atingido (Intervalo III) e após esse pico, há um rápido decréscimo (Intervalo IV) até que a polimerização termina.

Tabela 1 - Comparação entre diferentes processos heterogêneos de polimerização

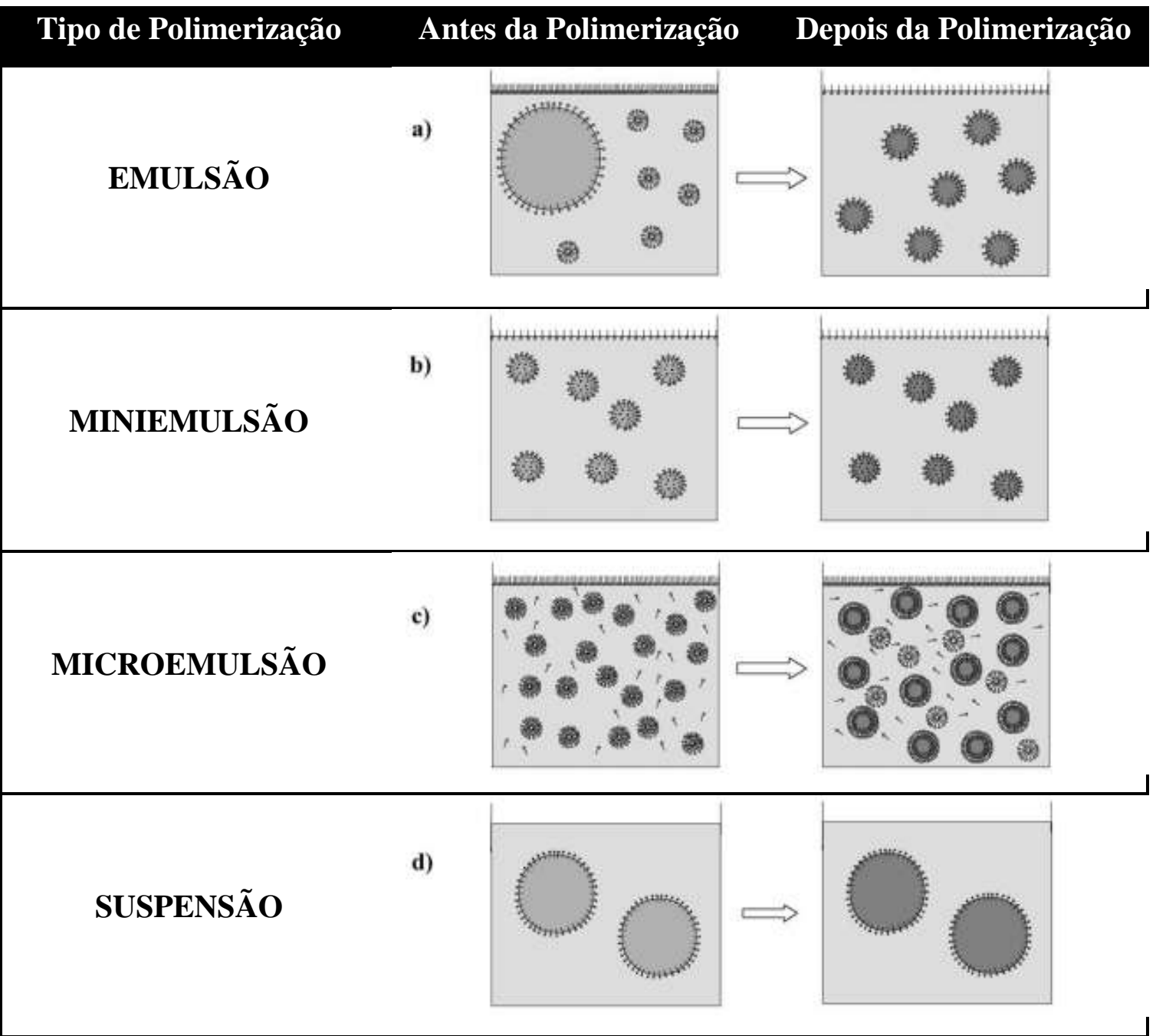

Fonte: Antonietti; Landfester (2002).

De acordo com Smith-Ewart (1948), o número de partículas por unidade de volume de água e a concentração dos monômeros nas partículas contribuem para a variação na taxa de polimerização em função da conversão do monômero. Quanto maior a população de partículas de látex ou a concentração de monômeros nas partículas, maior a taxa de polimerização.

Na polimerização em miniemulsão, o primeiro máximo na taxa de polimerização não corresponde necessariamente ao final da nucleação, neste momento a nucleação ainda pode estar acontecendo, no entanto, a menor concentração de monômero livre na partícula de látex conduz a uma redução da taxa de polimerização. A nucleação das 
partículas acontece até que a conversão dos monômeros atinja de 40 a 60\%, conforme pode ser observado na Figura 5.

Tabela 2 - Diferenças entre polimerizações realizadas em meios heterogêneos.

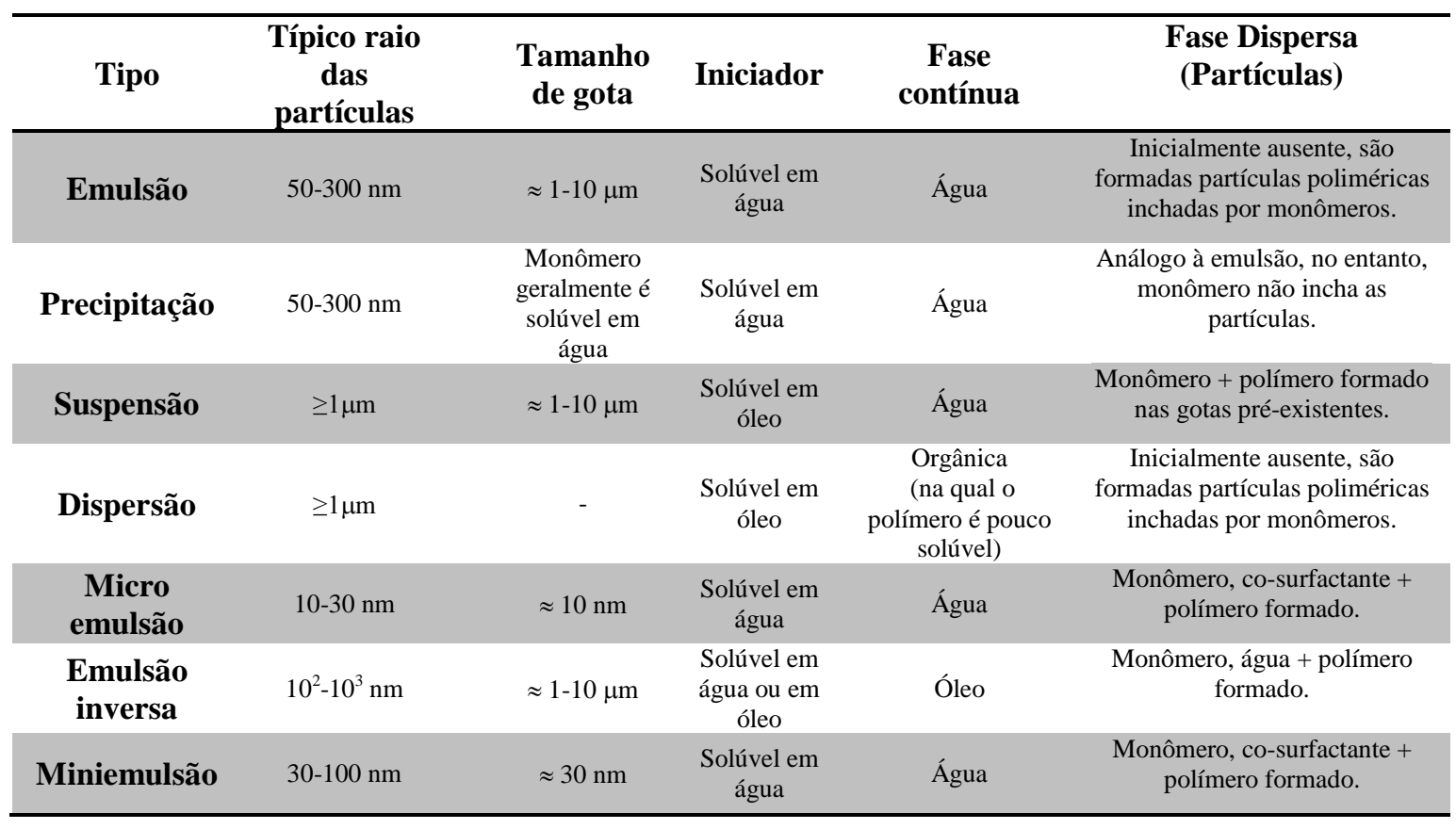

Fonte: Gilbert (1995).

O segundo máximo observado na taxa de polimerização da miniemulsão está relacionado com o efeito gel, em que a terminação bimolecular torna-se limitada e controlada pela difusão nas partículas. Assim, há um aumento na concentração de radicais livres no último estágio da polimerização, acelerando a taxa de polimerização. Após isso, a taxa de polimerização diminui devido ao esgotamento dos monômeros.

Em geral a velocidade de polimerização é mais alta na polimerização em emulsão, devido à segregação dos radicais livres presentes nas partículas de polímero inchadas com monômero dispersas na fase aquosa, levando a uma menor taxa de terminação bimolecular e na ausência de transferência de cadeias, proporcionando também cadeias poliméricas maiores. 


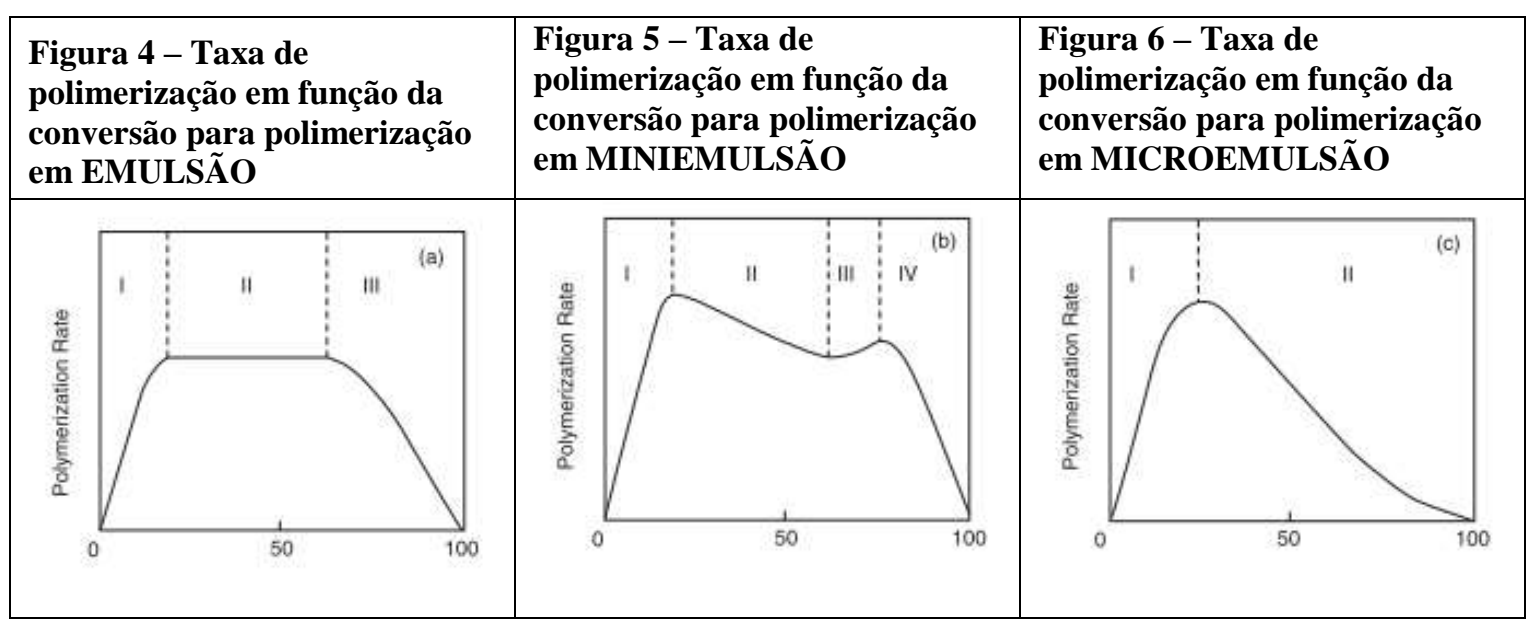

Fonte: Chern (2008).

As concentrações de tensoativo (S) e iniciador (I) influenciam diretamente no número de partículas poliméricas $\left(N_{p}\right)$ formadas conforme mostrado pela clássica Equação 1, que pode ser deduzida teoricamente (THICKETT; GILBERT, 2007).

$$
N_{p} \propto I^{0,4} S^{0,6}
$$

Equação 1

Assim, para a mesma quantidade de iniciador e maior concentração do tensoativo, o número de partículas poliméricas produzidas será maior.

A velocidade também se diferencia em função da quantidade de loci ativos, assim, um maior número de partículas proporciona maior velocidade de polimerização, no entanto, quando se compara a razão entre taxa de polimerização e o número de partículas para emulsões e miniemulsões, essa última é maior, pois apresenta menor número de partículas.

Na polimerização em miniemulsão, a taxa não apresenta patamar como nas emulsões.

\subsection{Miniemulsões Monoméricas}

A polimerização em miniemulsão acontece na miniemulsão monomérica preparada antes que a reação efetivamente se inicie.

Miniemulsões adequadas para o processo de polimerização são formadas de gotas submicrométricas de monômero disperso em água, estabilizadas contra degradação difusional e coagulação de gotas utilizando, respectivamente, um coestabilizante hidrofóbico de baixo peso molecular e um tensoativo hidrossolúvel 
eficiente. As questões fundamentais no preparo das miniemulsões monoméricas são a formulação e o método de preparação (ASUA, 2002).

Em geral, as miniemulsões são preparadas através da adição de todos os seus componentes, exceto o iniciador, que é adicionado ao reator apenas no momento em que as condições adequadas para a reação acontecer forem obtidas, por exemplo, a temperatura.

No entanto, o processo de dispersão do monômero na fase contínua por agitação mecânica convencional não é capaz de quebrar as gotas até tamanhos submicrométricos. Ele requer uma homogeneização altamente eficiente e altamente intensiva em energia. Para isso há vários equipamentos disponíveis comercialmente, sendo os mais utilizados: Rotor-estator, Ultrassom e Homogeneizador de alta pressão, conforme ilustrado na Figura 7.

Figura 7 - Mecanismos utilizados para preparação da miniemulsão monomérica. (a)Ultrassom, (b) Rotor-estator e (c) Homogenizador de alta pressão.

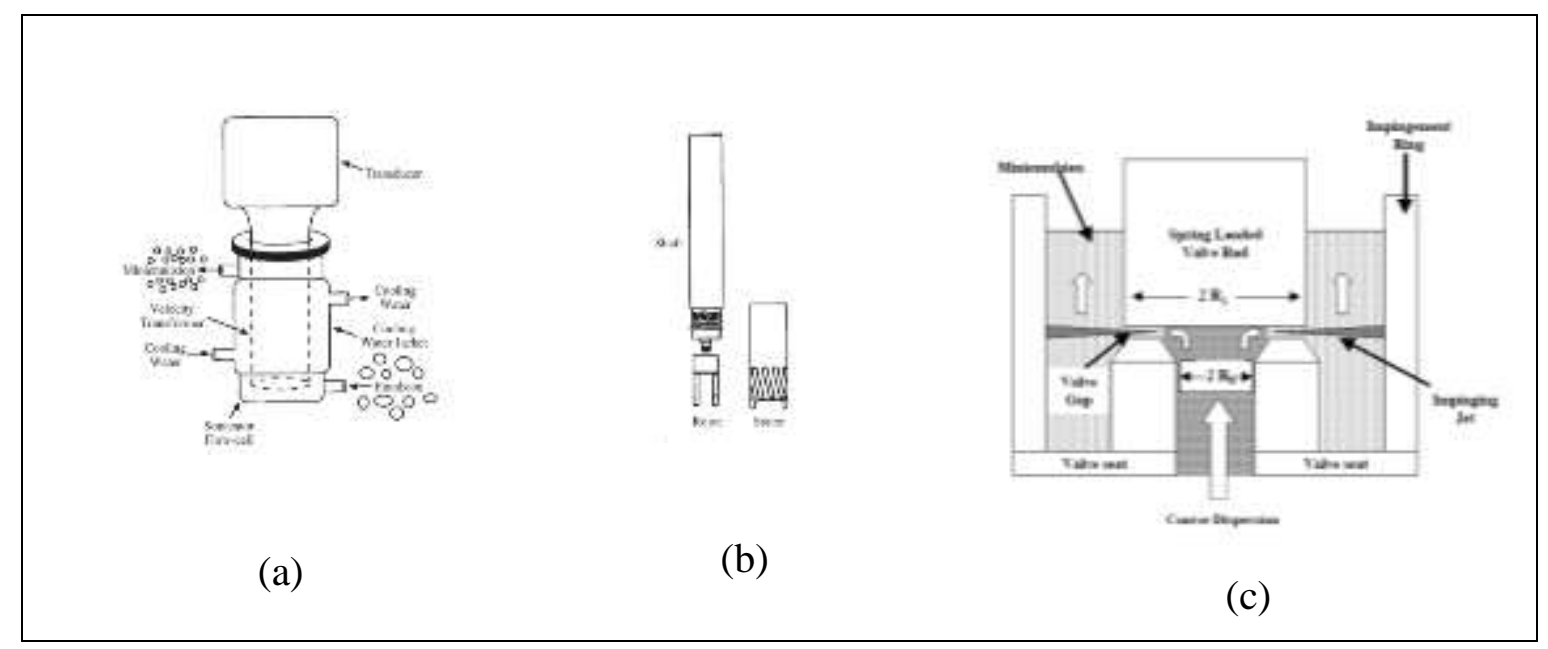

\section{Fonte: Asua (2002).}

A estabilidade das miniemulsões após seu preparo é bastante importante porque o sucesso da polimerização em miniemulsão depende da nucleação das gotas de monômero e, por isso, elas devem ser preservadas. Sendo assim, há uma preocupação com a estabilidade da miniemulsão durante o tempo decorrido entre a preparação e a polimerização, assim como durante o processo de polimerização. Uma vez formadas e não polimerizadas, as miniemulsões monoméricas podem degradar-se por causa da coalescência e pela difusão do monômero, levando à sedimentação ou creaming (ASUA, 2002). 
Os dois principais fenômenos que geram instabilidade nas miniemulsões são a coalescência ou coagulação das gotas e a degradação difusional, também chamado de envelhecimento de Ostwald. Esses dois fenômenos estão ilustrados na Figura 8.

Figura 8 - Principais fenômenos que geram instabilidade nas miniemulsões

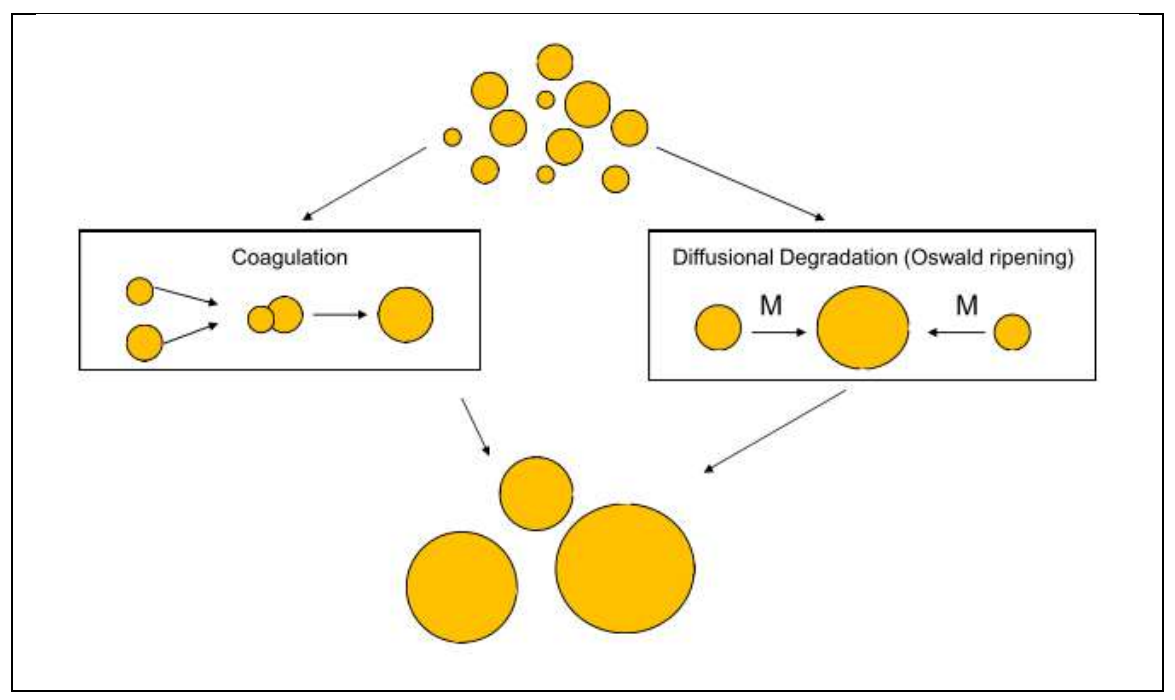

Fonte: Asua (2012).

A degradação difusional acontece devido à diferença de potencial químico do monômero presente em gotas de tamanhos diferentes, conforme mostra a Figura 9. Quanto maior o raio da gota, menor o seu potencial químico, portanto, quando houver uma mistura de gotas com tamanhos diferentes, haverá uma tendência do monômero presente nas gotas com raios menores se difundir para as gotas com raios maiores.

Figura 9 - Variação do potencial químico para monômero puro em função do raio da gota

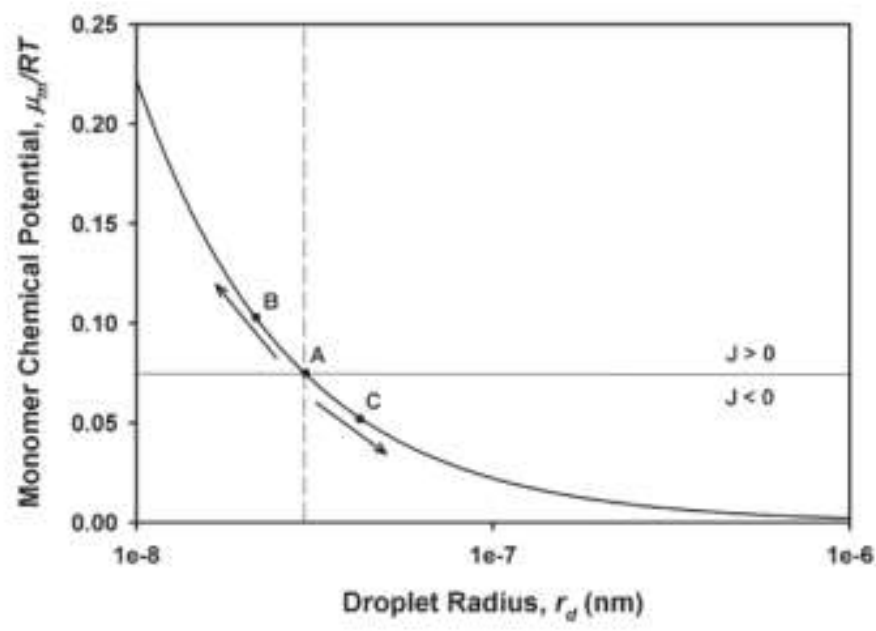

Fonte: Schork et al. (2005). 
Quando duas gotas de tamanhos diferentes e com a mesma composição volumétrica estiverem juntas no mesmo meio, a diferença de potencial entre elas estará associada apenas ao tamanho das gotas, portanto, nesse caso, também haverá difusão de monômero da gota de menor raio para a gota de maior raio. O co-estabilizante deve ser muito mais hidrofóbico que o próprio monômero, de maneira que, ao contrário do monômero, ele não se difunda através da fase aquosa. Como consequência disso, será gerada uma diferença de concentração do co-estabilizante nas gotas, ou seja, as gotas menores ficarão mais concentradas em co-estabilizante. Assim, será gerado também um fluxo contrário de monômero, até que seja atingido um equilíbrio.

O amadurecimento de Ostwald pode ser evitado, portanto, pela utilização de um co-estabilizante que apresente pouca ou nenhuma afinidade com a fase aquosa.

A coalescência, por sua vez, pode ser evitada adicionando tensoativo hidrossolúvel suficiente ao sistema, que atuará na interface entre o monômero das gotas e a fase aquosa, de modo a evitar o contato entre as gotas de monômeros (SCHORK et al., 2005).

Portanto, um dos indicativos da estabilidade de uma emulsão ou miniemulsão é o diâmetro médio das gotas.

\subsection{Monitoramento in-line, on-line e off-line}

Os sensores e mecanismos de análise e monitoramento de processos dividem-se em três tipos, a depender da localização do sensor e da defasagem de tempo entre o processo real e as respostas dos sensores e análises.

Sensores In-line são sensores localizados dentro do reator e que transmitem continuamente os dados adquiridos para o usuário que poderá interferir, monitorando, ou controlando o processo em tempo real.

Sensores On-line: são sensores localizados próximos ao processo, onde amostras são coletadas por algum mecanismo de amostragem e as amostras são analisadas quase que continuamente.

Sensores Off-line são sensores que recebem amostras retiradas do processo e inseridas em equipamentos que fornecem respostas com defasagem de tempo entre o real e o analisado.

Há benefícios em se fazer análises in-line ou on-line, pois, em ambos os casos, esses sensores permitem obter dados continuamente e em tempo real, permitindo que ações sejam tomadas rapidamente a fim de garantir a qualidade desejada do produto ou 
de evitar até mesmo um descontrole (run-away) da reação, (FONSECA ; DUBÉ; PENLIDIS, 2009).

Quando comparadas com análises realizadas off-line, essas possuem como desvantagens resultados defasados no tempo e dados descontínuos, pois os intervalos de análises são maiores do que quando realizadas por sensores in-line ou on-line. Essas duas características das análises off-line podem levar a diversas consequências quando se detecta um problema no processo: tempo de reação maior do que o necessário, produto com qualidade comprometida, entre outros.

O desenvolvimento dos sensores acoplados a fibras óticas permitiu o avanço das tecnologias que utilizam sensores in-line, como Espectroscopia Raman, Espalhamento de luz, Espectroscopia de Infravermelho, Espectroscopia de fluorescência, Espectroscopia de ultravioleta. Existem dois tipos de sensores, extrínsecos e intrínsecos. Os sensores extrínsecos são aqueles que modulam o feixe de luz em função da resposta do meio ambiente em que estão colocados e então a fibra carrega a informação para um processador. Os sensores intrínsecos usam a fibra ótica para levar o feixe de luz para o meio que imprime uma informação do meio que o qualifica e o feixe de luz que retorna para o processador.

O monitoramento do processo apresentado neste trabalho será realizado com equipamentos e sensores que fornecem dados in-line e off-line.

Conforme indicado na Figura 10, o monitoramento in-line será realizado através de Espectroscopia de Infravermelho Próximo (Near Infra Red - NIR) e o monitoramento off-line será utilizado através de Espalhamento de Luz, com o equipamento Coulter; Espectroscopia Raman e Gravimetria.

Além dessas técnicas, será realizado monitoramento de estabilidade através de Turbidimetria com o equipamento Turbiscan.

A seguir, é apresentada uma breve descrição de cada técnica de monitoramento utilizada. 
Figura 10 - Etapa de síntese e monitoramento de processo

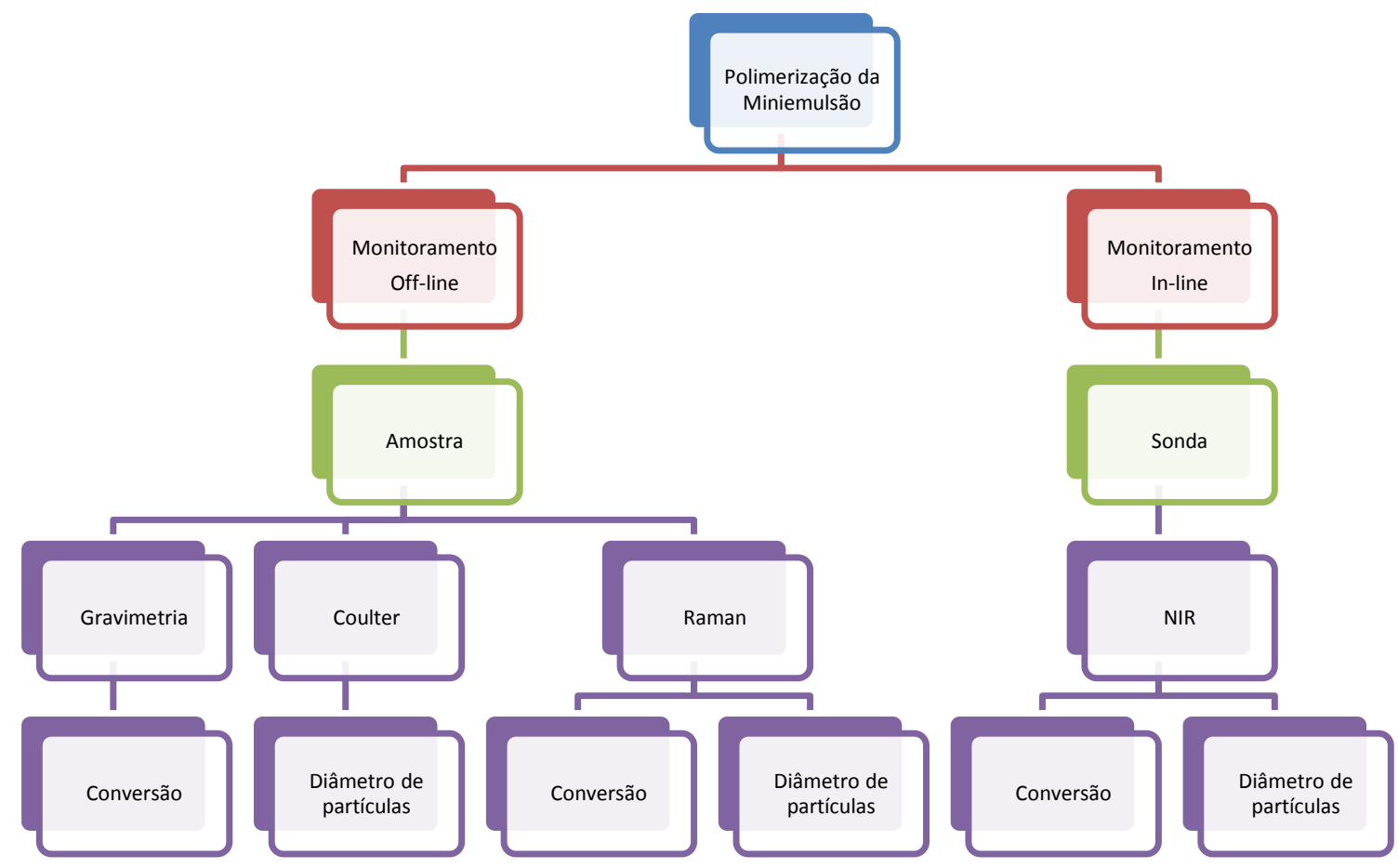

\subsubsection{Espalhamento de Luz}

Os métodos de espalhamento de luz são utilizados para caracterizar macromoléculas e partículas, e se baseiam no espalhamento que a luz sofre ao iluminar um pedaço de matéria. A luz poderá ser absorvida ou espalhada (ou ambas) pela molécula ou partícula, e isso dependerá do comprimento de onda da luz incidente e das propriedades óticas do material. A densidade do espalhamento será função do índice de refração do material e do meio que o contém além de outras propriedades do material. Os métodos de espalhamento podem ser classificados como espalhamento de luz dinâmico (Dynamic Light Scattering - DLS) e espalhamento de luz estático (Static Light Scattering - SLS).

No SLS, as partículas iluminadas espalham a luz em múltiplas direções e a intensidade da luz espalhada é detectada em função do ângulo de espalhamento e analisada. Esta técnica é em geral apropriada para partículas de tamanhos entre $1 \mu \mathrm{m}$ e 1 $\mathrm{mm}$.

Por outro lado, o DLS mede as flutuações da intensidade do espalhamento em função do tempo, em um ângulo fixo de espalhamento ou em múltiplos ângulos. Essas 
flutuações são geradas pelo movimento Browniano das partículas iluminadas. Esta técnica é apropriada para partículas menores, na faixa submicrométrica.

As partículas com menor tamanho se movem com maior velocidade do que as partículas grandes e, portanto, possuem coeficiente de difusão (D) maior ("Dynamic Light Scattering: An Introdution in 30 minutes.”, [s.d.]). Para uma dispersão de partículas esféricas, com viscosidade $\eta$, à temperatura $T$ constante, o coeficiente de difusão D é inversamente proporcional ao diâmetro hidrodinâmico $\left(\mathrm{d}_{\mathrm{h}}\right)$ das partículas, como mostra a equação de Stokes-Einstein, Equação 2, onde $\sigma$ é a constante de Boltzmann:

$D=\frac{\sigma \cdot T}{3 \cdot \pi \cdot \eta \cdot d_{h}}$

Equação 2

Devido ao movimento Browniano, a intensidade da luz espalhada por um conjunto de partículas sofre flutuações ao longo do tempo e a intensidade da luz que atinge o detector irá flutuar por causa do movimento das partículas. Quando o tamanho das partículas for menor, essa flutuação espalhada irá aumentar, pois as partículas vão se movimentar mais rapidamente e irão passar pelo detector mais vezes dentro de um intervalo de tempo. Portanto, existe uma relação entre a velocidade de flutuação da luz espalhada e o coeficiente de difusão das partículas, e uma auto correlação da intensidade da luz espalhada. No caso de partículas pequenas essa auto correlação entre as intensidades diminui ligeiramente quando comparada com partículas grandes. (COLMÁN, 2013)

\subsubsection{Múltiplo Espalhamento de Luz}

Para monitorar a estabilidade das emulsões utilizou-se o equipamento Turbiscan que também se baseia no espalhamento de luz.

A fonte de luz é um diodo eletroluminescente que emite luz no comprimento de onda do infravermelho $\left(\lambda_{a r}=880 \mathrm{~nm}\right)$. Dois sensores óticos recebem a luz transmitida pela amostra, um localizado a $180^{\circ}$ da luz incidente, que detecta a luz transmitida pela amostra, e outro localizado a $45^{\circ}$ da luz incidente, que detecta a luz retro espalhada pela amostra, conforme apresentado na Figura 12.

Quando um feixe de luz é emitido, conforme ilustrado na Figura 12, passa por um frasco de vidro, contendo uma dispersão opticamente densa. O feixe é dividido em duas componentes, uma central e outra periférica. A parte central corresponde a fótons 
que atravessaram um pequeno caminho de luz, isto é, fótons que sofrem pouco espalhamento antes de sair do meio. A parte periférica corresponde aos fótons que atravessaram um longo caminho, ou seja, fótons que sofrem um grande número de eventos de espalhamento antes de sair do meio.

Caminho livre (I*) representa a distância viajada pelos fótons quando eles se desviam de sua trajetória inicial, ou seja, é à distância penetrada pelo fóton na dispersão.

O equipamento Turbiscan analisa principalmente essa parte central. Assim, a medição do fluxo de luz retroespalhado (Backscattering - BS) pode ser associada com $I^{*}$ através de uma primeira aproximação que considera BS inversamente proporcional à raiz quadrada de I*, conforme mostra a Equação 3. (“Turbiscan User Guide”, [s.d.]).

Pela Teoria de Mie, I* é inversamente proporcional à fração volumétrica das partículas $\Phi$ e proporcional ao seu diâmetro médio (d), conforme mostra a Equação 4. Onde Qs e g são parâmetros fornecidos pela Teoria de Mie. (HERGERT; WRIEDT, 2012)

$$
\begin{gathered}
B S=\frac{1}{\sqrt{I^{*}}} \\
I^{*}(d, \emptyset)=\frac{2 d}{3 \emptyset(1-g) Q_{S}}
\end{gathered}
$$

Equação 3

Equação 4

Assim sendo, o BS medido pelo equipamento Turbiscan é diretamente dependente do diâmetro médio das partículas (d) e de sua fração volumétrica $(\Phi)$.

O equipamento pode operar com amostras com concentrações baixas a altas $(0,0001-95 \% \mathrm{v} / \mathrm{v})$, não requer nenhum preparo prévio e detecta partículas com dimensões de $1 \mathrm{~nm}$ a $1 \mathrm{~mm}$.

Os vários processos de desestabilização que uma miniemulsão pode sofrer estão ilustrados na Figura 11.

Assim, as variações no diâmetro e na fração volumétrica estão diretamente relacionadas com a instabilidade das amostras, pois quando uma emulsão se desestabiliza, detectam-se gradientes de concentração ao longo da altura da amostra e/ou variação no diâmetro médio de suas partículas. O Turbiscan coleta o BS a cada 20 microns ao longo da altura da amostra, com uma varredura realizada à velocidade constante. As leituras da amostra são realizadas durante o tempo de envelhecimento da amostra para detectar qualquer variação do sinal devido a uma desestabilização, como a migração de partículas e / ou alteração de tamanho de partícula. 
Figura 11 - Processos de desestabilização que uma emulsão pode sofrer.

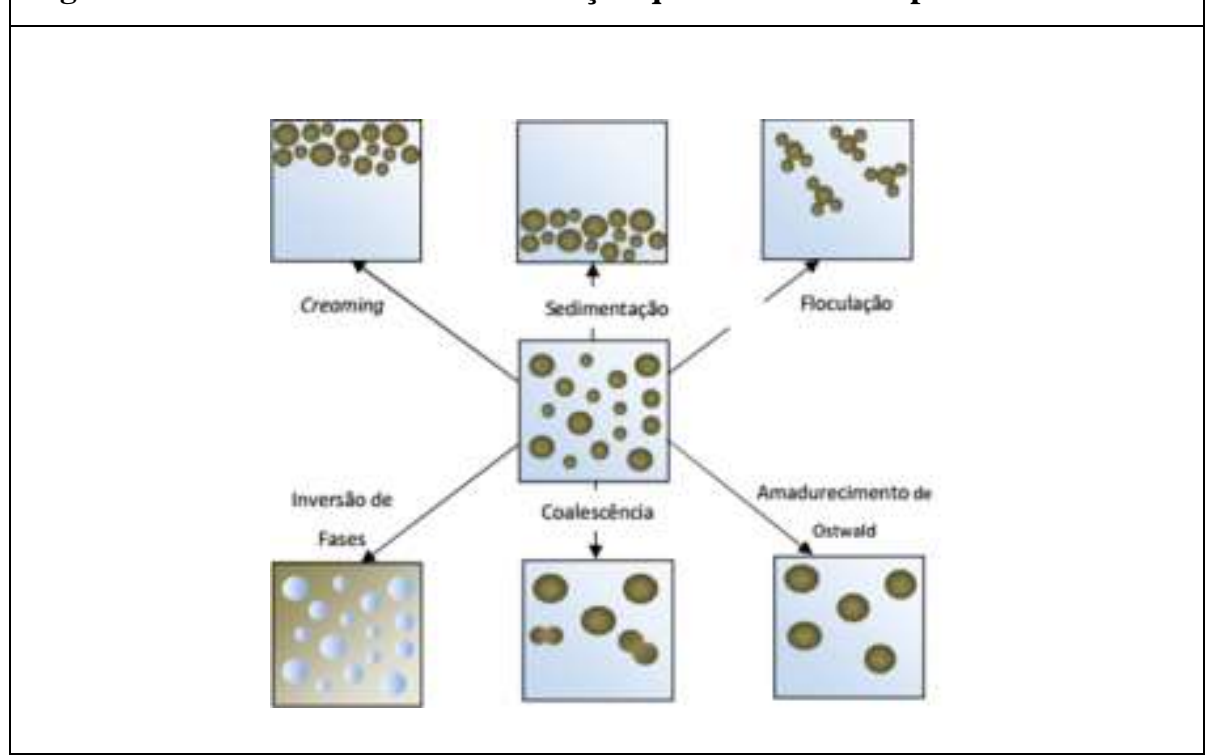

Fonte: Formulation - Smart Scientific Analysis (2015).

Princípio de medição: A amostra analisada é colocada em uma célula de vidro cilíndrica.

O equipamento faz varreduras através do comprimento do frasco, ao longo de seus $55 \mathrm{~mm}$ a cada $40 \mu \mathrm{m}$. As intensidades da luz transmitida ou retroespalhada são fornecidas como uma porcentagem da intensidade da luz transmitida ou retroespalhada pela referência, neste caso, uma suspensão monodispersa de esferas e óleo de silicone.

A transmissão é utilizada para analisar amostras límpidas a turvas e o retroespalhamento é usado para analisar amostras opacas.

Figura 12 - Esquema ilustrativo do Turbiscan com sua fonte de luz e seus dois sensores

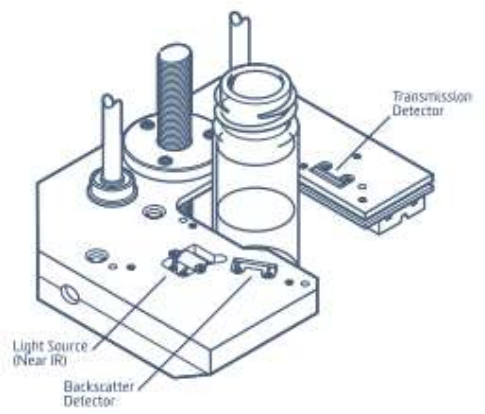

Fonte: Formulation - Smart Scientific Analysis ([s.d.]) 
Através dos gráficos de retroespalhamento e transmissão, pode-se verificar qual amostra apresentou instabilidade, e também qual a origem da instabilidade, se floculação, coalescência, creaming, clarificação, como consequência de variação diâmetro de partícula, e variação na transmissão e espalhamento da luz.

\subsubsection{Espectroscopia de Infravermelho Próximo}

O infravermelho é dividido em três regiões: infravermelho próximo, médio e distante, dependendo da faixa de comprimento de onda empregado. Cada faixa corresponde a diferentes intensidades de interação entre a onda eletromagnética e as ligações químicas (vibrações fundamentais, sobretons ou combinações, diferentes tipos ou modos de vibrações das ligações, etc.), conforme mostrado na Tabela 6.

Neste trabalho, utilizou-se radiação no comprimento de onda do infravermelho próximo, ou seja, de 14.000 a $4.000 \mathrm{~cm}^{-1}$. Com esta técnica é possível fazer a identificação de propriedades físicas, composição química e determinação de propriedades da matéria, conforme apresenta a Tabela 4. É possível também realizar o monitoramento de reações para determinação da conversão e para determinação de tamanho de partículas.

Tabela 3 - Diferenciação entre as três regiões da Espectroscopia do Infravermelho e suas respectivas informações.

\begin{tabular}{|c|c|c|}
\hline Infravermelho & Região & Informação \\
\hline $\begin{array}{l}\text { Próximo } \\
\text { (NIR) }\end{array}$ & $14.000 \mathrm{a} 4.000 \mathrm{~cm}^{-1}$ & $\begin{array}{l}\text { Sobretons ou combinação de estiramento fundamental que ocorre de } 3.000 \\
\text { a } 1.700 \mathrm{~cm}^{-1} \text { devido ao estiramento das ligações C-H, N-H ou O-H. }\end{array}$ \\
\hline $\begin{array}{l}\text { Médio } \\
\text { (MIR) }\end{array}$ & $4.000 \mathrm{a}_{400 \mathrm{~cm}^{-1}}$ & $\begin{array}{l}\text { Vibrações moleculares fundamentais, chamada de região de impressão } \\
\text { digital da molécula. } \\
\text { Detecta ligações orgânicas e inorgânicas }\end{array}$ \\
\hline $\begin{array}{l}\text { Distante } \\
\text { (far-IR) }\end{array}$ & 400 a $10 \mathrm{~cm}^{-1}$ & $\begin{array}{l}\text { Estrutura molecular e propriedades das moléculas baseados nas transições } \\
\text { vibracionais. }\end{array}$ \\
\hline
\end{tabular}

Fonte: Workman (2001).

A espectroscopia NIR apresenta alta sensibilidade para ligações C-H, O-H e N$\mathrm{H}$, conforme indicado na Tabela 5 que sumariza algumas diferenças entre as Espectroscopias NIR e Raman. 
Tabela 4 - Aplicações possíveis da técnica de Espectroscopia de Infravermelho Próximo

\begin{tabular}{|c|c|c|}
\hline Composição Química & Propriedades da Matéria & Propriedades Físicas \\
\hline Proteína & Densidade & Tamanho de partículas/ \\
& diâmetro de fibras \\
Umidade/água & Digestibilidade & Temperatura \\
Hidrocarbonetos & Viscosidade & Propriedades mecânicas \\
Ácidos Carboxílicos & Número de octanos de motor & Pré-tratamentos térmicos e \\
& a combustão & mecânicos \\
Aminas & Pressão reid & Massa molar de polímeros \\
Óleos/gorduras & Germinação de sementes & \\
Sucralose/glicose & Parâmetros de destilação & \\
Aditivos em combustíveis & Maturação de frutas & \\
& Sólidos totais dissolvidos & \\
\hline
\end{tabular}

Fonte: Pasquini (2003).

Para o caso particular das reações de polimerização em meio heterogêneo, com a presença de partículas, os espectros apresentam regiões com características distintas: uma região onde se podem identificar informações químicas da reação, relacionadas com as vibrações das principais ligações presentes no monômero consumido e no polímero formado, e outra região com informações físicas, onde há variação na inclinação da linha base do espectro que está relacionada com variações físicas da amostra como área, volume e raio, conforme apresentado na Tabela 6 e Figura 13.

Tabela 5 - Comparação entre Espectroscopia NIR e Raman

\begin{tabular}{|c|c|c|}
\hline Espectroscopia & Infravermelho Próximo (NIR) & Espectroscopia Raman \\
\hline $\begin{array}{l}\text { Absorção } \\
\text { relacionada com }\end{array}$ & $\begin{array}{ll}\text { - } & \text { Mudanças nos momentos de dipolos } \\
\text { - } & \text { Vibrações assimétricas }\end{array}$ & $\begin{array}{l}\text { - } \quad \text { Mudanças na polarizabilidade } \\
\text { das moléculas } \\
\text { - } \quad \text { Vibrações simétricas }\end{array}$ \\
\hline Sensibilidade & - $\quad \mathrm{C}-\mathrm{H}, \mathrm{O}-\mathrm{H}, \mathrm{N}-\mathrm{H}$ & - $\mathrm{C}=\mathrm{C}, \mathrm{C}-\mathrm{S}, \mathrm{S}-\mathrm{S}$ \\
\hline $\begin{array}{l}\text { Resolução das } \\
\text { bandas }\end{array}$ & $\begin{array}{l}\text { - } \quad \text { Baixa resolução das bandas (largas e } \\
\text { sobrepostas), } \\
\text { - } \quad \text { Requer calibração multivariável } \\
\text { (PCA, PLS). }\end{array}$ & $\begin{array}{ll}\text { - } & \text { Alta resolução dos picos } \\
\text { - } & \text { Não requer calibração }\end{array}$ \\
\hline $\begin{array}{l}\text { Sensibilidade à } \\
\text { água }\end{array}$ & $\begin{array}{l}\text { - Interferência da água (em sistemas } \\
\text { aquosos), efeito da temperatura. }\end{array}$ & - $\quad$ Baixa sensibilidade à água. \\
\hline
\end{tabular}

Fonte: Workman (2001) 
Tabela 6 - Informações presentes nos espectros de NIR e Raman em reações de polimerização em meio heterogêneo.

\begin{tabular}{|llll|}
\hline \multicolumn{1}{|c}{ Informação } & \multicolumn{1}{c}{ Tipo } & \multicolumn{1}{c|}{ Cálculo } & \multicolumn{1}{c|}{ Determinação } \\
\hline Química & Vibração & Áreas dos picos & Conversão \\
\hline Física & Espalhamento & Inclinação da linha base & Diâmetro médio \\
\hline
\end{tabular}

Figura 13 - Espectro NIR com indicação da região de espalhamento para determinação de propriedades físicas e região de absorbância, para determinação de propriedades da amostra.

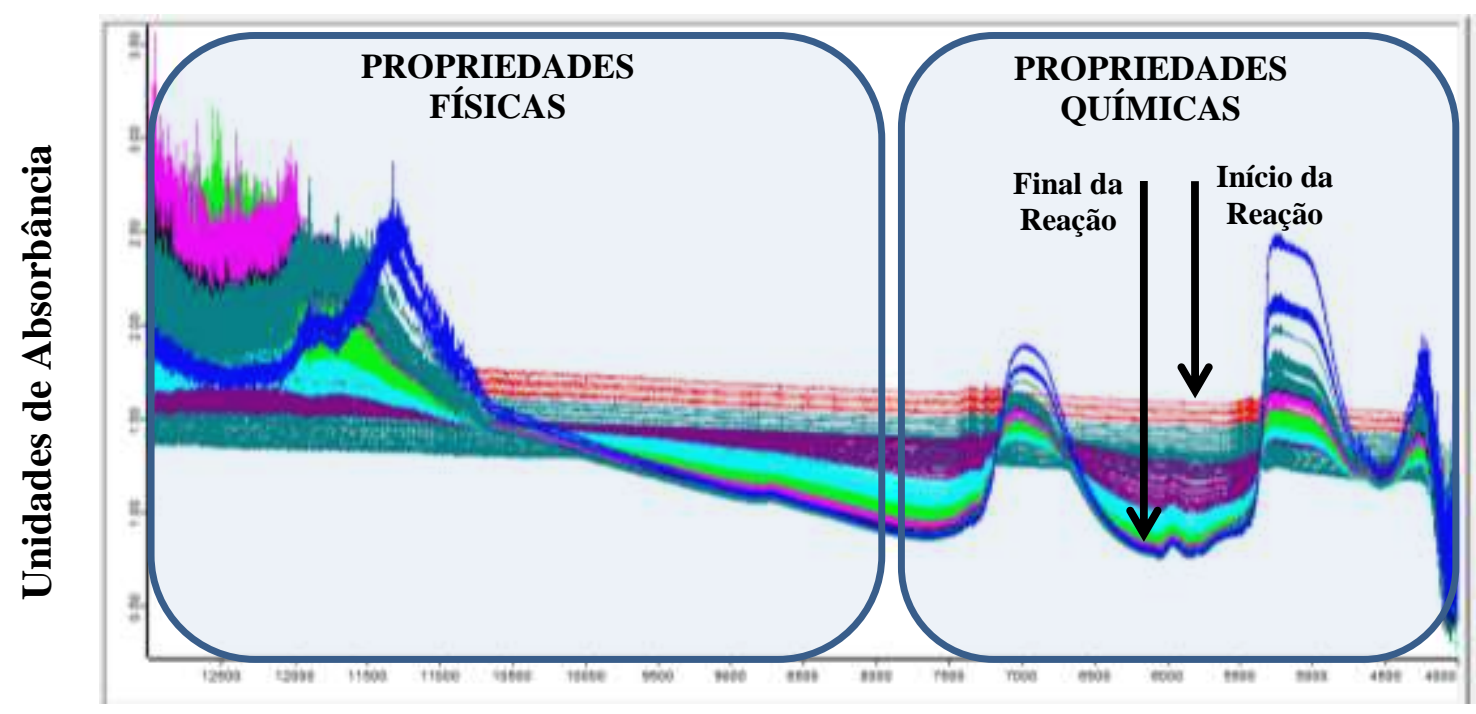

Número de Onda $\left(\mathrm{cm}^{-1}\right)$

\subsubsection{Espectroscopia Raman}

As espectroctoscopias NIR e Raman possuem o mesmo princípio físico: absorção de bandas na região do espectro NIR e Raman como consequência das vibrações moleculares dos compostos químicos (SIESLER et al., 2002).

A principal diferença entre as técnicas Raman e NIR é a forma de análise: Raman utiliza a técnica de detecção de luz espalhada e NIR absorção. Assim, na espectroscopia NIR se opera com luz policromática na qual as moléculas absorvem frequências específicas correspondentes a transição vibracional molecular (overtones e bandas de combinação). Na espectroscopia Raman a amostra é irradiada por meio de uma luz de laser monocromática, cuja frequência pode variar desde o espectro visível até o NIR. Esta radiação pode excitar a molécula para um estado virtual de energia muito acima dos níveis de vibração do oscilador harmônico para um espectro visível e no intervalo de altos sobretons da excitação NIR. A partir deste nível de energia de excitação, a molécula pode retornar ao estado fundamental pelo espalhamento elástico, 
no qual o fóton incidente tem a mesma frequência que a luz espalhada (Rayleigh), que tem a mesma frequência que a linha de excitação e não contém informações em termos de vibração molecular.

A Espectroscopia Raman é bastante utilizada por ser uma técnica não destrutiva e não invasiva e também por permitir análises em meios aquosos e não aquosos, pois apresenta baixa sensibilidade a água. Detecta facilmente a quebra da dupla ligação $(\mathrm{C}=\mathrm{C})$ em reações de polimerização gerando espectros com picos fortes e bem definidos para muitos monômeros comumente utilizados, como por exemplo: acrilatos, acetato de vinila e estirenos.

A intensidade Raman varia ao longo do tempo devido a mudanças na intensidade do laser ou devido a propriedades da luz espalhada. Por isso, é comum a utilização de uma banda de referência, cuja concentração não muda ao longo do tempo, como por exemplo, o anel aromático, apresentado em algumas referências. A Tabela 7 apresenta alguns picos do espectro Raman característicos do estireno e poliestireno.

Tabela 7 - Picos característicos do estireno e poliestireno identificados através de Espectroscopia Raman.

\begin{tabular}{|c|c|c|c|}
\hline \multicolumn{2}{|r|}{ Molécula } & $\begin{array}{l}\text { Pico } \\
\left(\mathrm{cm}^{-1}\right)\end{array}$ & Ligação e Tipo de vibração \\
\hline \multirow{3}{*}{ 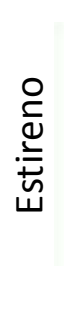 } & & 1631 & Ligação $C=C$ \\
\hline & $\mathrm{H}$ & 1317,1413 & Estiramento da ligação C-H \\
\hline & & 775,1002 & $\begin{array}{l}\text { Estiramento fora do plano do } \mathrm{C}-\mathrm{H} \text { do anel } \\
\text { aromático }\end{array}$ \\
\hline \multirow{2}{*}{ 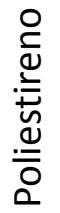 } & & 2904,2852 & Vibração assimétrica da ligação $\mathrm{CH}_{2}$ \\
\hline & {$\left[\begin{array}{l}C \\
1 \\
H\end{array}\right.$} & 796,760 & Estiramento fora do plano da ligação $\mathrm{C}-\mathrm{H}$ \\
\hline
\end{tabular}

Fonte: BEYERS (2003) e WORKMAN (2001).

Na Tabela 8 são apresentados os espectros Raman do monômero, estireno; polímero, poliestireno e da água e seus picos caraterísticos. 
Tabela 8 - Espectros Raman

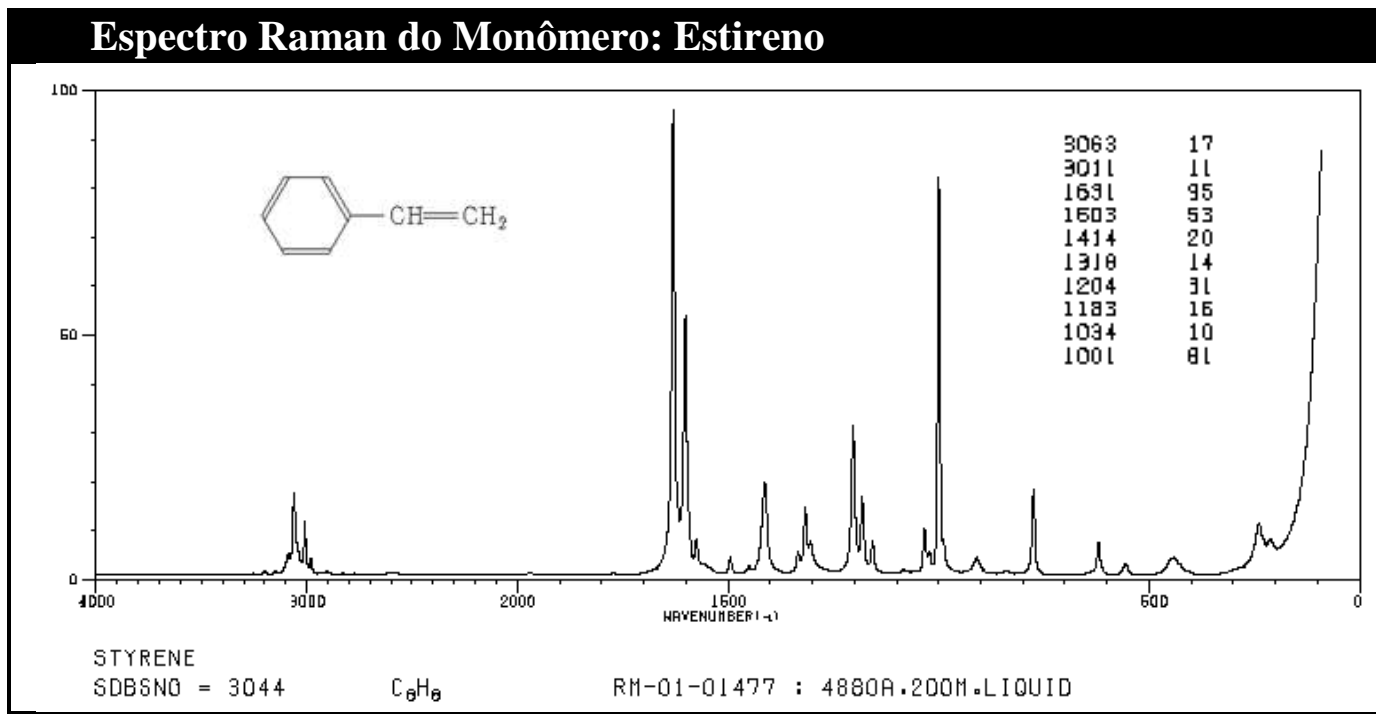

\section{Espectro Raman do Polímero: Poliestireno}

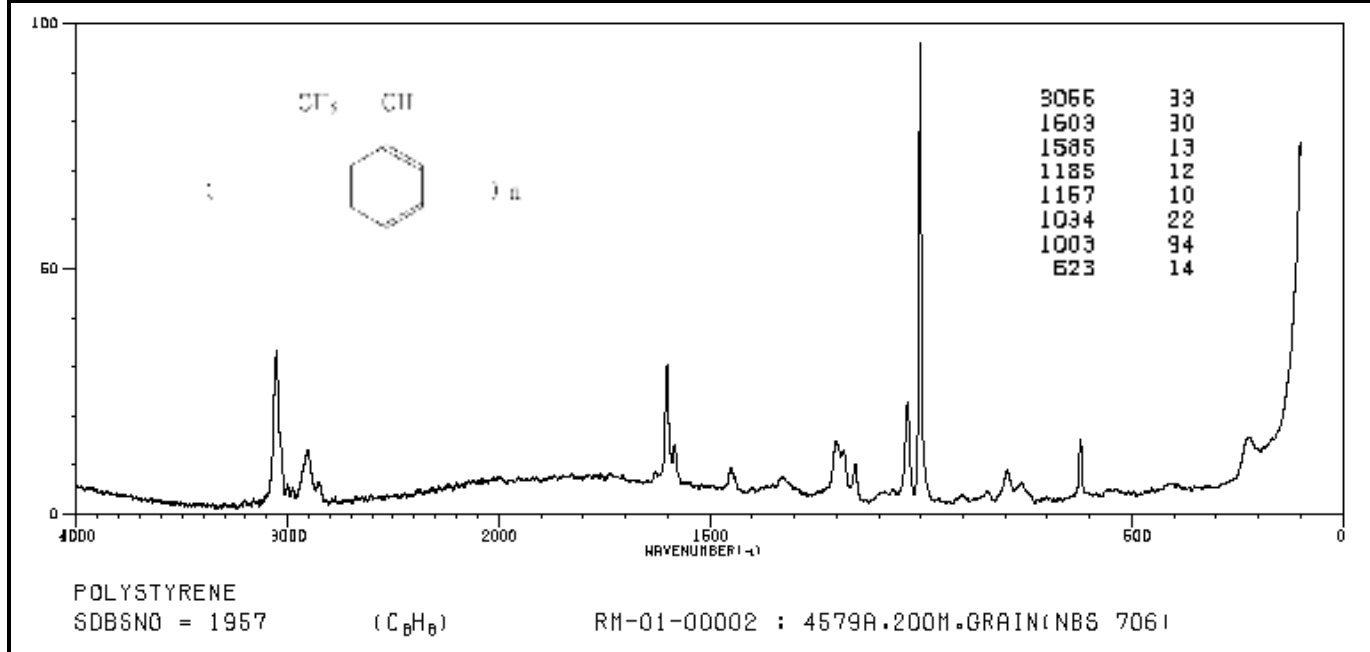

\section{Espectro Raman da Água}

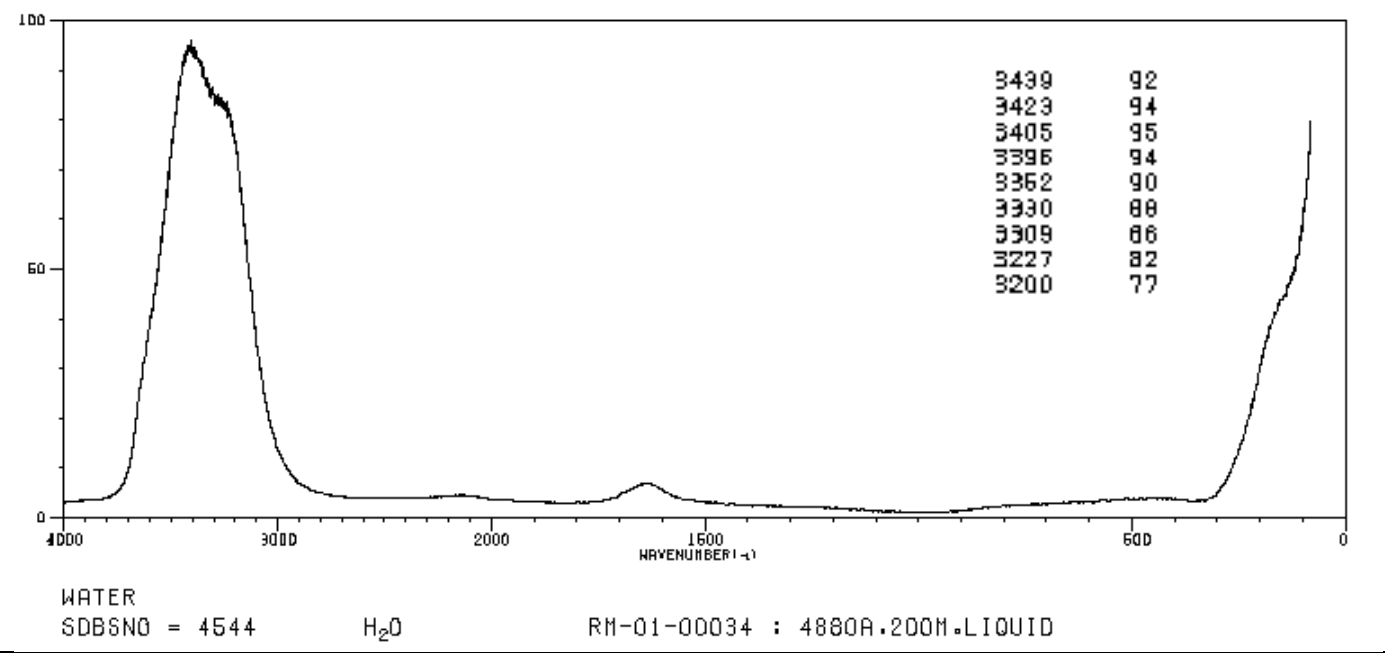

Fonte: "Spectral Database for Organic Compounds SDBS" ( 2015). 


\subsection{Modelagem da Cinética de polimerização em miniemulsão}

O desenvolvimento, entendimento, uso e aprimoramento de modelos matemáticos são importantes para permitir um melhor entendimento do processo antes da sua experimentação. Os modelos funcionam como um reservatório de informações sobre o processo e permitem que algumas interações e informações sejam obtidas e, que dificilmente seriam conhecidas ou visualizadas experimentalmente. Além disso, por concentrarem informações e serem transferíveis, são muito importantes também para o treinamento de pessoas e, para o ensino (DUBE; HAMIELEC, 1997).

O processo de polimerização em miniemulsão é amplamente estudado. No entanto, do ponto de vista de mecanismos de nucleação, ainda apresenta diversas oportunidades de melhoria.

A polimerização em miniemulsão envolve compostos com baixa afinidade por isso acontece na presença de agentes estabilizantes e co-estabilizantes. Ao longo da polimerização, a composição do meio muda e suas propriedades também, pois as propriedades dos reagentes e produtos são diferentes.

Essas e outras questões são levadas em consideração para elaboração do modelo matemático. O equacionamento dos fenômenos envolvidos no processo de polimerização em miniemulsão é bastante complexo por se tratar de um processo muito dinâmico. Há diversas referências na literatura para o processo em questão com diferentes abordagens propostas para os fenômenos envolvidos no processo. A seguir, uma breve descrição das principais referências utilizadas.

Cortina (2007) em sua dissertação de mestrado e Bresolin (2013) em sua tese de doutorado apresentaram a modelagem matemática de polimerização em miniemulsão utilizando iniciador organossolúvel e hidrossolúvel.

Asua (2003) propôs um novo modelo para a dessorção de radicais para polimerização em emulsão. Esse trabalho demonstra que os modelos anteriores a este estavam errados com relação à dependência da taxa de dessorção de radicais. A nova abordagem leva em consideração a dependência da taxa de dessorção em função do número de radicais poliméricos, tamanho de partículas, tipo de iniciador e concentração. Pelo ponto de vista mecanístico do processo, a compartimentalização dos radicais é uma das características mais marcantes da polimerização em emulsão. Tanto a taxa de polimerização quanto o peso molecular dependem do número de radicais por partículas, e esse por sua vez, depende da razão entre a entrada de radicais nas partículas e a saída 
de radicais das partículas e também da terminação bimolecular nas partículas poliméricas. Por essa razão, é de extremo interesse o desenvolvimento de modelos preditivos para esses processos.

Penlidis et al. (2002) publicaram uma revisão bibliográfica com modelagem matemática, simulação e base de dados para polimerização em emulsão. Revisam nesse trabalho abordagens clássicas e propõem um modelo genérico para balanço de massa molar, balanço de energia, balanço populacional e balanço de partículas com validação experimental. O objetivo do modelo proposto foi ser simultaneamente flexível, confiável e prático.

Dubé et al. (1997) apresentaram uma revisão bibliográfica com a modelagem matemática de polimerização multicomponente por crescimento de cadeia em reatores batelada, semi-batelada e continuo. Trata-se de uma extensão do trabalho de Hamielec et al (1987). Entre as abordagens apresentadas, inclui modelos para as constantes cinéticas de terminação, propagação e iniciação controlados por difusão, ou e seja, relacionam as constantes com a composição do meio reacional, quantidade de radicais, tipo de radicais. Inclui modelagem para a nucleação das partículas micelar e homogênea. E adota a hipótese de que as partículas são monodispersas.

A seguir, apresenta-se a modelagem matemática do processo detalhadamente com todas as equações e premissas adotadas no modelo. 


\section{MODELO MATEMÁTICO DO PROCESSO DE POLIMERIZAÇÃO EM MINIEMULSÃO DE ESTIRENO}

A reação de polimerização em miniemulsão é realizada via radicais livres. A Tabela 9 apresenta as etapas da cinética do polimerização para o monômero estireno em que cada reação do mecanismo está referenciada juntamente com sua respectiva constante cinética.

Tabela 9- Cinética de polimerização via radicais livres.

\begin{tabular}{|c|l|c|c|c|}
\hline \multirow{2}{*}{ Iniciação } & Decomposição do iniciador & $I \rightarrow 2 I \bullet$ & $\mathrm{k}_{\mathrm{d}}$ & (1) \\
\cline { 2 - 5 } & Iniciação do monômero & $I \bullet+M \rightarrow R_{1} \bullet$ & $\mathrm{k}_{\mathrm{i}}$ & (2) \\
\hline Propagação & De radicais & $R_{n} \bullet+M \rightarrow R_{n+1} \bullet$ & $\mathrm{k}_{\mathrm{p}}$ & (3) \\
\hline \multirow{2}{*}{ Terminação } & Combinação & $R_{j} \bullet+R_{n} \bullet \rightarrow P_{j+n}$ & $\mathrm{k}_{\mathrm{tc}}$ & $(4)$ \\
\cline { 2 - 5 } & Desproporcionamento & $R_{j} \bullet+R_{n} \bullet \rightarrow P_{j}+P_{n}$ & $\mathrm{k}_{\mathrm{td}}$ & $(5)$ \\
\hline \multirow{3}{*}{$\begin{array}{c}\text { Transferência } \\
\text { de cadeia }\end{array}$} & Monômero & $R_{j} \bullet+M \rightarrow P_{j}+R_{1} \bullet$ & $\mathrm{k}_{\mathrm{tm}}$ & $(6)$ \\
\cline { 2 - 5 } & Polímero & $R_{j} \bullet+P_{n} \rightarrow P_{j}+R_{n} \bullet$ & $\mathrm{k}_{\mathrm{tp}}$ & (7) \\
\cline { 2 - 5 } & Impurezas ou solvente & $R_{j} \bullet+N \rightarrow P_{j}+N \bullet$ & $\mathrm{k}_{\mathrm{tmp}}$ & (8) \\
\hline
\end{tabular}

Cada etapa pode ser sucintamente descrita como segue:

A Iniciação é caracterizada pela decomposição do iniciador (I), produzindo dois radicais livres $(\mathrm{I} \bullet)$, os quais reagem com o monômero $(\mathrm{M})$, iniciando uma cadeia polimérica $\left(R_{1} \bullet\right)$.

A Propagação é caracterizada pela reação entre um monômero $(\mathrm{M})$ e um radical monomérico $\left(R_{n} \bullet\right)$ produzindo um radical polimérico $\left(R_{n+1} \bullet\right)$.

A Terminação é caracterizada pela inativação de radicais poliméricos através da combinação de dois radicais poliméricos $\left(R_{j} \bullet e R_{n} \bullet\right)$ que reagem produzindo uma $\left(P_{j+n}\right)$ ou duas $\left(P_{j}\right.$ e $\left.P_{n}\right)$ cadeias poliméricas inativas.

Por fim, a Transferência de cadeia é caracterizada pela reação entre uma molécula e um radical polimérico, na qual o radical é tranformado em cadeia inativa. Quando essa molécula for um monômero (M), será denominada de transferência de cadeia para monômero; quando for um polímero $\left(P_{n}\right)$, será denominada por transferência de cadeia para polímero e, para impurezas e/ou solvente $(\mathrm{N})$, também será denominada transferência de cadeia. 
Nas reações de polimerização em miniemulsão, ocorrem também variações devido à variação na composição do meio reacional durante a reação de polimerização e devido a gradientes de concentrações e solubilidades das espécies nas fases contínua e dispersa. Podem-se elencar as principais variações que ocorrem com as transferências e massas abaixo:

- Transferência de radicais livres entre as partículas e a fase aquosa - entrada e saída de radicais das partículas;

- Transferência de emulsificante entre a fase aquosa e as partículas de polímero em crescimento;

- Transferência de emulsificante e/ou monômero entre as gotículas de monômero e a fase aquosa;

- Transferência de monômero livre entre a fase aquosa e as partículas poliméricas em crescimento.

Todas essas considerações foram levadas em conta para a elaboração do modelo matemático. Além disso, para a construção do modelo, foram consideradas como premissas: reator batelada perfeitamente agitado, reações elementares e irreversíveis, sistema isotérmico, constantes cinéticas não dependem do tamanho da cadeia polimérica ou do radical livre e radicais na fase aquosa em estado pseudo-estacionário.

\subsection{Balanço de Massa Global}

A reação de polimerização modelada acontece em um reator batelada. Por essa razão, não há corrente de entrada $\left(F_{\text {entrada }}=0\right)$ nem de saída no reator $\left(F_{\text {saída }}=0\right)$. Assim:

$$
\frac{d m_{\text {reator }}}{d t}=\rho_{\text {entrada }} F_{\text {entrada }}-\rho_{\text {saída }} F_{\text {saída }}=0
$$

onde: $m_{\text {reator }}$ é a massa dentro do reator; $\rho_{\text {entrada }} \rho_{\text {saída }}$ são as densidades da corrente de entrada e da corrente de saída e $F_{\text {entrada }}, F_{\text {saída }}$ são as vazões volumétricas de entrada e saída. 


\subsection{Balanço de Massa por Componentes}

\subsubsection{Monômero}

Novamente, a reação modelada acontece em reator batelada, por isso, não há corrente de entrada de monômero, apenas os termos de consumo.

O monômero é consumido pelas reações do monômero com radicais livres na fase dispersa e com radicais poliméricos presentes na fase dispersa.

$$
V_{r} \frac{d M}{d t}=-\frac{k_{p}^{i i} M^{i i} \tilde{n} N_{p}}{N_{A}}-k_{p}^{i} R_{t o t} M^{i} V^{i}
$$

Equação 6

onde: $k_{p}^{i}$ e $k_{p}^{i i}$ são as constantes cinéticas de propagação do monômero na fase contínua e na fase dispersa; $M, M^{i}$ e $M^{i i}$ são as concentrações mássicas de monômero total no reator, na fase contínua e na fase dispersa; $V_{r}$ e $V^{i}$ são os volumes total do reator e o volume da fase contínua; $N_{p}$ é o número de partículas; $N_{A}$ é o número de Avogadro; $\tilde{n}$ é o número médio de radicais por partícula e $R_{\text {tot }}$ é a concentração mássica total de radicais.

\subsubsection{Iniciador}

O iniciador sofre decomposição térmica e participa apenas da reação de decomposição.

$$
\frac{d m_{I}}{d t}=\frac{d I V_{r}}{d t}=-k_{d} I V_{r} \leftrightarrow \frac{d I}{d t}=-k_{d} I
$$

onde: $m_{I}$ é a massa de iniciador; I é a concentração mássica de iniciador; $k_{d}$ é a constante cinética de decomposição do iniciador e $V_{r}$ é o volume do reator.

\subsection{3 Água}

A água não é consumida por nenhuma reação e também não é alimentada nem retirada do reator ao longo do processo. Por isso, não há variação da quantidade de água ao longo de todo o processo.

$$
\frac{d W}{d t}=0
$$

onde: W é a concentração mássica de água no reator 


\subsubsection{Emulsificante}

O emulsificante tem papel decisivo durante o processo de polimerização. A sua concentração definirá o tipo de nucleação que acontecerá, conforme apresentado na Tabela 10.

Tabela 10 - Tipo de nucleação em função da concentração de tensoativo

\begin{tabular}{|l|l|}
\hline$E \geq E_{C M C}$ & Nucleação Micelar \\
\hline$E<E_{C M C}$ & Nucleação das Gotas \\
\hline
\end{tabular}

A quantidade total de tensoativo presente no reator, E, está distribuída na forma de tensoativo presente nas micelas, adsorvido nas partículas poliméricas e dissolvido na fase contínua, conforme mostra a Equação 9.

$$
V_{r} E=V^{i} E^{i}+\beta_{E} N_{m i c}+A_{p t} E_{a d s}
$$

onde: $\mathrm{N}_{\text {mic }}$ é o número total de micelas no reator; E, $E^{i}$ e $E_{a d s}$ são as concentrações de tensoativo total, na fase aquosa e adsorvido nas partículas; $V_{r}$ e $V^{i}$ são os volumes total do reator e volume da fase aquosa; $A_{p t}$ é a área superficial total de todas as partículas poliméricas e, $\beta_{\mathrm{E}}$ é a massa de tensoativo por micela que é calculado por:

$$
\beta_{E}=\frac{P M_{E} 4 \pi r_{m}^{2}}{a_{s}}=\frac{P M_{E} f_{m i c}}{N_{a}}
$$

onde: $a_{s}$ é a área superficial coberta por uma molécula de tensoativo; $P M_{E}$ é o peso molecular do tensoativo; $N_{a}$ é o número de Avogadro; $f_{m i c}$ é o número de moléculas de tensoativo por micela e $r_{m}$ é o raio de uma micela.

A reação de polimerização em miniemulsão é caracterizada pela nucleação nas gotas de monômero estabilizadas pelo tensoativo e co-estabilizante. E isso acontece em concentrações de tensoativo na fase aquosa abaixo da concentração micelar crítica.

A concentração de surfactante na fase aquosa é calculada por:

$$
E^{i}=E^{\text {total }}-\frac{a_{p t}}{a_{s} V^{i}}
$$


onde: $E^{\text {total }}$ e $E^{i}$ são as concentrações de tensoativo total e na fase aquosa; $V^{i}$ é o volume da fase aquosa; $a_{s}$ é e a área superficial coberta por uma molécula de tensoativo e, $a_{p t}$ é a área total das partículas, sendo dada por:

$$
a_{p t}=\pi D_{p}^{2} N_{p}
$$

Equação 12

onde: $D_{p}$ é o diâmetro médio das partículas poliméricas e $N_{p}$ é o número de partículas.

Os valores de $a_{s}$ dependem do tensoativo utilizado e também do monômero. Para lauril sulfato de sódio utilizou-se $a_{s}=42,0 \dot{A} /$ molécula (BRESOLIN, 2013).

O modelo proposto primeiramente compara a concentração de tensoativo presente na fase contínua com a concentração micelar crítica do tensoativo, e após isso, calcula o número de micelas presentes no reator e a concentração de tensoativo adsorvido nas partículas. Com os resultados, o processo em questão pode ser enquadrado em dois casos: CASO 1 ou CASO 2, conforme descrição a seguir:

- CASO 1: onde a concentração de tensoativo na fase contínua é maior do que a concentração micelar crítica, então, há formação de micelas e o tensoativo encontra-se adsorvido na superfície das partículas e o restante formando micelas. Nesse caso há nucleação micelar.

- CASO 2: onde a concentração de tensoativo na fase contínua é menor do que a concentração micelar crítica, então, não haverá formação de micelas e o tensoativo encontra-se adsorvido na superfície das partículas. Nesse caso há nucleação nas gotas.

Caso 1:

$$
E_{a d s}=E_{a d s}^{s a t}=\frac{P M_{E}}{a_{s}}
$$

$E^{i}>E_{C M C}$

$$
N_{\text {mic }}=\frac{1}{\beta_{E}}\left(V_{r} E-E_{C M C} V^{i}-A_{p t} E_{\text {ads }}^{s a t}\right)
$$

onde: $E_{\text {ads }}$ é a concentração de tensoativo adsorvido nas partículas; $E_{\text {ads }}^{\text {sat é a }}$ concentração de saturação do tensoativo; $E_{C M C}$ é a concentração micelar crítica; E é a concentração total de tensoativo no reator; $P M_{E}$ é o peso molecular do tensoativo; $a_{s}$ é a área superficial coberta por uma molécula de tensoativo; $A_{p t}$ é a área superficial total de todas as partículas poliméricas; $N_{\text {mic }}$ é o número total de micelas no reator; $\beta \_$E é a massa de tensoativo por micela e, $V^{i}$ e $V_{r}$ são os volume total e da fase aquosa. 
Caso 2: $\quad N_{m i c}=0$

Equação 15

$$
\begin{aligned}
& E^{i} \leq E_{C M C} \quad \theta=\frac{k^{\prime} E^{i}}{1+k^{\prime} E^{i}} \\
& E_{a d s}=\frac{P M_{E} \theta}{a_{s}}
\end{aligned}
$$

Equação 17

onde: $E_{a d s}$ é a concentração de tensoativo adsorvido nas partículas; $E^{i}$ é a concentração total de tensoativo na fase aquosa; $P M_{E}$ é o peso molecular do tensoativo; $a_{s}$ é a área superficial coberta por uma molécula de tensoativo; $N_{\text {mic }}$ é o número total de micelas no reator; $k^{\prime}$ é o coeficiente de adsorção de tensoativo pelas partículas e, $\theta$ é a fração de área recoberta pelo tensoativo.

\subsubsection{Partição entre as Fases}

Há duas fases presentes na miniemulsão: a fase contínua e a fase dispersa.

A fase contínua (i) é composta por água e pelo monômero que de acordo com o coeficiente de partição apresenta-se presente na fase contínua em pequena concentração.

A fase dispersa (ii) é composta principalmente por monômero não reagido e pelo polímero formado

O monômero se divide entre as duas fases, de acordo com o coeficiente de partição $\mathrm{K}^{p}$ :

$$
K^{p}=\frac{M^{i i}}{M^{i}}
$$

onde: $M^{i}$ é a concentração mássica de monômero na fase contínua; $M^{i i}$ é a concentração de monômero na fase dispersa e $\mathrm{K}^{p}$ é o coeficiente de partição.

Isolando Mi, obtém-se:

$$
M^{i}=\frac{M^{i i}}{K^{p}}
$$

Equação 19

$\mathrm{O}$ volume total do reator, $V_{r}$, é fornecido pela somatória entre o volume da fase contínua, $V^{i}$, e o volume da fase dispersa, $V^{i i}$ :

$$
V_{r}=V^{i}+V^{i i}
$$


A massa total de monômero é fornecida pela soma da massa de monômero presente na fase aquosa e na fase contínua:

$$
V_{r} M=V^{i} M^{i}+V^{i i} M^{i i}
$$

Substituindo-se a Equação 19 na Equação 21, obtém-se:

$$
M^{i i}=\frac{V_{r} M}{\left(\frac{V^{i}}{K^{p}}+V^{i i}\right)}
$$

Para validar os valores iniciais dos volumes supostos, recalculam-se os volumes da fase contínua $\left(V_{j+1}^{i}\right)$ e da fase dispersa $\left(V_{j+1}^{i i}\right)$.

Considerando-se que o volume total da fase contínua é a soma dos volumes de monômero e de água presentes na fase contínua, obtém-se:

$$
V_{j+1}^{i}=V_{j}^{i}\left(\frac{M^{i}}{\rho}+\frac{W^{i}}{\rho_{w}}\right)
$$

onde: $\rho$ é a densidade da mistura presente no reator; $\rho_{w}$ é a densidade da água; $W^{i}$ é a concentração mássica de água na fase contínua e $M^{i}$ é a concentração mássica de monômero na fase contínua.

Analogamente, considerando-se que o volume total da fase dispersa é a soma dos volumes de monômero, e de polímero presentes na fase dispersa, obtém-se:

$$
V_{j+1}^{i i}=V_{j}^{i i}\left(\frac{M^{i i}}{\rho}+\frac{P^{i i}}{\rho_{P}}\right)
$$

Equação 24

onde: $\rho$ é a densidade da mistura presente no reator; $\rho_{p}$ é a densidade do polímero; $P^{i i}$ é a concentração mássica de polímero na fase dispersa e $M^{i i}$ é a concentração mássica de monômero na fase dispersa.

Considerando-se que o polímero é formado pelo consumo de monômero, então, a concentração de polímero na fase dispersa será dada pela diferença entre a massa de monômero alimentada no reator $\left(M^{\text {alimentado }}(t=0)=M(0)\right)$ e a concentração de monômero no tempo em questão $(M(t))$.

$$
P^{i i}=\frac{V_{r}}{V^{i i}}\left(M^{\text {alimentado }}-M\right)
$$


O cálculo da partição do monômero entre as fases contínua e discreta é iterativo e leva em consideração que o volume total é a somatória dos volumes da fase dispersa com o volume da fase contínua. O algoritmo utilizado baseou-se em CORTINA (2007).

(1) Supor valor inicial para $V_{j}^{i}$,

(2) Calcular $V_{j}^{i i}$, com a Equação 20,

(3) Calcular $M^{i i}$ com a Equação 22,

(4) Calcular $M^{i}$ com aEquação 19,

(5) Calcular $V_{j+1}^{i}$ com a Equação 23,

(6) Calcular $P^{i i}$ com a Equação 25,

(7) Calcular $V_{j+1}^{i i}$ com a Equação 24,

(8) Continuar até que $V_{j}^{i} \approx V_{j+1}^{i}$ e $V_{j}^{i i} \approx V_{j+1}^{i i}$.

\subsubsection{Radicais}

De acordo com as premissas adotadas inicialmente, assume-se a Hipótese de Estado pseudo-estacionário para os radicais gerados ao longo da reação. Essa hipótese é adotada quando moléculas de intermediários ativos tem uma vida muito curta, devido à sua alta reatividade, isto é, quando apresentam altas velocidades específicas de reação (FOGLER, 2002). Assim, considera-se que a velocidade de formação dos radicais é igual a sua velocidade de consumo.

Os radicais dividem-se de acordo com o número de meros (h) que o compõem que alteram a sua solubilidade no meio, conforme mostra a Tabela 11.

Tabela 11 - Definição das equações de concentração mássica de radicais poliméricos de acordo com o tamanho da cadeia propagada.

\section{Quantidade de Meros $\quad$ Concentração mássica de radicais de tamanho $h$}

$$
\boldsymbol{h}=\mathbf{1} \quad R_{1}=\frac{2 f k_{d} I}{k_{p}^{i} A^{i}+k_{t}^{i} R_{\text {tot }}} \quad \text { Equação } 26
$$

$$
\begin{array}{ccc}
\mathbf{2} \leq \boldsymbol{h} \leq \mathbf{z}-\mathbf{1} & R_{\text {não entram }}=R_{1} \sum_{h=2}^{z-1} \propto^{h-1} & \text { Equação 27 } \\
\mathbf{z} \leq \boldsymbol{h} \leq \boldsymbol{j}_{\text {crit }}-\mathbf{1} & R_{\text {podem entrar }}=R_{1} \propto^{z-2} \sum_{h=z}^{j c r i t-1} \beta^{h-z+1} & \text { Equação 28 }
\end{array}
$$


Na Tabela 11, $h$ identifica a quantidade de meros presentes no radical polimérico; $z$ é o tamanho do menor radical que pode entrar em uma micela ou partícula; $\boldsymbol{j}_{\text {crit }}{ }^{-1}$ é o tamanho do maior radical presente na fase aquosa; $R_{1}$ é a concentração molar de radicais com um único mero; $R_{\text {não entram }}$ é a concentração molar de radicais que não

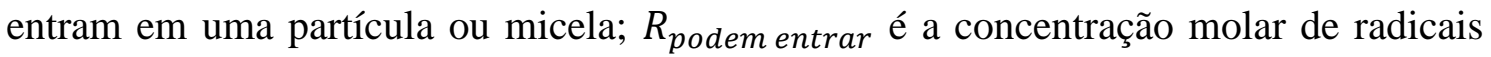
que podem entrar em uma partícula ou micela; $f$ é o fator de eficiência da decomposição térmica do iniciador; $k_{d}$ é a constante cinética de decomposição do iniciador; $k_{p}^{i}$ é a constante cinética de propagação na fase contínua; $k_{t}^{i}$ é a constante cinética de terminação na fase contínua; $A^{i}$ é a concentração molar de monômero na fase aquosa; $R_{\text {tot }}$ é a concentração molar total de radicais na fase contínua; I é a concentração mássica de iniciador e, $\alpha$ e $\beta$ serão definidos pela Equação 35 e Equação 36.

\subsubsection{Balanço dos radicais no meio contínuo}

Os radicais presentes no meio contínuo apresentam-se nas três formas apresentadas na Tabela 11. Com um mero, radicais que não podem entrar nas micelas ou partículas por sua solubilidade no meio aquoso e, radicais que já possuem pouca afinidade com água, podendo entrar na micela, partícula ou sofrer nucleação homogênea. Assim, a quantidade total de radicais presentes na fase aquosa é dada pela Equação 29.

$$
\begin{gathered}
R_{\text {tot }}=\sum_{h=1}^{j c r i t-1} R_{h} \\
R_{\text {tot }}=R_{1}+R_{\text {não entram }}+R_{\text {podem entrar }} \\
R_{\text {tot }}=R_{1}\left(1+\sum_{h=2}^{z-1} \propto^{h-1}+\propto^{z-2} \sum_{h=z}^{j c r i t-1} \beta^{h-z+1}\right)
\end{gathered}
$$

Para calcular $R_{\text {tot }}$ é necessário conhecer $R_{1}$, por isso, esse cálculo é realizado de maneira iterativa. Sendo: 


$$
\begin{aligned}
& A^{i}=\frac{M_{i}}{P M_{M}} \\
& \lambda=k_{p}^{i} A^{i} \\
& \psi=k_{p}^{i} A^{i}+k_{t}^{i} R_{\text {tot }} \\
& \alpha=\frac{\lambda}{\psi} \\
& \beta=\frac{\lambda}{\psi+\left(k_{e} \frac{N_{p}}{N_{a}}+k_{a m} \frac{N_{m i c}}{N_{a}}\right) V_{r}} \\
& k_{e}=f_{k e} 4 \pi D_{w} N_{a} R_{\text {pinch }} \\
& k_{a m}=f_{a m} 4 \pi D_{w} N_{a} R_{m} \\
& N_{p}=\frac{v_{\text {particulas }}^{\text {total }}}{v_{\text {particula }}^{\text {unitário }}} \\
& D_{p}=\frac{6}{\pi} \sqrt[3]{\frac{\frac{m_{m}}{\rho_{m}}(1-X)+\frac{m_{m} \cdot X+m_{P S}}{\rho_{p}}+\frac{m_{c o}}{\rho_{c o}}}{N_{p}}}
\end{aligned}
$$

onde: $A^{i}$ é a concentração molar de monômero na fase aquosa; $R_{\text {tot }}$ é a concentração mássica total de radicais; $k_{p}^{i}$ é a constante cinética de propagação na fase contínua; $k_{t}^{i}$ é a constante cinética de terminação na fase contínua; $\rho$ é a densidade da mistura presente no reator; $\rho_{p}, \rho_{c o}$ e $\rho_{a n}$ as densidades do polímero, co-etabilizante e agente nuclear; $m_{t}$, $m_{m}, m_{c o}$, e $m_{P S}$ são as massas total, de monômero, co-estabilizante hexadecano e poliestireno adicionado como co-estabilizante; $M^{i}$ é a concentração mássica de monômero na fase contínua; $P M_{M}$ é o peso molecular do monômero; $N_{\text {mic }}$ é o número total de micelas no reator; $N_{p}$ é o número de partículas; $N_{a}$ é o número de Avogadro; $D_{p}$ diâmetro médio das partículas poliméricas obtidas ao final da polimerização; $\mathrm{X}$ é a conversão de monômero; $k_{e}$ e $k_{a m}$ são os coeficientes de entrada de radicais pela micela e de absorção de radicais pela micela; $f_{k e}$ e $f_{a m}$ são os fatores de ajuste de $k_{e}$ e $k_{a m} ; D_{w}$ é a difusividade do monômero em água; $R_{\text {pinch }}$ é o raio da partícula inchada; $R_{m}$ é a o raio das micelas e $V_{r}$ é o volume total. 
O número total de partículas presentes foi obtido pela Equação 39, e o diâmetro médio das partículas pela Equação 40.

\subsubsection{Balanço de partículas}

O balanço das partículas presentes no látex é realizado considerando que a variação do número de partículas pode ser ocasionada por uma possível coagulação das partículas, e pela existência de nucleação homogênea ou nucleação micelar. A nucleação nas gotas não altera o número total de partículas presentes no meio.

O modelo em questão verifica a solubilidade do iniciador, se hidrossolúvel ou organo-solúvel, para prosseguir com a avaliação das possíveis formas de propagação do monômero.

A propagação pode ocorrer por três diferentes mecanismos de nucleação que dependerão da concentração do tensoativo e da concentração micelar crítica do tensoativo.

- Nucleação Micelar: quando a concentração de tensoativo está acima da concentração micelar crítica CMC;

- Nucleação Homogênea: dependerá da solubilidade do monômero na água e nas gotas.

- Nucleação nas gotas: ocorre quando a concentração do tensoativo estiver abaixo da concentração micelar crítica.

Para o processo de polimerização em miniemulsão, uma de suas características determinantes é a nucleação ocorrendo nas gotas de monômeros estabilizadas. No entanto, o modelo desenvolvido segue o raciocínio descrito na Figura 14. 
Figura 14 - Sequência para determinação do mecanismo de nucleação

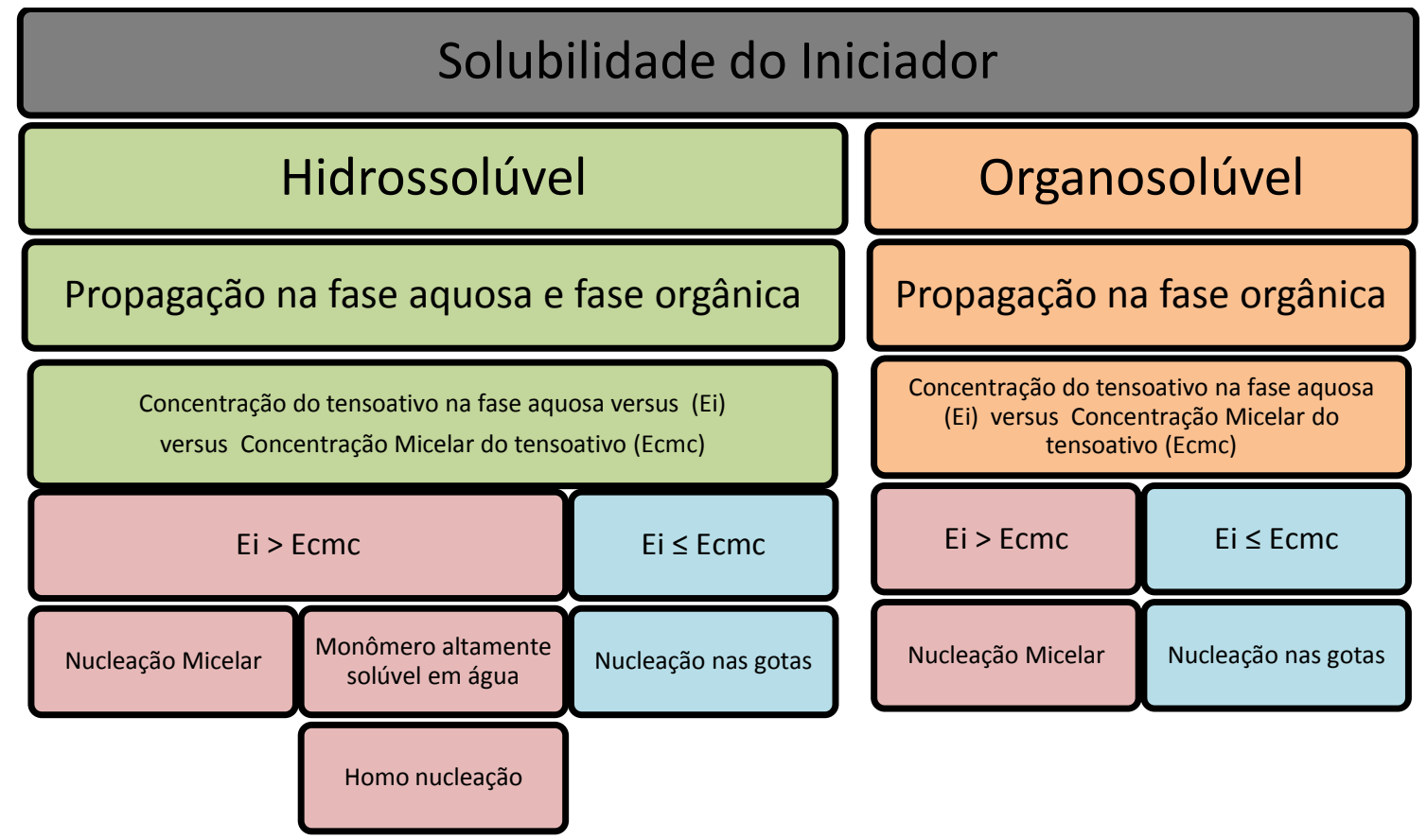

Assim, o balanço para as partículas pode ser escrito conforme a Equação 41.

$$
\begin{array}{cc}
\frac{d N_{p}}{d t}=\frac{\left(\text { NucTot }-k_{\text {coag }} \cdot N_{p}^{2}\right)}{V_{r}} & \text { Equação } 41 \\
N u c T o t=N u c M i+N u c H o & \text { Equação } 42 \\
N u c M i c=k_{a m} N_{m i c} R_{T}^{e n t} & \text { Equação } 43 \\
N u c H o=N_{A} V^{i} R_{1} \alpha^{j z-2} \beta^{j c r i t-j z}\left(k_{h} M^{i}\right) & \text { Equação } 44
\end{array}
$$

onde: NucTot é o número total de partítulas que sofreram nucleação; NucMi é o número de partículas que sofreram nucleação micelar; $N u c H o$ é o número de partículas que sofreram nucleação homogênea; $N_{p}$ é o número de partículas; $N_{a}$ é o número de Avogadro; $N_{\text {mic }}$ é o número total de micelas no reator; $k_{a m}$ é o coeficiente de absorção de radicais pela micela; $z$ é o tamanho do menor radical que pode entrar em uma micela ou partícula; $j_{\text {crit }}$ é o tamanho do maior radical presente na fase aquosa; $R_{1}$ é a concentração mássica de radicais com um único mero; $R_{T}^{e n t}$ é a concentração mássica de radicais que podem entrar em uma partícula ou micela; $M^{i}$ é a concentração mássica de monômero na fase contínua; $v^{i}$ é o volume da fase contínua; $k_{h}$ é a constante cinética de nucleação homogênea; $k_{\text {coag }}$ é a constante cinética de coagulação. 
Sendo $\alpha$ fornecido pela Equação $35, \beta$ pela Equação $36, k_{h}$ dado pela Equação 45 e L pela Equação 46, segundo FITCH, R. M.; TSAI (1971) apud DUBE; HAMIELEC, (1997).

$$
\begin{gathered}
k_{h}=k_{h o}\left(1-\frac{L \cdot A_{p}}{4 . V_{i}}\right) \\
L=\left(\frac{2 D_{w} \cdot j_{\text {crit }}}{k_{p} \cdot C_{\text {sat_mw }}}\right)
\end{gathered}
$$

onde: $C_{\text {sat_mw }}$ é a concentração de saturação do monômero em água, $D_{w}$ é a difusividade do monômero em água, $j_{\text {crit }}$ é o tamanho do maior radical presente na fase aquosa, $k_{p}$ é a constante cinética de propagação, $k_{h o}$ e $k_{h}$ são as constantes de nucleação homogênea ausente de interação e com interação entre as fases, $A_{p}$ é a área das partículas e $V_{i}$ é o volume da fase aquosa e L é o comprimento de cadeia crítico para polimerização na fase aquosa.

$$
\begin{gathered}
k_{d e s}=\frac{k_{f} M_{i i} k_{o}}{\beta \cdot k_{o}+k_{p i i} \cdot M_{i i}} \\
\operatorname{para} \beta=1 ; P=\frac{k_{o}}{k_{o}+k_{p i i} \cdot M_{i i}} \\
k_{o}=\frac{\frac{12 D_{w}}{k_{a} \cdot d_{p}^{2}}}{1+\frac{2 D_{w}}{k_{a} D_{p}}} \\
k_{a}=\frac{1}{K_{j w p}} \\
K_{j w p}=\frac{\emptyset_{m i}}{\emptyset_{p i i}} \\
\emptyset_{m i}=\frac{v_{m i}}{v_{i}} \\
\emptyset_{p i i}=\frac{v_{p i i}}{v_{i i}}
\end{gathered}
$$

onde: $k_{f}$ é a constante cinética de transferência de radicais para monômeros; $\emptyset_{m i}$ e $\emptyset_{p i i}$ são as frações volumétricas de monômero na fase contínua e de polímero na fase dispersa; $v^{i}$ e $v^{i i}$ são os volumes da fase contínua e da fase dispersa; $v_{m i}$ é o volume de monômero na fase contínua; $v_{p i i}$ é o volume de polímero na fase dispersa; $k_{p}^{i i}$ é a 
constante cinética de propagação na fase dispersa; $D_{w}$ é a difusividade do monômero em água; $D_{p}$ é a difusividade dos radicais monoméricos na fase dispersa; $M^{i i}$ é a concentração mássica de monômero na fase dispersa; $d_{p}$ é o diâmetro das partículas; $K_{j w p}$ é o coeficiente de partição do monômero entre a fase aquosa e a fase dispersa; $k_{a}$ é a taxa de absorção de radicais pelas partículas; $\mathrm{P}$ é a probabilidade de dessorção e $k_{o}$ é a taxa aproximada de difusão dos radicais para fora das partículas poliméricas. A constante de dessorção de radicais, $k_{\text {des }}$, é calculada pela Equação 47, segundo Asua et al. (1989) apud DUBE; HAMIELEC, (1997) e apud GAO; PENLIDIS, (2002).

\subsubsection{Número médio de radicais por partícula}

Para calcular o número médio de radicais por partícula, um balaço populacional deve ser escrito para partículas com zero, um, dois ou mais radicais por partícula. A solução para esse balanço pode ser obtida fazendo duas hipóteses de estado estacionário:

(a) O fluxo de radicais fluindo para a fase aquosa, ou seja, dessorção de radicais da fase dispersa, deve ser igual à taxa de absorção de radicais pela fase dispersa;

(b) A taxa de formação de partículas com $\mathrm{n}$ radicais é igual à taxa de desaparecimento de partículas com n radicais (GAO; PENLIDIS, 2002).

Toda a modelagem desenvolvida nesse trabalho depende da concentração de monômeros direta ou indiretamente e esta depende do número médio de radicais por partícula $(\tilde{n})$.

Segundo Li e Brooks (1993), existem diversas abordagens para o cálculo de $\tilde{n}$. A abordagem utilizada nesse trabalho está baseada na equação recursiva de Ugelstad et al (1967) apud GAO; PENLIDIS,(2002). Essa abordagem usa a equação de Bessel modificada e propõe uma solução numérica aproximada conforme apresentada na Equação 54. 


$$
\begin{gathered}
\tilde{n}=\frac{1}{2} \frac{a^{2} / 4}{a^{2} / 4} \\
a^{2} / 4 \\
a^{2}=\frac{8 \cdot k_{e} \cdot R_{\text {total }} \cdot N_{A} \cdot v}{k_{t} \cdot \emptyset_{p}^{p}} \\
m=\frac{a^{2} / 4}{k_{t e s} \cdot N_{A} \cdot v} \\
k_{p}^{p}
\end{gathered}
$$

Equação 55

Equação 56

onde: $\tilde{n}$ é o número médio de radicais por partícula; $k_{t}$ é a constante cinética de terminação; $k_{d e s}$ é a constante de dessorção de radicais; $\emptyset_{p}^{p}$ é a fração volumétrica de polímero na fase dispersa; $v$ é o volume de uma partícula; $N_{A}$ é o número de Avogadro; $k_{e}$ é o coeficiente de entrada de radicais nas partículas; $R_{t o t}$ é a concentração mássica total de radicais na fase contínua.

\subsection{Constantes Cinéticas}

\subsubsection{Propagação}

A constante cinética da reação de propagação leva em consideração o efeito vítreo e só começa a ser alterada quando se inicia o efeito vítreo, ou seja, quando o volume livre encontra-se abaixo do volume livre crítico.

$$
\begin{gathered}
k_{p}=k_{p}^{0} \exp \left[-B\left(\frac{1}{v_{f}}-\frac{1}{v_{f c r 2}}\right)\right], \text { sendo } \mathrm{B}=1 \\
k_{p}^{0}=1,8 \cdot 10^{12} \exp \left(-\frac{10400}{1,987 T}\right) \\
v_{f}=\left[0,025+\alpha_{P}\left(T-T_{g p}\right)\right] \frac{v_{p}}{v_{r}}+\left[0,025+\alpha_{m}\left(T-T_{g m}\right)\right] \frac{v_{m}}{v_{r}}
\end{gathered}
$$

onde: $k_{p}$ é a constante cinética de propagação; $k_{p}^{0}$ é a constante cinética de propagação na ausência de efeito das inicial; $v_{f}$ é o volume livre; $v_{f c r 2}$ é o fração de volume livre crítica para o início do efeito vítreo; B é uma constante; $T, T_{g m}$ e $T_{g p}$ são as 
temperaturas do reator, de transição vítrea do monômero e de transição vítrea do polímero; $v_{r}, v_{p}$ e $v_{m}$ são os volumes do reator, de polímero e de monômero; $\alpha_{P}$ e $\alpha_{m}$ são os coeficientes de expansão do polímero e do monômero.

\subsubsection{Terminação}

A constante cinética da reação de terminação está baseada na correlação de Hui \& Hamielec (1972), na qual a constante cinética leva em consideração o fator efeito gel.

$$
\begin{array}{cc}
k_{t}=k_{t}^{0} g_{t} & \text { Equação } 60 \\
k_{t}^{0}=6,52 \cdot 10^{16} \exp \left(\frac{-8870}{1,987 T}\right) & \text { Equação } 61
\end{array}
$$

onde: $k_{t}^{0}$ é a constante cinética de terminação inicial; $k_{t}$ é a constante cinética de terminação; T é a temperatura e, $g_{t}$ é o fator para o efeito gel, calculado por:

$$
\begin{array}{cc}
g_{t}=\exp \left[-\left(b_{s} \Phi_{p}+c_{s} \Phi_{p}^{2}+d_{s} \Phi_{p}^{3}\right)\right] & \text { Equação 62 } \\
\Phi_{p}=\frac{P i i}{\rho_{p}} & \text { Equação 63 } \\
P i i=\frac{v_{r}}{v_{i i}}\left(M W_{o}-M W_{t}\right) & \text { Equação 64 }
\end{array}
$$

onde: $\Phi_{p}$ é a fração volumétrica de polímeros nas partículas; Pii é a concentração mássica de polímero na fase dispersa; $\rho_{p}$ é a densidade do polímero; $v_{r}$ e $v_{i i}$ são os volumes do reator e o volume da fase dispersa; $M W_{o}$ e $M W_{t}$ são as concentrações mássicas do monômero no reator no instante inicial e no instante de tempo $t ; b_{s}, c_{s}$ e $d_{s}$ são constantes dependentes da temperatura calculadas por Equação 65, Equação 66 e Equação 67 respectivamente. 


$$
\begin{array}{cc}
b_{s}=2,57-0,0055 T & \text { Equação } 65 \\
c_{s}=9,56-0,0165 T & \text { Equação } 66 \\
d_{s}=-3,03-0,00785 T & \text { Equação } 67
\end{array}
$$

\subsubsection{Transferência de Cadeia de Radicais}

A transferência de cadeia de radicais para polímero é considerada desprezível pela dinâmica proporcionada pelo uso do co-estabilizante e pelo lócus da polimerização ser a própria gota.

$$
k_{f P=0}
$$

Equação 68

onde: $k_{f}$ é a constante cinética de transferência de cadeia para polímero

\subsubsection{Decomposição}

A constante de decomposição da reação de decomposição do iniciador é específica para cada molécula de iniciador utilizada. Para o caso em questão, o iniciador estudado é o KPS, portanto, a equação abaixo deve ser substituída quando outro iniciador for utilizado.

$$
k_{d}=8 \cdot 10^{15} \exp \left(\frac{-1,35 \cdot 10^{15}}{8,314 T}\right)
$$

Onde: $k_{d}$ é a constante cinética de decomposição do iniciador e $\mathrm{T}$ é a temperatura no reator.

\subsection{Simulação Matemática}

A simulação matemática foi realizada com o software MATLAB e a integração das equações diferenciais ordinárias utilizou o método explícito de Runge-Kutta de 2 e 3 ordem, através da ferramente ode23 disponível no próprio software.

Os principais dados de entrada do modelo foram:

- Condições iniciais $(\mathrm{t}=0)$ : massas dos reagentes, diâmetro, temperatura de reação;

- Parâmetros conhecidos;

- Massas molares;

- Constantes cinéticas; 
- Propriedades: densidade, concentração micelar crítica, concentração de saturação;

- Parâmetros ajustados.

Os pricipais dados de saída calculados pelo modelo são:

- Conversão;

○ Diâmetro;

- Número de partículas;

- Número médio de radicais por partícula;

- Taxa de nucleação homogênea;

- Taxa de nucleação micelar;

- Efeitos gel e vítreo;

- Concentração de monômeros e radicais poliméricos;

A validação do modelo matemático foi realizada utilizando como referência os dados experimentais de conversão obtidos através das análises gravimétricas.

\subsubsection{Simulação matemática}

O simulador é composto por 7 arquivos, sendo um, o arquivo principal e os demais, funções que são chamadas nos momentos em que seus algoritmos são necessários, conforme descrição na Tabela 12.

Tabela 12 - Descrição dos arquivos MatLab

\begin{tabular}{|ll|}
\hline Nome & Descrição \\
\hline miniemulsão & arquivo por onde a simulação se inicia \\
\hline fintegracao & função que realiza a integração das equações diferenciais ordinárias \\
\hline fpropriedades & função que calcula as propriedades dos componentes \\
\hline fgraficos & função que formata e plota os gráficos \\
\hline fdiametros & função que fornece os diâmetros experimentais para cada caso \\
\hline fotimo & função que otimiza parâmetros \\
\hline
\end{tabular}

A simulação segue o fluxo lógico apresentado na Figura 15. 
Figura 15 - Fluxo das informações calculadas ao longo da simulação

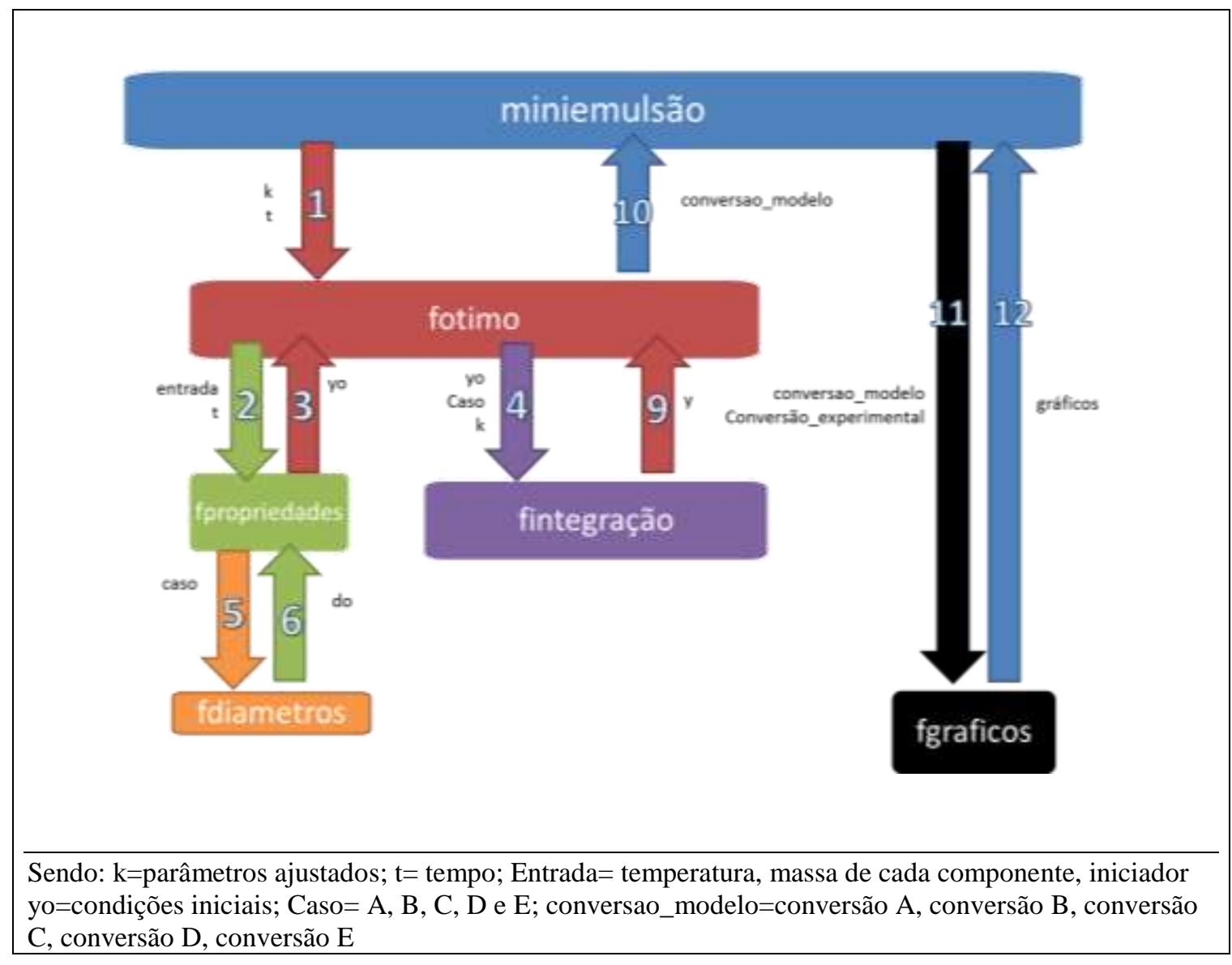

\subsubsection{Validação}

A simulação é realizada para os cinco casos avaliados experimentalmente e ao final, os dados calculados através do modelo são comparados com os dados experimentais. 


\section{MATERIAIS E MÉTODOS}

A metodologia científica adotada para o desenvolvimento deste trabalho possui duas abordagens específicas: (1 $\left.{ }^{\mathrm{a}}\right)$ Síntese e Monitoramento e, $\left(2^{\mathrm{a}}\right)$ Modelagem e Simulação. Para o desenvolvimento de cada abordagem, executaram-se diversas etapas.

$1^{\mathrm{a}}$ Abordagem - Monitoramento e Síntese: Estudo do processo, Definição de condições operacionais, Definição da formulação, Delineamento dos experimentos, Montagem do aparato experimental, Preparo da miniemulsão, Estabilidade da miniemulsão, Síntese - Polimerização, Monitoramento do processo - in line, Monitoramento do processo - off line.

$2^{\mathrm{a}}$ Abordagem - Modelagem e Simulação: Estudo das reações, Modelagem da cinética da reação, Simulação matemática, Validação.

A Figura 16 ilustra a divisão de tratamentos para a $1^{\mathrm{a}}$ Abordagem entre dois ramos principais. $O$ primeiro relaciona-se à caracterização da miniemulsão não polimerizada e o segundo relaciona-se as etapas realizadas durante e após a polimerização da miniemulsão.

Figura 16- Esquema ilustrativo da $1^{\text {a }}$ Abordagem - Monitoramento e Síntese

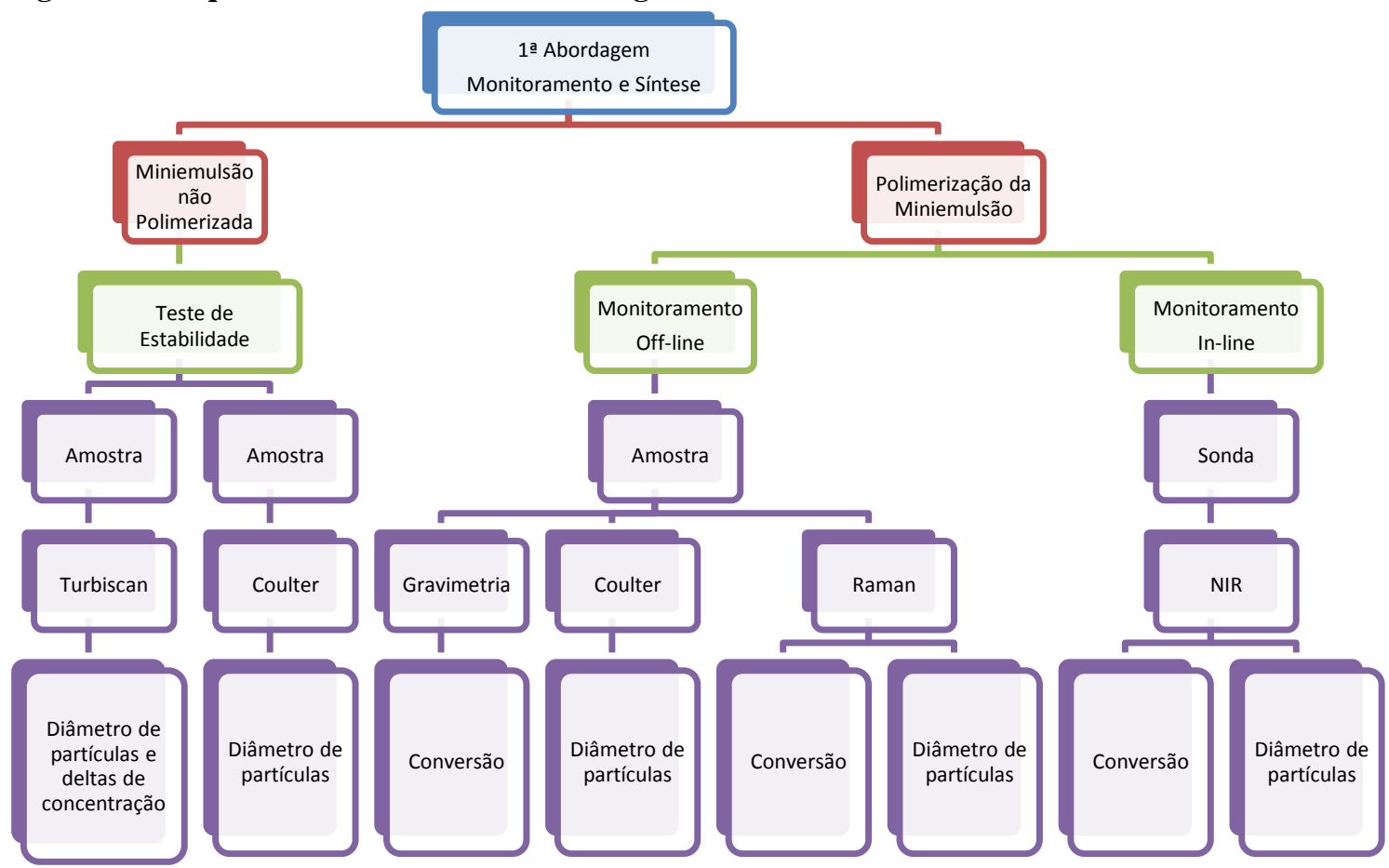


Figura 17 - Esquema ilustrativo da $2^{\mathrm{a}}$ Abordagem - Modelagem e Simulação

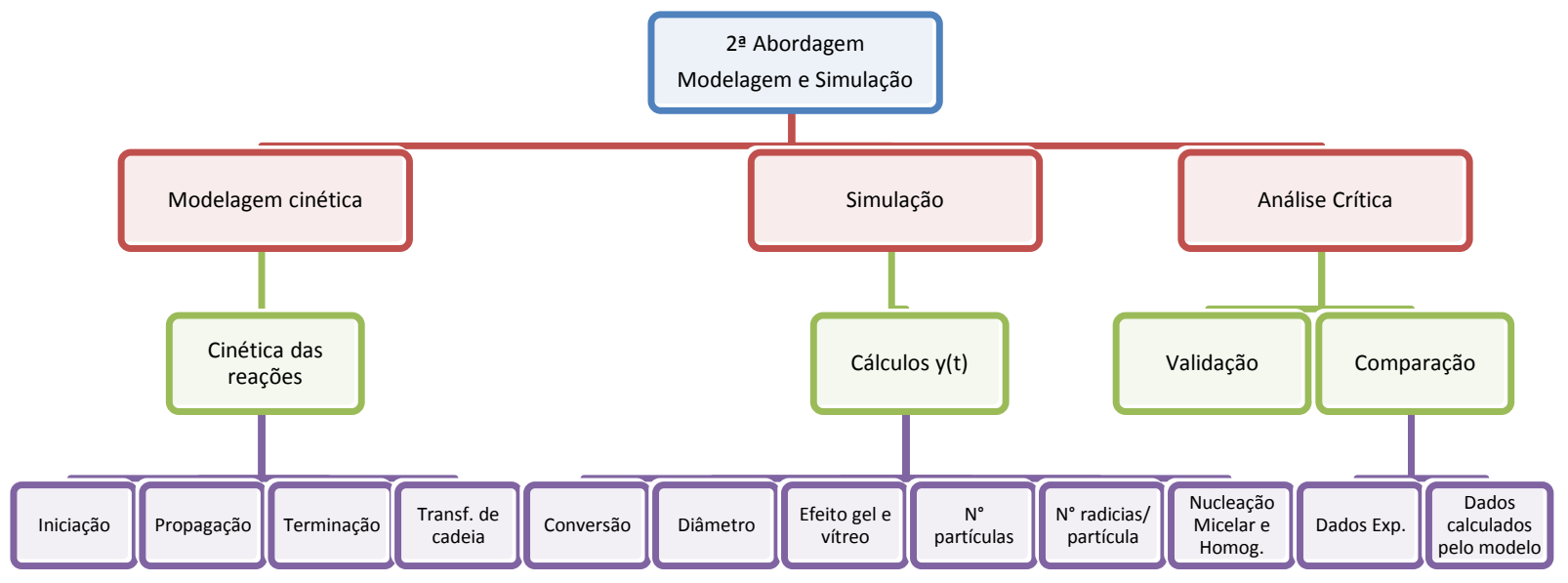

A Figura 17 ilustra a divisão de tratamentos para a $2^{\text {a }}$ Abordagem, em que há três ramos principais: o primeiro relaciona-se à modelagem da cinética de polimerização, o segundo relaciona-se com a simulação propriamente dita e o terceiro relaciona-se com a validação através de comparação dos dados experimentais com os dados calculados através do modelo matemático.

O presente capítulo está dividido em dois subitens principais, 4.1 Materiais e 4.2 Métodos. Esses subitens dividem-se de acordo com as etapas previstas em cada abordagem citada e estão apresentados de acordo com a ordem cronológica em que foram executados.

\subsection{Materiais}

\subsubsection{Unidade Experimental}

As reações foram realizadas em um reator de vidro, tipo tanque agitado, com um volume interno de $250 \mathrm{~mL}$, dotado de camisa com circulação de água, a partir de um banho termostático para controle da temperatura do meio reacional; agitador magnético para promover a mistura do meio reacional; termômetro para monitorar a temperatura do meio reacional, e condensador para evitar o arraste de monômero. A unidade experimental montada para realização dos experimentos está ilustrada na Figura 18.

A utilização de cada equipamento justifica-se pelas seguintes razões:

- Béquer de vidro de 1L: para preparo da miniemulsão monomérica;

- Condensador: Volatilidade do monômero, por isso a necessidade de um condensador para condensar eventual arraste de monômero do reator pelo gás 
inerte e para evitar erros na avaliação da conversão causados por esta evaporação.

- Termopar: para monitoramento da temperatura do meio reacional.

- Agitador Magnético: para manter o meio homogêneo ao longo do processo e evitar coalescência e depósito de polímero nas paredes do reator e da sonda

- Pipeta com fluxo contínuo de $\mathrm{N}_{2}$ : para deixar o meio inertizado e evitar a inativação dos radicais livres através de oxidação desses radicais com o oxigênio presente no ar.

- Banho termostático: para realizar a troca térmica com o reator, em duas situações: aquecimento para atingir a temperatura de reação e resfriamento para manter a temperatura durante a polimerização exotérmica.

- Reator de Vidro: equipamento onde a reação foi realizada, com capacidade de $250 \mathrm{~mL}$. O reator possui uma tampa com quatro bocais, sendo eles: o primeiro bocal (B1) utilizado para inserir a pipeta para borbulhar nitrogênio no meio reacional e também por onde as amostras são retiradas no momento da coleta; o segundo bocal (B2) utilizado para a inserção da sonda de infravermelho próximo dentro do reator; o terceiro bocal (B3) utilizado inserir o termopar e o quarto bocal (B4) utilizado para inserir o condensador.

- Sonda de Infravermelho Próximo (NIR): utilizada para o monitoramento on-line da reação.

Figura 18 - Unidade Experimental para Polimerização em Miniemulsão

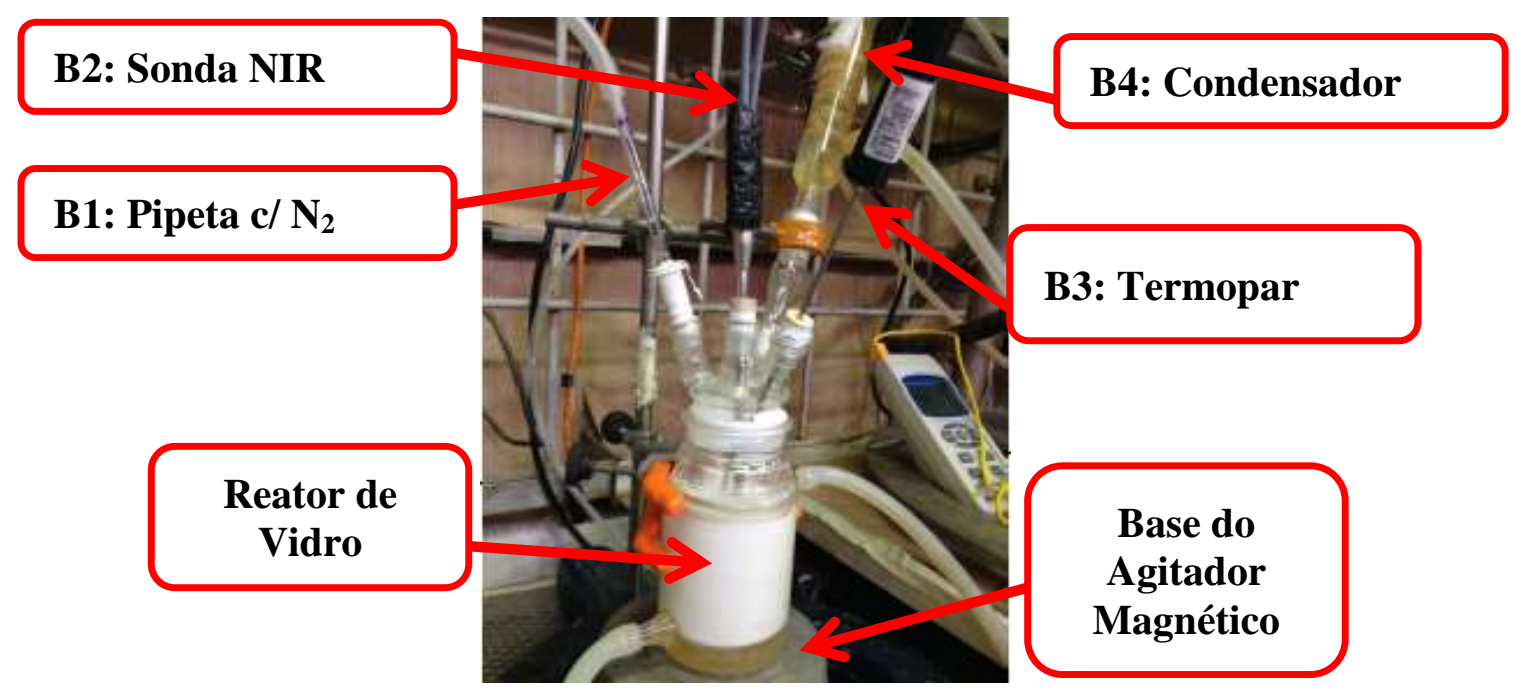




\subsubsection{Equipamentos}

A Tabela 13 apresenta uma breve descrição de cada equipamento utilizado, sua finalidade no estudo em questão e seus respectivos modelos e fabricantes.

Tabela 13- Listagem de equipamentos utilizados nos experimentos

\begin{tabular}{|c|c|c|c|}
\hline Equipamento & Modelo & Fabricante & Uso \\
\hline $\begin{array}{l}\text { Espalhamento } \\
\text { Dinâmico de Luz }\end{array}$ & N4 Plus & $\begin{array}{l}\text { Beckman } \\
\text { Coulter }\end{array}$ & $\begin{array}{l}\text { Monitoramento off-line } \\
\text { do diâmetro médio de } \\
\text { partículas }\end{array}$ \\
\hline $\begin{array}{l}\text { Espectroscopia } \\
\text { Vibracional Raman }\end{array}$ & $\begin{array}{l}\text { IFS 28/N-FT- } \\
\text { Raman } \\
\text { FRA106 }\end{array}$ & Bruker & 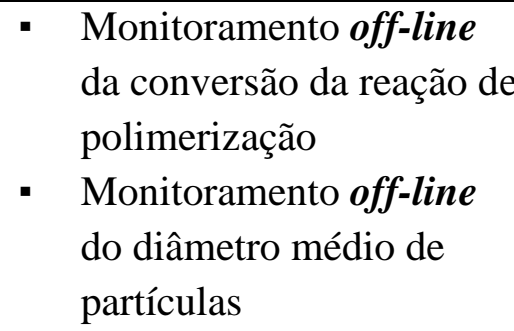 \\
\hline $\begin{array}{l}\text { Espectroscopia de } \\
\text { Infravermelho } \\
\text { Próximo (NIR) }\end{array}$ & $\begin{array}{l}\text { IFS 28/N-FT- } \\
\text { Raman } \\
\text { FRA106 }\end{array}$ & Bruker & 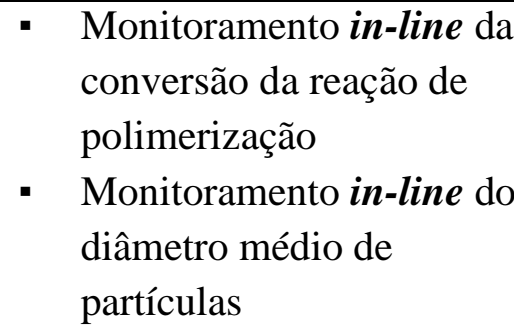 \\
\hline Balança Analítica & Adventurer ${ }^{\mathrm{TM}}$ & Ohaus & $\begin{array}{l}\text { - } \quad \text { Pesagem dos reagentes } \\
\text { da conversão através do } \\
\text { Método Gravimétrico }\end{array}$ \\
\hline $\begin{array}{l}\text { Estufa de Secagem e } \\
\text { esterilização }\end{array}$ & $3155 \mathrm{SE}$ & FANEM & $\begin{array}{l}\text { Monitoramento off-line } \\
\text { da conversão através do } \\
\text { Método Gravimétrico }\end{array}$ \\
\hline $\begin{array}{l}\text { Equipamento } \\
\text { Dispersor de Alto } \\
\text { Desempenho }\end{array}$ & $\begin{array}{l}\text { T25-Ultra } \\
\text { Turrax com } \\
\text { elemento } \\
\text { dispersor } \\
\text { S25N-25G }\end{array}$ & IKA & 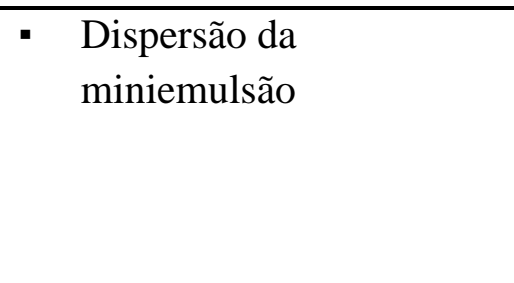 \\
\hline $\begin{array}{l}\text { Equipamento para } \\
\text { análise de estabilidade }\end{array}$ & $\begin{array}{l}\text { Turbiscan } \\
\text { LAB }\end{array}$ & $\begin{array}{l}\text { Formulaction } \\
\text { Smart } \\
\text { Scientific } \\
\text { Analysis }\end{array}$ & $\begin{array}{l}\text { Estabilidade da } \\
\text { miniemulsão monomérica }\end{array}$ \\
\hline Agitador Mecânico & RW 20 Digital & IKA & $\begin{array}{l}\text { Manter meio homogêneo } \\
\text { ao longo do processo de } \\
\text { polimerização }\end{array}$ \\
\hline Sonda NIR & 661.622-NIR & Hellma & - $\quad$ Monitoramento in-line \\
\hline
\end{tabular}


O monitoramento on-line foi realizado com auxílio da sonda de imersão, modelo 661.622-NIR, conforme especificação apresentada na Figura 19. Trata-se de uma mini sonda de imersão provida de diferentes caminhos óticos. O caminho ótico utilizado neste trabalho foi de $2 \mathrm{~mm}$. No entanto, a sonda utilizada permite substituir facilmente esses caminhos óticos por caminhos óticos variando de $1 \mathrm{~mm}$ a $20 \mathrm{~mm}$. A sonda transmite o feixe de luz emitido pela fonte que atravessa a emulsão, presente no caminho ótico, sofre reflexão no espelho e passa uma segunda vez pela emulsão, conforme representado na Figura 19.

\section{Figura 19 - Especificação da Sonda-NIR}

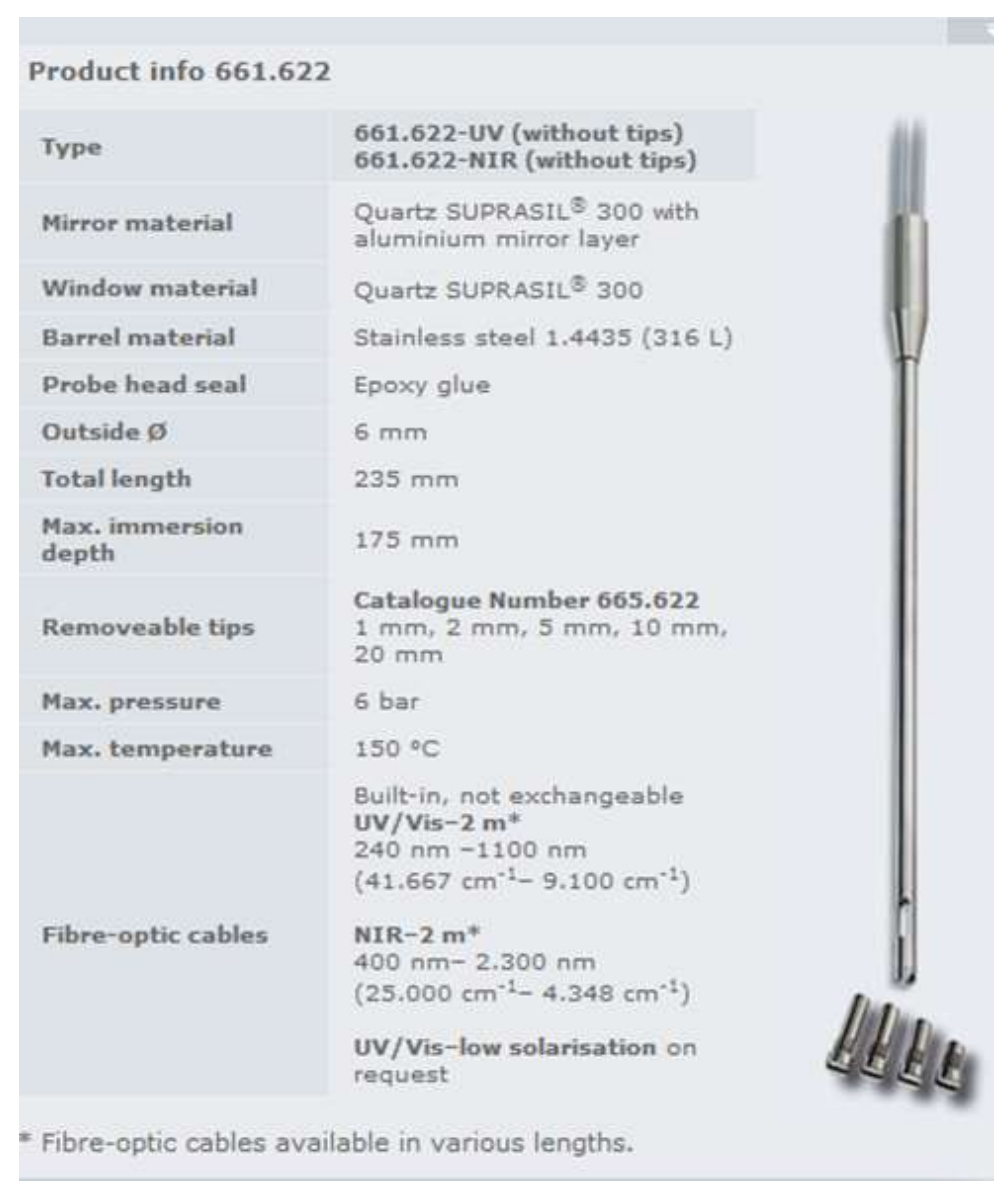

Fonte: Analytics (2013).

A sonda foi utilizada para aquisição de espectros in-line detecta absorções relacionadas com os momentos de dipolo e vibrações assimétricas referentes aos compostos químicas presentes nos componentes que participam da reação de polimerização. 


\subsubsection{Reagentes}

Os experimentos foram realizados com os reagentes apresentados na Tabela 14 que identifica os reagentes, seus fabricantes e seu grau de pureza. Os reagentes foram usados como fornecidos, sem purificação adicional.

Tabela 14- Reagentes utilizados para polimerização em miniemulsão de estireno.

\begin{tabular}{|ccccc|}
\hline Reagente & Função & Fórmula Molecular & Fabricante & Pureza \\
\hline Água & Fase contínua & $\mathrm{H}_{2} \mathrm{O}$ & - & $100 \%$ \\
\hline Lauril Sulfato de Sódio & Tensoativo & $\mathrm{C}_{12} \mathrm{H}_{25} \mathrm{NaO}_{4} \mathrm{~S}$ & Vetec & $>90 \%$ \\
\hline Estireno & Monômero & $\mathrm{C}_{8} \mathrm{H}_{8}$ & Innova & $>99,7 \%$ \\
\hline Hexadecano & Co-estabilizante & $\mathrm{C}_{16} \mathrm{H}_{34}$ & Sigma-Aldrich & $>99 \%$ \\
\hline Poliestireno & Co-estabilizante & $\left(\mathrm{C}_{8} \mathrm{H}_{8}\right) \mathrm{x}$ & Comercial & $\mathrm{ND}$ \\
\hline Bicarbonato de Sódio & Agente tamponante & $\mathrm{NaHCO}_{3}$ & Synth & $>99,7 \%$ \\
\hline Persulfato de Potássio & Iniciador Hidrossolúvel & $\mathrm{K}_{2} \mathrm{~S}_{2} \mathrm{O}_{8}$ & Synth & $>99 \%$ \\
\hline Hidroquinona & Inibidor & $\mathrm{C}_{6} \mathrm{H}_{6} \mathrm{O}_{2}$ & Vetec & $>99 \%$ \\
\hline
\end{tabular}

As estruturas moleculares dos principais reagentes utilizados estão apresentadas na Tabela 15.

Tabela 15 - Estrutura molecular dos principais reagentes

\begin{tabular}{|c|c|c|}
\hline Reagente & Estireno & Estrutura Molecular \\
\hline Persulfato de Potássio & & \\
\hline Lauril Sulfato de Sódio & & \\
\hline Hexadecano
\end{tabular}




\subsection{Métodos}

\subsubsection{Sintese e Monitoramento}

\subsubsection{Definição de Condições Operacionais}

O processo de polimerização em miniemulsão tem início com a preparação da miniemulsão, que já deve conter em sua formulação todos os reagentes da formulação, exceto o iniciador. Este foi acrescentado no reator após o preparo da miniemulsão e após alcance da temperatura de reação desejada, quando tem início o processo de polimerização.

Essas duas etapas, preparação da miniemulsão e a polimerização, possuem condições operacionais determinantes para o sucesso do processo.

Para o preparo da miniemulsão, as condições operacionais determinantes são: mecanismo de homogeneização, parâmetros para homogeneização, potência aplicada no meio para cisalhamento das partículas e tempo de processo.

Para a reação de polimerização em miniemulsão, as condições operacionais determinantes são: temperatura, tempo e agitação, além da escolha da formulação (proporção entre os ingredientes) e inertização do reator ao longo de toda reação.

\subsection{Condições Operacionais - Miniemulsão}

A preparação da miniemulsão monomérica foi realizada utilizando o equipamento T25-Ultra Turrax com elemento dispersor S25N-25G conforme mostrado na Figura 20.

Figura 20 - Preparação da Miniemulsão de Estireno com Ultra Turrax.

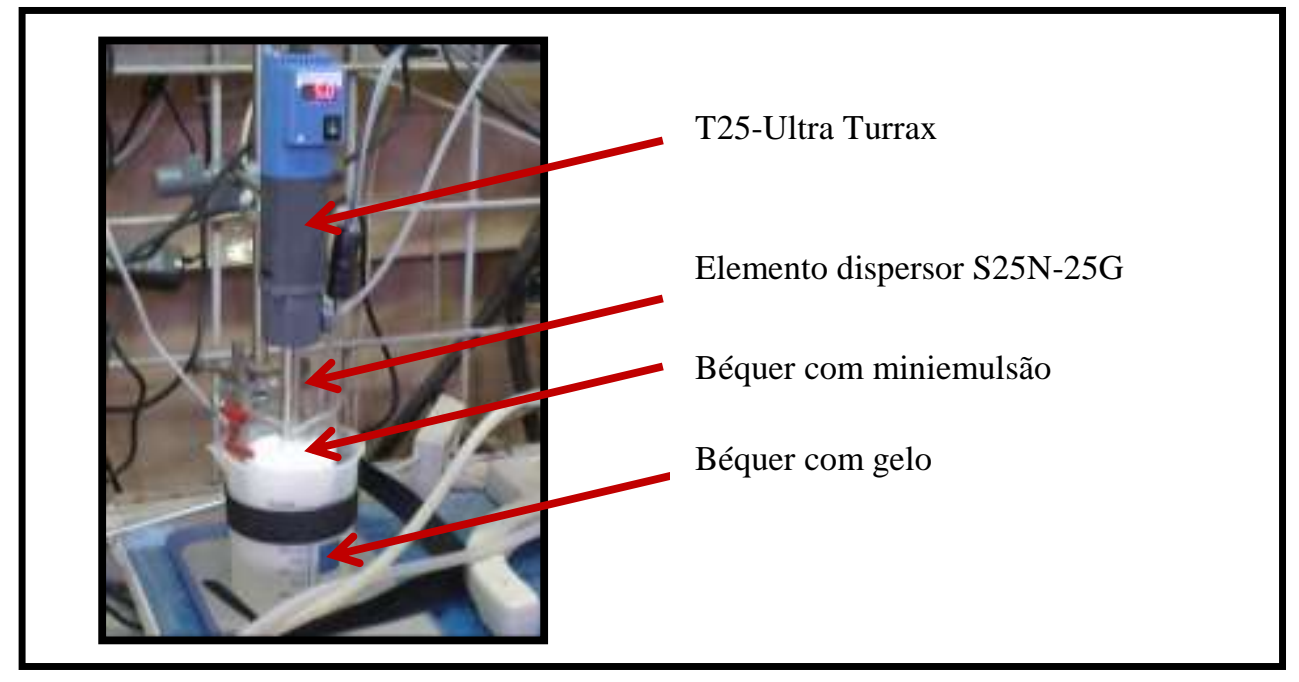


Este equipamento é um homogeneizador mecânico do tipo rotor-estator que possui um sistema de cisalhamento capaz de produzir um fluxo turbulento e uma faixa de frequência de rotação de 3.000 a 25.000 rpm.

A determinação da frequência de rotação para o preparo das miniemulsões foi definida através do estudo de estabilidade das miniemulsões monoméricas, realizado de acordo com o Planejamento Experimental citado no subitem 4.2.1.4 Delineamento dos experimentos.

\subsection{Condições Operacionais - Polimerização}

A cinética de uma reação é mais ou menos eficiente a depender da reação em questão, do balanceamento dos reagentes e de suas constantes cinéticas.

No presente caso, a temperatura de reação influencia diretamente a velocidade de reação, pois é utilizado como iniciador de processo um composto que é ativado pela temperatura, o persulfato de potássio $\left(\mathrm{K}_{2} \mathrm{~S}_{2} \mathrm{O}_{4}\right)$. O persulfato produz radicais $\mathrm{SO}_{\dot{4}}$ como resultado da quebra homolítica da ligação O-O. A energia de ativação necessária para realizar essa cisão é relativamente alta, por isso o iniciador geralmente é utilizado em temperaturas altas, acima de $50^{\circ} \mathrm{C}$ (GILBERT, 1995). Nos experimentos realizados, fixou-se a temperatura em $70^{\circ} \mathrm{C}$.

\subsubsection{Definição da Formulação}

O processo de polimerização em miniemulsão é um processo realizado em meio heterogêneo formado, em geral, por: monômero, água, tensoativo, co-estabilizante, iniciador, agente de transferência de cadeia, agente tamponante, chaser e eletrólitos.

$\mathrm{O}$ agente tamponante é utilizado para controlar o $\mathrm{pH}$ da fase aquosa da miniemulsão. Previne a hidrólise do surfactante e garante a eficiência do iniciador.

Para definição da formulação, base para o estudo de monitoramento e modelagem, optou-se por utilizar um processo de polimerização conhecido, permitindo assim, realizar melhor validação dos dados obtidos experimentalmente e através da modelagem. A grande diferença entre os dados da literatura disponíveis é a condição operacional de processo em MINIEMULSÃO.

A utilização de um processo conhecido auxiliou na construção de um modelo baseado em equações fenomenológicas com parâmetros conhecidos disponíveis na literatura, permitindo assim, que o modelo fosse desenvolvido com o mínimo possível de parâmetros ajustados. 
Assim, optou-se por estudar a polimerização em miniemulsão de estireno com persulfato de potássio como iniciador hidrossolúvel com base na formulação proposta por Costa (2010).

Os experimentos foram realizados com diferentes composições, conforme mostra a Tabela 16. Como um dos objetivos deste trabalho é o monitoramento da evolução da reação de polimerização através de técnicas espectroscópicas, utilizaram-se as mesmas condições operacionais de temperatura, pressão e agitação, e variou-se apenas a concentração de tensoativo em cada formulação e o teor de co-estabilizante, visando assim obter miniemulsões com diferentes tamanhos médios de partícula. No entanto, no preparo da miniemulsão monomérica, avaliou-se a melhor combinação tempo, velocidade de agitação através de delineamento de experimento.

Tabela 16 - Composição dos reagentes utilizados em cada experimento de miniemulsão

\begin{tabular}{|c|c|c|c|c|c|c|c|}
\hline Reagente & Função & Fórmula Molecular & $\begin{array}{c}\text { Mini_01 } \\
\text { Massa (g) }\end{array}$ & $\begin{array}{c}\text { Mini_02 } \\
\text { Massa (g) }\end{array}$ & $\begin{array}{c}\text { Mini_03 } \\
\text { Massa (g) }\end{array}$ & $\begin{array}{c}\text { Mini_04 } \\
\text { Massa (g) }\end{array}$ & $\begin{array}{c}\text { Mini_05 } \\
\text { Massa (g) }\end{array}$ \\
\hline $\mathrm{H}_{2} \mathrm{O}$ & Fase contínua & $\mathrm{H}_{2} \mathrm{O}$ & 154,99 & 150,02 & 155,89 & 160,12 & 154,92 \\
\hline SLS & Tensoativo & $\mathrm{C}_{12} \mathrm{H}_{25} \mathrm{NaO}_{4} \mathrm{~S}$ & 0,86 & 0,71 & 0,70 & 0,57 & 0,28 \\
\hline Hexadecano & Co-estabilizante & $\mathrm{C}_{16} \mathrm{H}_{34}$ & 1,50 & 1,41 & 1,40 & 1,40 & 1,41 \\
\hline PS & Co-estabilizante & $\left(\mathrm{C}_{8} \mathrm{H}_{8}\right) \mathrm{x}$ & - & 0,36 & 0,44 & - & - \\
\hline$\overline{\mathbf{H}_{2} \mathbf{O}^{* *}}$ & Fase contínua & $\mathrm{H}_{2} \mathrm{O}$ & 3,34 & 2,98 & 3,20 & 3,35 & 3,21 \\
\hline
\end{tabular}

\subsubsection{Preparo da Miniemulsão}

O preparo da miniemulsão foi realizado em duas ETAPAS, como mostram as Figura 21 e Figura 22. Na ETAPA 1, preparou-se a fase aquosa e a fase orgânica separadamente para facilitar a dissolução do tensoativo e dos co-estabilizantes e após a preparação as duas fases foram misturadas e mantidas sob agitação por um agitador magnético formando um emulsão. 
Figura 21 - Esquema da Etapa 1 para preparação da miniemulsão monomérica.

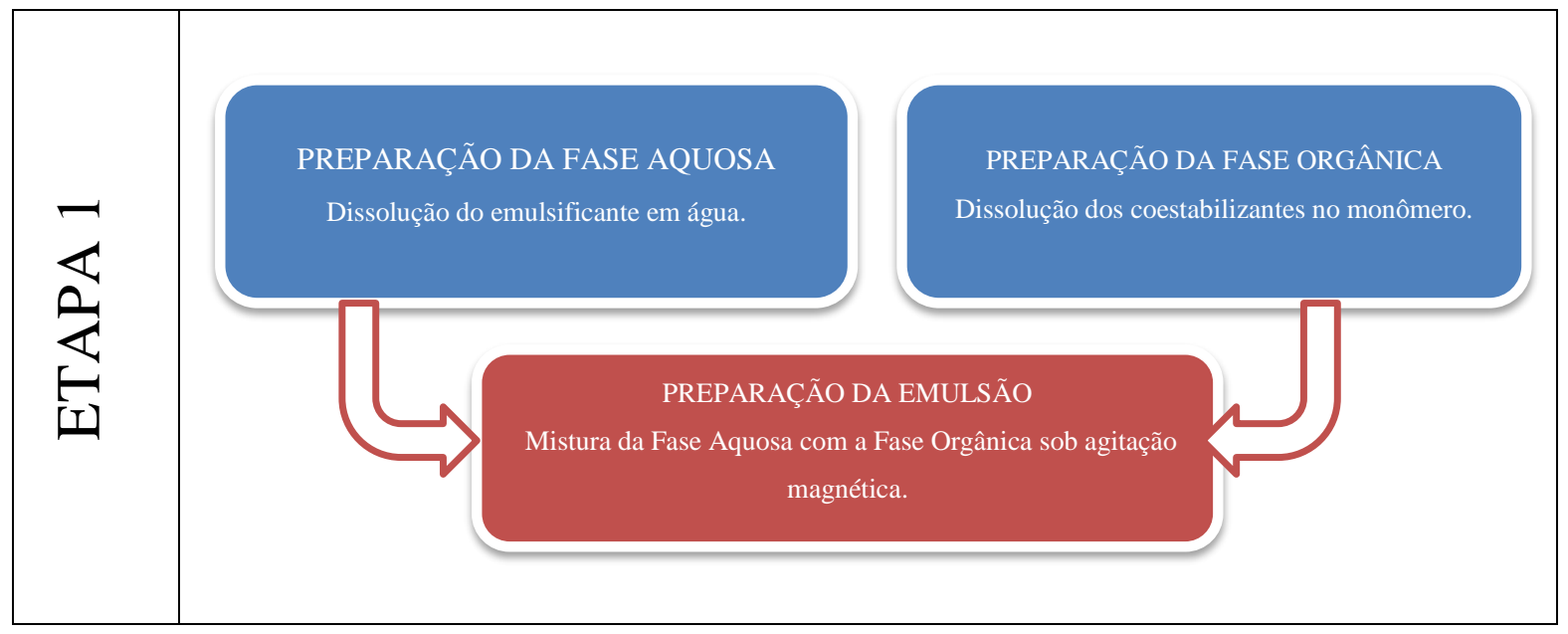

Na ETAPA 2, o sistema rotor-estator é preparado. Coloca-se o Becker, onde se encontra a emulsão, em um banho de gelo para que a energia gerada pela dispersão possa ser dissipada. Assim, a mistura composta pelas fases orgânica e aquosa, passa pela etapa de dispersão em que a fase dispersa, no caso em questão, a fase orgânica, sofre cisalhamento e são formadas as gotas de monômero em água com tamanhos na faixa submicrométrica.

Figura 22 - Esquema da Etapa 2 para preparação da miniemulsão monomérica.

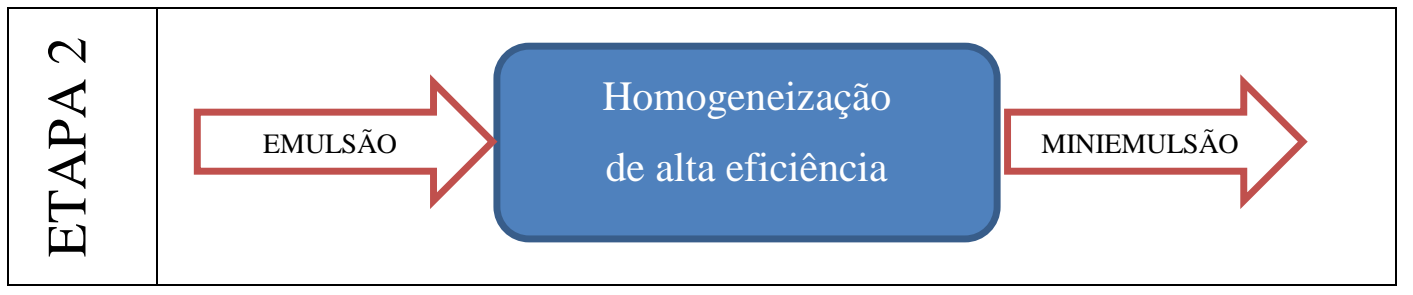

\subsubsection{Delineamento dos experimentos}

A etapa de preparação da miniemulsão monomérica antecede a polimerização. A fim de garantir a estabilidade da miniemulsão após seu preparo e durante a polimerização, realizou-se uma avaliação da estabilidade da miniemulsão monomérica.

Para isso, realizou-se um Planejamento de Experimentos, mostrado na Tabela 17, avaliando-se primeiramente a influência das variáveis $x_{1}=$ tempo de agitação e $x_{2}=$ frequência de rotação. Realizou-se o planejamento em dois níveis, mínimo e máximo e como resposta para avaliação da estabilidade, avaliou-se $y_{1}\left(x_{1}, x_{2}\right)=$ diâmetro médio das miniemulsões, $y_{2}\left(x_{1}, x_{2}\right)=$ índice de estabilidade e $y_{3}\left(x_{1}, x_{2}, t\right)=$ delta backscattering. 
Tabela 17 - Planejamento Experimental: $\mathbf{2}^{2}$ + duplicata do ponto central dos experimentos de preparação da miniemulsão.

\begin{tabular}{|ccccc|}
\hline Ordem padrão & Ordem de Execução & Nome da Amostra & $\begin{array}{c}\boldsymbol{x}_{\mathbf{1}} \\
\text { Tempo }\end{array}$ & $\begin{array}{c}\boldsymbol{x}_{\mathbf{2}} \\
\text { Agitação }\end{array}$ \\
\hline $\mathbf{1}$ & 4 & mini_07 & -1 & -1 \\
\hline $\mathbf{2}$ & 2 & mini_08 & -1 & 1 \\
\hline $\mathbf{3}$ & 6 & mini_10 & 1 & -1 \\
\hline $\mathbf{4}$ & 5 & mini_06 & 1 & 1 \\
\hline $\mathbf{5}$ & 1 & mini_09 & 0 & 0 \\
\hline $\mathbf{6}$ & 3 & mini_11 & 0 & 0 \\
\hline
\end{tabular}

Foi adicionado ao Planejamento Experimental o ponto central em duplicata, a fim de permitir a avaliação dos desvios experimentais da técnica adotada. A estabilidade foi avaliada para a variável $x_{1}$ nos tempos 10,15 e 25 minutos, referentes aos tempos mínimo, médio e máximo, respectivamente. A variável $x_{2}$ foi avaliada com as seguintes velocidades de rotação, $12.000,14.500$ e $17.000 \mathrm{rpm}$, referentes aos níveis mínimo, médio e máximo da variável, respectivamente. A Tabela 18 sintetiza essas informações.

Tabela 18 - Níveis mínimo, médio e máximo das variáveis.

\begin{tabular}{|cccc|}
\hline Variável & Nível Mínimo & Nível Médio & Nível Máximo \\
\hline Tempo $(\mathbf{m i n})$ & 10 & 15 & 20 \\
\hline Agitação $(\mathrm{rpm})$ & 12.000 & 14.500 & 17.000 \\
\hline
\end{tabular}

\subsubsection{Estabilidade da miniemulsão}

A estabilidade das miniemulsões foi avaliada através do planejamento experimental citado no item 4.2.1.4. Foi adotada, como procedimento padrão, a retirada de duas amostras do Béquer, imediatamente após o preparo da miniemulsão, conforme apresentado na Figura 23. Uma amostras foi usada para avaliar a estabilidade em equipamento Turbiscan de retroespalhamento de luz, e a outra amostra usada para medição do tamanho das gotas por espectroscopia de Correlação de Fótons/Espalhamento Dinâmico de Luz, equipamento Coulter N4 Plus. 
Figura 23 - Avaliação da estabilidade da miniemulsão monomérica

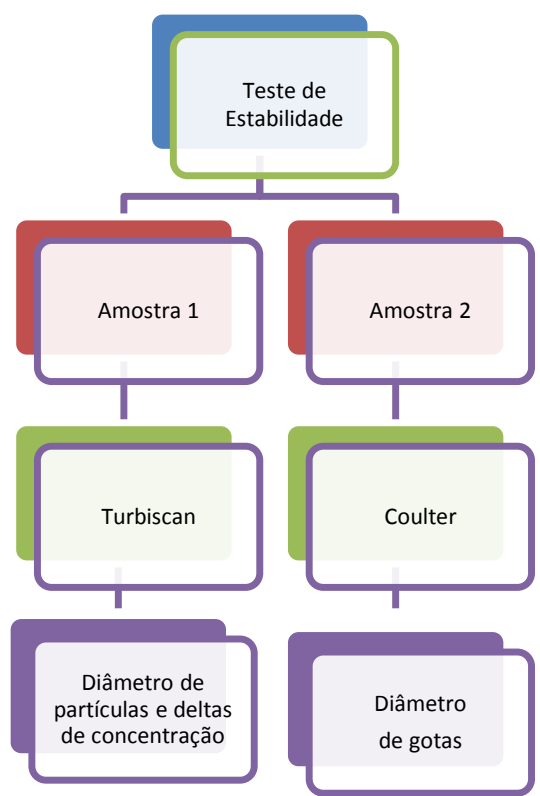

Para cada experimento realizado, retirou-se uma Amostra 1, que foi colocada tal qual foi retirada do Bécker, em um frasco de vidro até atingir o nível do topo do frasco, imediatamente abaixo da tampa, conforme mostra a Figura 24 pois as análises do retro espalhamento de luz são feitas através da varredura de toda a altura do frasco, e é necessário, identificar-se o topo e o fundo da amostra para análises e conclusões posteriores.

Figura 24 - Frasco de Amostra utilizado no Turbiscan Lab

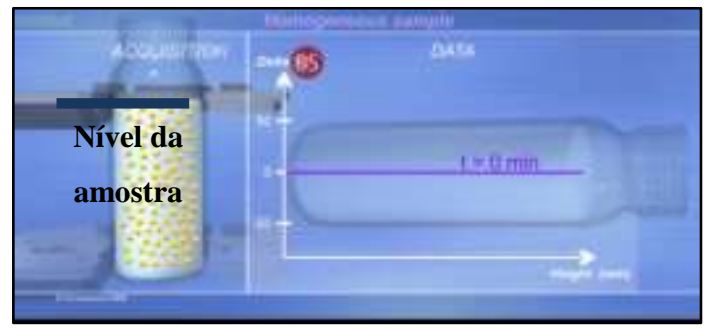

Fonte: "Turbiscan - Formulaction dispersion stability" (s.d.).

Depois de preparada a Amostra 1, coloca-se então a amostra no Turbiscan Lab para que seja realizada a medição do retro espalhamento ao longo do tempo. Todas as amostras foram sujeitas às condições mostradas na Tabela 19.

Tabela 19 - Condições operacionais das análises realizadas no Turbiscan

\section{Amostra 1}

\begin{tabular}{|ll|}
\hline Temperatura $\left({ }^{\circ} \mathbf{C}\right)$ & 25 \\
\hline Tempo Total $(\min )$ & 120 \\
\hline Intervalo entre as medições (min) & 10 \\
\hline
\end{tabular}


Retirou-se também, para cada experimento realizado, a Amostra 2. Essa amostra passa por etapa de preparação antes de ser analisada, que consiste de diluição da amostra, em água deionizada saturada com monômero estireno $(0,3 \mathrm{~g}$ estireno/100 $\mathrm{mL}$ de água a $20^{\circ} \mathrm{C},(\mathrm{CETESB}$, [s.d.])). Para estas análises, a diluição foi ajustada para que, com um ângulo de incidência do laser de $90^{\circ}$, apresentasse faixa de espalhamento de luz entre $5 \times 10^{4}$ e $1 \times 10^{6}$ contagens/segundo, que é a faixa de velocidade recomendada pelo fabricante, para que os fótons de luz atinjam o fotomultiplicador. Para avaliar a estabilidade, a mesma amostra ficou em análise durante 120 minutos e foi analisada a cada 10 minutos, permitindo assim, avaliar a variação, com o tempo, do tamanho das gotas monoméricas de cada miniemulsão preparada. A Tabela 20 apresenta as condições utilizadas na análise do tamanho das gotas da miniemulsão.

Tabela 20 - Condições operacionais das análises realizadas no Equipamento de Espalhamento de Luz (Coulter)

\begin{tabular}{|ll|}
\multicolumn{2}{|c|}{ Amostra 2 } \\
\hline Temperatura $\left({ }^{\circ} \mathbf{C}\right)$ & $25^{\circ} \mathrm{C}$ \\
\hline Tempo Total (min) & 120 \\
\hline Intervalo entre as medições (min) & 10 \\
\hline Repetições & $2 \mathrm{x}$ \\
\hline Tempo de equilíbrio (min) & 5 \\
\hline Diluente & Água \\
\hline Índice de refração & 1,33 \\
\hline Ângulo de Incidência & $90^{\circ}$ \\
\hline Viscosidade (cP) & 0,89 \\
\hline
\end{tabular}

\subsubsection{Síntese-Polimerização}

Para a etapa de polimerização, utilizou-se então, a miniemulsão monomérica preparada na fase anterior, adicionando-a no reator através de um dos bocais do tampo do reator. Após a adição, o nitrogênio passou a ser borbulhado na miniemulsão monomérica. 
Iniciou-se então o aquecimento da miniemulsão monomérica até a temperatura de $70^{\circ} \mathrm{C}$. Ao atingir $70^{\circ} \mathrm{C}$, o iniciador foi adicionado no reator. Esse é considerado o início do processo de polimerização em miniemulsão e é chamado de tempo zero em tabelas e gráficos, conforme indicado na Figura 25.

Figura 25 - Esquema da Etapa 3 para polimerização da miniemulsão monomérica.

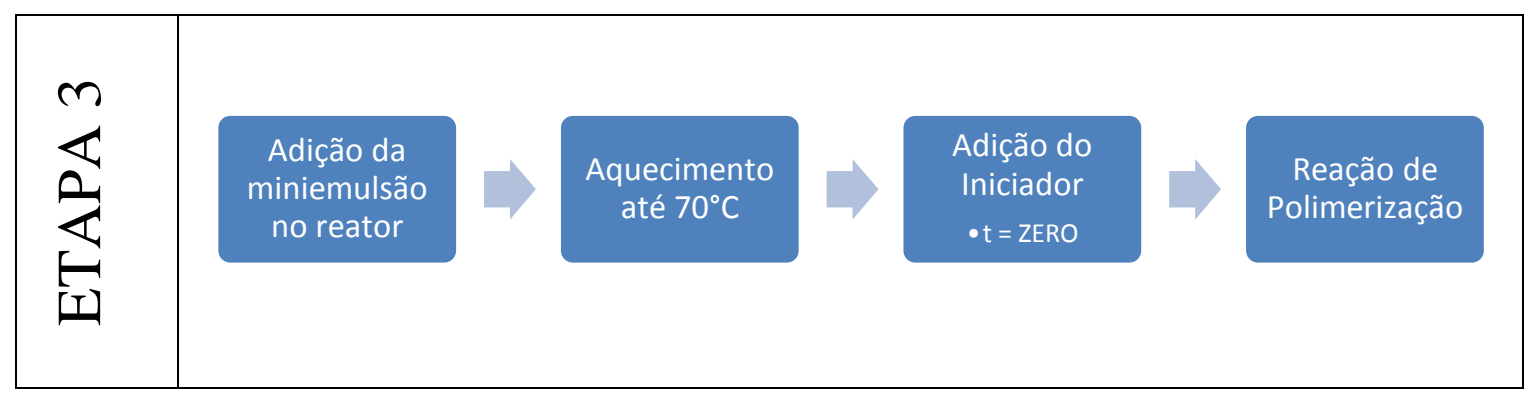

Ao longo de toda a reação de polimerização, amostras foram periodicamente retiradas do reator para análises off-line de conversão do monômero e o diâmetro médio das partículas poliméricas. A sonda de NIR imersa diretamente no meio reacional foi usada para obter os espectros NIR in-line, conforme apresentado na Figura 10. As duas modalidades de monitoramento se fazem necessárias para permitir que seja construído um modelo de calibração robusto, capaz de utilizar apenas os dados in-line (os espectros NIR) para inferir a conversão e o tamanho médio das partículas ao acompanhar posteriores reações de polimerização em miniemulsão.

\subsubsection{Monitoramento do processo - in line}

\subsection{Espectroscopia NIR}

Para o monitoramento in-line, a coleta e armazenamento das informações da sonda foram realizados através da interface com o software OPUS 3.1, que recebeu a configuração para análises conforme indicado na Tabela 21.

Com as informações coletadas in-line e com os dados de referência coletados off-line é realizada uma calibração multivariável onde é encontrado um modelo que representa a variável monitorada. Neste estudo, conversão de monômero e diâmetro de partículas foram as variáveis analisadas.

A conversão das reações foi obtida através de ajuste de modelo de calibração multivariável à região espectral contida no intervalo 5.700 a $6.200 \mathrm{~cm}^{-1}$ através de regressão pelo método dos mínimos quadrados parciais (PLS). 
Tabela 21 - Set-up OPUS para NIR e Raman

\begin{tabular}{|lcc|}
\hline Dados & NIR & Raman \\
\hline Resolução $\left(\mathbf{c m}^{-1}\right)$ & 4 & 4 \\
\hline $\begin{array}{l}\text { Número de varreduras por amostra } \\
\text { (scans) }\end{array}$ & 4 & 300 \\
\hline $\begin{array}{l}\text { Número de varreduras para Background } \\
\text { (scans) }\end{array}$ & 4 & - \\
\hline Resultados do Espectro & Absorbância & Intensidade Raman \\
\hline Sonda & Hellma Probe & QS Hellma \\
\hline Intervalo dos Espectros $\left.\mathbf{( c m}^{-1}\right)$ & 14.000 - 4.000 & 4.000 - 0 \\
\hline Potência do Laser $(\mathbf{m W})$ & - & 510 \\
\hline Estado da amostra & líquido & líquido \\
\hline Fonte & Tungstênio & Laser \\
\hline
\end{tabular}

Regressão linear múltipla, MLR (Simões, 2008); o método da análise/regressão de componentes principais, PCA/PCR, ilustrado na Figura 26; método dos mínimos quadrados parciais, PLS (Chicoma, 2009 e Colmán, 2013) e Redes neurais artificiais, ANN são alguns exemplos de métodos de calibração multivariáveis.

O método dos mínimos quadrados parciais (PLS), análise de componentes principais (PCA) e regressão de componentes principais (PCR) são considerados eficientes para lidar com ruídos experimentais e co-linearidades.

Figura 26 - Esquema de aplicação de análise de componentes principais

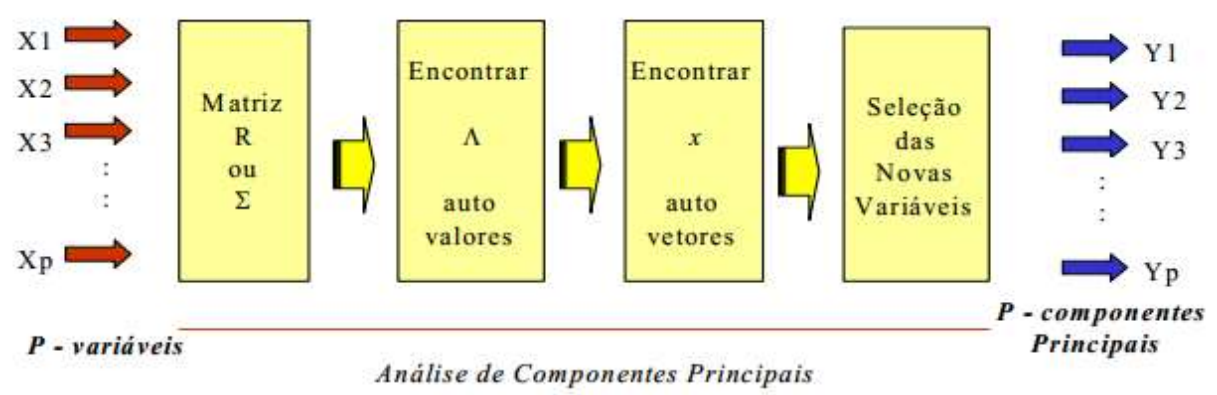

Fonte: Vicini; Adriano; Souza (2005).

Estes métodos analisam o espectro com um todo. No entanto, focam o conjunto de calibração. Todas as variáveis são incluídas nos modelos PCR ou PLS, o que torna a calibração mais simples, permitindo que esta seja feita mesmo na presença de interferentes, sem necessidade de conhecer o número e a natureza dos mesmos. São métodos robustos. Portanto, mesmo com a inclusão de novas amostras no modelo de calibração, os seus parâmetros permanecem praticamente inalteráveis. 
O método PLS foi escolhido para o presente trabalho, pois se mostrou mais adequado e robusto para tratar o monitoramento do processo de polimerização.

A determinação do modelo de calibração passa pelas seguintes etapas (SERRA, 2014):

(1) Escolha do grupo de espectros que será utilizado para calibração do modelo;

(2) Escolha do grupo de espectros que será utilizado para validação do modelo;

(3) Avaliação dos espectros: Uma vez escolhido o grupo de amostras de calibração torna-se necessário o processamento dos espectros. Os espectros são normalmente obtidos para apurar a reprodutibilidade de cada amostra de calibração, logo, no caso de existirem espectros da mesma amostra que não sejam idênticos, é fundamental realizar um pré-processamento dos dados, a fim de torná-los semelhantes. Algumas variações que podem ocorrer na aquisição de espectros num sistema de emulsão:

○ Interação complexa entre os componentes da amostra - gotas de monômero, formação das partículas, interação entre as fases aquosa, monomérica e polimérica;

○ Dispersão de luz em amostras sólidas ou líquidas turvas;

- Medições com uma reprodutibilidade pobre;

- Distorções causadas pelo hardware do equipamento - deslocamento da linha de base, deslocamento do comprimento de onda, efeitos de nãolinearidade do detector, etc.

(4) Pré-processamento dos espectros: Os métodos mais utilizados na eliminação dos efeitos referidos acima são os de SCO (do inglês, Subtraction Constant Offset), vetor de normalização, correção de espalhamento múltiplo e o cálculo da segunda derivada. As definições desses métodos são apresentadas a seguir (COLMÁN, 2013):

- Subtraction Constant Offset - desloca o espectro de forma a definir o valor mínimo de absorbância como zero;

○ Vetor Padronização - calcula o valor médio das intensidades e subtrai-o ao espectro, portanto a soma dos quadrados das intensidades (Y) é calculada e o espectro é dividido pela raiz quadrada dessa soma;

○ Correção de Espalhamento Múltiplo (MSC) - executa uma transformação linear de cada espectro para corresponder melhor à média 
do conjunto de espectros. Este método é frequentemente utilizado para espectros medidos por reflectância;

- Segunda Derivada - calcula a segunda derivada do espectro, dando ênfase às variações mais acentuadas. Assim, oscilações de linha de base e picos sobrepostos são minimizados.

(5) Avaliação dos parâmetros quimiométricos pelo coeficiente de correlação $\left(\mathrm{R}^{2}\right)$ e erro quadrático médio (RMSECV), (BRUKER OPTIK, 2004):

- Coeficiente de Correlação, $\mathrm{R}$ - gera uma reta de ajuste entre os valores preditos e os valores experimentais, conforme Equação 70.

$$
R=\frac{\sum_{i=1}^{L}\left(y_{i, N I R}-\overline{y_{\exp }}\right)}{\sum_{i=1}^{L}\left(y_{i, \exp }-\overline{y_{\exp }}\right)}
$$

- Erro Médio Quadrático, RMSECV - é uma medida quantitativa da proximidade do valor predito pelo modelo ao valor experimental, definido pela Equação 71:

$$
R M S E C V=\sqrt{\frac{\sum_{1=1}^{L}\left(y_{\text {exp }} y_{i, N I R}\right)^{2}}{L}}
$$

onde,

$y_{i, N I R}$ - Valor predito pelo modelo de calibração;

$y_{i, e x p}$ - Valor medido experimentalmente;

$\overline{y_{\text {exp }}}$ - Média dos valores experimentais;

$\mathrm{L}$ - Total de amostras do conjunto de calibração.

○ Validação do modelo de predição. - A validação é feita comparando-se os valores previstos pelos modelos de calibração (tendo como entrada os espectros NIR) com as medições off-line das variáveis em amostras não usadas na calibração e em corridas experimentais não usadas na calibração.

O monitoramento in-line foi realizado por Espectroscopia NIR usando como referências coletadas off-line para conversão as análises gravimétricas e para diâmetro de partículas as análises de espalhamento de luz, de acordo com o apresentado na Tabela 23. 
Tabela 22 - Resumo das técnicas de monitoramento in-line

\begin{tabular}{|c|c|c|}
\hline Variável & $\begin{array}{c}\text { Referência } \\
\text { Off-line }\end{array}$ & $\begin{array}{l}\text { Monitoramento } \\
\text { In-line }\end{array}$ \\
\hline Conversão & Gravimetria & $\begin{array}{c}\text { NIR } \\
+ \\
\text { modelo de calibração }\end{array}$ \\
\hline Diâmetro & DLS & $\begin{array}{c}\text { NIR } \\
+ \\
\text { modelo de calibração }\end{array}$ \\
\hline
\end{tabular}

\subsubsection{Monitoramento do processo-off-line.}

O monitoramento off-line foi realizado com três diferentes técnicas: Espalhamento de Luz, Gravimetria e Espectroscopia Raman, cada uma com o seu objetivo, de acordo com o apresentado na Tabela 23.

Os dados obtidos por gravimetria foram utilizados para o cálculo da conversão da reação experimental, sendo: $\mathrm{y}_{\text {gravimetria }}=\mathrm{y}_{\text {experimental }}$

Os dados obtidos por espalhamento de luz, através do equipamento Coulter, forneceram os diâmetros médios das partículas experimentais sendo: $d_{\text {coulter }}=$ $d_{\text {experimental }}$.

Assim como para os espectros obtidos on-line, os espectros obtidos off-line foram comparados com os dados experimentais de conversão para ajuste dos modelos de calibração para conversão e diâmetro de partículas.

Tabela 23 - Resumo das técnicas de monitoramento off-line

\begin{tabular}{|c|c|c|}
\hline Variável & $\begin{array}{c}\text { Referência } \\
\text { Off-line }\end{array}$ & $\begin{array}{c}\text { Monitoramento } \\
\text { Off-line }\end{array}$ \\
\hline \multirow[b]{2}{*}{ Conversão } & \multirow[b]{2}{*}{ Gravimetria } & Raman - áreas \\
\hline & & $\begin{array}{c}\text { Raman } \\
+ \\
\text { modelo de calibração }\end{array}$ \\
\hline Diâmetro & DLS & $\begin{array}{c}\text { Raman } \\
+ \\
\text { modelo de calibração }\end{array}$ \\
\hline
\end{tabular}

\subsection{Gravimetria}

A conversão do monômero em polímero foi analisada off-line a partir de amostras retiradas periodicamente do reator e analisadas por gravimetria. O princípio dessa técnica gravimétrica é fazer a evaporação de todos os componentes da amostra 
que não sejam sólidos, ou seja, monômero não polimerizado e água, conforme indicado na Figura 27.

Figura 27 - Esquema representativo da análise gravimétrica

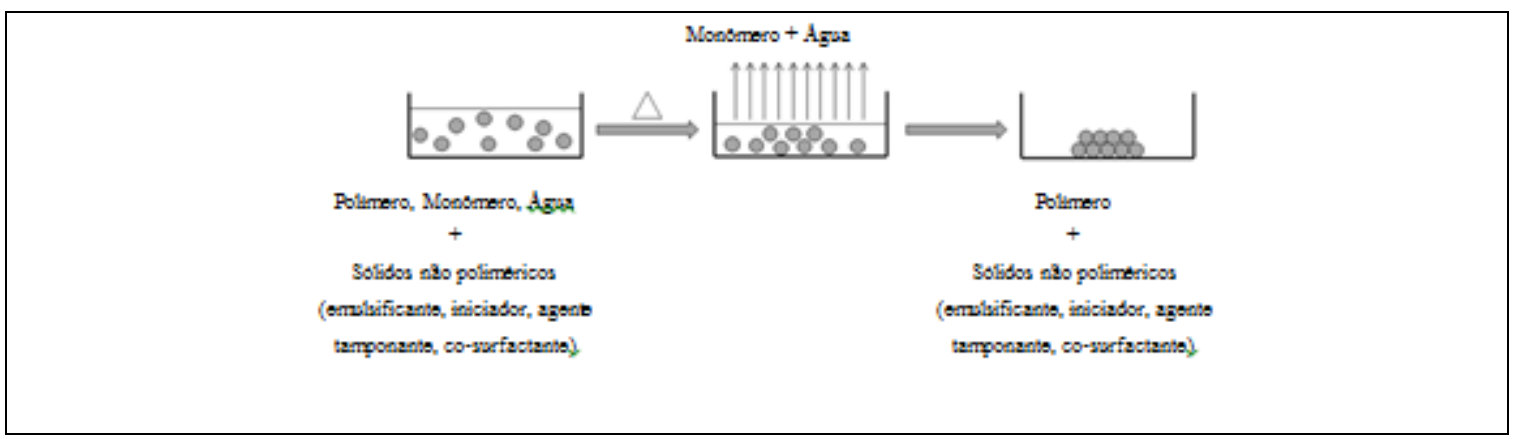

Fonte: Barbosa (2014).

As amostras (aproximadamente $1 \mathrm{~g}$ ) foram coletadas e acondicionadas em capsulas de alumínio (feitas de papel alumínio e moldadas em uma placa de Petri) previamente pesadas. Para interromper a reação de polimerização, todas as amostras receberam, aproximadamente, $0,3 \mathrm{~g}$ de solução aquosa de hidroquinona com concentração $1 \%$.

A massa de hidroquinona adicionada em cada amostra foi determinada, assim como a massa da amostra após adição do látex, ou seja, massa de hidroquinona+amostra.

Após pesagem inicial, todas as cápsulas foram conduzidas à estufa a $100^{\circ} \mathrm{C}$ por um período de $24 \mathrm{~h}$ (testes prévios de maior duração indicaram que estas condições de secagem eram suficientes para garantir secagem completa da amostra, ou seja, a evaporação dos componentes voláteis, monômero e água). Ao retirar as amostras da estufa, elas foram pesadas novamente, a fim de verificar a massa de sólidos restante após evaporação. Esses sólidos restantes, correspondem ao polímero formado e aos sólidos não poliméricos presentes na formulação da miniemulsão, como tensoativo, iniciador, co-estabilizante, e agente tamponante, bem como o inibidor (hidroquinona) adicionado à amostra.

O plano de amostragem contou com amostras coletadas desde o instante inicial, em que o iniciador foi acrescentado no reator, até o instante final da reação. O intervalo de tempo variou, pois no início da reação a polimerização é mais rápida. Então, retiraram-se amostras com um menor intervalo entre elas. Esse intervalo foi aumentado, 
pois a velocidade de reação diminui ao longo do tempo, e tende a se estabilizar no final da reação.

Portanto, para o cálculo da conversão global da reação, utilizaram-se as massas das amostras, medidas antes da evaporação ( $\left.\boldsymbol{m}_{\boldsymbol{a m o s t r a}}\right)$ e após $24 \mathrm{~h}$ na estufa $\left(\boldsymbol{m}_{\boldsymbol{s e c} \boldsymbol{a}}\right)$. Além disso, deve ser descontado da $\boldsymbol{m}_{\text {seca }}$, a massa de sólidos não poliméricos ( $\left.\boldsymbol{m}_{\text {sólidos não poliméricos }}\right)$, conforme mostra a Equação 72.

$$
X_{T}=\frac{\left(\frac{\boldsymbol{m}_{\text {seca }}}{\boldsymbol{m}_{\text {amostra }}}\right)-\left(\frac{\boldsymbol{m}_{\text {sólidos não poliméricos }}}{\boldsymbol{m}_{\text {total }}}\right)}{\left(\frac{\boldsymbol{m}_{\text {monômero total }}}{\boldsymbol{m}_{\text {total }}}\right)}
$$

Equação 72

sendo: $X_{T}$ : conversão global; $m_{\text {seca }}$ : massa da amostra seca; $m_{\text {amostra }}$ : massa da amostra antes da secagem; $m_{\text {sólidos não poliméricos }}$ : massa de sólidos não poliméricos; $\mathrm{m}_{\text {total }}$ : massa total de reagentes carregados no reator; $\mathrm{m}_{\text {monômero total }}$ massa de monômero total carregado no início da reação.

\subsection{Espectroscopia Raman}

A conversão do monômero em polímero foi também analisada off-line por espectroscopia Raman usando um Espectrofotômetro Bruker IFS 28/N-FT-Raman (modelo FRA106). Essas mesmas amostras foram analisadas também por gravimetria para permitir posterior comparação entre os dados obtidos por gravimetria e obtidos por espectroscopia.

Cada amostra analisada apresenta em seu espectro picos característicos relacionados com os grupos funcionais e ligações presentes na amostra. Para o caso da polimerização de estireno a poliestireno, alguns os picos característicos nos espectros Raman estão apresentados na Tabela 7.

A reação de polimerização do estireno se dá através da quebra da dupla ligação $\mathrm{C}=\mathrm{C}$, e assim, o espectro Raman apresenta um pico característico que tem sua área decrescente ao longo do processo de polimerização, caracterizando o consumo da dupla ligação para a formação do polímero. Sendo assim, a conversão pode ser calculada através da relação entre as áreas normalizadas do pico correspondente à ligação $\mathrm{C}=\mathrm{C}$ no instante referente à amostragem (tempo=t) e no instante inicial (tempo=inicial=0), conforme Equação 74.

Assim, o cálculo da conversão é realizado com as áreas dos picos correspondentes às vibrações das ligações $\mathrm{C}=\mathrm{C}$, que são consumidas no processo de polimerização, e com a área de um pico de referência, correspondente a um grupo que mantem-se constante ao longo da reação, e é utilizado para normalizar os dados, 
conforme mostra a Equação 73. O pico escolhido como referência corresponde às ligações C-H presentes no anel aromático e está localizado próximo ao número de onda $1.002 \mathrm{~cm}^{-1}$.

$$
\text { Área }_{\text {normalizada }}=\frac{\text { área pico } C=C}{\text { área pico anel aromático }}=\frac{\text { área do pico } 1631 \mathrm{~cm}^{-1}}{\text { área do pico } 1002 \mathrm{~cm}^{-1}} \quad \text { Equação } 73
$$

$$
X_{\text {Raman }}=\text { Conversão }=1-\frac{\text { Área }_{\text {normalizada } C=C \text { tempo: } t}}{\text { Área }} \quad \text { Equação } 74
$$

Para o monitoramento off-line, a coleta e armazenamento das informações também utilizou como interface o software OPUS 3.1, que recebeu a configuração para análises conforme indicado na Tabela 21.

\subsection{Espalhamento de Luz}

Para determinação do tamanho médio das partículas utilizou-se o equipamento de espalhamento dinâmico de luz (DLS), Coulter N4 Plus, com as mesmas condições citadas no item 4.2.1.5 (Estabilidade da miniemulsão), na Tabela 20. Os resultados do espalhamento de luz foram comparados com os resultados da espectroscopia Raman e NIR. Por isso, existem amostras analisadas por essas técnicas nos mesmos instantes, para permitir, novamente, posterior comparação e construção de modelo matemático de calibração.

\subsubsection{Avaliação preliminar das técnicas}

Antes de sua utilização, as técnicas de espalhamento de luz e espectroscópicas foram avaliadas a fim de confirmar a sua capacidade de avaliar os diâmetros e teor de polímero das amostras.

Assim, realizou-se uma verificação preliminar da capacidade do equipamento Coulter detectar a multimodalidade das partículas poliméricas e a capacidade da Espectroscopia NIR e Raman detectar o teor de polímero.

Para essa avaliação, foram preparadas três amostras diferentes, com diferentes teores de tensoativo para produzirem partículas poliméricas de diferentes tamanhos.

Essas amostras foram produzidas por polimerização em emulsão convencional com as composições apresentadas na Tabela 24. A terminação E na identificação dessas 
amostras é apenas para reforçar que essas amostras foram produzidas em polimerização em EMULSÃO.

Tabela 24 - Composição da formulação da reação de polimerização em emulsão (em porcentagem mássica de cada componente) usada para produzir amostras com diferentes tamanhos de partículas.

\begin{tabular}{|c|c|c|c|c|c|}
\hline Amostra & \% Sty & \% KPS & \% SLS & \% $\mathbf{N a H C O}_{\mathbf{3}}$ & \% $\mathbf{H}_{\mathbf{2}} \mathbf{O}$ \\
\hline $\mathbf{1 E}$ & 10.01 & 0.09 & 0.10 & 0.05 & 89.75 \\
\hline $\mathbf{2 E}$ & 10.16 & 0.09 & 0.05 & 0.05 & 89.65 \\
\hline $\mathbf{3 E}$ & 10.04 & 0.09 & 0.21 & 0.05 & 89.61 \\
\hline
\end{tabular}

Depois de produzidas, essas três amostras (1E, 2E e 3E) foram misturadas, com

a finalidade de produzir amostras adicionais (4E, 5E e 6E) com distribuição bimodal, conforme composição mostrada na Tabela 25.

Tabela 25 - Composição das amostras 4, 5 e 6.

\begin{tabular}{|c|c|}
\hline Identificação das Amostras & Composição das Misturas \\
\hline 4E & $1 E(50 \%)+2 E(50 \%)$ \\
\hline $5 \mathrm{E}$ & $1 E(50 \%)+3 E(50 \%)$ \\
\hline 6E & $2 \mathrm{E}(50 \%)+3 \mathrm{E}(50 \%)$ \\
\hline
\end{tabular}

\subsubsection{Multimodalidade x Espalhamento de Luz}

As seis amostras produzidas foram analisadas pelo Coulter e os resultados de diâmetro e polidispersidade estão reportados na Tabela 26. A mesma tabela apresenta os diâmetros calculados através da média ponderada dos diâmetros das amostras de origem.

Tabela 26 - Composição das amostras preparadas com as amostras 1, 2 e 3.

\begin{tabular}{|c|c|c|c|c|}
\hline Amostra & $\begin{array}{l}\text { Diâmetro } \\
\text { (nm) } \\
\text { (medido) }\end{array}$ & $\begin{array}{l}\text { Polidispersidade } \\
\text { (medido) }\end{array}$ & $\begin{array}{l}\text { Diâmetro } \\
\text { (nm) } \\
\text { (calculado) }\end{array}$ & Equação para cálculo do diâmetro \\
\hline 1E & 176,4 & 0,024 & - & \\
\hline $2 \mathrm{E}$ & 380,1 & 0,095 & - & - \\
\hline $3 E$ & 74,5 & 0,054 & - & 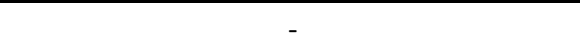 \\
\hline $4 \mathrm{E}$ & 240,8 & 0,036 & 278,25 & $\begin{array}{c}\text { diâmetro } \text { amostra4E }_{\text {diâmetro }} \text { amostra } 1 E * \\
0,5+\text { diâmetro }_{\text {amostra } 2 E} * 0,5\end{array}$ \\
\hline $5 \mathrm{E}$ & 160,1 & 0,105 & 125,45 & $\begin{array}{c}\text { diâmetro }_{\text {amostra5E }}=\text { diâmetro }_{\text {amostra } 1 E} * \\
0,5+\text { diâmetro }_{\text {amostra } 3 E} * 0,5\end{array}$ \\
\hline $6 \mathrm{E}$ & 256,8 & 0,251 & 227,3 & $\begin{array}{c}\text { diâmetro }_{\text {amostra } 6 \mathrm{E}}=\text { diâmetro }_{\text {amostra } 2 E} * \\
0,5+\text { diâmetro }_{\text {amostra } 3 E} * 0,5\end{array}$ \\
\hline
\end{tabular}




\subsubsection{Teor de Polímero x Espectroscopia NIR e Raman}

Da mesma forma que os diâmetros medidos e calculados, os teores de polímeros das amostras foram analisados por gravimetria. Os resultados estão apresentados na Tabela 26.

Tabela 26 - Teor de sólidos das amostras determinados por gravimetria

\begin{tabular}{|cc|}
\hline Identificação das amostras & TEOR DE POLIMERO (\%) \\
\hline 1E & 9,2 \\
\hline 2E & 6,0 \\
\hline 3E & 10,2 \\
\hline
\end{tabular}

Para as amostras preparadas pela mistura das anteriores, calculou-se o teor de polímero pela média ponderada do teor polimérico de suas amostras de origem.

$$
\begin{aligned}
& \text { teor }_{\text {polímeroE } 4}=\text { teor }_{\text {polímero } 1 E} * 0,5+\text { teor }_{\text {polímero } 2 E} * 0,5 \\
& \text { teor }_{\text {polímero } 5 E}=\text { teor }_{\text {polímero } 1 E} * 0,5+\text { teor }_{\text {polímero } 3 E} * 0,5 \\
& \text { teor }_{\text {polímero } 6 E}=\text { teor }_{\text {polímero } 2 E} * 0,5+\text { teor }_{\text {polímero } 3 E} * 0,5
\end{aligned}
$$

As seis amostras foram diluídas em água deionizada nas concentrações de $100 \%, 75 \%, 50 \%$ e $25 \%$, totalizando 24 amostras. Os teores de polímero dessas amostras também foram calculados analogamente aos anteriores e estão apresentados na Tabela 27.

Assim, foram produzidas amostras com diferentes tamanhos médios de partículas e diferentes distribuições de tamanho (amostras 1E a 6E) e também amostras com a mesma distribuição de partículas, mas com diferentes teores de polímero. As vinte e quatro amostras foram avaliadas através de Espectroscopia NIR e Raman para que através de um modelo de calibração, os espectros forneçam o teor de polímeros. 
Tabela 27 - Diluição das amostras 1E, 2E e 3E e teor de sólidos resultante.

\begin{tabular}{|c|c|c|}
\hline Amostra & Diluição (\%) & Teor de polímero (\%) \\
\hline 1E & 100 & 9,2 \\
\hline $2 \mathrm{E}$ & 100 & 6,0 \\
\hline $3 \mathrm{E}$ & 100 & 10,2 \\
\hline 4E & 100 & 7,6 \\
\hline $5 E$ & 100 & 9,7 \\
\hline $6 \mathrm{E}$ & 100 & 8,1 \\
\hline 7E & 75 & 6,9 \\
\hline $8 \mathrm{E}$ & 75 & 4,5 \\
\hline $9 \mathrm{E}$ & 75 & 7,6 \\
\hline $10 \mathrm{E}$ & 75 & 5,7 \\
\hline 11E & 75 & 7,2 \\
\hline $12 \mathrm{E}$ & 75 & 6,1 \\
\hline $13 E$ & 50 & 4,6 \\
\hline $14 E$ & 50 & 3,0 \\
\hline $15 E$ & 50 & 5,1 \\
\hline $16 E$ & 50 & 3,8 \\
\hline 17E & 50 & 4,8 \\
\hline $18 \mathrm{E}$ & 50 & 4,0 \\
\hline 19E & 25 & 2,3 \\
\hline $20 E$ & 25 & 1,5 \\
\hline 21E & 25 & 2,5 \\
\hline 22E & 25 & 1,9 \\
\hline 23E & 25 & 2,4 \\
\hline 24E & 25 & 2,0 \\
\hline
\end{tabular}




\section{RESULTADOS E DISCUSSÃO}

Da mesma forma como foi organizada a metodologia científica estão apresentados, a seguir, os resultados obtidos, de acordo com as abordagens específicas: $\left(1^{a}\right)$ Síntese e Monitoramento e, ( $\left.2^{\mathrm{a}}\right)$ Modelagem e Simulação.

\subsection{Resultados Síntese e Monitoramento}

\subsubsection{Avaliação Preliminar da Bimodalidade da Distribuição de Tamanhos das Partículas}

As distribuições dos diâmetros para as seis amostras preparadas e medidas pelo equipamento Coulter estão apresentadas nas Figuras 28 à 30. 
Figura 28 - Distribuição de diâmetros das amostras 1E, amostra 2E e amostra 4E que é composta por $50 \%$ vol amostra $1 \mathrm{E}+\mathbf{5 0 \%}$ vol amostra $2 \mathrm{E}$

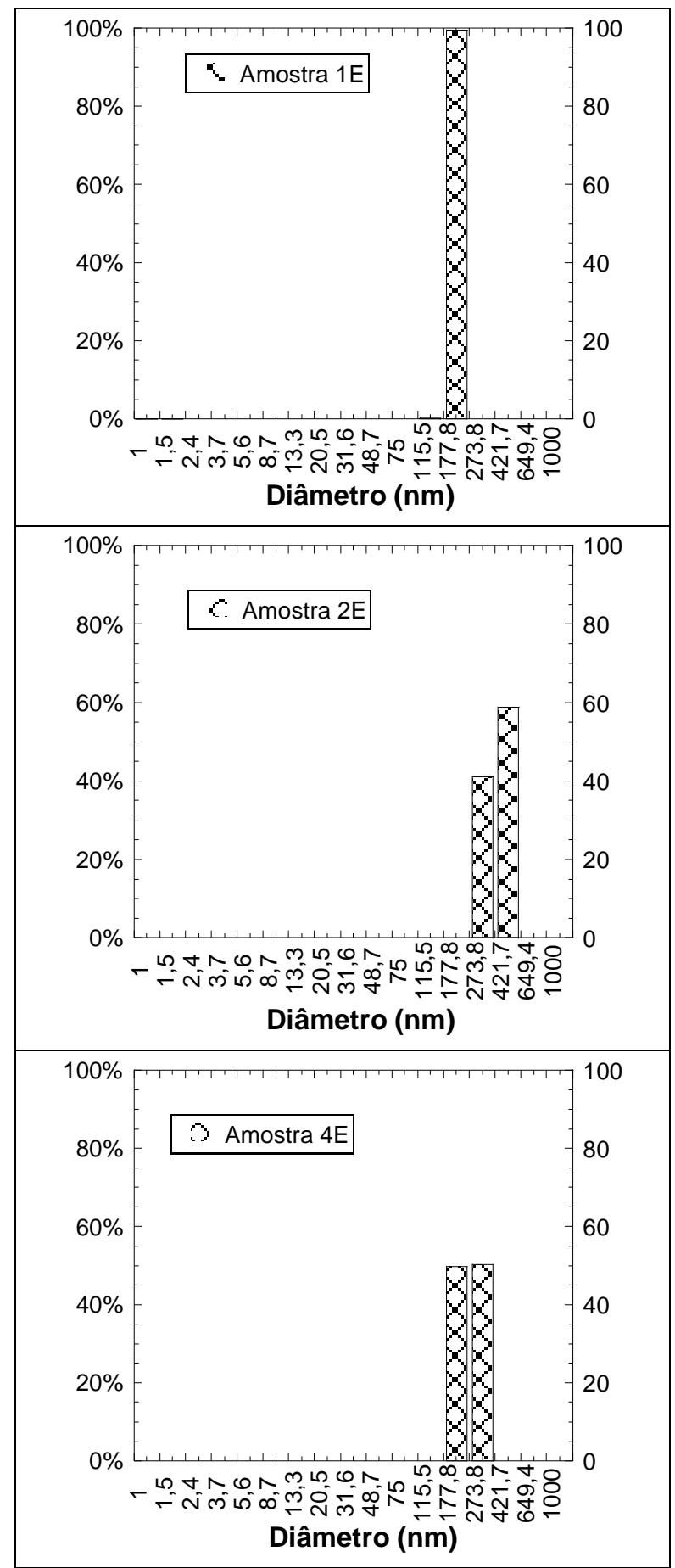


Figura 29 - Distribuição de diâmetros das amostras 1E, amostra 3E e amostra 5E que é composta por $50 \%$ vol amostra $1 \mathrm{E}+\mathbf{5 0 \%}$ vol amostra $3 \mathrm{E}$

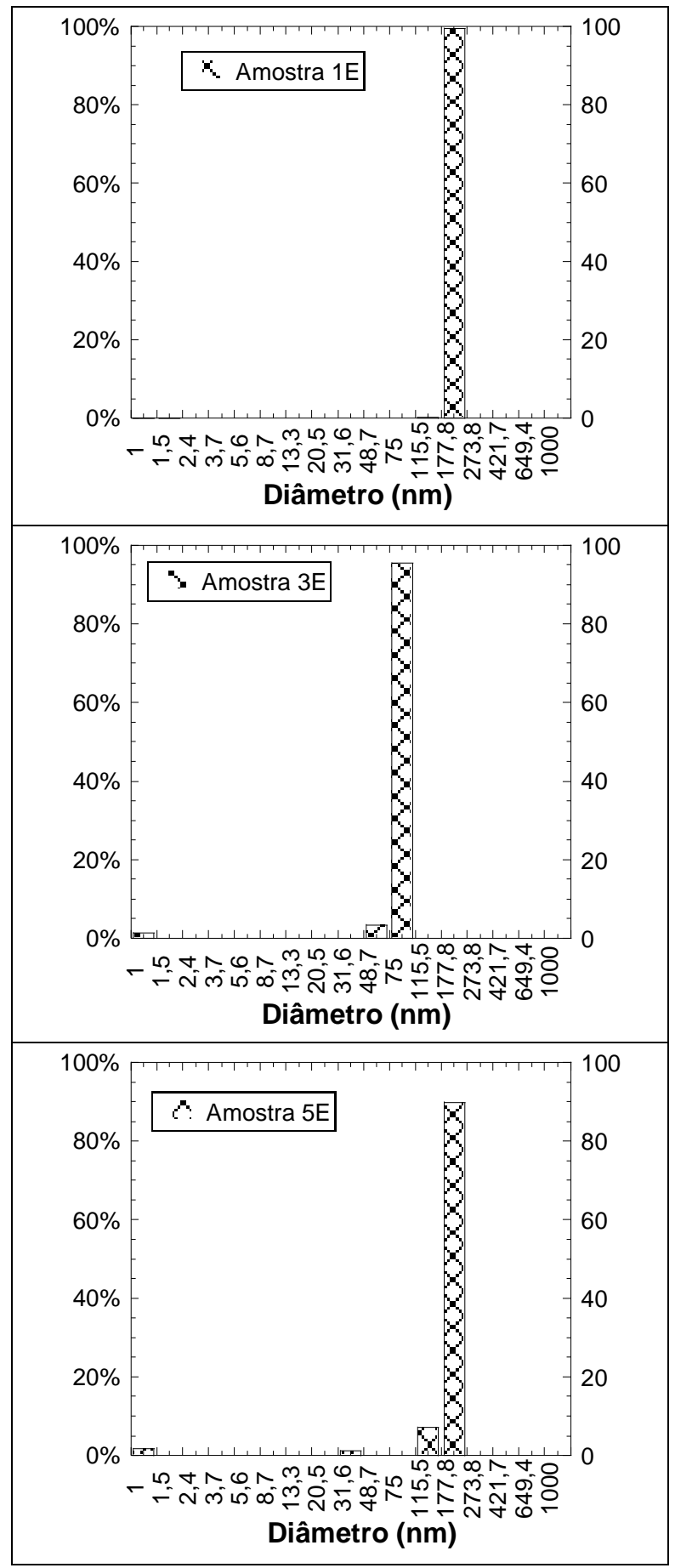


Figura 30 - Distribuição de diâmetros das amostras 2E, amostra 3E e amostra 6E que é composta por $50 \%$ vol amostra $2 \mathrm{E}+\mathbf{5 0 \%}$ vol amostra $3 \mathrm{E}$

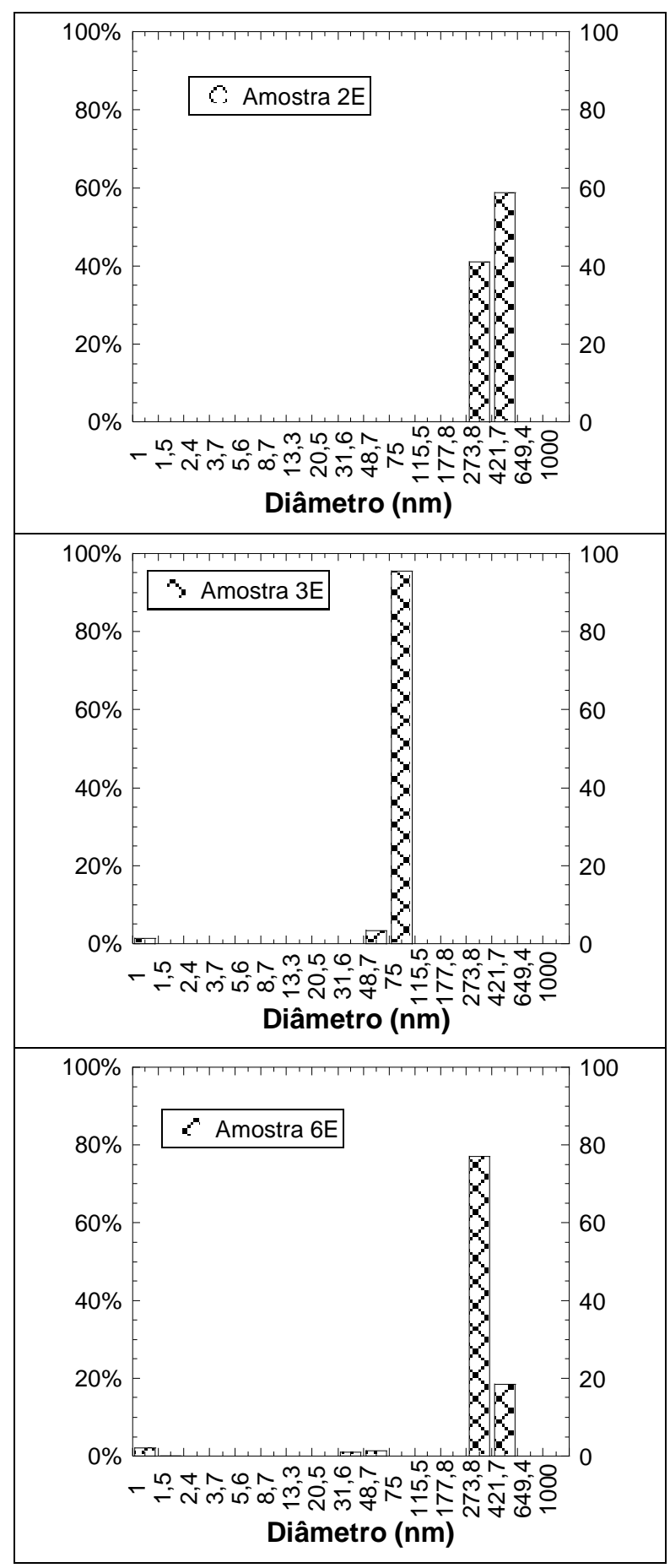


Os resultados mostram que as amostras $1 \mathrm{E}$ e $3 \mathrm{E}$, que apresentam maior teor de tensoativo, apresentam também distribuição de partículas monomodal estreita. A amostra 2E também apresenta uma distribuição monomodal, no entanto, mostra uma distribuição mais larga, em função da menor concentração de tensoativo utilizada em sua formulação.

As distribuições de diâmetros das amostras 4E, 5E e $6 \mathrm{E}$ foram medidas e os diâmetros médios calculados pela média ponderada entre os diâmetros médios das amostras de origem e também através da distribuição de tamanhos das amostras de origem. A comparação entre os dados medidos e calculados está apresentada na Figura 31 e Figura 32.

Após as misturas, as amostras produziram uma distribuição de tamanhos com um desvio de até $20 \%$ em relação ao esperado.

A avaliação realizada mostrou que o equipamento detectou a distribuição de tamanhos das amostras, e detectou a bimodalidade das amostras 5E e 6E. A amostra 4E não mostrou a bimodalidade esperada. No entanto, as amostras apresentam grande variabilidade, e isso foi identificado também nas análises dos diâmetros das amostras de miniemulsões apresentadas no item 5.1.4.2.3.

Figura 31 - comparação entre os diâmetros calculados e medidos para as amostras $4 \mathrm{E}, 5 \mathrm{E}$ e 6E.

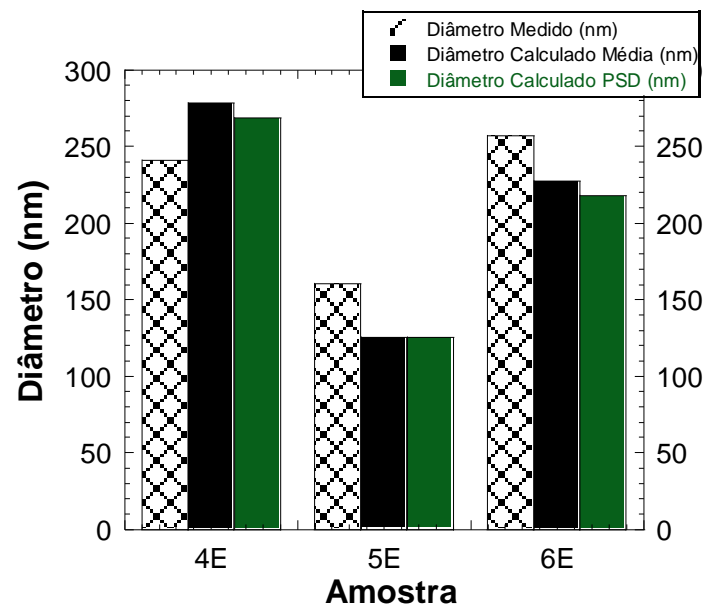

Figura 32- Desvio entre os diâmetros calculados e os diâmetros medidos para as amostras 4E, 5E e 6E.

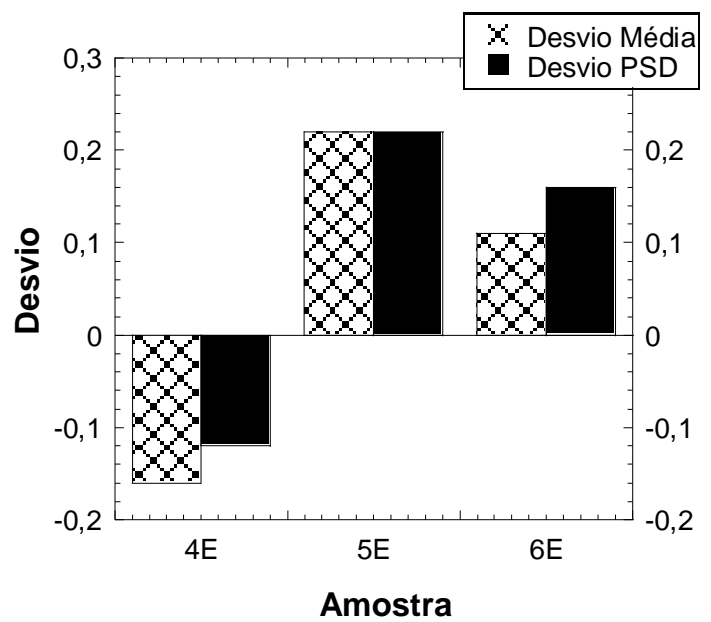


Os resultados comprovam que amostras com maiores teores de tensoativo apresentam menores diâmetros de partículas, como pode ser observado na Figura 33.

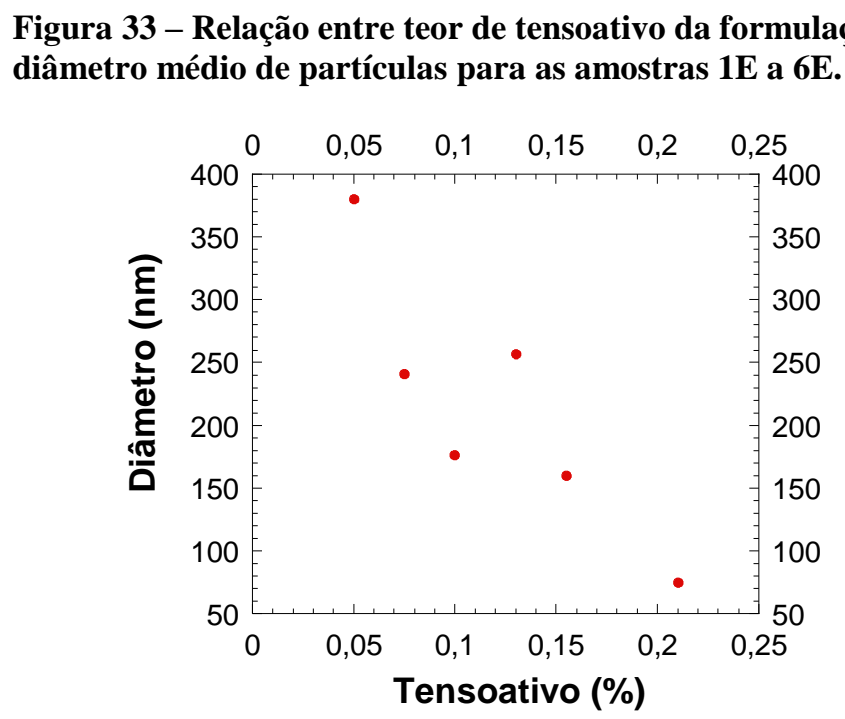

A avaliação da polidispersidade das gotas monoméricas em função da variação da agitação e do tempo de agitação das amostras mostra uma grande dispersão dos dados o que dificulta uma conclusão conforme mostram as Figuras 34 a 39. Essa dispersão pode estar relacionada com a metodologia analítica que requer uma grande diluição no preparo da amostra, o que pode influenciar nos resultados obtidos.

No entanto, com base nos dados obtidos, apresentados na Figura 34 e Figura 35, pode-se concluir que o tempo de agitação foi mais significativo na diferenciação das polidispersidades das amostras do que a velocidade de rotação. Pela Figura 34, o aumento da velocidade de agitação influi muito pouco (ou mesmo não influi, se consideradas as barras de incerteza das medidas replicadas) na polidispersidade, mas pela Figura 35 o aumento do tempo de homogeneização fez aumentar a polidispersidade da distribuição de tamanhos das gotas da miniemulsão. Para diâmetro médio das partículas, apresentados nas Figuras 36 e 37, os resultados mostraram que quanto maior o tempo de agitação e maior a velocidade de rotação, menor o diâmetro médio das gotas obtido. Estes resultados estão de acordo com resultados similares apresentados na literatura (SCHORK et al., 2005). 
Figura 34 - Variação da polidispersidade em função da velocidade de agitação

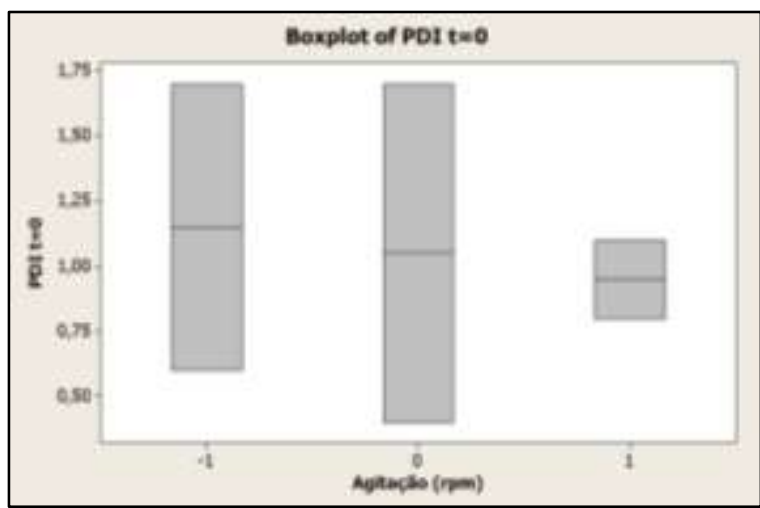

Figura 36 - Variação do diâmetro médio das gotas em função da velocidade de agitação

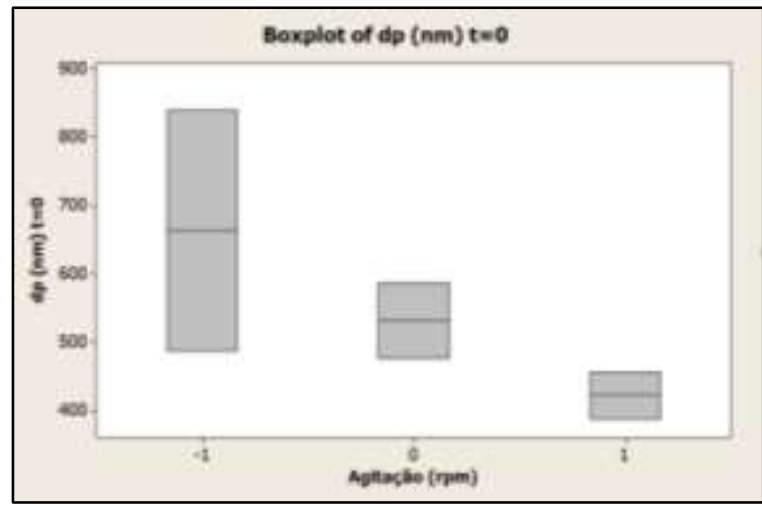

Figura 38 - Variação no índice de estabilidade da miniemulsão monomérica em função da velocidade de agitação

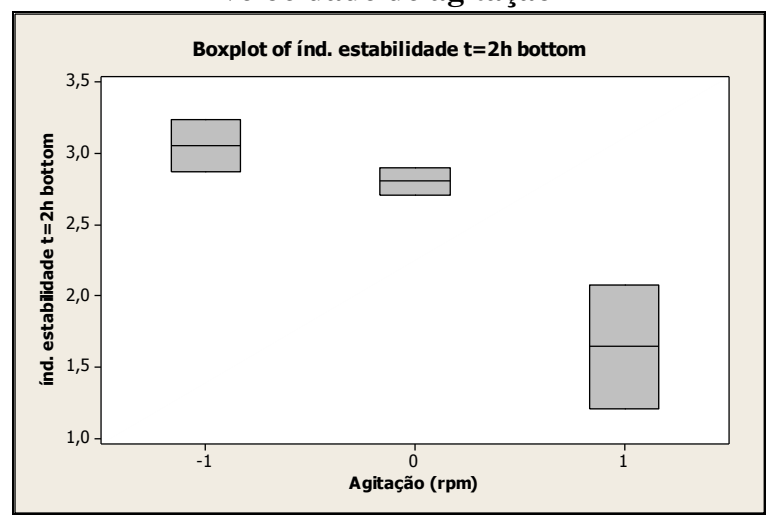

Figura 35 - Variação da polidispersidade em função do tempo de agitação

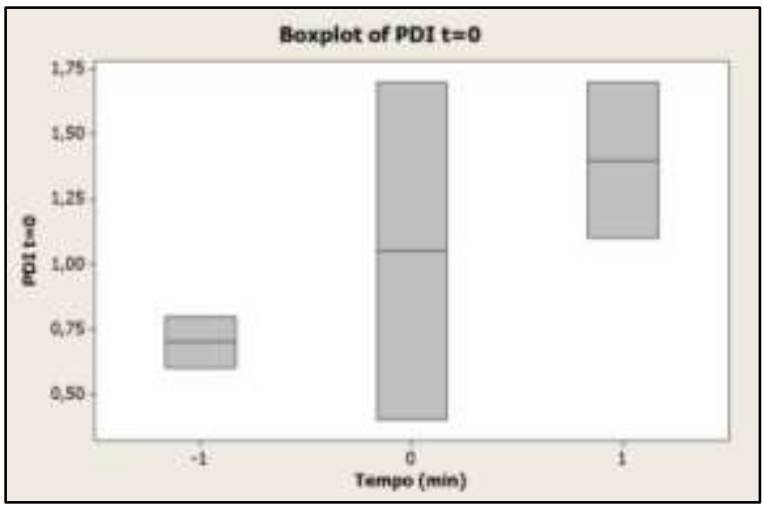

Figura 37 - Variação do diâmetro médio das gotas em função do tempo de agitação

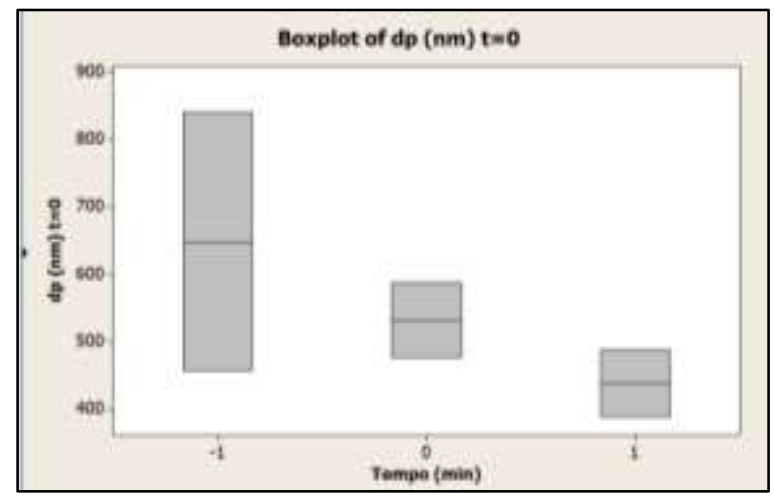

Figura 39 - Variação no índice de estabilidade da miniemulsão monomérica em função do tempo de agitação

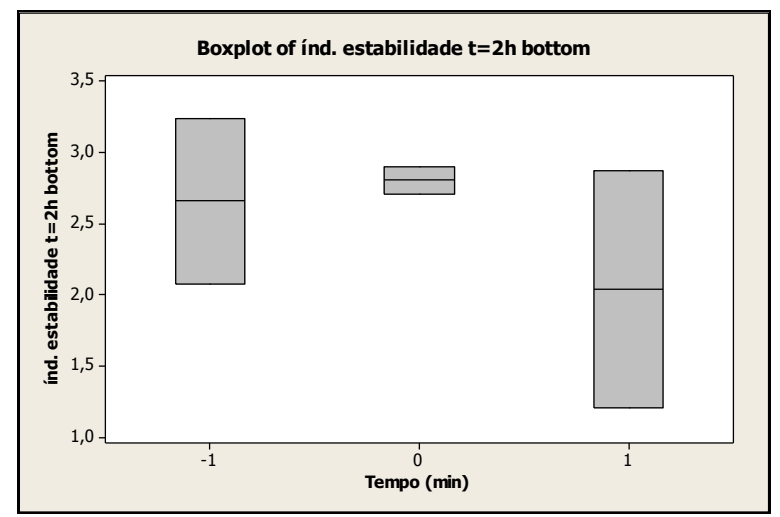




\subsubsection{Resultados - Miniemulsão}

\subsubsection{Influência das Condições de Processo na Miniemulsão Monomérica}

As condições de processo avaliadas foram apresentadas na Tabela 17 no item 4.2.1.4. As amostras preparadas sob as condições propostas foram analisadas imediatamente após seu preparo e também após duas horas mantidas em estabilidade.

A estabilidade de uma miniemulsão pode ser avaliada indiretamente pelo índice de estabilidade, conforme mostra a Figura 38 e Figura 39. Assim, quanto menor o índice de estabilidade, maior a estabilidade da amostra. Portanto, as amostras que mostraram maior estabilidade foram aquelas produzidas com maior o tempo de agitação e maior a velocidade de rotação.

\subsubsection{Estabilidade das Miniemulsões Monoméricas}

Os resultados dos testes de estabilidade encontram-se subdivididos nos subitens a seguir. Apenas para contextualizar os resultados, as amostras foram analisadas ao término de seu preparo e ao longo das duas horas subsequentes.

Duas amostras foram coletadas do Béquer, ao final do preparo da miniemulsão monomérica e foram analisadas paralelamente através de medições do diâmetro médio das gotas monoméricas (medidas por DLS) e também, através da variação (ao longo do tempo e da posição) da turbidez das amostras (medidas no Turbiscan).

\subsubsection{Avaliação da Estabilidade pela Variação do Diâmetro Médio das Gotas}

A Figura 35 apresenta os valores de tamanho médio das gotas em função do tempo, medidas ao longo de um período de 2 horas imediatamente após o preparo da miniemulsão, para as diferentes preparações reportadas na Tabela 16, variando-se a rotação e o tempo de homogeneização. As miniemulsões Mini 06 a Mini 11 diferenciam-se pelo tempo em que foram submetidas ao processo de cisalhamento pelo equipamento Ultra Turrax e também pela rotação utilizada.

Uma das evidências da instabilidade de uma miniemulsão é a variação do diâmetro das gotas como consequência da degradação difusional (amadurecimento de Ostwald) ou da coalescência.

A Figura 40 mostra que houve pequena variação no diâmetro médio das partículas ao longo das duas horas de repouso. Portanto, pode-se afirmar que todas as 
miniemulsões avaliadas mostraram estabilidade durante as duas horas em que foram submetidas à avaliação de estabilidade.

Figura 40 - Variação no diâmetro médio das partículas durante teste de estabilidade

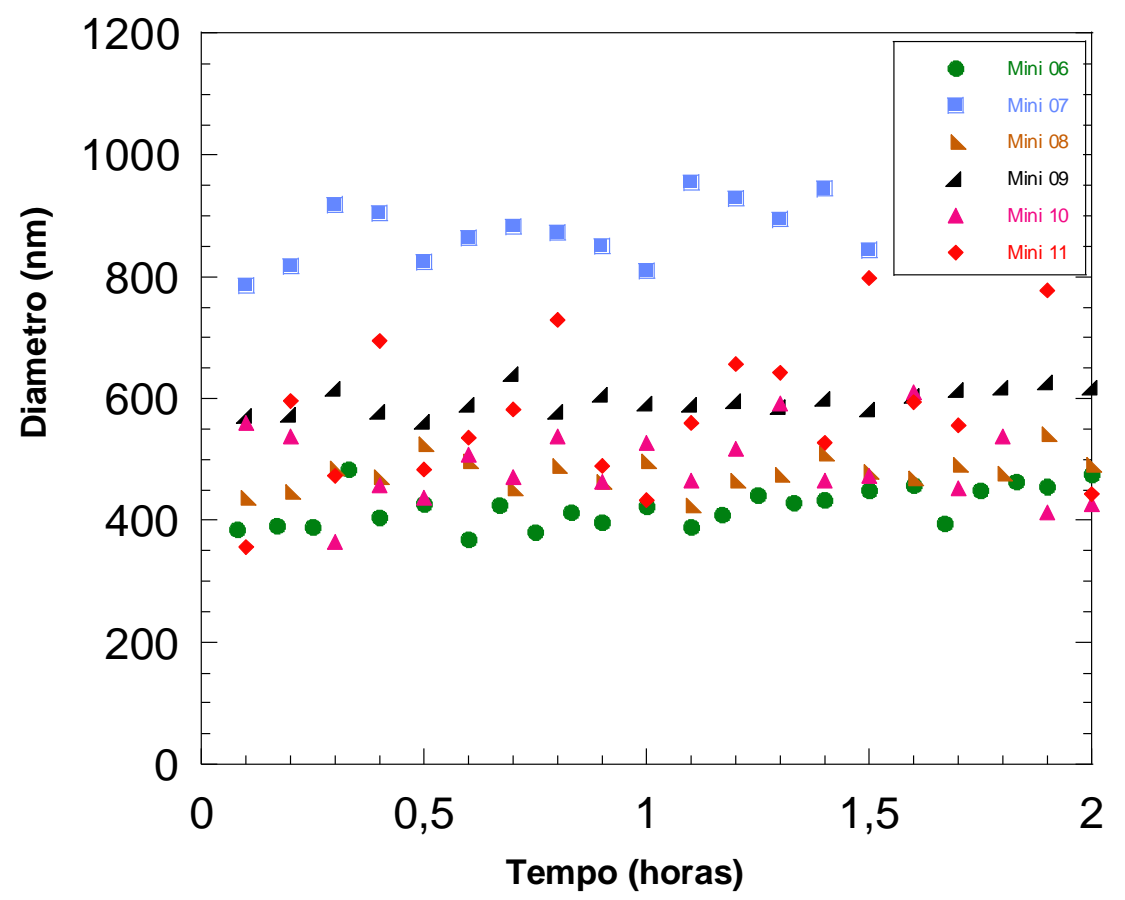

No entanto, entre as amostras avaliadas pode-se afirmar que houve diferença de estabilidade. A amostra Mini_06 apresentou maior estabilidade. Essa amostra foi obtida através do processo de dispersão que utilizou maior velocidade e tempo de agitação e apresentou menor tamanho médio de gotas.

A amostra menos estável foi a Mini_07, obtida com menor velocidade de rotação e menor tempo de agitação, resultando também na amostra com maior diâmetro médio.

O resultado desse Planejamento Experimental comprova o que ASUA (2002) descreve em seu artigo de revisão, que quanto maior o tempo de agitação e quanto maior a velocidade de agitação, menor será o diâmetro médio das partículas monoméricas obtidas e maior a estabilidade.

\subsubsection{Estabilidade por Retro espalhamento de Luz}

O gráfico gerado pelo equipamento Turbiscan é uma combinação dos dados coletados ao longo do tempo e ao longo da altura da amostra. Mostra a variação com o tempo do perfil de retroespalhamento da luz (Backscattering - BS) ao longo da altura da amostra. Sua interpretação pode ser realizada com auxílio do diagrama apresentado na Figura 41 ("Turbiscan User Guide", [s.d.]). 
Figura 41 - Diagrama para interpretação do retroespalhamento de luz (BS) e transmissão (T)

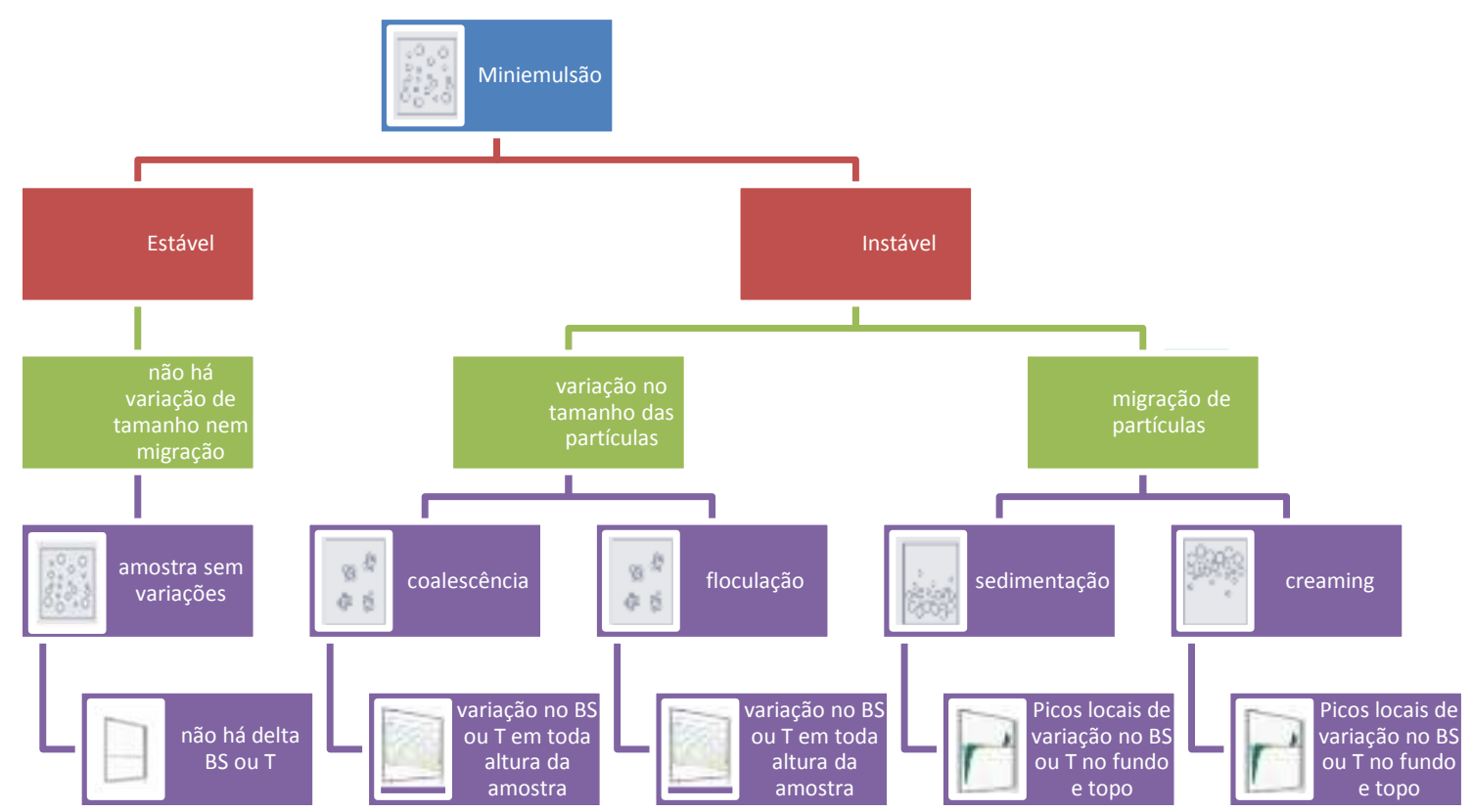

Com base nos gráficos apresentados na Figura 42 a Figura 47 e no diagrama auxiliar para interpretação dos dados, pode-se concluir que não há variação no tamanho das partículas.

Tabela 28 - Variações no perfil de retroespalhamento de luz (BS) para cada tipo de instabilidade

\begin{tabular}{|ccccc|}
\hline$\Delta$ BS & Topo & Meio & Fundo & Característica \\
\hline $\mathbf{1}$ & $\downarrow$ & - & $\uparrow$ & Sedimentação \\
\hline $\mathbf{2}$ & $\uparrow$ & - & $\downarrow$ & Creaming \\
\hline $\mathbf{3}$ & $\downarrow$ & $\downarrow$ & $\downarrow$ & Floculação ou coalescência \\
\hline
\end{tabular}

As amostras apresentaram pequeno aumento no BS no topo e pequeno decréscimo no fundo da cubeta, o que poderia ser resultado da migração de partículas para o topo das amostras conforme indicado na Tabela 28. No entanto, como a Figura 40 apresentada no item 5.1.3.1 não mostra variação no diâmetro médio das partículas e também a variação está abaixo de 5\% para todas as amostras, então, pode-se considerar a variação desprezível.

Assim, conclui-se que as variações de BS apresentados resultaram da migração do menisco das amostras, possivelmente pela presença de bolhas. Essa grande variação é refletida também na Figura 50 que apresenta a variação global do backscattering. Por esse motivo, utilizou-se a Figura 49 para avaliar a estabilidade que mostra menor 
variação para a amostra Mini_06, que é também a amostra que apresentou menor diâmetro médio das partículas e também menor variação ao longo das duas horas de observação. Portanto, trata-se da amostra mais estável.

Com isso, pode-se concluir que todas as amostras mostraram estabilidade, exceto a amostra Mini_10. Esta apresentou grande variação de BS e pequena variação no diâmetro das partículas, o que evidencia que a amostra apresentou clarificação.

As Figuras, Figura 48 a Figura 50, mostram como o Backscattering das amostras varia ao longo do tempo. A Figura 48 apresenta o Backscattering no topo da cubeta, onde pode notar-se grande variação para a amostra mini_10 que pode ser atribuída principalmente à variação na altura da amostra devido à presença de bolhas na miniemulsão, que ao longo do tempo tendem a migrar para a superfície, fazendo com que o volume da amostra diminua, diminuindo também a altura da amostra na cubeta. 
Figura 42 - Variação do Backscattering da Amostra Mini_06 ao longo do tempo.

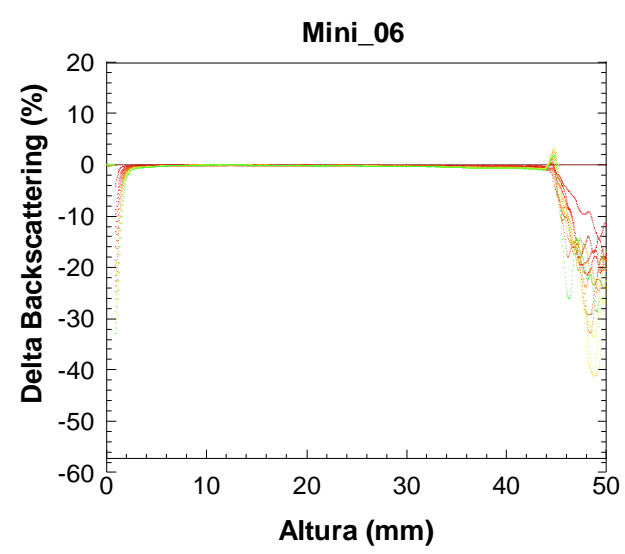

Figura 44 - Variação do Backscattering da Amostra Mini_08 ao longo do tempo.

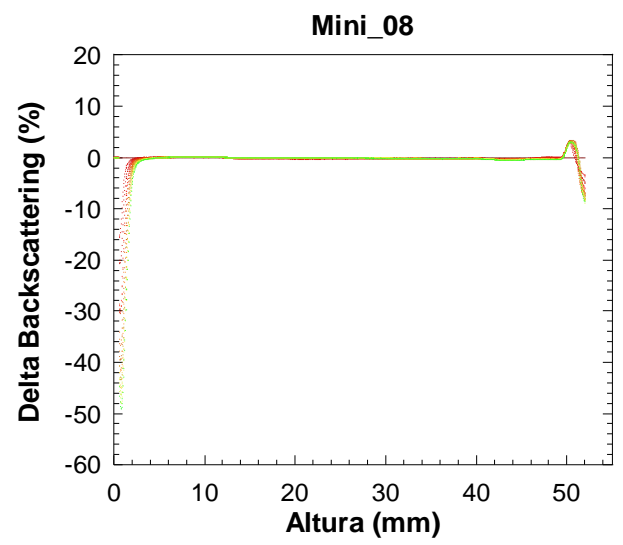

Figura 46 - Variação do Backscattering da Amostra Mini_10 ao longo do tempo.

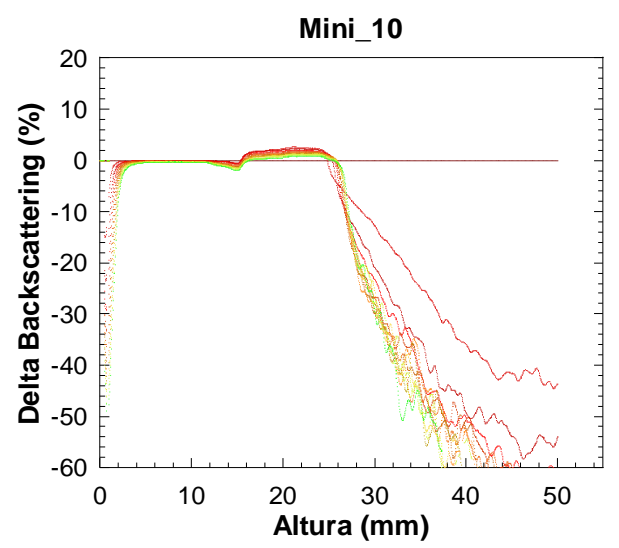

Figura 43 - Variação do Backscattering da Amostra Mini_07 ao longo do tempo.

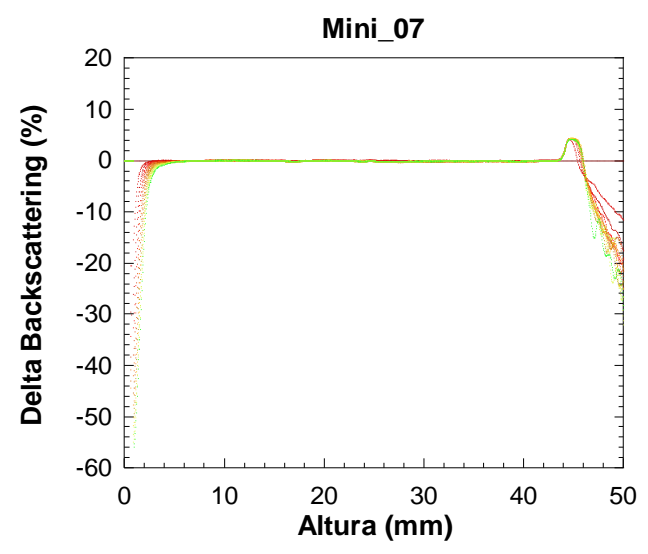

Figura 45 - Variação do Backscattering da Amostra Mini_09 ao longo do tempo.

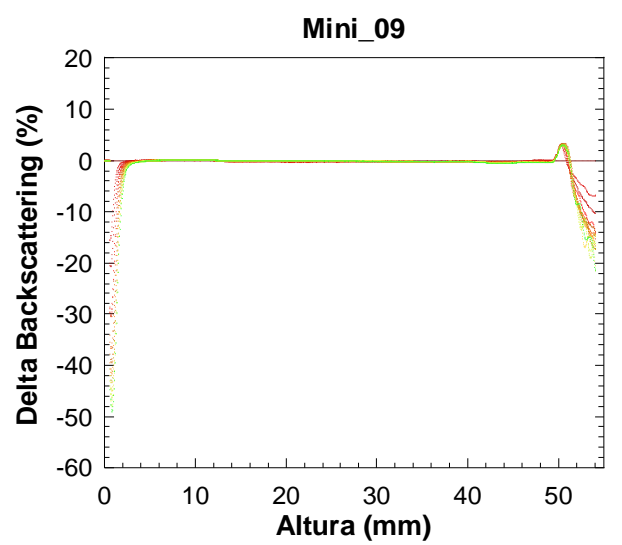

Figura 47 - Variação do Backscattering da Amostra Mini_11 ao longo do tempo.

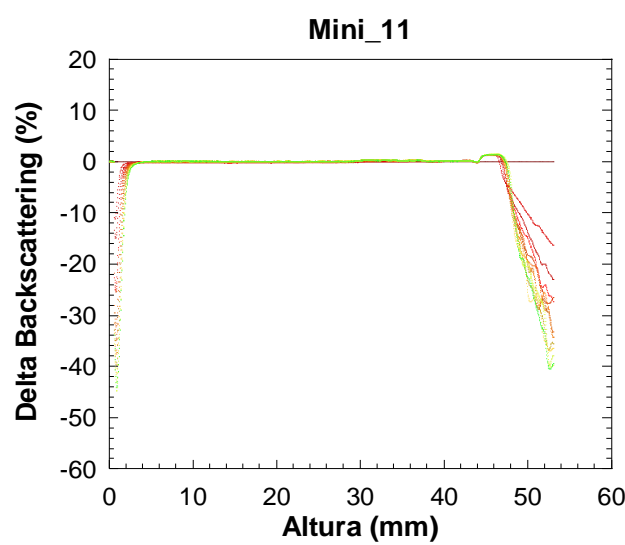


Figura 48 - Variação de Backscattering no TOPO das amostras ao longo do tempo.

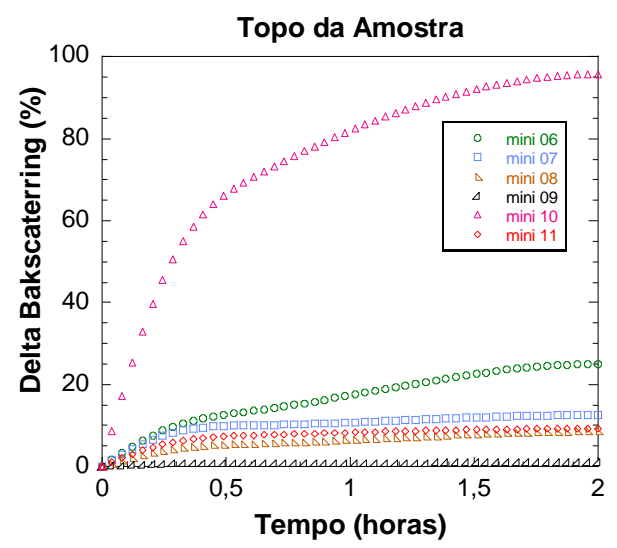

Figura 50 - Variação de Backscattering GLOBAL ao longo do tempo.

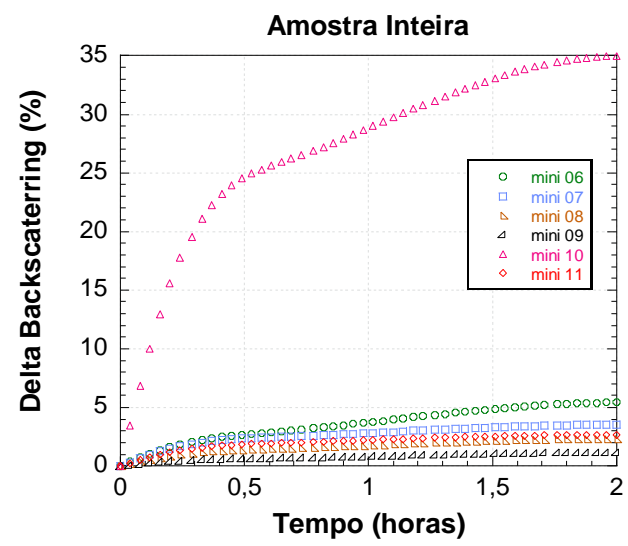

Figura 49 - Variação de Backscattering no FUNDO das amostras ao longo do tempo.

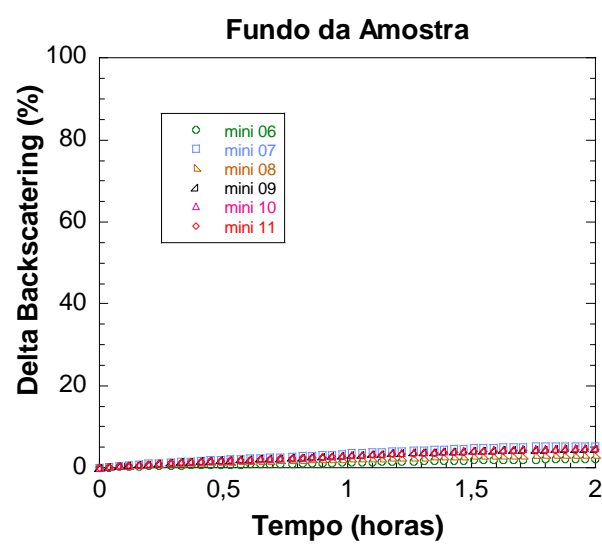

Figura 51 - Comparação entre a variação de Backscattering para todas as amostras do DOE após 120 minutos em estabilidade.

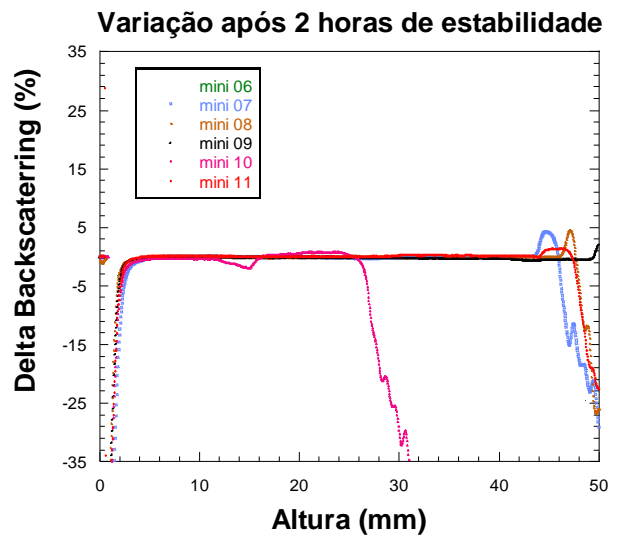

\subsubsection{Resultados - Polimerização}

\subsubsection{Monitoramento do processo - in line}

Realizou-se o monitoramento do processo in-line através da sonda de infravermelho próximo imersa no meio reacional. Os espectros coletados podem fornecer diversas informações, conforme citado no Item 2.2, Tabela 4. No presente estudo, os espectros NIR foram usados para estabelecer um modelo de calibração que os relacionasse com o tamanho médio de partículas e com a conversão do monômero.

A Figura 52 apresenta o conjunto de espectros de infravermelho próximo coletado ao longo da reação de polimerização (Mini_03), apresentados em três dimensões, tempo (representado pela ordem cronológica das amostras), intensidade e número de onda. 
Figura 52 - Espectro NIR Mini_03 em 3 dimensões: (x) número de onda, (y) intensidade e (z) ordem cronológica das amostras.

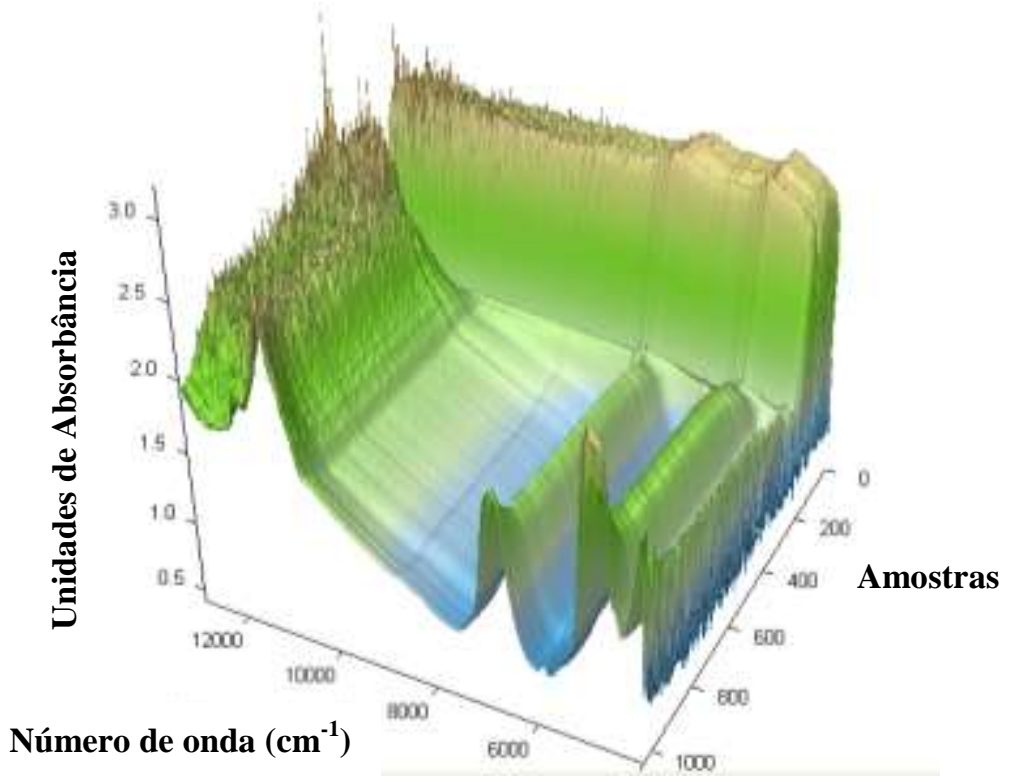

Quando plotados em duas dimensões, intensidade e número de onda, apresentam o comportamento observado na Figura 13, em que as duas regiões de interesse para determinação da conversão e diâmetro são claramente identificáveis,

Além da espectroscopia NIR, também foi monitorada a temperatura do reator inline. A seguir, apresentam-se os resultados do monitoramento in-line assim como suas análises.

\subsection{Conversão (Espectroscopia NIR)}

Um modelo de calibração foi construído relacionando os dados experimentais de conversão (medidos por gravimetria) e os espectros obtidos do monitoramento on-line (espectros NIR) dos experimentos.

Para a elaboração do modelo de calibração da conversão, escolheram-se dois experimentos, Mini_02 e Mini_04, que foram os dois experimentos que apresentaram valores extremos de conversão, ou seja, máxima e mínima conversão. Assim, o modelo de calibração obtido pode representar uma faixa mais ampla de dados. Diversas faixas espectrais foram testadas para a construção do modelo de calibração. Selecionou-se a faixa espectral correspondente à informação química dos espectros, $5.700 \mathrm{a} 6.200 \mathrm{~cm}^{-1}$.

O modelo de calibração foi construído utilizando como pré-tratamentos a subtração da linha base e a primeira derivada com 17 pontos de alisamento nos 
espectros. A escolha destas opções de pré-tratamento dos espectros foi baseada na avaliação de diferentes tratamentos sendo que o melhor ajuste foi obtido com essa opção.

Conforme Reis (2004) os modelos podem apresentar divergências devido à heterogeneidade do meio analisado, conforme ilustra a Figura 53. Por essa razão, o espectro não está diretamente relacionado apenas com a quantidade de monômero presente no látex, mas também com o número de partículas poliméricas que resulta de diferenças na composição do látex. Para o modelo ser aplicado para diferentes formulações, precisaria incluir no modelo informações da composição do látex analisado.

Figura 53 - Ilustração do volume iluminado pelo laser em (a) meio heterogêneo e (b) em meio homogêneo.

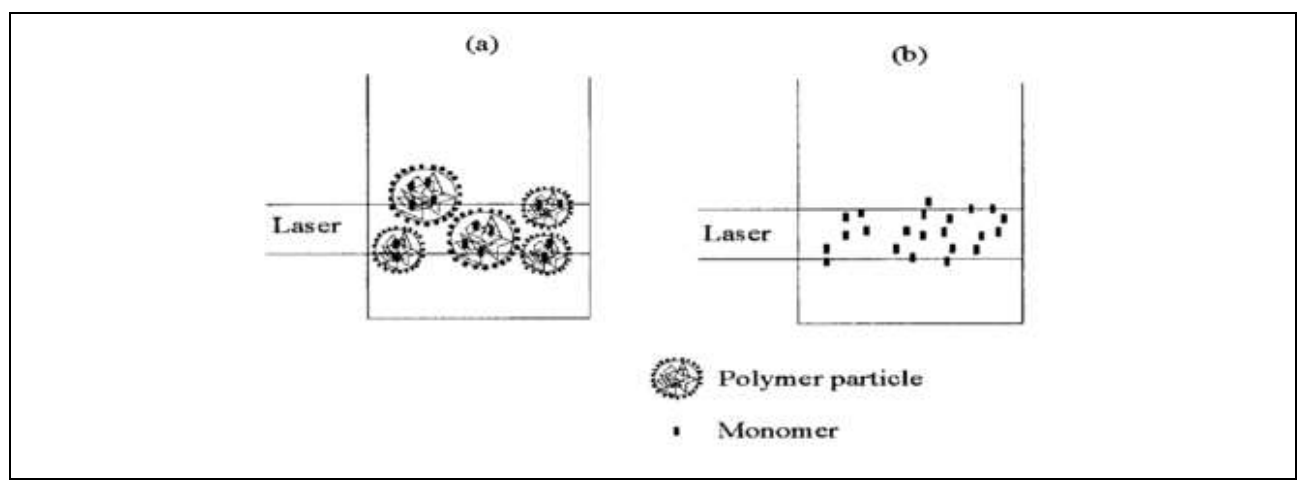

Fonte: Reis et al. (2004).

O resultado do ajuste do modelo de calibração está apresentado na Figura 54, onde o ajuste do modelo apresentou RMSEE igual a 0,055 e $\mathrm{R}^{2}$ de 0,9646.

A Figura 55 mostra a variação do RMSEE com o número de componentes principais e para o modelo adotado, escolheu-se o modelo com 4 componentes principais. A validação interna, conforme Figura 56 e Figura 57, gerou RMSECV de 0,112 e $\mathrm{R}^{2} 0,8375$.

Realizou-se a validação externa do modelo com dados dos experimentos Mini_01, conforme Figura 58 e com os dados do experimenrto Mini_03, conforme Figura 59. Esses dois experimentos não foram utilizados para a construção do modelo (REIS et al., 2004) e ambos mostram que o modelo foi capaz de representar de forma satisfatória a evolução da conversão da reação ao logo do tempo.

Nas Figuras 58 e 59 estão destacados os intervalos iniciais das reações que podem ser atribuídos ao tempo de inibição para que a reação inicie. 
Figura 54 - Comparação entre conversão calculada pelo modelo com conversão experimental para Mini_02 e Mini_04.

Conversão NIR Calibração Mini_02 e Mini_ 04

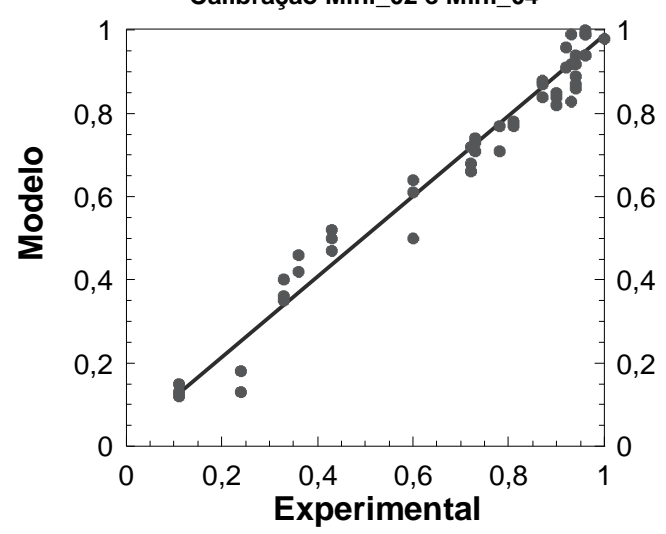

Figura 56 - Validação interna da conversão com dados da Mini_02 e Mini_04.

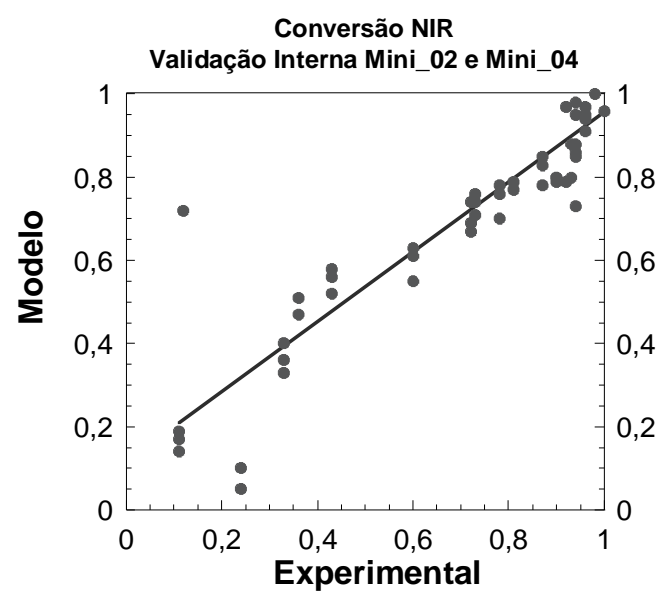

Figura 58 - Validação externa do modelo de calibração com dados da Mini_01

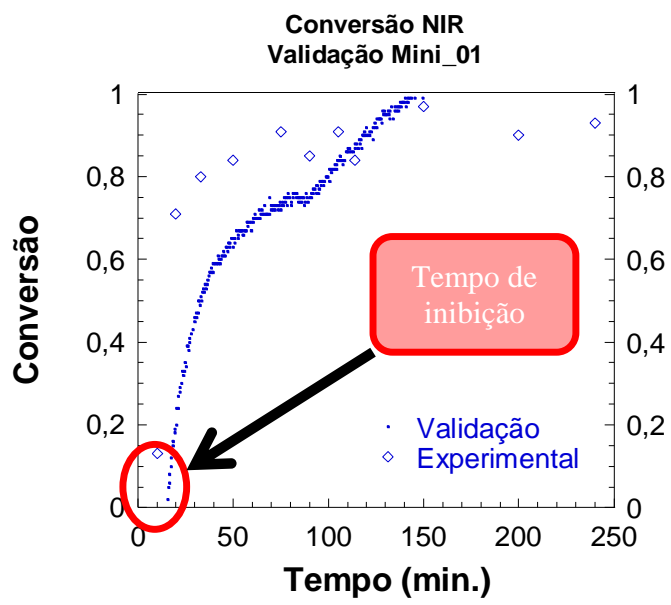

Figura 55 - Análise dos componentes principais para o modelo de calibração obtido com dados da Mini_02 e Mini_04.

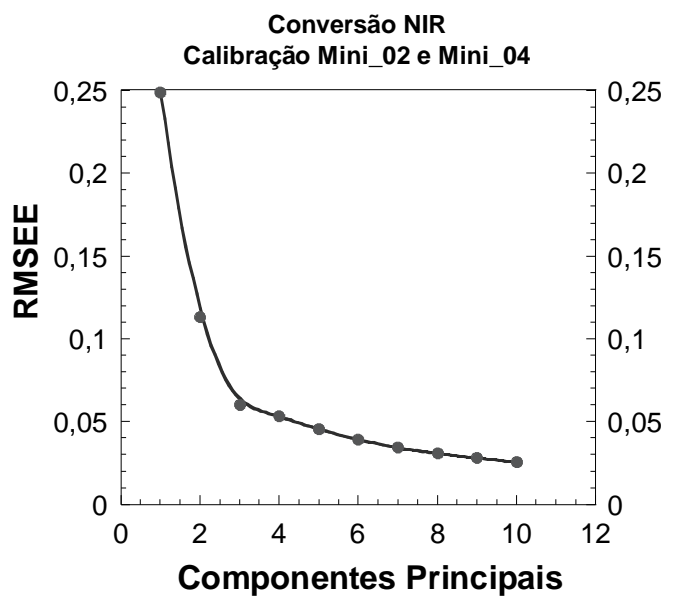

Figura 57 - Análise dos componentes principais para a validação interna do modelo de calibração obtido com dados da Mini_02 e Mini_04.

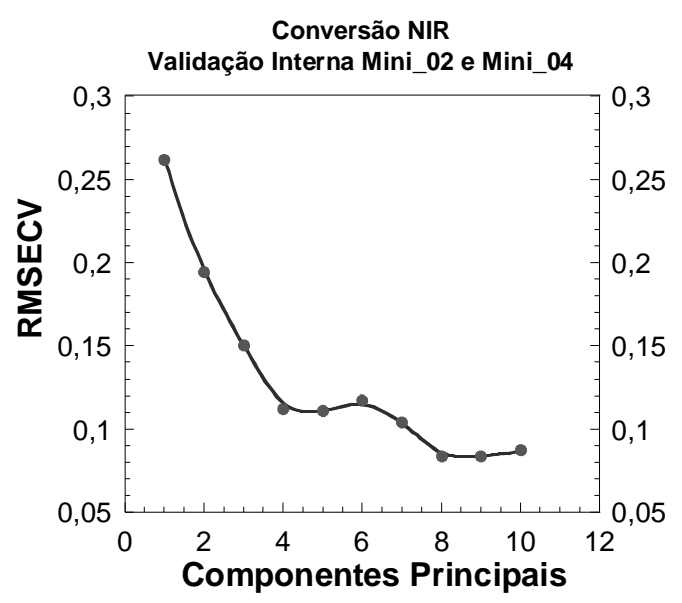

Figura 59 - Validação externa do modelo de calibração com dados da Mini_03

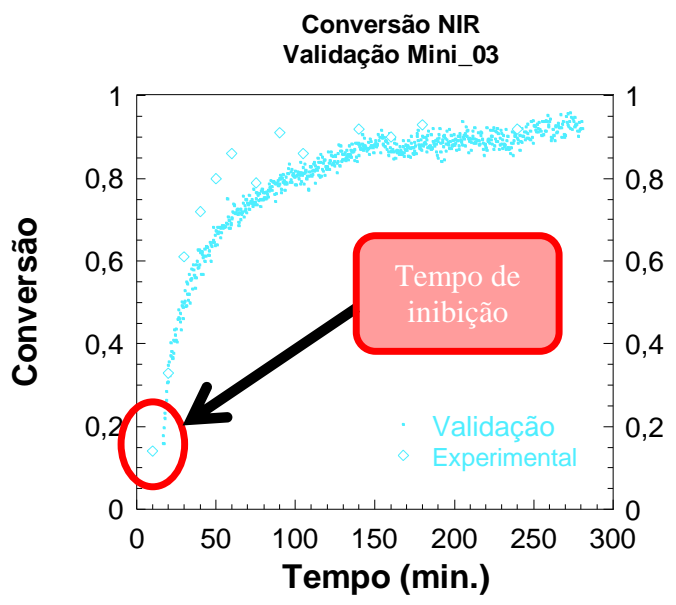




\subsection{Diâmetro de partículas (Espectroscopia NIR)}

Um modelo de calibração foi construído para relacionar o diâmetro das partículas (medidos experimentalmente com o Coulter) e os espectros obtidos do monitoramento on-line (espectros NIR) dos experimentos.

Da mesma forma que o modelo de conversão, a construção do modelo de calibração para o diâmetro utilizou dois experimentos, Mini_01 e Mini_05, pois foram os dois experimentos que apresentaram valores extremos de diâmetro, ou seja, máximo e mínimo diâmetro. Assim, o modelo de calibração obtido poderia representar uma faixa mais ampla de diâmetros. Diversas faixas espectrais foram testadas para a construção do modelo de calibração. Selecionou-se a faixa espectral correspondente à informação física dos espectros, 7.590 a $11.700 \mathrm{~cm}^{-1}$.

$\mathrm{O}$ modelo de calibração foi obtido sem realizar pré-tratamentos nos espectros. $\mathrm{O}$ resultado está apresentado na Figura 60, onde o ajuste do modelo apresentou RMSEE 2,35 e $\mathrm{R}^{2}$ de 0,9991. A Figura 61 mostra a variação do RMSEE com o número de componentes principais e para o modelo adotado, escolheu-se o modelo com 6 componentes principais. A validação interna do modelo, conforme Figura 62 e Figura 63, gerou RMSECV de 28,4 e $\mathrm{R}^{2} 0,8585$.

As Figura 64 e Figura 65 apresentam a validação externa do modelo com dados dos experimentos Mini_02 e Mini_04, que não foram utilizados para a construção do modelo (REIS et al., 2004) e ambos mostram que o modelo foi capaz de representar de forma satisfatória o diâmetro ao longo da reação.

\subsection{Temperatura de Reação (Termopar)}

A temperatura da reação foi monitorada in-line, através de um sensor termopar inserido no meio reacional. As Figura 66 e Figura 67 mostram que a temperatura do reator foi mantida entre 68 e $71^{\circ} \mathrm{C}$ ao longo de quase toda a reação, sendo a maior variação observada no início das reações que pode ser atribuída a uma possível micelização. 
Figura 60 - Comparação entre diâmetro calculada pelo modelo com diâmetro experimental da Mini_01 e Mini_05.

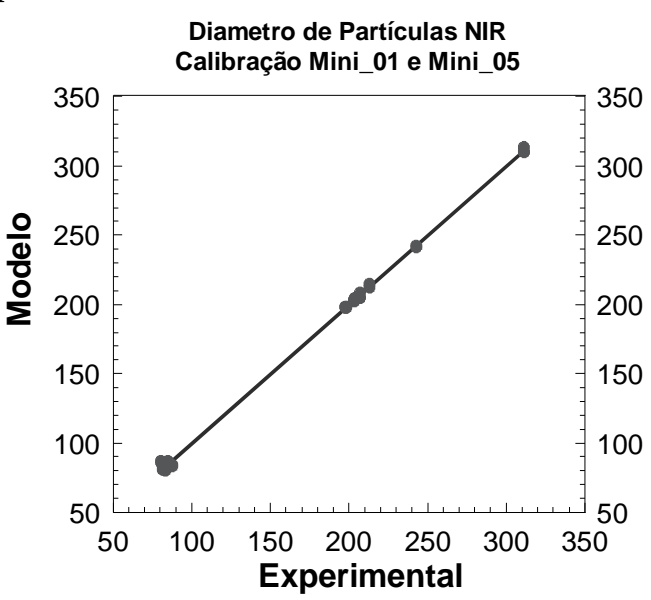

Figura 62 - Validação interna do modelo de diâmetro com dados da Mini_o1 e Mini_o5.

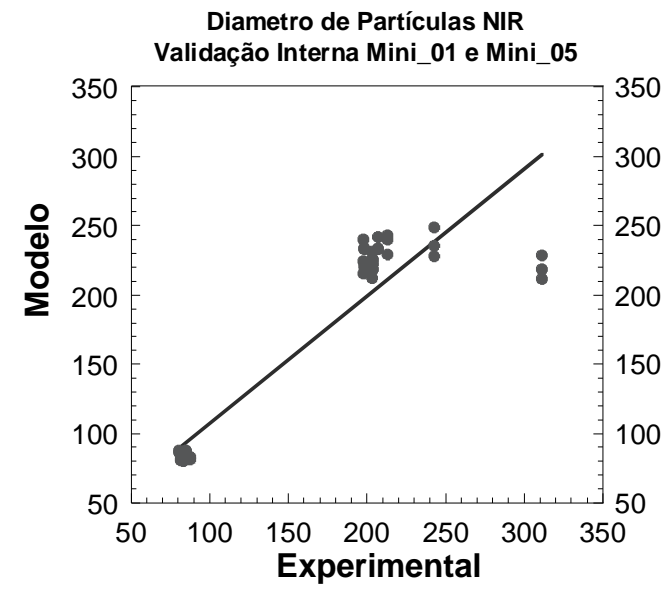

Figura 64 - Validação externa do modelo de calibração com dados da Mini_02.

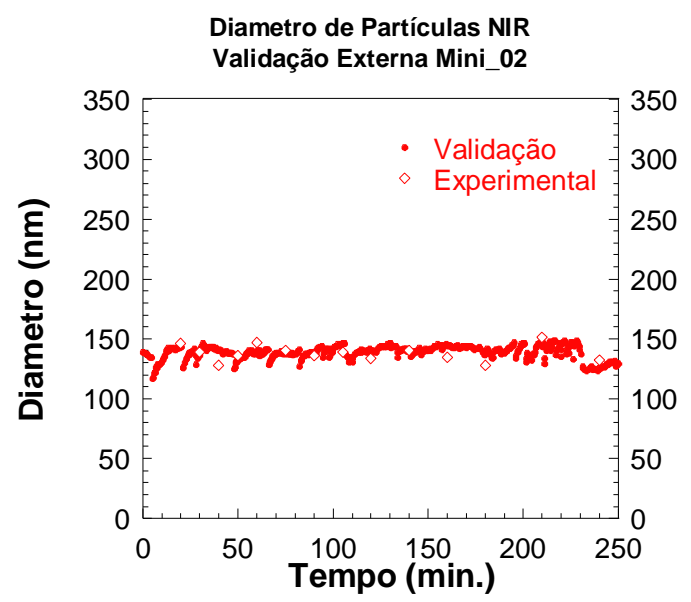

Figura 61 - Análise dos componentes principais para o modelo de calibração obtido com dados da Mini_o1 e Mini_o5.

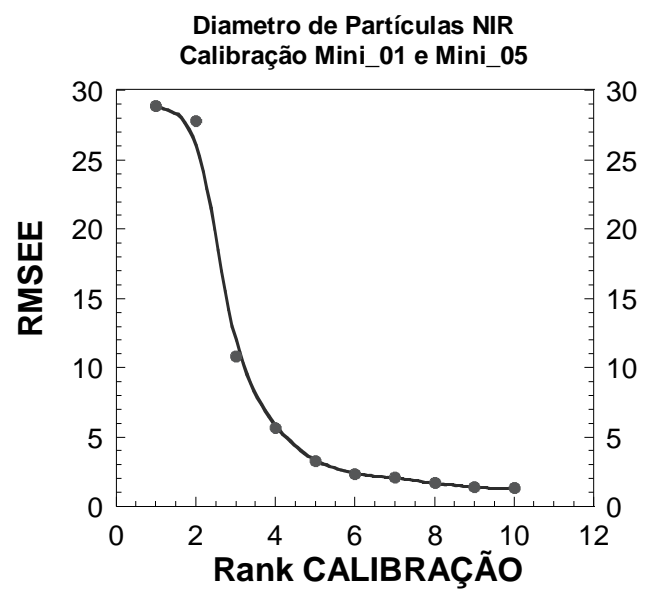

Figura 63 - Análise dos componentes principais para a validação interna do modelo de calibração obtido com dados da Mini_01 e Mini_05.

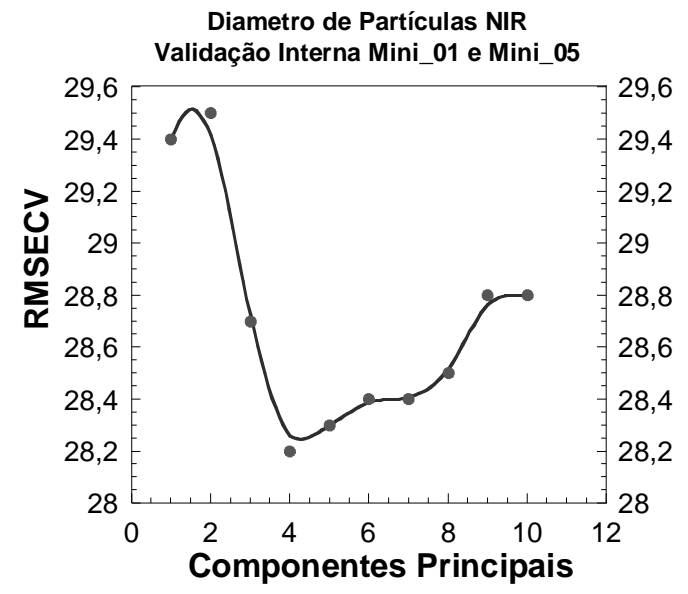

Figura 65 - Validação externa do modelo de calibração com dados da Mini_o4.

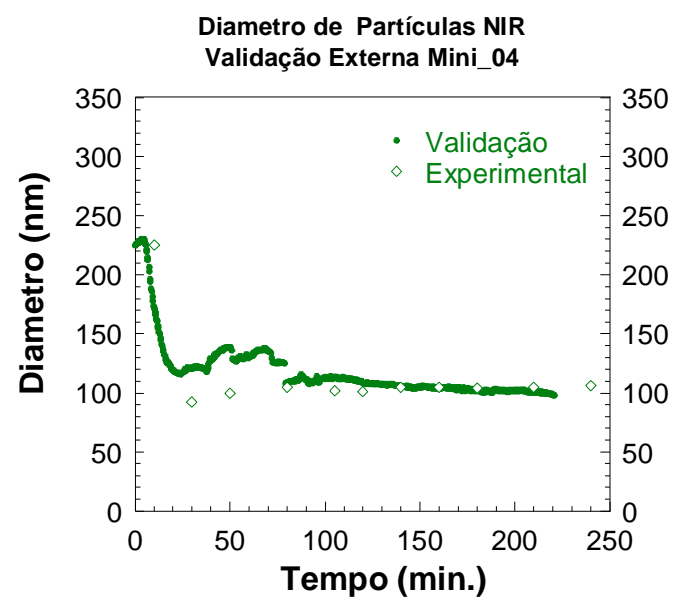


Figura 66 - Monitoramento da temperatura de reação em função do tempo.

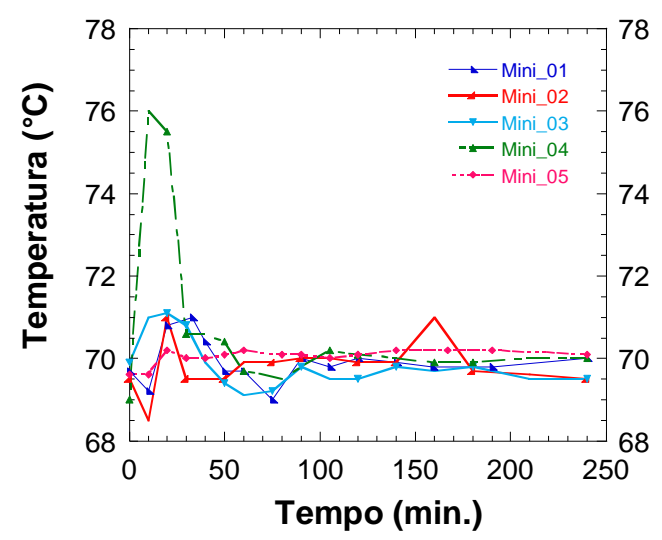

Figura 67 - Monitoramento da temperatura de reação em função da conversão.

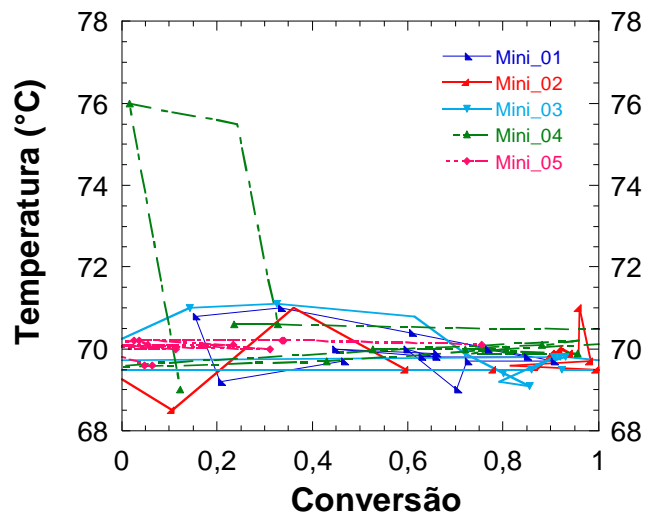

\subsubsection{Monitoramento do processo - off line}

\subsection{Conversão (Gravimetria)}

A conversão do monômero em polímero foi analisada off-line a partir de amostras retiradas periodicamente do reator e analisadas por gravimetria (usando balança analítica e estufa) conforme metodologia apresentada no item 4.2.1.8.1. Os resultados de conversão (gravimetria) estão apresentados na Figura 68.

Na Figura 68 observa-se um comportamento mais estável, com menor oscilação nas conversões medidas e finalmente, maior conversão para os Experimentos Mini_02 e Mini_03. Quando comparados com o experimento Mini_01, que utilizou a maior quantidade de tensoativo, observa-se que apesar de não serem os experimentos com maior teor de tensoativo, foram os que apresentaram maiores conversões.

Os experimentos Mini_02 e Mini_03 diferenciam-se do experimento Mini_01, pela concentração de tensoativo, mas também, pelo uso de poliestireno como coestabilizante, além do hexadecano. Assim, esses experimentos possuem em sua formulação dois co-estabilizantes, um polimérico e outro não polimérico. 
Figura 68 - Evolução da conversão da reação medida por gravimetria

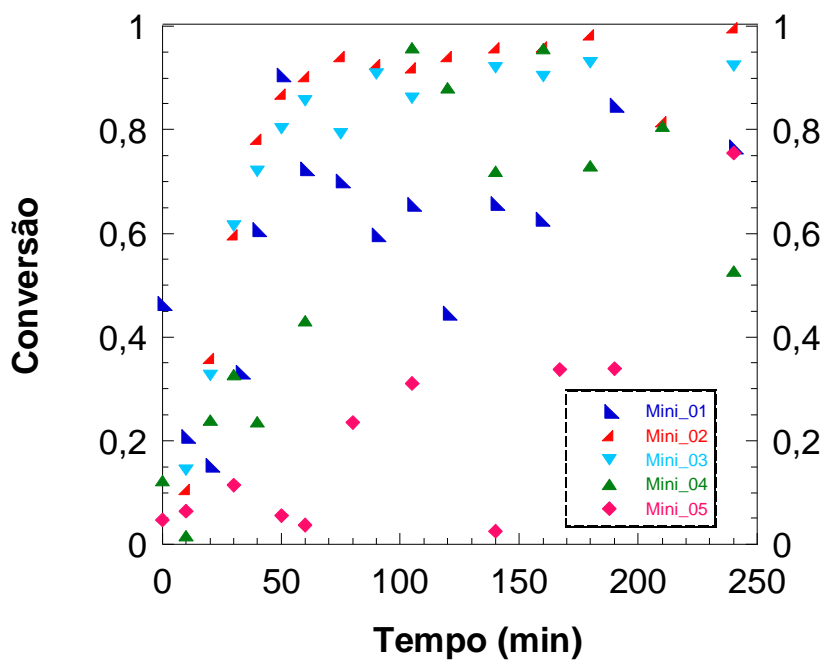

De acordo com ASUA (2002), os polímeros usados como co-estabilizantes não funcionam especificamente como estabilizantes. Funcionam como hidrófobos, que interferem na pressão osmótica do sistema, reduzindo a difusão dos monômeros de gotas pequenas para gotas grandes, reduzindo, portanto, o amadurecimento de Ostwald. Os polímeros funcionam também como barreiras eletrostáticas, para evitar a aproximação entre as partículas. Quando duas partículas histericamente estabilizadas se aproximam, elas ficam em um estado energético termodinamicamente instável e, por isso, tendem a se afastar, evitando também a coagulação das partículas (CHERN, 2008). Isso justifica a menor variação no diâmetro apresentada pela Mini_02 e Mini_03.

\subsection{Conversão (Espectroscopia Raman)}

A conversão também foi avaliada através dos espectros Raman das amostras coletadas ao longo da reação de polimerização.

A seguir, estão apresentados os resultados das duas metodologias de cálculo adotadas: Método Indireto - modelo de calibração multivariada e Método Direto - áreas dos espectros.

\subsection{Método Indireto - Calibração Multivariada}

Para o calculo da conversão pelo método indireto, foram avaliados dois prétratamentos dos dados espectrais, apresentados na Tabela 29. Através da Figura 75 pode-se concluir que a calibração utilizando-se a segunda derivada como pré-tratamento mostrou-se mais adequado para a determinação da conversão de monômero a polímero. 
Tabela 29 - identificação entre tratamentos espectrais utilizados para calibração de modelo multivariado para determinação da conversão da reação.

\begin{tabular}{llll}
\hline Identificação & Pré-tratamentos & & Faixa espectral \\
\hline Tratamento I & Primeira derivada + Filtro (suavização) & 150 a 400 \\
Tratamento II & Segunda derivada & & 150 a 400 \\
\hline
\end{tabular}

\subsection{Método Direto - Áreas dos Espectros}

Para a determinação da conversão pelo Método Direto, utilizam-se as áreas dos picos dos espectros de Raman e suas variações, que estejam relacionados com as vibrações dos compostos que participam da reação. Para a polimerização de estireno a poliestireno, os picos característicos identificados nos espectros de Raman são os relacionados com a dupla ligação $(\mathrm{C}=\mathrm{C})$ contida no monômero e a ligação presente no anel aromático $(\mathrm{C}-\mathrm{H})$ que se mantém intacta durante a polimerização.

Figura 69 - Conversão determinada por Espectroscopia Raman através do método indireto.

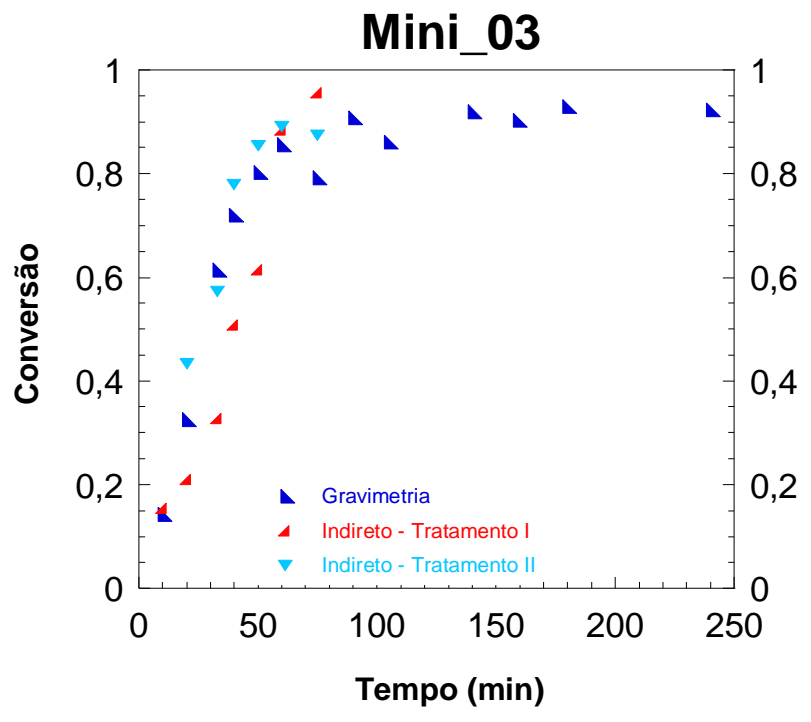

Esses picos característicos estão identificados nas Figura 70 a Figura 73. Observa-se que há redução na área referente à dupla ligação $\mathrm{C}=\mathrm{C}$, o que caracteriza a quebra da dupla ligação do monômero e por isso há redução na intensidade do pico e consequentemente, redução em sua área. A área referente à ligação C-H mantém-se praticamente constante, pois o anel aromático não participa da reação, servindo apenas como pico referência para normalização das áreas coletadas em cada instante da reação. 
Figura 70 - Intensidade Raman da amostra Mini_02 em 3D.

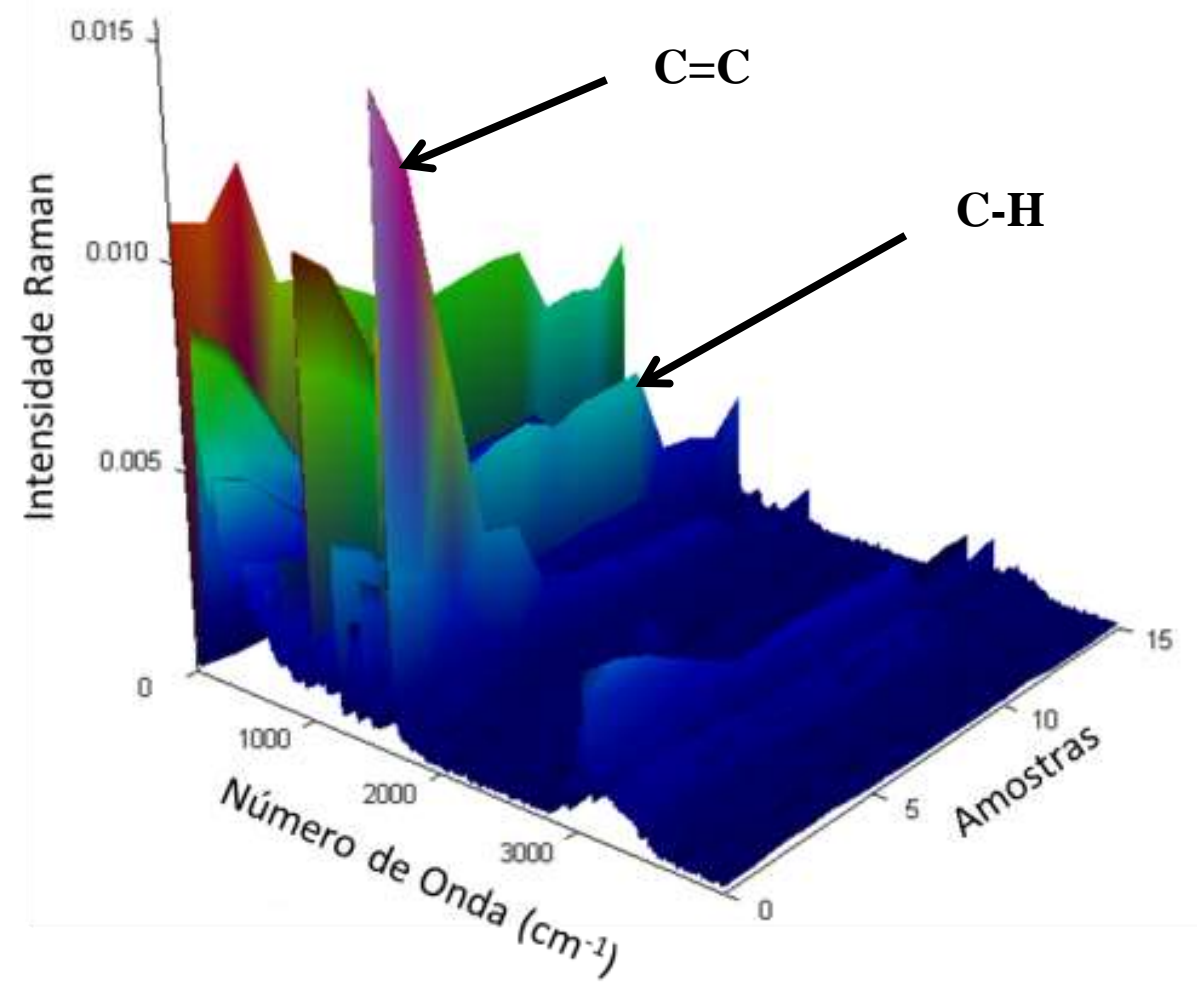

Figura 71 - Intensidade Raman da amostra Mini_02 em 2D.

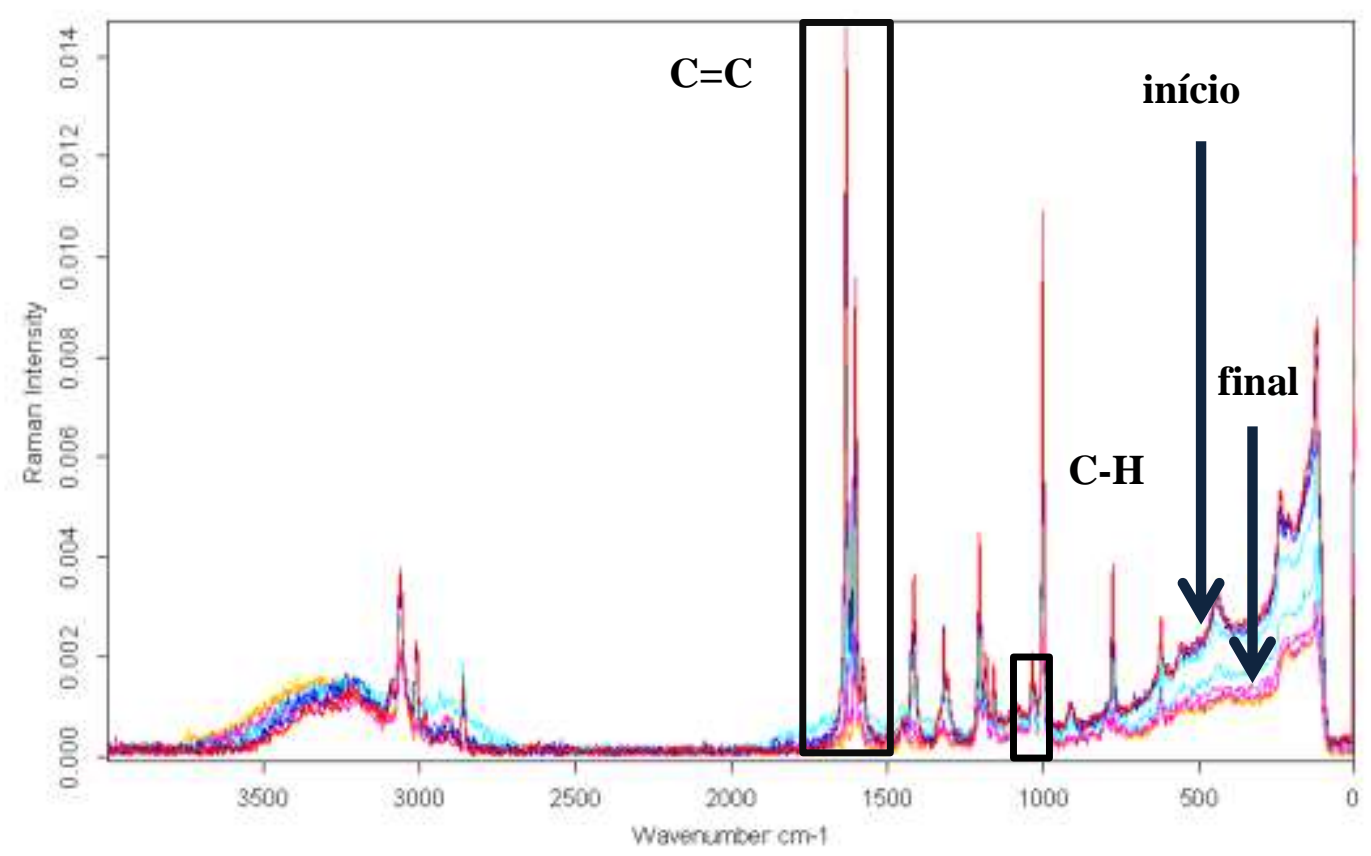


Figura 72 - Intensidade Raman da amostra Mini_03 em 3D.

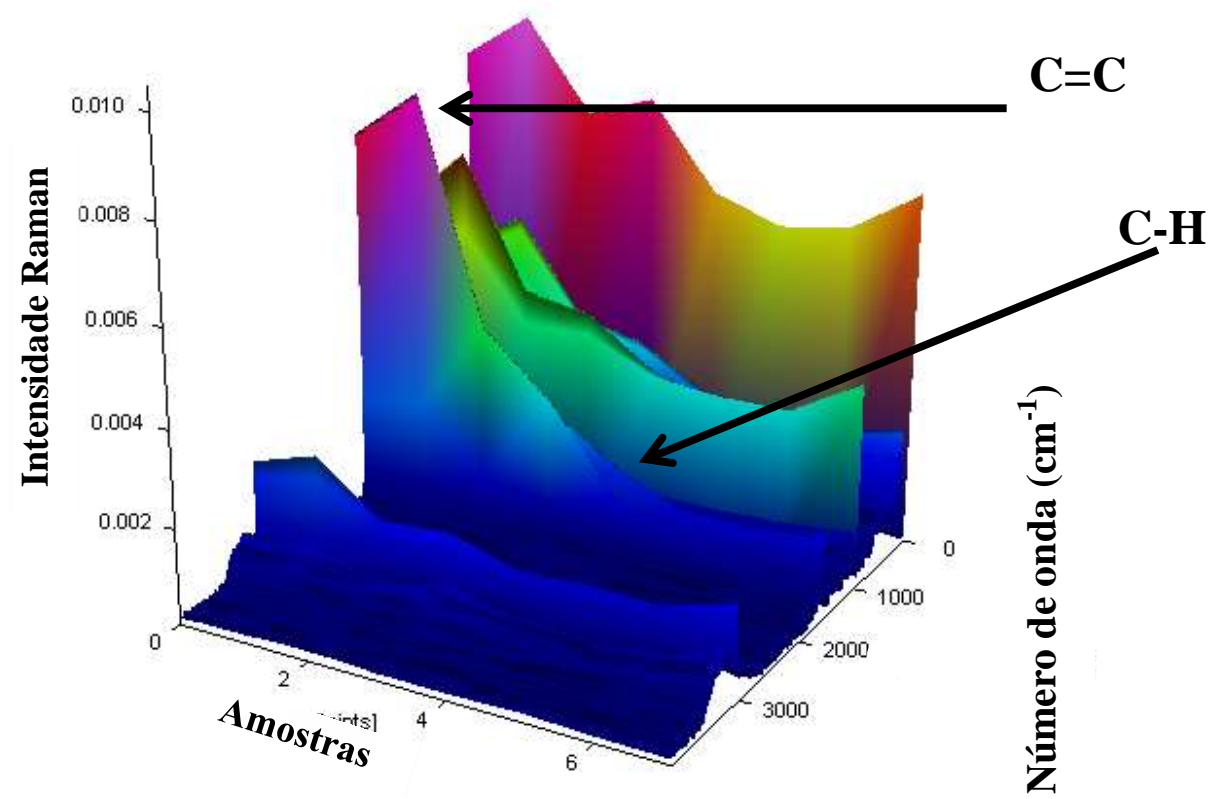

Figura 73 - Intensidade Raman da amostra Mini_03 em 2D.

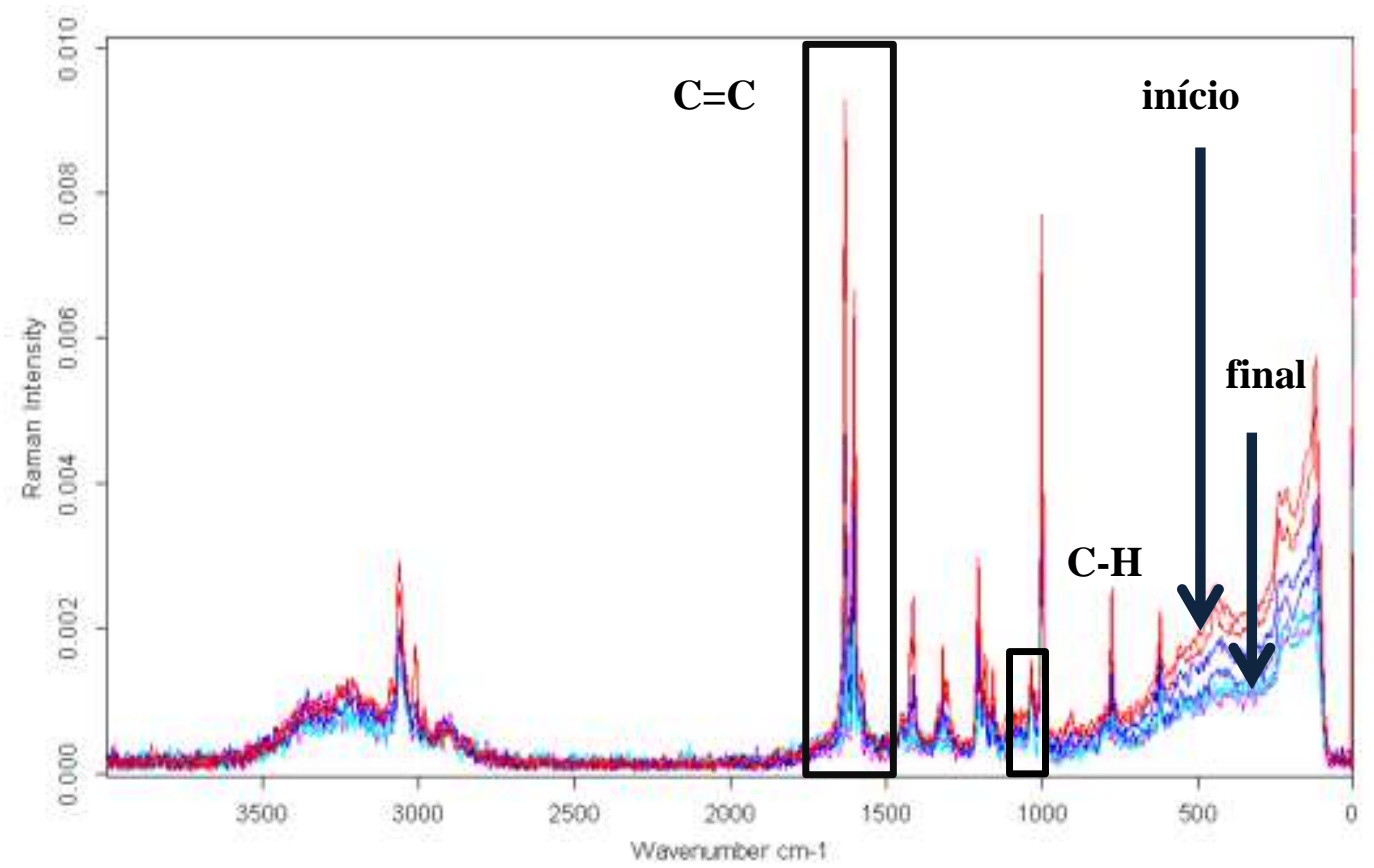

A conversão calculada pelo método direto está apresentada na Figura 74.

O mesmo comportamento da conversão observado para conversão obtida por gravimetria pode ser observado na conversão obtida através dos espectros Raman. 
Figura 74 - Conversão da reação determinada por Raman através do método direto.

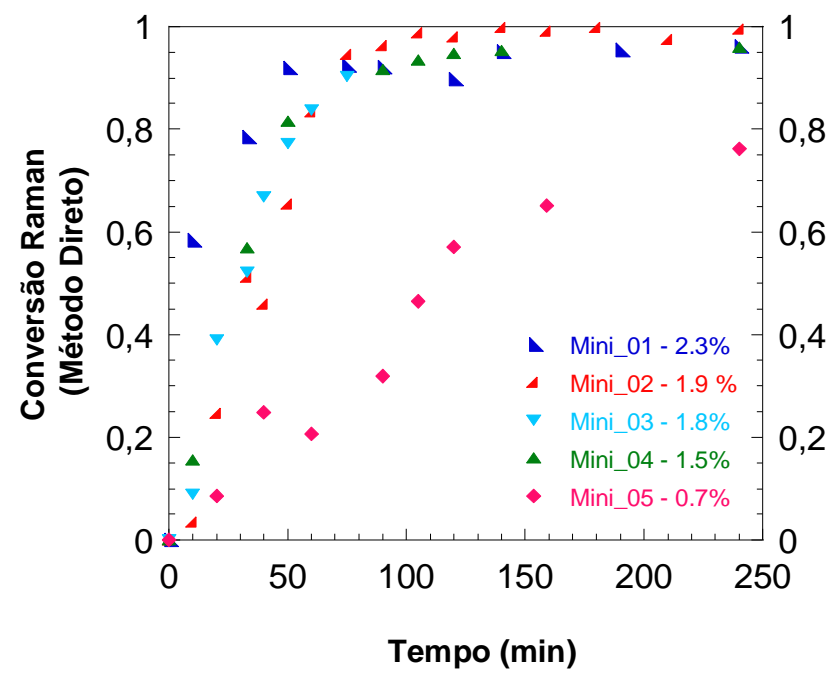

Isso confirma, mais uma vez, que o uso da Espectroscopia Raman é eficaz para determinação da conversão dos monômeros, seja através do Método Direto ou através do Método Indireto, conforme evidenciam as Figura 75 e Figura 76.

Figura 75 - Comparação entre as conversões determinadas através de Gravimetria, área dos espectros de Raman e Modelos de Calibração obtidos dos espectros de Raman para o experimento Mini_03.

Mini 03

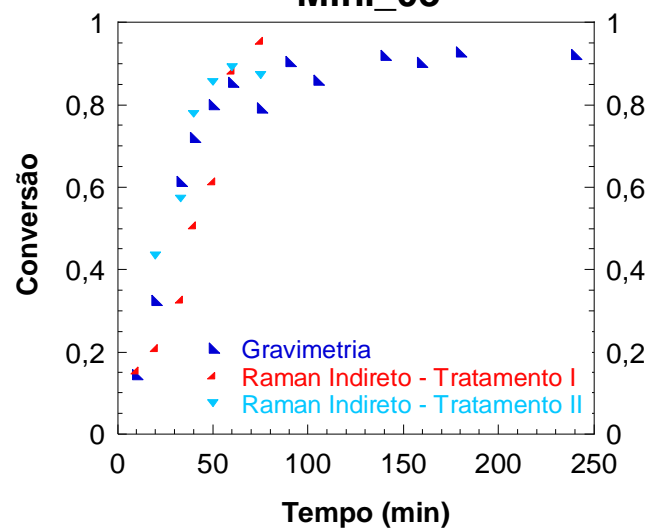

Figura 76 - Comparação entre a conversão obtida por gravimetria e por Raman, pelo método direto para o experimento Mini_03.

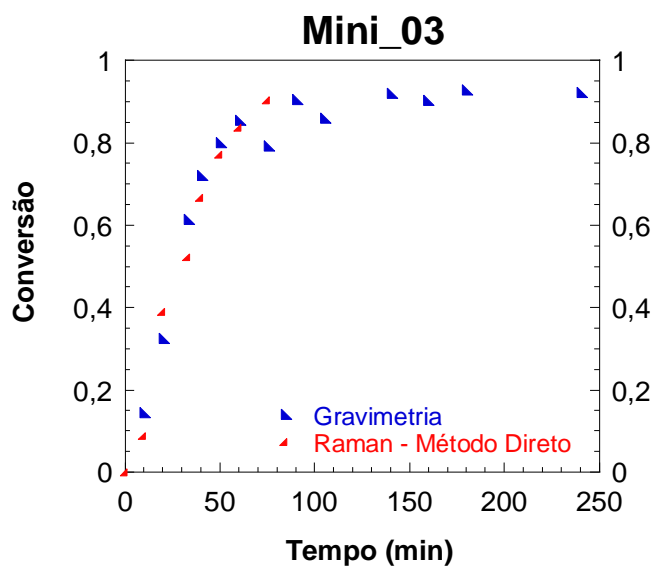




\subsection{Diâmetro de partículas}

Na Figura 77 observa-se a evolução do diâmetro médio das partículas. Esse diâmetro foi medido através de espalhamento de luz dinâmico, que considera a distribuição das partículas como monomodal.

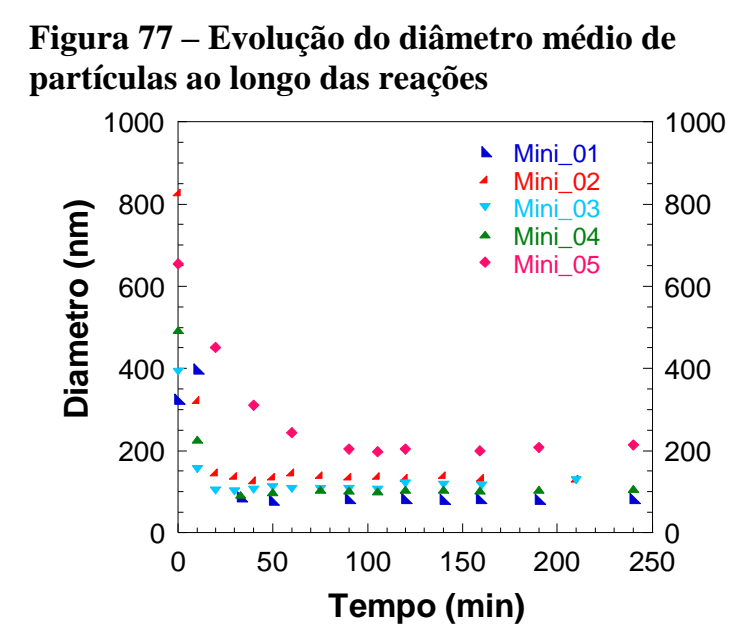

Figura 78- Taxa de variação do diâmetro médio de partículas ao longo das reações

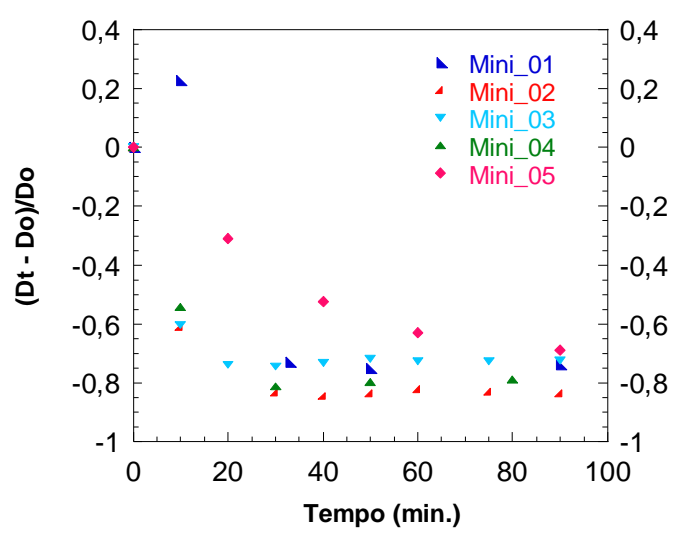

Todos os experimentos apresentaram variação no diâmetro médio das partículas nos primeiros minutos de reação e depois, todos se estabilizaram e mantiveram o mesmo diâmetro até o final da reação.

Ao final da reação de polimerização, o diâmetro médio das partículas da Mini_01 é o menor em relação aos demais. Isso é consequência da maior concentração de tensoativo, que conduz à formação de maior número de gotas e como consequência, maior velocidade de polimerização. A mesma justificativa, agora na situação oposta, justifica também o maior diâmetro da Mini_05, que utilizou menor concentração de tensoativo em relação às demais, com isso há formação de gotas maiores, em menor número, e consequentemente menor velocidade de reação (LANDFESTER; SCHORK; KUSUMA, 2003).

O diâmetro constante das partículas, devido à nucleação das gotas de monômeros e a não existência de difusão de monômero pelo meio continuo, é uma característica da polimerização em miniemulsão. Porém, na primeira hora das reações, observou-se variação no tamanho das partículas, evidenciando a coexistência de outro fenômeno ocorrendo além da nucleação das gotas.

As hipóteses levantadas para essa variação no diâmetro foram: (i) instabilidade das gotas monoméricas formadas, (ii) nucleação homogênea e/ou (iii) nucleação micelar. 
A estabilidade das miniemulsões monoméricas foi avaliada através dos testes de estabilidade que mostraram a estabilidade das miniemulsões avaliadas. Por essa razão, a hipótese (i) de instabilidade das gotas formadas, pôde ser descartada.

Todos os casos avaliados usaram concentração de tensoativo abaixo da concentração micelar crítica, por isso, a hipótese (iii), nucleação micelar, também pôde ser descartada.

Restando apenas a hipótese (ii) de haver nucleação homogênea coexistindo com a nucleação das gotas no início do processo de polimerização.

Para verificar a possibilidade de haver nucleação homogênea, podem-se observar as Figuras: Figura 79 e Figura 80 para a Mini 1; Figura 81 e Figura 82 para a Mini 2 e; Figura 83 e Figura 84 para a Mini 3. As figuras representam a distribuição de tamanho de tamanhos de partículas avaliados por espalhamento de luz dinâmico (SDS) no início da reação e após um intervalo de tempo. Cada amostra foi analisada em triplicata para o mesmo instante, por isso os índices $1 / 3,2 / 3,3 / 3$ ou em quadriplicata, $1 / 4,2 / 4,3 / 4$ e $4 / 4$.

Considerando a hipótese de existir nucleação homogênea, os gráficos deveriam apresentar redução no diâmetro das partículas e o aparecimento de partículas formadas por polímeros de baixo peso molecular, oligômeros, pois para o poliestireno, devido a sua pequena solubilidade em água, só seria possível encontrar partículas compostas por até 4 monômeros pois $\boldsymbol{j}_{\text {crit }}$ é igual a 5. Como referência para o tamanho desses oligômeros, foi considerado o diâmetro de uma micela. Para o caso em questão, o surfactante utilizado foi o lauril sulfato de sódio, cujo raio característico da micela é 2,6 nm (COEN et al., 2006). Então, as partículas teriam diâmetros da ordem de $1 \mathrm{~nm}$. Observando-se as figuras com as distribuições de tamanho, podem-se identificar partículas com tamanho de $1 \mathrm{~nm}$ no início do processo, evidenciando a existência de nucleação homogênea. 


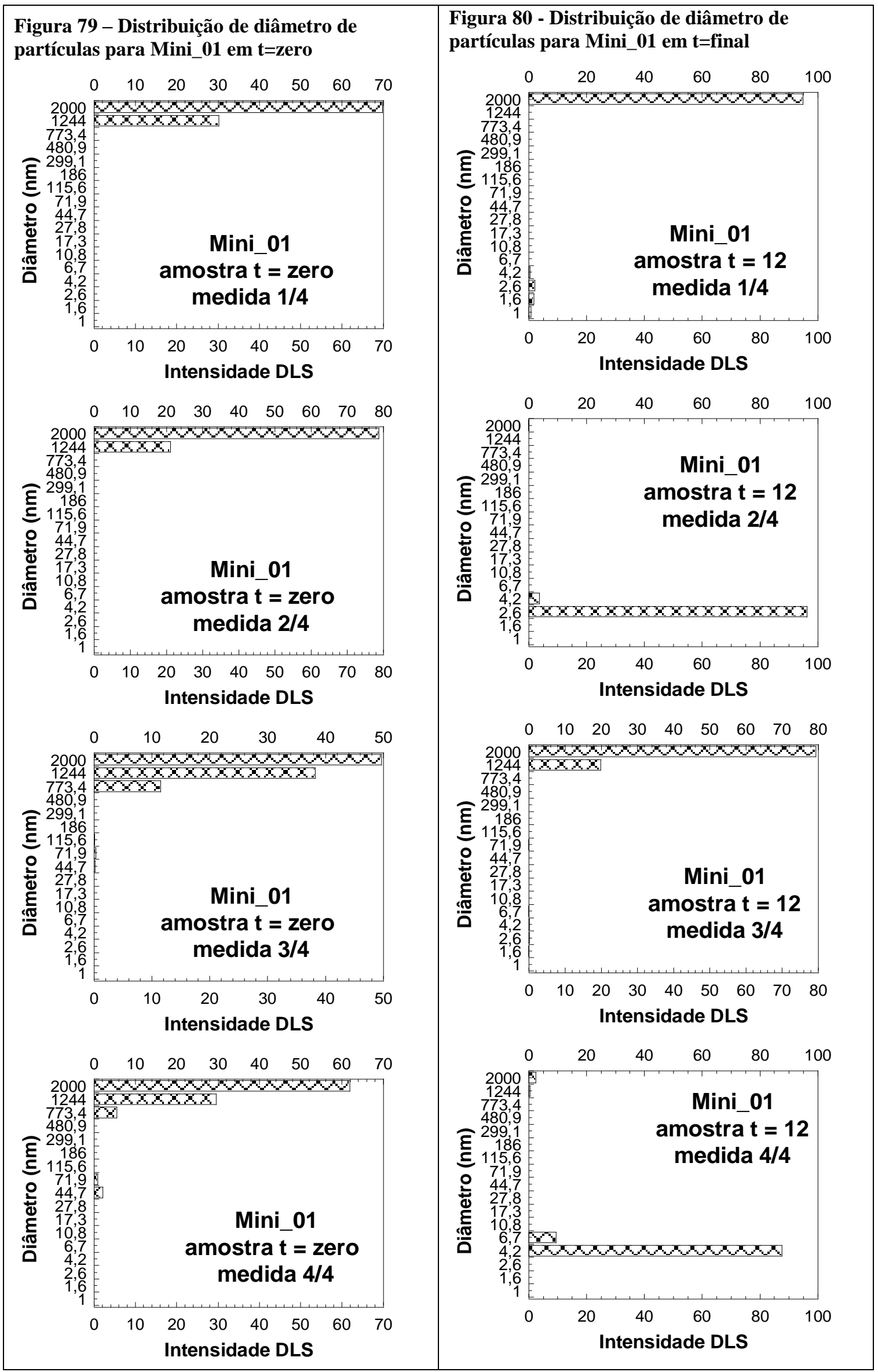




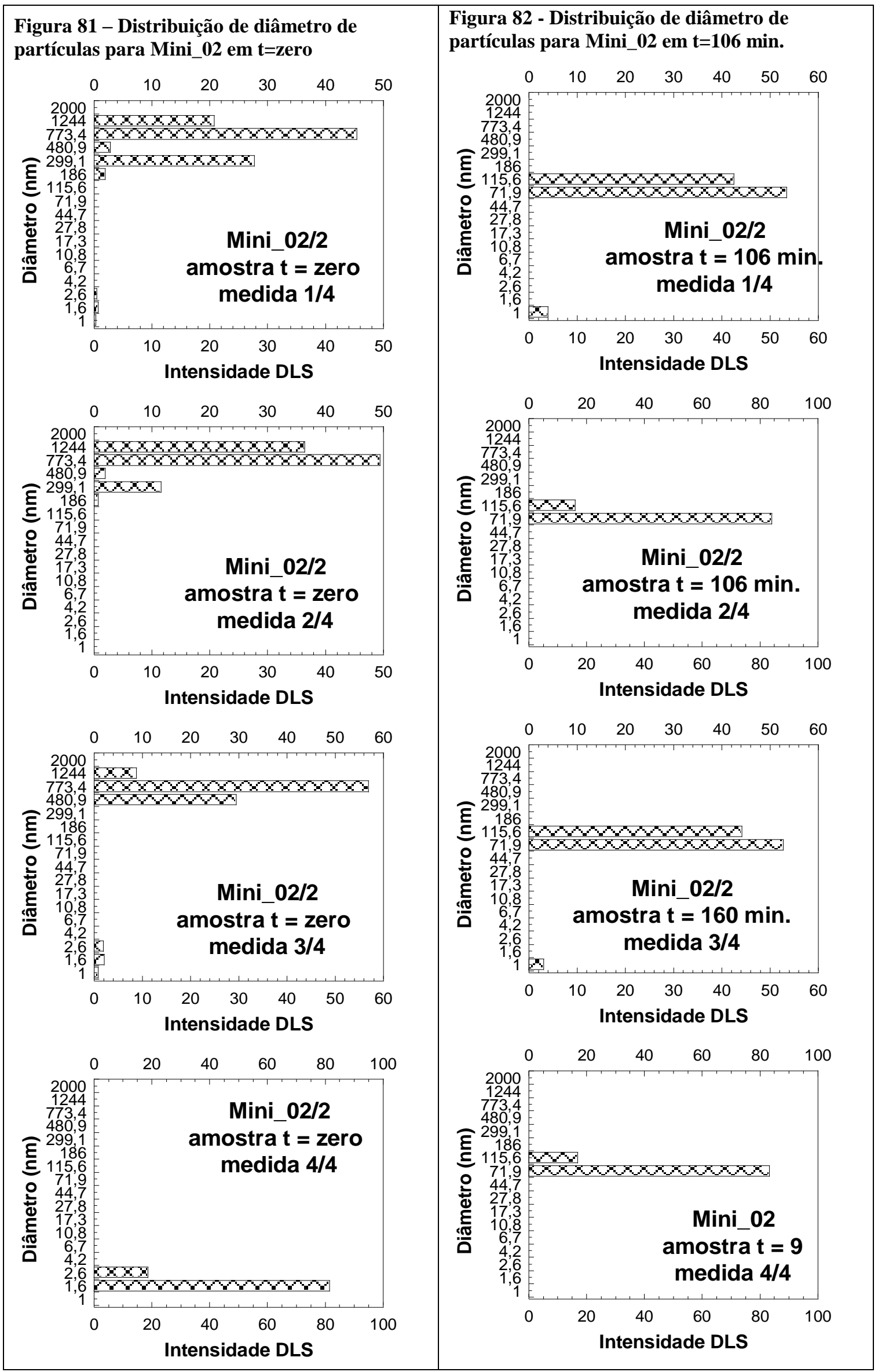




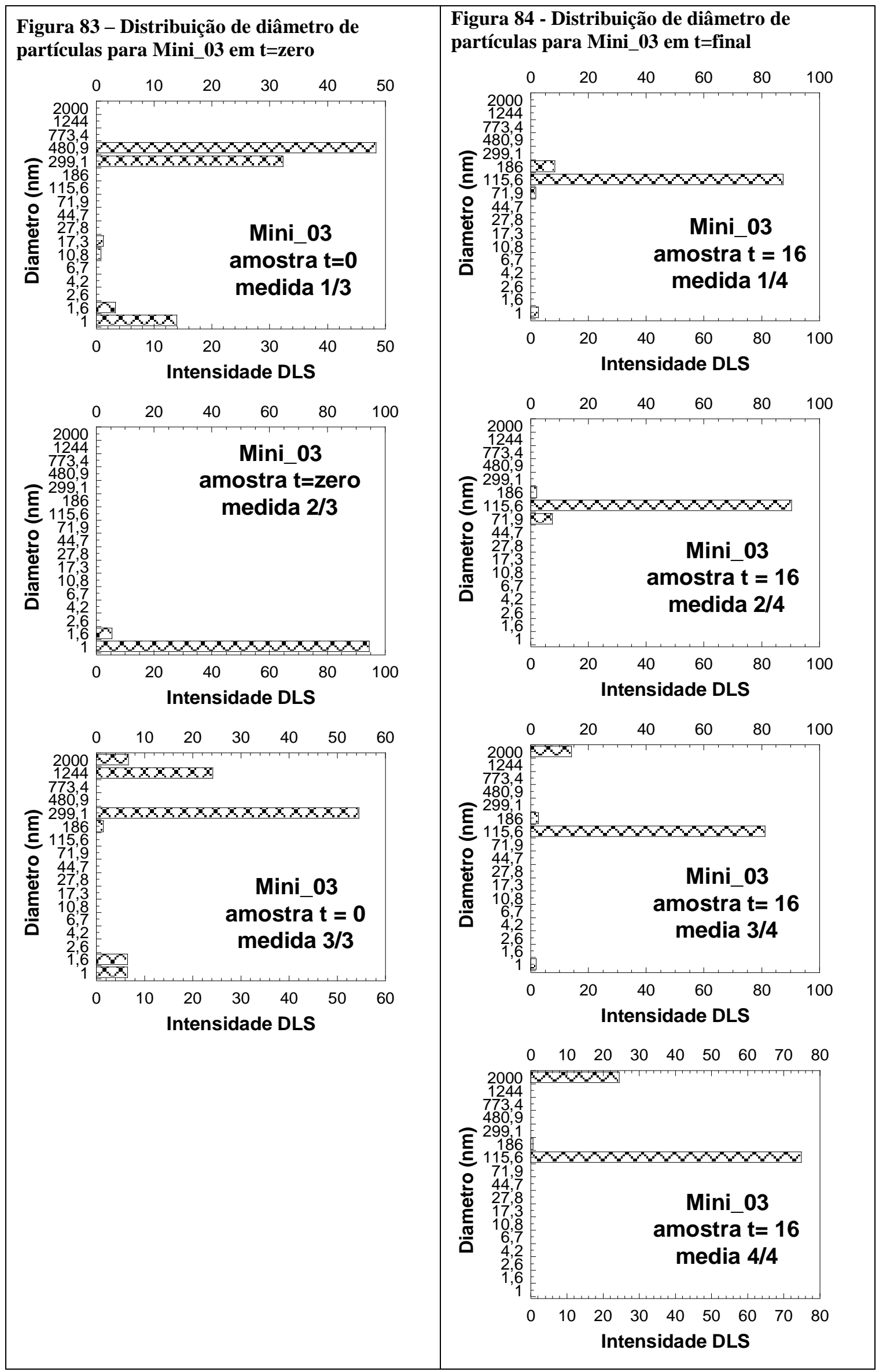


Associada a essa evidência dos diâmetros há também a variação do número de partículas $(\mathrm{Np})$ presentes no meio, calculado através da Equação 39. Essa variação também pode evidenciar a nucleação homogênea, pois, na nucleação homogênea há formação de partículas, e, consequentemente, aumento de Np como mostra a Figura 85 e Figura 86.

Figura 85- Variação do número de partículas (Np) em função do tempo

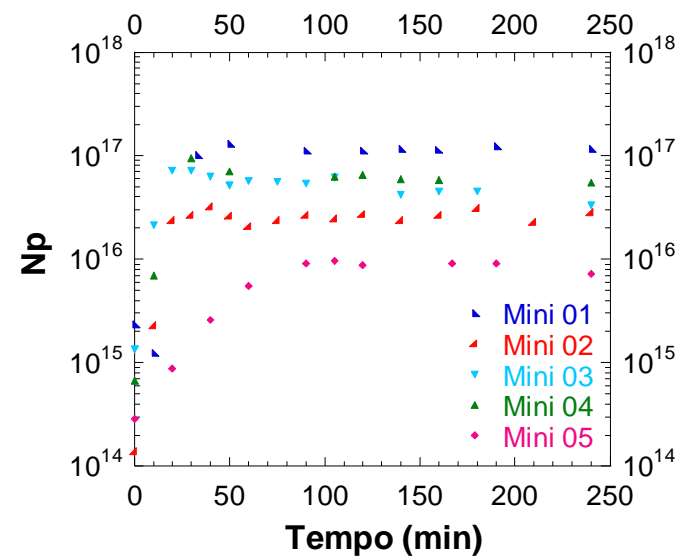

Figura 86 - Variação do número de partículas (Np) em função da conversão

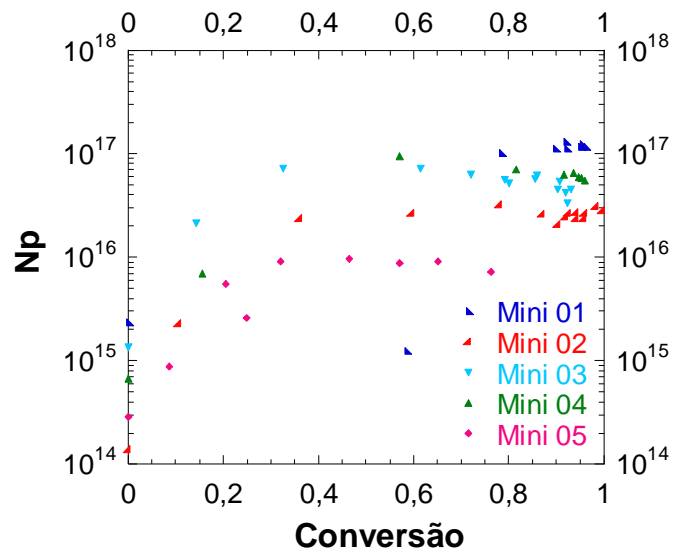

Assim, a quantidade inicial de gotas será menor do que a quantidade de partículas devido à formação de partículas através da nucleação homogênea. As Figuras Figura 93, Figura 94 e Figura 95 confirmam essa hipótese, pois nos primeiros minutos da polimerização há crescimento da razão $\frac{N_{p}}{N_{g}}=\frac{\text { número de partículas }}{\text { número de gotas }}$.

Após os primeiros dez minutos de reação, que também correspondem a aproximadamente $25 \%$ de conversão, conforme Figura 96, essa razão permanece constante, demonstrando que não há mais geração de partículas. 
Figura 87 - Diâmetro versus conversão global

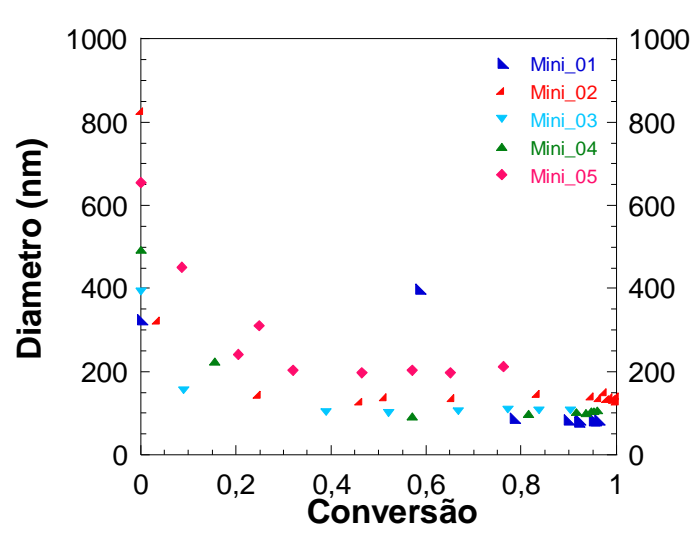

Figura 89 - Diâmetro versus conversão Mini_02

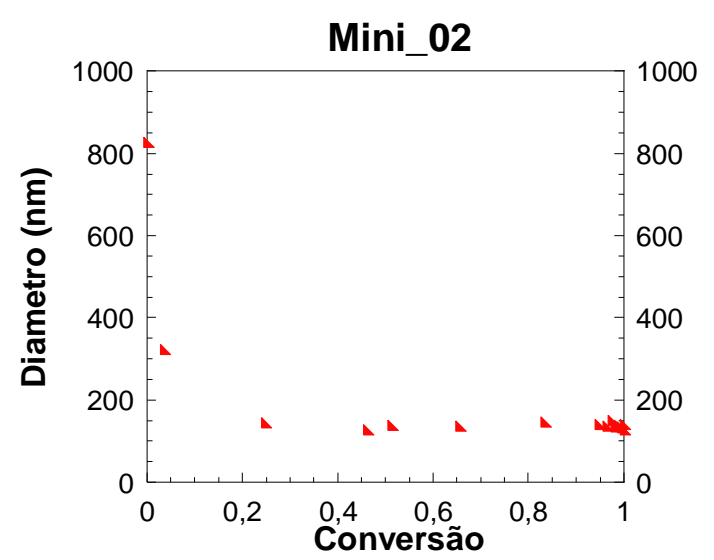

Figura 91 - Diâmetro versus conversão Mini_04

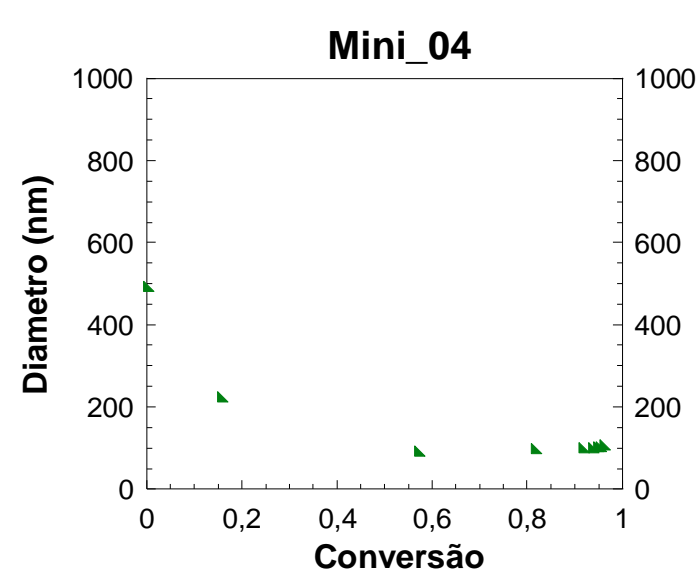

Figura 88 - Diâmetro versus conversão Mini_01

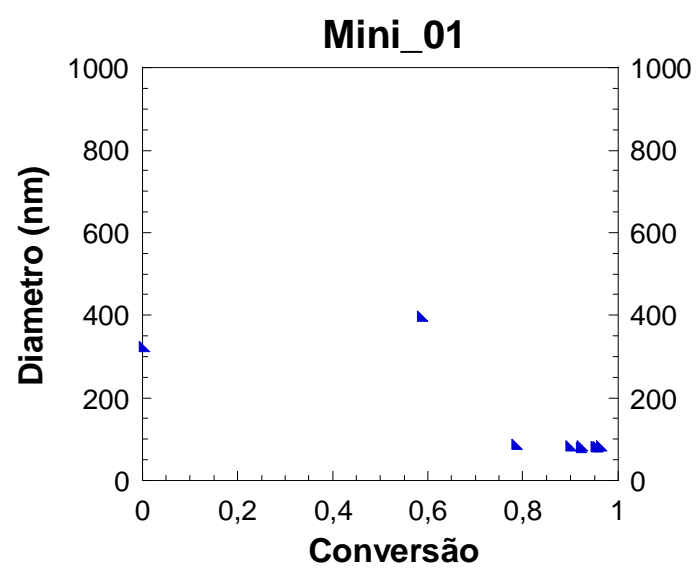

Figura 90 - Diâmetro versus conversão Mini_03

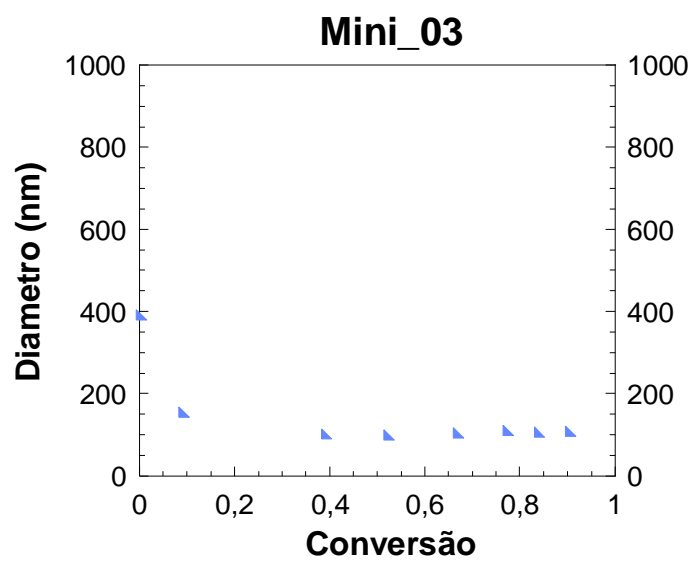

Figura 92 - Diâmetro versus conversão Mini_05

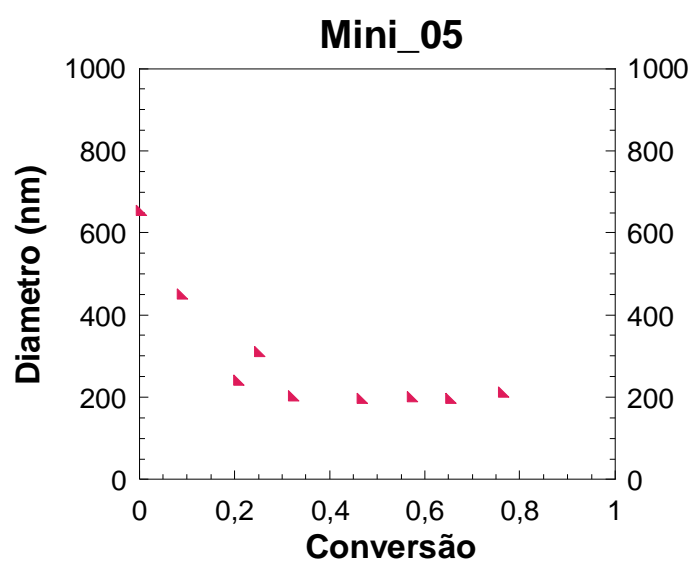


Figura 93 - Variação da razão $\mathrm{Np} / \mathrm{Ng}$ para Mini_02 em função do tempo.

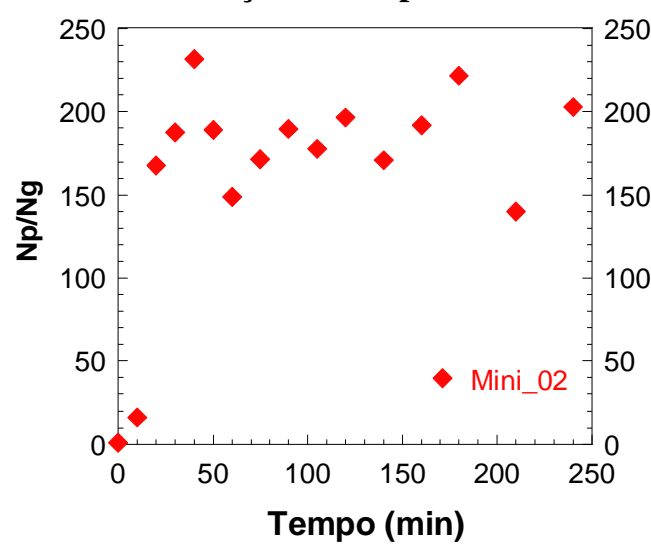

Figura 95 - Variação da razão $\mathrm{Np} / \mathrm{Ng}$ em função do tempo.

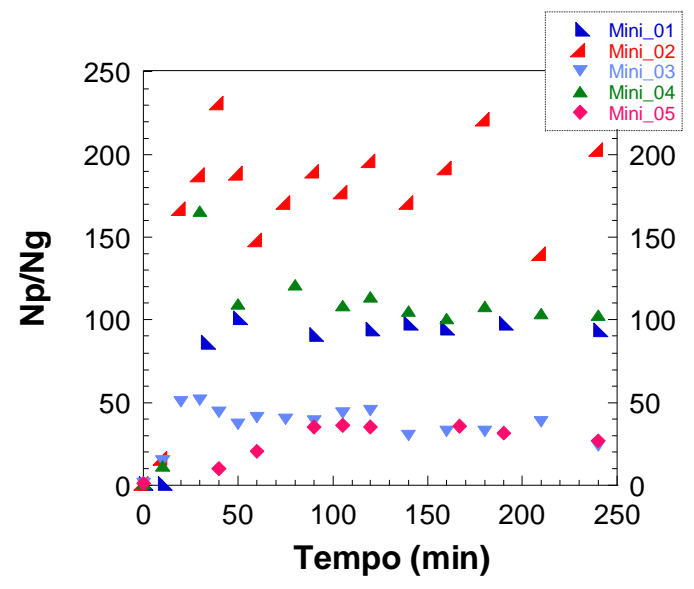

Figura 94 - Variação da razão Np/Ng para Mini_03 em função do tempo.

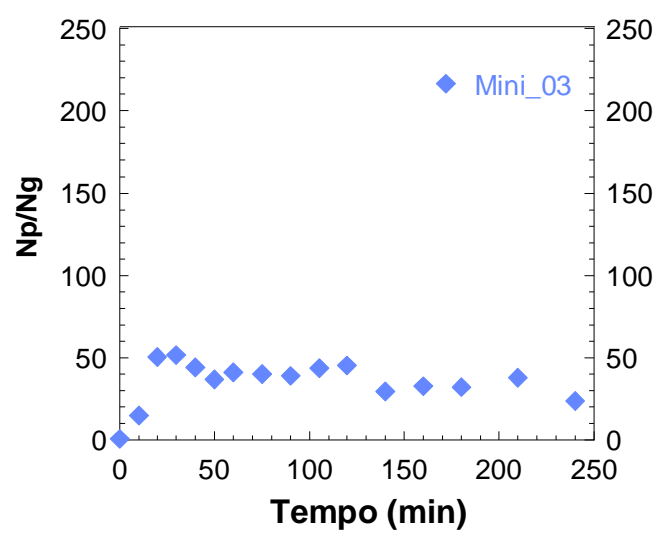

Figura 96 - Variação da razão $\mathrm{Np} / \mathrm{Ng}$ em função da conversão.

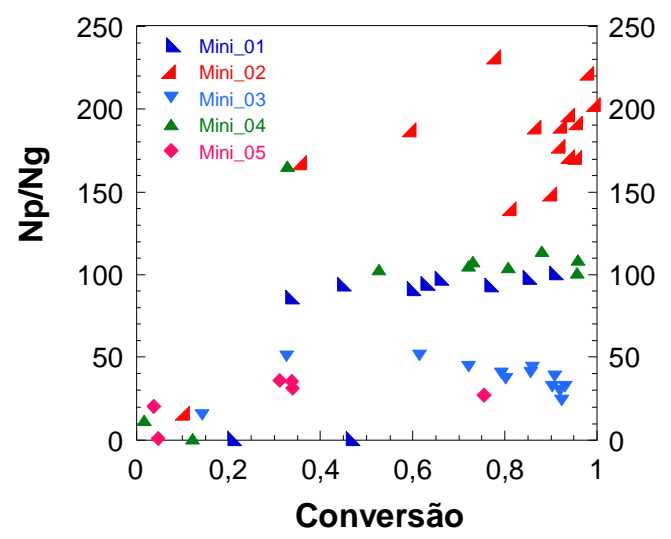

\subsection{Diâmetro de partículas (Espectroscopia Raman)}

O diâmetro das partículas foi avaliado através do método indireto, utilizando calibração multivariada dos espectros Raman.

Foram analisados quatro diferentes modelos, que se diferenciam pelo prétratamento dos dados espectrais e também pela faixa espectral utilizada para construção do modelo, conforme descrição na Tabela 30.

Tabela 30 - Identificação dos tratamentos realizados nos espectros Raman

\begin{tabular}{lcl}
\hline Identificação & Pré-tratamentos & Faixa espectral \\
\hline Tratamento III & Primeira derivada + Filtro (suavização) & 150 a 400 \\
Tratamento IV & Segunda derivada & 150 a 400 \\
Tratamento V & Segunda derivada & 0 a 4.000 \\
Tratamento VI & Primeira derivada + Filtro (suavização) & 0 a 4.000 \\
\hline
\end{tabular}


Conforme Figura 97, entre os quatro tratamentos avaliados, os que mostraram melhor ajuste em relação aos diâmetros medidos por espalhamento de luz foram os Tratamentos IV e V que utilizam a segunda derivada.

\section{Figura 97 - Comparação entre os diâmetros de partículas avaliados através do Espalhamento de Luz e calculados através de Modelos de Calibração obtidos dos espectros de Raman para o experimento Mini_3.}

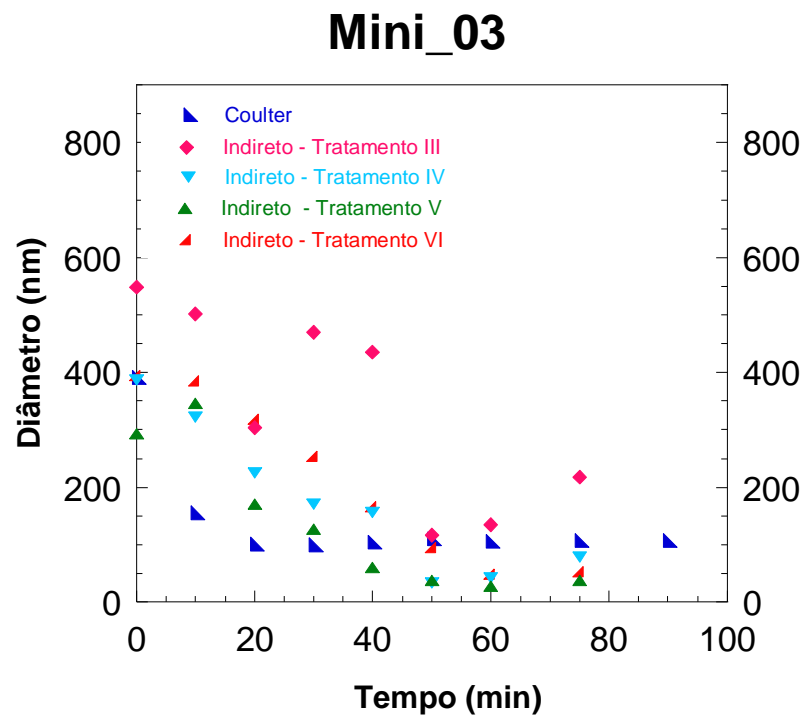

Pode-se concluir então que o tratamento de dados via espectroscopia Raman mostrou-se satisfatório para a previsão do diâmetro médio das partículas durante a reação de polimerização, permitindo que o mesmo seja monitorado durante toda a reação.

\subsubsection{Avaliação da Taxa de Polimerização}

A taxa de polimerização em miniemulsão, também apresenta um comportamento característico, conforme discutido no item 2.1, Figura 5, reproduzida abaixo. Quando comparada a Figura 98 com a Figura 99, observa-se a mesma tendência para a Mini_03, ou seja, a taxa de polimerização pode ser dividida em quatro intervalos. No primeiro intervalo, há um rápido aumento na taxa de polimerização devido à formação das partículas de látex que ocorre até um primeiro máximo (Intervalo I) seguido de uma diminuição na taxa de polimerização à medida que aumenta a conversão do monômero (Intervalo II). Na sequência, há um segundo aumento na taxa de polimerização até que um segundo máximo é atingido (Intervalo III) e após esse pico, há um rápido decréscimo (Intervalo IV) até que a polimerização termina.

Continuando as comparações, o intervalo II da Mini_03 mostra um período menor quando comparado com a taxa de polimerização referência. Isso pode ser devido 
a um maior consumo de monômero no intervalo I, onde houve polimerização micelar e/ou homogênea, conforme discutido anteriormente.

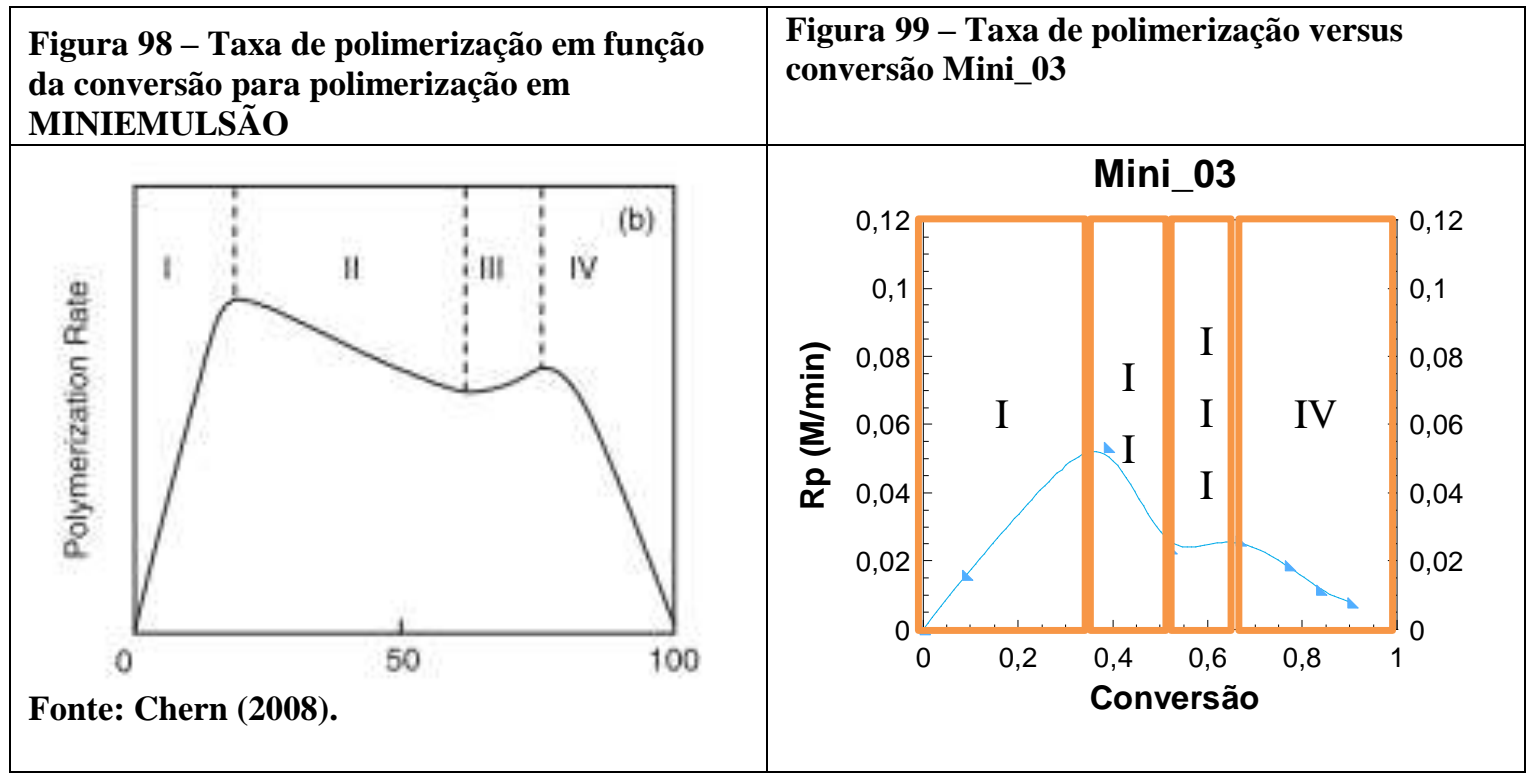

Comparando-se a taxa de polimerização da Mini_04, na Figura 101, com a taxa de polimerização da miniemulsão referência observa-se que ela não apresenta os dois picos conforme a referência e, quando comparada com a taxa de polimerização referência para emulsões, nota-se que há maior similaridade com esta do que com a miniemulsão. No entanto essa similaridade pode ser função da rápida polimerização e com isso a inexistência de dados intermediários entre a conversão de $20 \%$ e $60 \%$ que pode ter mascarado a tendência da curva.

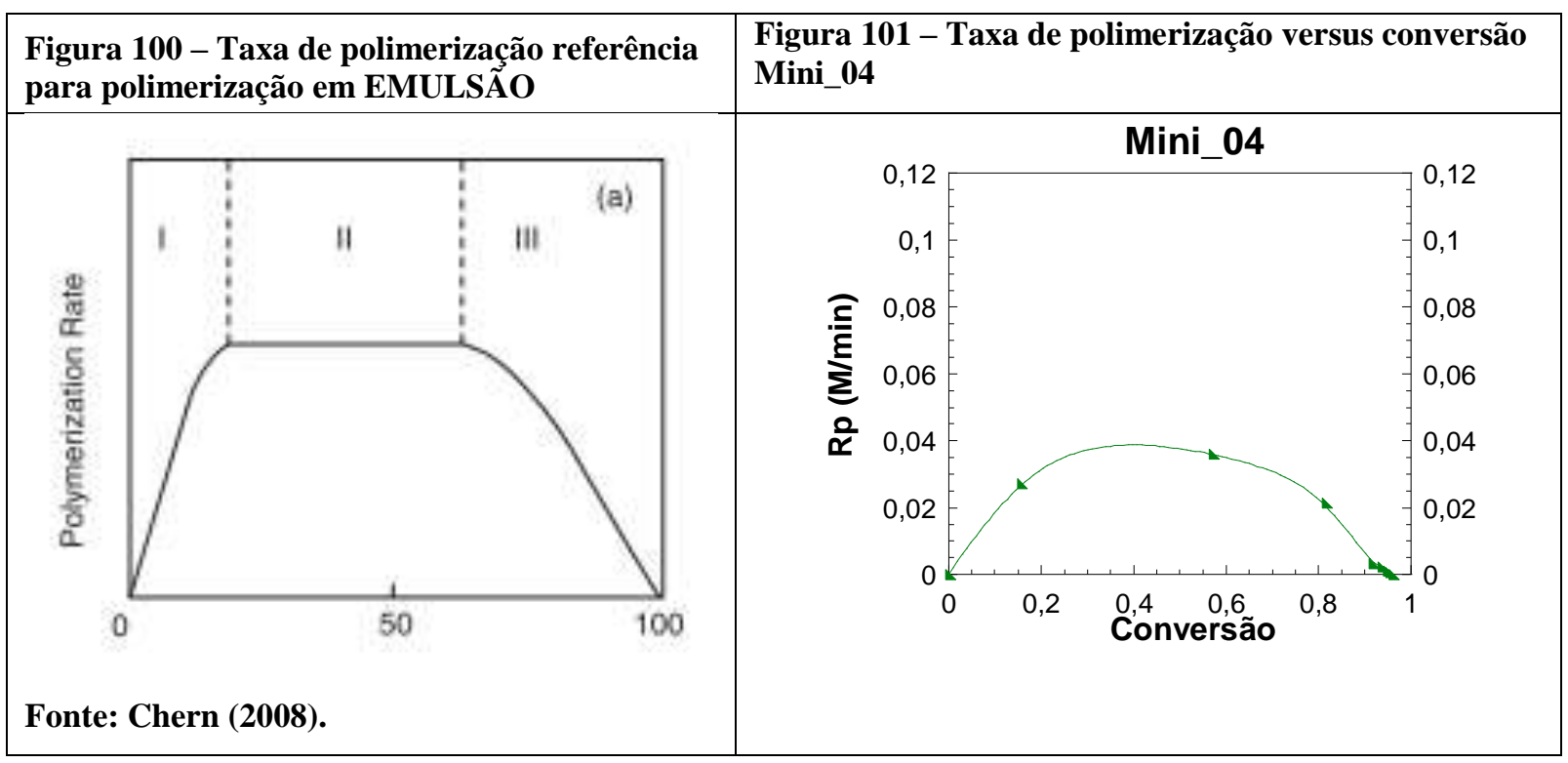


Para as demais reações, conforme Figura 103 a Figura 105, pode-se observar que todas apresentam dois picos na taxa de polimerização de acordo com a referência na Figura 98.

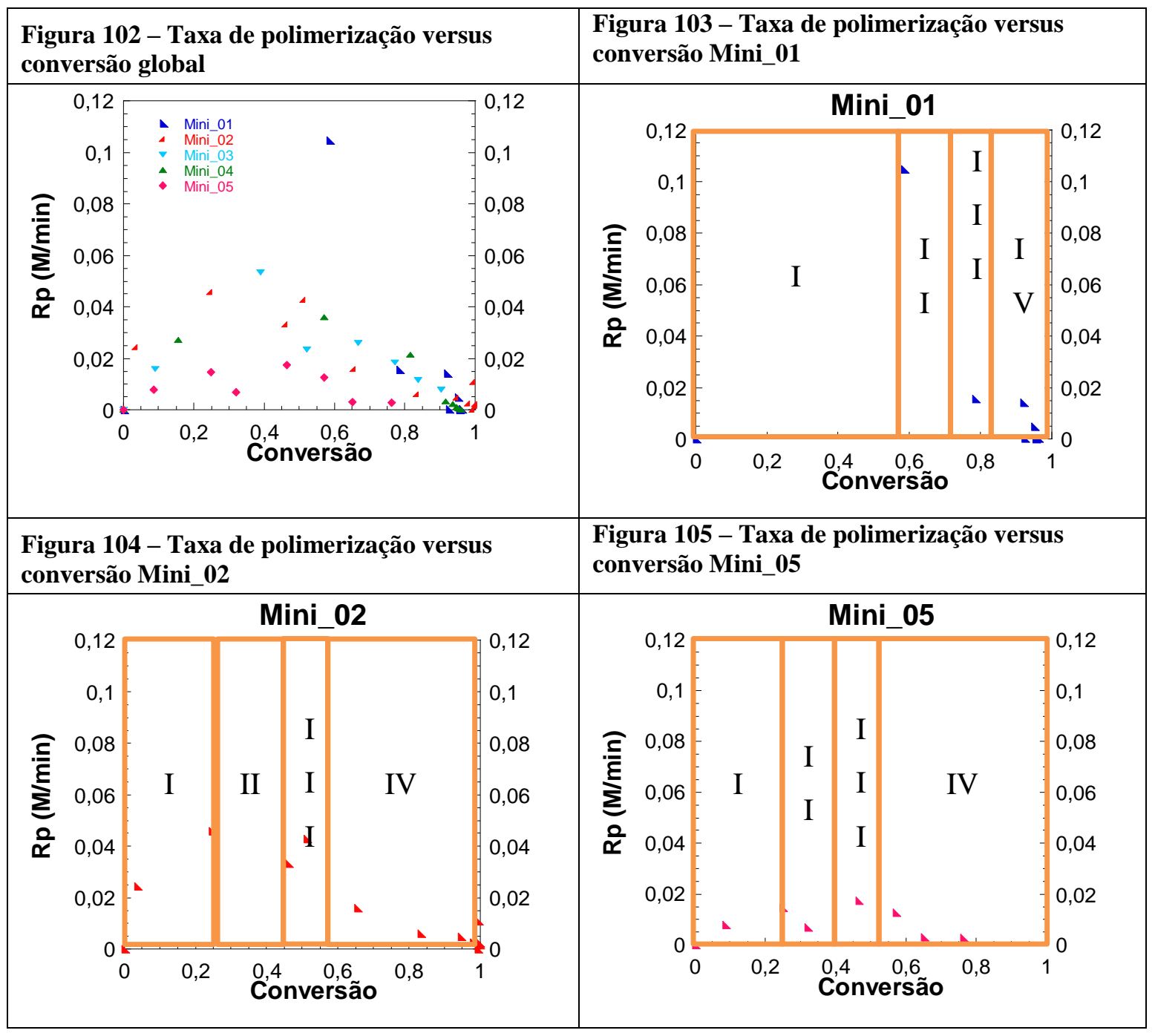

\subsection{Resultados Modelagem e Simulação}

O detalhamento do modelo encontra-se no item 3 deste documento. Todos os arquivos necessários para executar a simulação do modelo matemático encontram-se no APÊNDICE .

O modelo utilizou como dados de entrada, as condições operacionais para cada experimento realizado (Mini_01 a Mini_05), sendo elas: temperatura de reação, identificação dos reagentes, massa real utilizada de cada reagente e diâmetro inicial das partículas. Outros parâmetros foram alimentados no modelo, conforme identificados na Tabela 31. 
A seguir estão apresentadas algumas das variáveis calculadas pelo modelo matemático e que foram importantes para a interpretação do processo e para consolidação do modelo proposto em função do conhecimento teórico do comportamento esperado das variáveis e dos resultados experimentais disponíveis para validação do modelo.

Tabela 31 - Valores de constantes e parâmetros utilizados na simulação

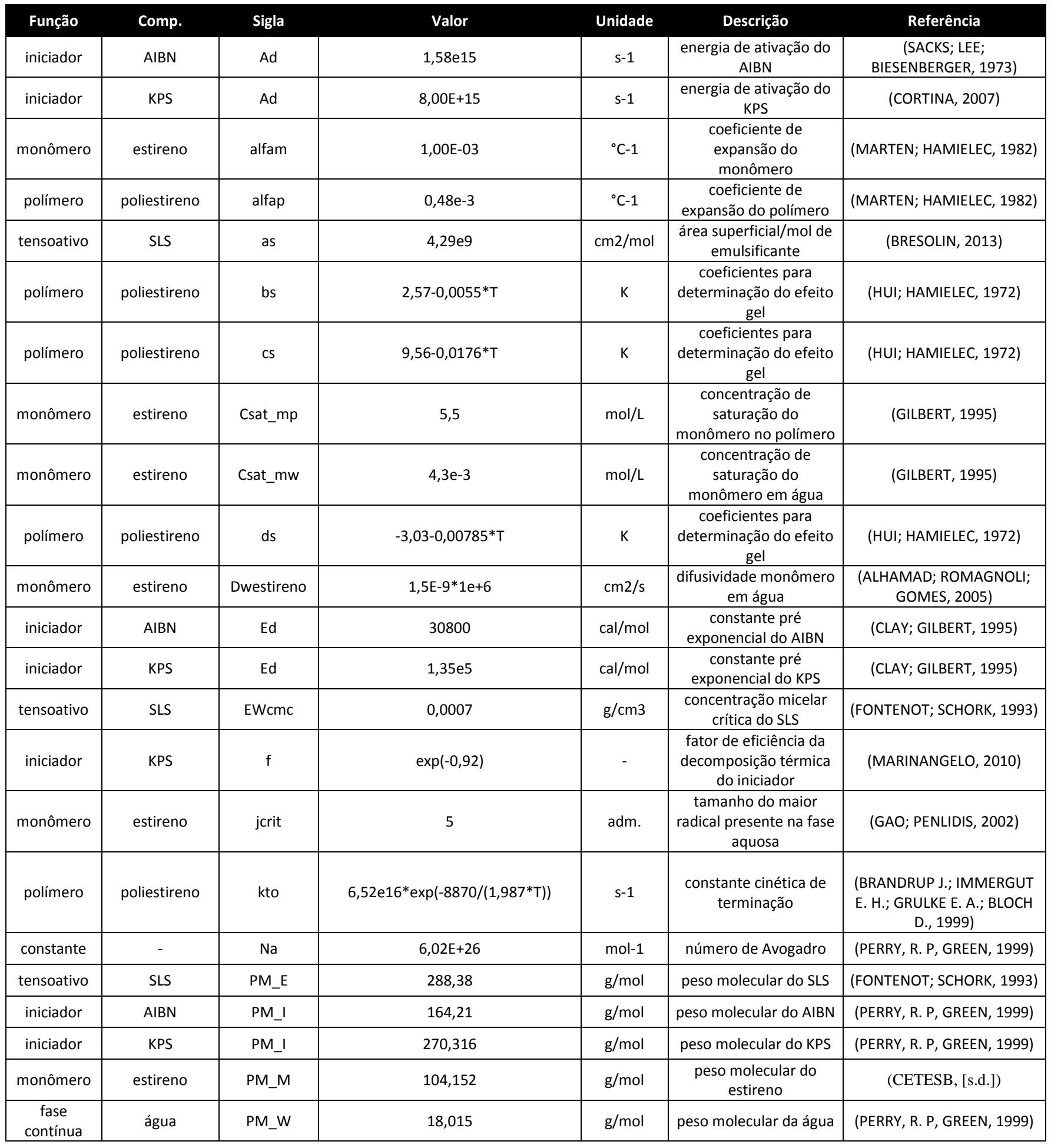




\begin{tabular}{|c|c|c|c|c|c|c|}
\hline constante & - & $\mathrm{R}$ & 0,082 & $\begin{array}{l}\text { atm.L/(K. } \\
\mathrm{mol})\end{array}$ & $\begin{array}{c}\text { constante universal dos } \\
\text { gases ideais }\end{array}$ & (PERRY, R. P, GREEN, 1999) \\
\hline tensoativo & SLS & $\mathrm{rm}$ & $2,5 e-7$ & $\mathrm{~cm}$ & raio de uma micela & $\begin{array}{l}\text { (MIN, K.W.; RAY, 1978, } \\
\text { apud CORTINA, 2007) }\end{array}$ \\
\hline $\begin{array}{c}\text { co- } \\
\text { tensoativo }\end{array}$ & hexadecano & roCo & 0,77 & $\mathrm{~g} / \mathrm{cm} 3$ & densidade & (SIGMA-ALDRICH, 2015) \\
\hline tensoativo & $\begin{array}{l}\text { lauril sulfato } \\
\text { de sódio }\end{array}$ & roe & 1,1 & $\mathrm{~g} / \mathrm{cm} 3$ & densidade & (CETESB, 2015) \\
\hline iniciador & KPS & rol & 2,48 & $\mathrm{~g} / \mathrm{cm} 3$ & densidade & (SIGMA-ALDRICH, 2011) \\
\hline monômero & estireno & rom & $(0,924-(0,000918 *(T-273,15)))$ & $\mathrm{g} / \mathrm{cm} 3$ & densidade & (MARTEN; HAMIELEC, 1982) \\
\hline polímero & poliestireno & rop & $(1,084-0,000605 *(T-273,15))$ & $\mathrm{g} / \mathrm{cm} 3$ & densidade & (PINTO; RAY, 1995) \\
\hline $\begin{array}{c}\text { co- } \\
\text { tensoativo }\end{array}$ & poliestireno & roPS & 1,05 & $\mathrm{~g} / \mathrm{cm} 3$ & densidade & (INNOVA, 2005) \\
\hline $\begin{array}{c}\text { fase } \\
\text { contínua }\end{array}$ & água & row & $(-0,0004 * T$ _celsius $+1,0048)$ & $\mathrm{g} / \mathrm{cm} 3$ & densidade & ASPEN \\
\hline polímero & poliestireno & Tgp & 373 & K & $\begin{array}{l}\text { temperatura de } \\
\text { transição vítrea }\end{array}$ & $\begin{array}{c}\text { (TEFERA, N.; WEICKERT, G.; } \\
\text { WESTERTERP, 1997, apud } \\
\text { CORTINA, 2007) }\end{array}$ \\
\hline polímero & poliestireno & Vfcr2 & 0,002 & adm. & $\begin{array}{c}\text { fração de volume livre } \\
\text { crítico }\end{array}$ & Estimado \\
\hline monômero & estireno & $z$ & 3 & adm. & $\begin{array}{c}\text { tamanho do menor } \\
\text { radical que pode entrar } \\
\text { em uma micela ou } \\
\text { partícula }\end{array}$ & (BALLARD et al., 1986) \\
\hline
\end{tabular}

\subsubsection{Conversão}

Através do balanço de massa do estireno calculou-se a conversão do monômero em polímero, conforme apresentado na Figura 106.

Comparando o conjunto dos resultados obtidos pela simulação matemática, primeiramente observa-se uma maior continuidade nos dados calculados pelo modelo matemático e a inexistência de outliers. Isso se deve à inexistência de variáveis externas não controladas que afastam os dados experimentais da idealidade

Além disso, os resultados evidenciam que a velocidade de polimerização é alta ao longo da primeira hora de reação e que após esse período a velocidade diminui e tende a estabilizar após duas horas de reação. Isso se deve ao consumo de monômeros, o que diminui sua concentração no interior das partículas e que por outro lado aumenta a viscosidade no interior das partículas e com isso reduz a velocidade de reação.

A validação da conversão utilizou dados experimentais obtidos por gravimetria e também por espectroscopia Raman. Em alguns casos, a conversão por Gravimetria mostrou dispersão dos dados e outliers e por isso optou-se por utilizar os dados experimentais de conversão obtidos por espectroscopia Raman. 
Figura 106 - Conversão em função do tempo, calculada pelo modelo matemático proposto.

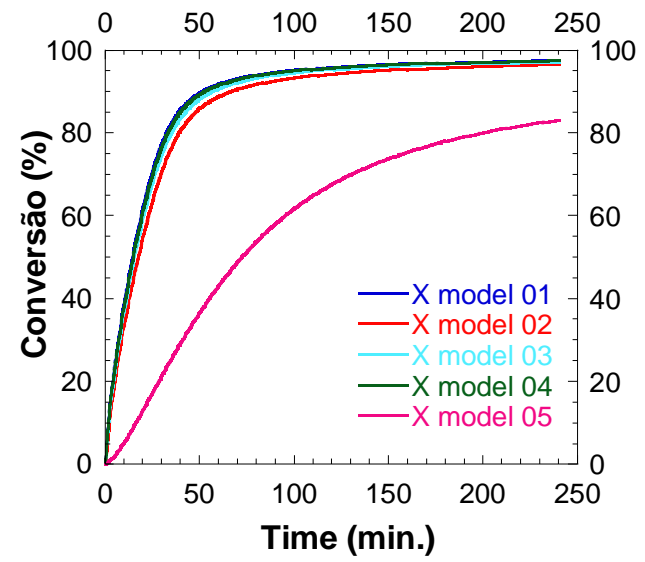

Figura 107 - Conversão em função do tempo, obtida por experimentalmente por Gravimetria para os experimentos Mini 2 e 3 e, por Raman para os experimentos Mini 1, 4 e 5.

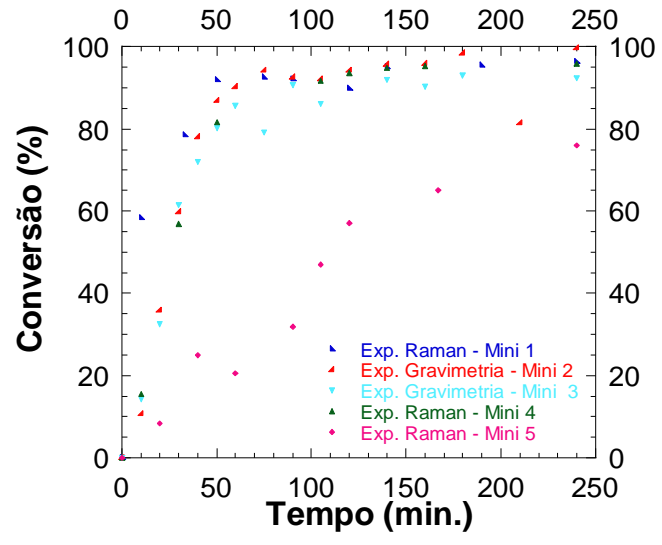

Em cada gráfico, da Figura 108 à Figura 112, há duas curvas, uma referente aos dados de conversão obtidos experimentalmente, de acordo com o apresentado na Figura 107 e outra com os dados de conversão calculados através do modelo proposto.

Embora os dados experimentais de conversão apresentem algumas flutuações de natureza experimental, as curvas calculadas pelo modelo seguem corretamente a tendência geral dos dados de maneira satisfatória.

Além disso, os resultados evidenciam que a velocidade de polimerização é alta ao longo da primeira hora de reação e que após esse período a velocidade diminui e tende a estabilizar após duas horas de reação. Isso se deve ao consumo de monômeros, o que diminui sua concentração no interior das partículas e com isso reduz a velocidade de reação. 
Figura 108 - Comparação entre conversão experimental e calculada em função do tempo para a Mini_01.

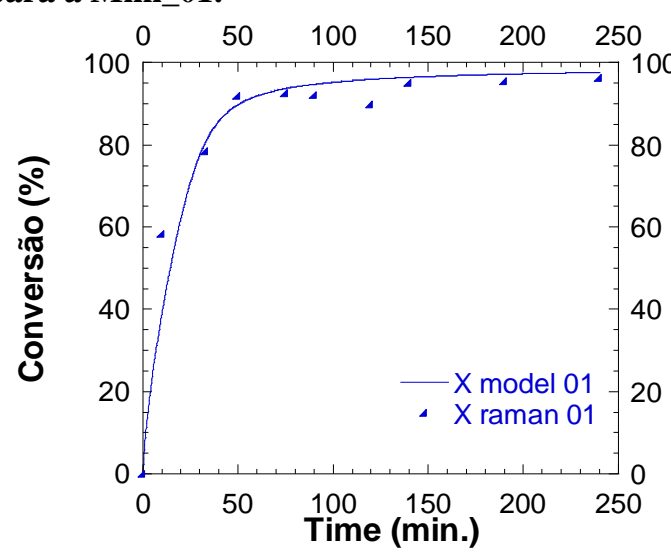

Figura 110 - Comparação entre conversão experimental e calculada em função do tempo para a Mini_03.

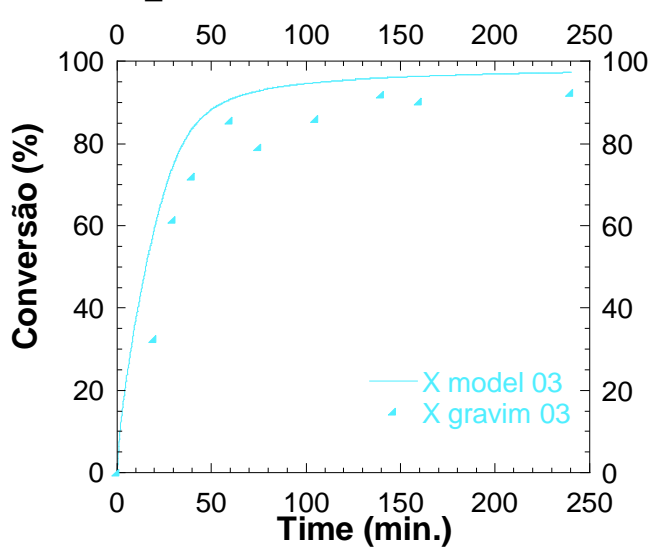

Figura 112 - Comparação entre conversão experimental e calculada em função do tempo para a Mini_05.

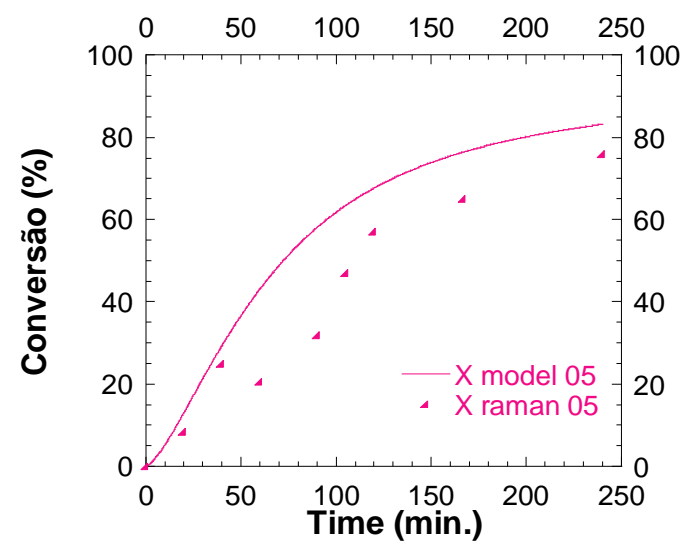

Figura 109 - Comparação entre conversão experimental e calculada em função do tempo para a Mini_02.

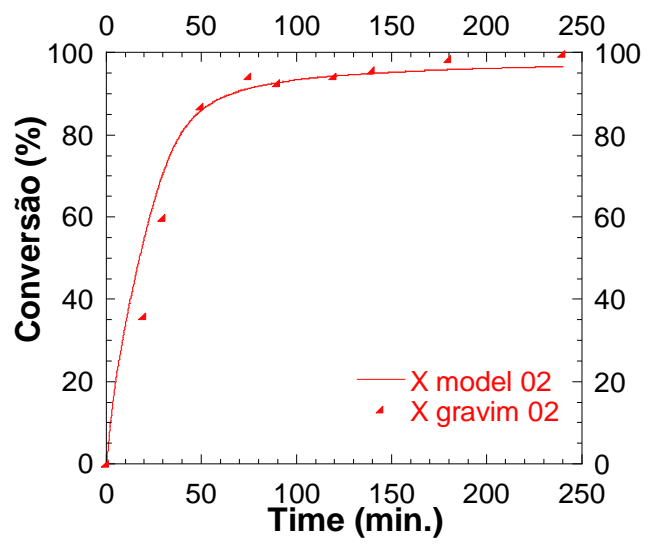

Figura 111 - Comparação entre conversão experimental e calculada em função do tempo para a Mini_04.

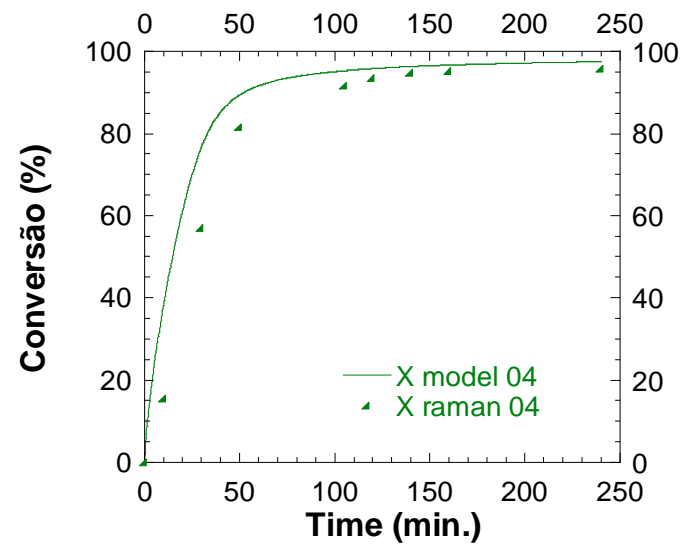




\subsubsection{Diâmetro}

A simulação utilizou como parâmetro de entrada os diâmetros iniciais de cada ensaio avaliado. Os diâmetros das partículas ao longo da reação previstos pelo modelo, apresentados na Figura 113, foram obtidos indiretamente a partir do número de partículas presentes no meio, que por sua vez depende do tipo da nucleação existente. Quando se comparam qualitativamente os diâmetros calculados pelo modelo, com os diâmetros obtidos experimentalmente pelo Coulter, apresentados na Figura 114, observa-se a mesma tendência de queda de diâmetro, o que comprova que o modelo foi capaz de prever essa redução no diâmetro.

Figura 113 - Diâmetro em função do tempo, calculada pelo modelo matemático proposto.

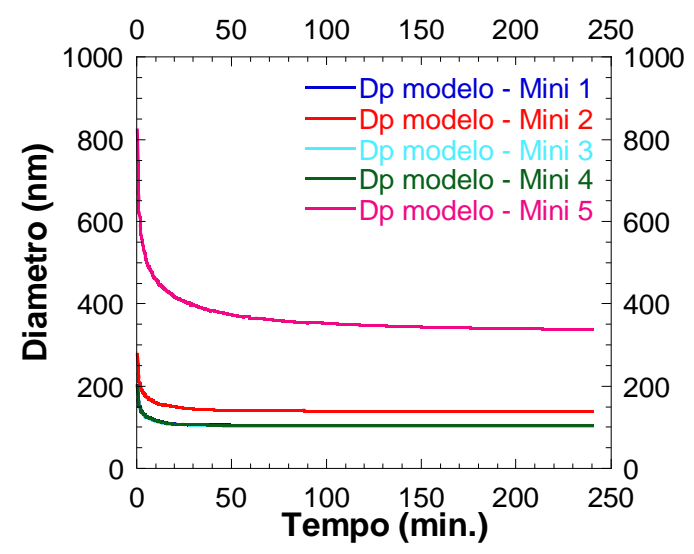

Figura 114 - Diâmetro em função do tempo, obtida por experimentalmente por Espalhamento de Luz Coulter

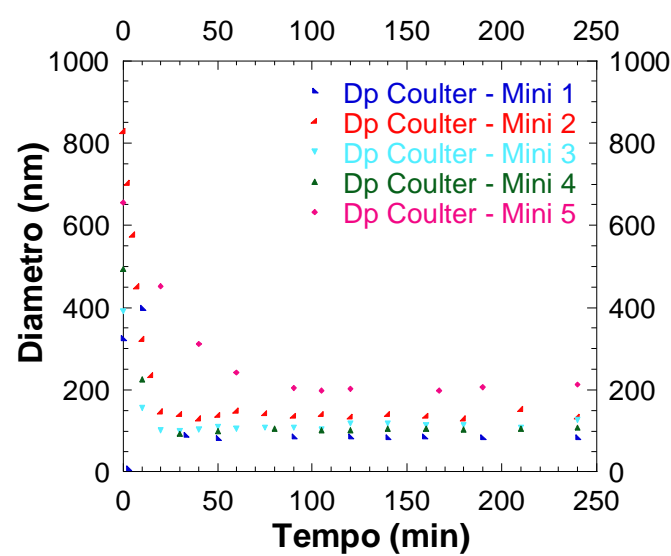

Observando-se isoladamente cada conjunto de dados experimentais com suas respectivas curvas calculadas pelo modelo matemático, conforme apresentado nas Figura 115 a Figura 119, pode-se concluir que o modelo matemático forneceu um bom ajuste aos dados experimentais. $\mathrm{O}$ único ensaio em que os desvios foram significativos foi o ensaio Mini_05, no qual foi utilizada menor quantidade de tensoativo, e também o que apresentou menor conversão de monômero (conforme Figura 112).

O modelo considera a distribuição monodispersa dos diâmetros, enquanto que os diâmetros experimentais referem-se ao diâmetro médio das amostras. Sendo assim, alguns desvios podem ser atribuídos a essa hipótese. Outra fonte de desvios é que, no modelo, o diâmetro das partículas é o diâmetro médio volumétrico (conforme Equação 40), enquanto que o valor experimental é o diâmetro médio baseado na intensidade do espalhamento de luz. 
Figura 115 - Comparação entre diâmetro experimental e calculado em função do tempo para a Mini_01.

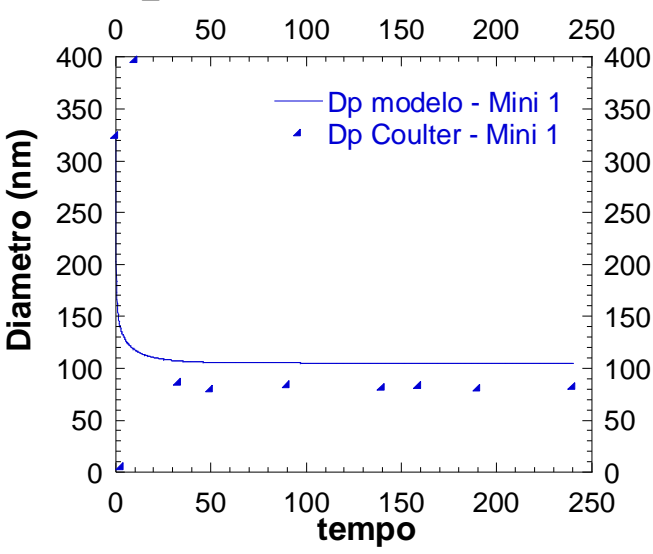

Figura 117 - Comparação entre diâmetro experimental e calculado em função do tempo para a Mini_03.

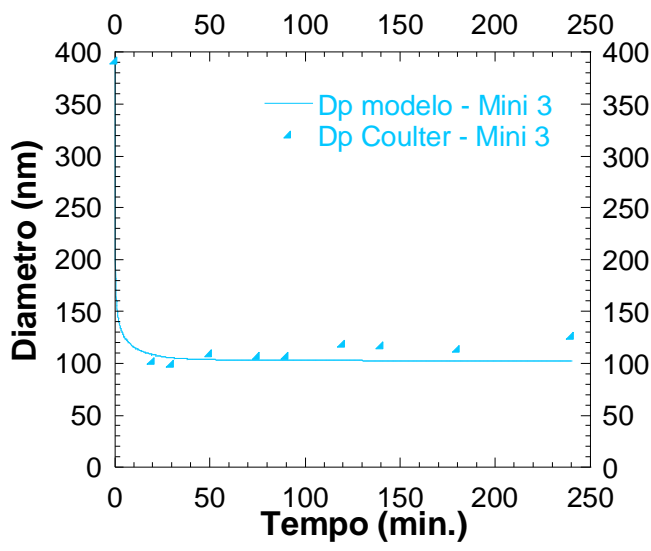

Figura 119 - Comparação entre diâmetro experimental e calculado em função do tempo para a Mini_05.

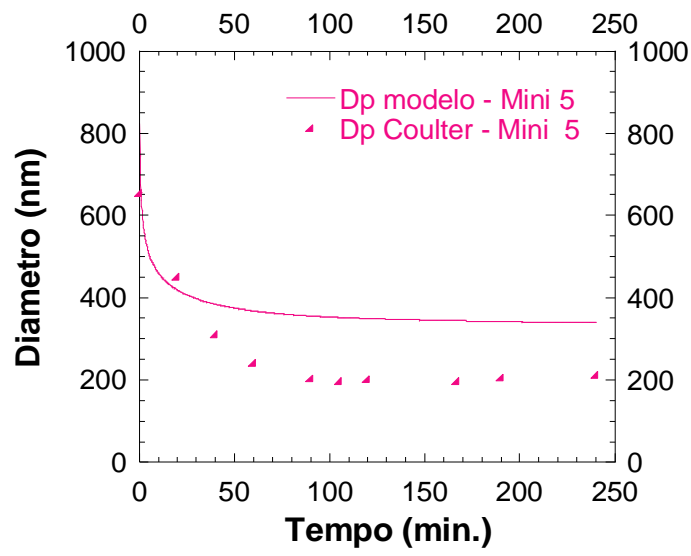

Figura 116 - Comparação entre diâmetro experimental e calculado em função do tempo para a Mini_02.

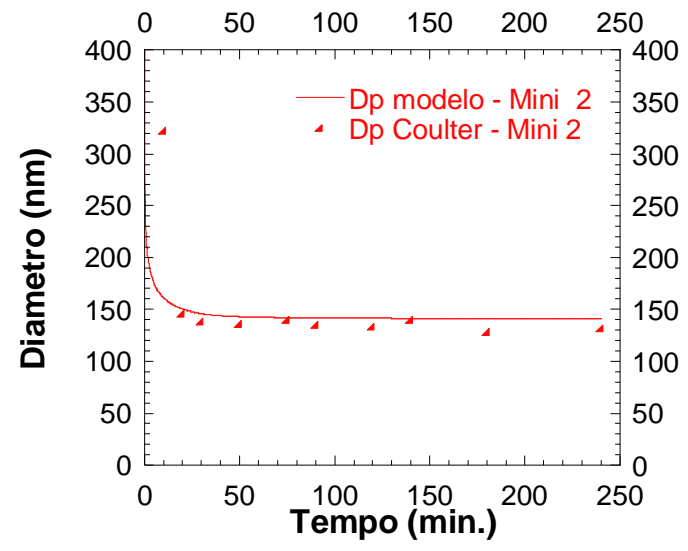

Figura 118 - Comparação entre diâmetro experimental e calculado em função do tempo para a Mini_04.

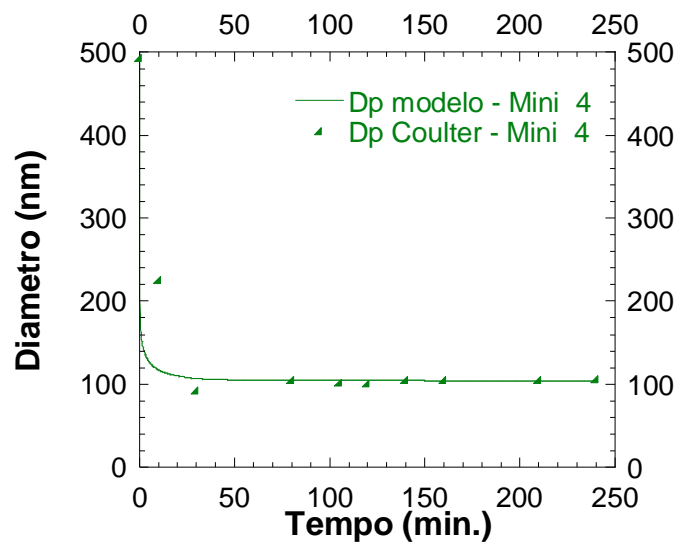




\subsubsection{Numero médio de radicais por partícula}

A Figura 120 apresenta o número médio de radicais por partícula em função do tempo e a Figura 121 em função da conversão.

Observa-se uma queda no número de radicais que está relacionado com a nucleação homogênea presente nos casos avaliados, o que aumenta a quantidade de partículas poliméricas no meio disperso, diminuindo, portanto o número de radicais por partícula.

No entanto, o número médio de radicais por partículas $(\bar{n})$ esperado deveria estar em torno de 0,5 . O cálculo do $\bar{n}$ depende do número de partículas presentes no reator, por essa razão, supõe-se que o númro de partículas calculado deveria ser menor, assim, $\bar{n}$ diminuiria. A verificação dessa constatação foi proposta como trabalhos futuros.

Figura 120 - Número médio de radicais por partícula em função do tempo

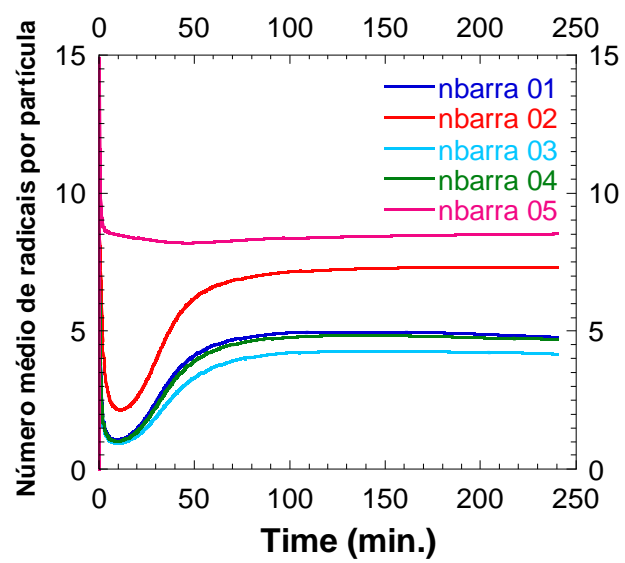

Figura 121- Número médio de radicais por partícula em função da conversão

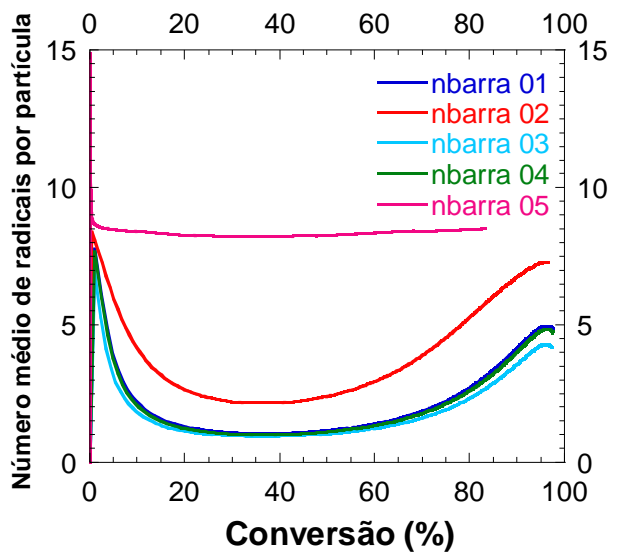

\subsubsection{Concentração de Monômero nas fases contínua e dispersa}

A Figura 122 apresenta a concentração do monômero na fase contínua em função do tempo. Devido à baixa solubilidade do monômero em água, observa-se que a concentração do monômero já inicia o processo com um valor baixo e, ao longo do tempo, essa concentração diminui ainda mais devido à conversão global do monômero nas partículas, já que a concentração de monômero na fase aquosa mantém-se em equilíbrio com o monômero na fase dispersa.

A Figura 124 apresenta a concentração do monômero na fase dispersa em função do tempo. Observa-se que a concentração de monômero na fase dispersa diminui ao longo do tempo, em função do seu consumo na reação. Simultaneamente, observa-se 
um aumento na concentração de polímero na fase dispersa, conforme mostra a Figura 125.

A Figura 123 apresenta a concentração de radicais poliméricos presentes na fase aquosa e que podem entrar nas partículas ou micelas em função do tempo. A sua concentração é pequena, o que se justifica pela baixa concentração de monômero da fase aquosa.

Figura 122 - Concentração de monômero na fase contínua em função do tempo

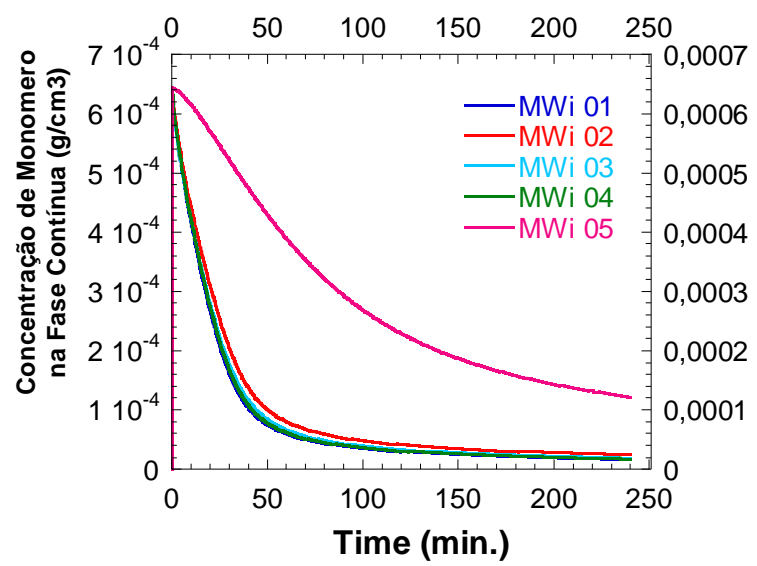

Figura 124 - Concentração de monômero na fase dispersa em função do tempo

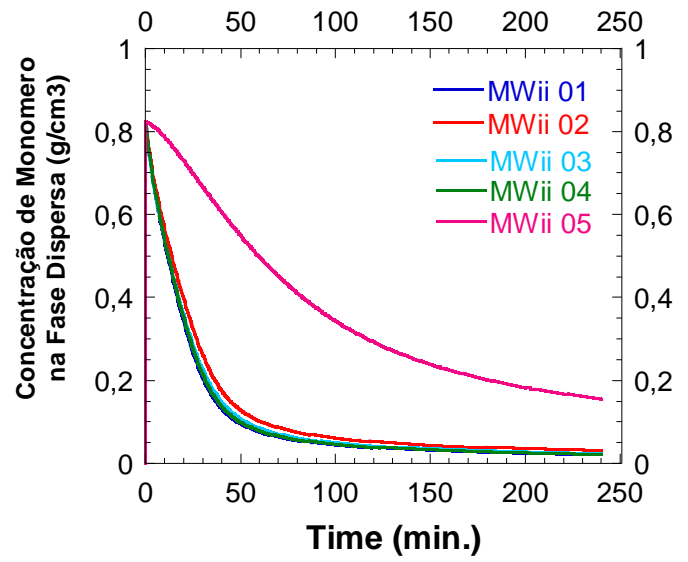

Figura 123 - Concentração de radicais poliméricos que podem entrar nas partículas ou micelas em função do tempo

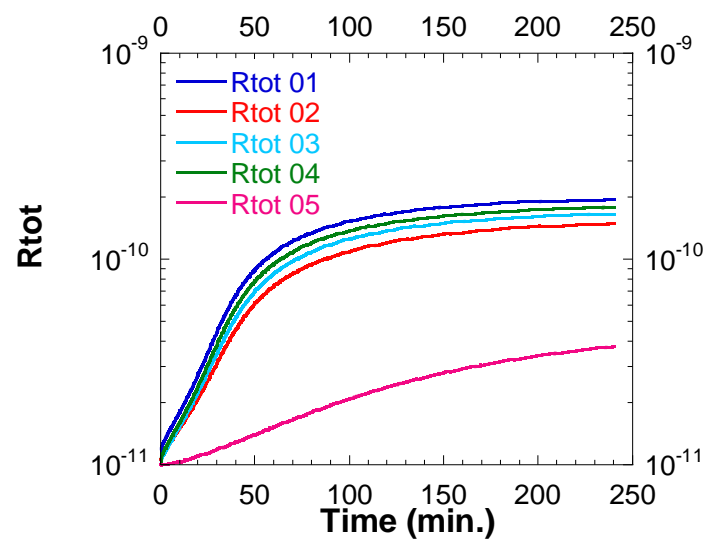

Figura 125 - Concentração de polímero na fase dispersa em função do tempo

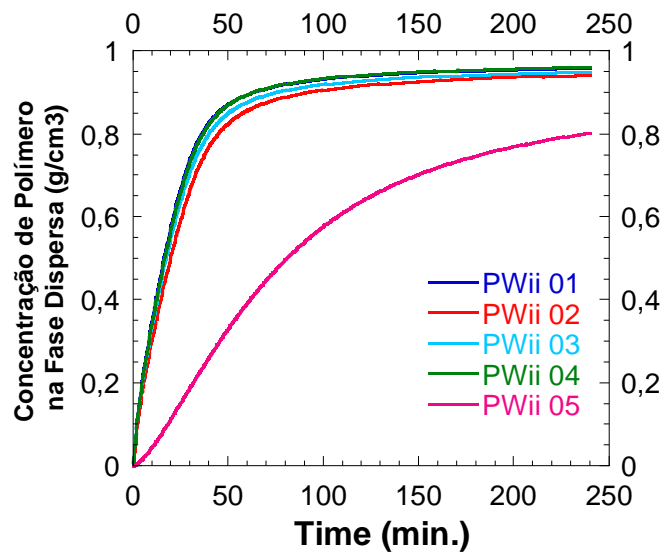

\subsubsection{Efeito gel e Efeito Vítreo}

O efeito gel afeta diretamente a reação de terminação na fase dispersa, assim, quanto menor o fator para o efeito gel, menor será a taxa de terminação.

A Figura 125 apresenta o fator para o efeito gel em função do tempo e a Figura 126 apresenta o fator para o efeito gel em função da conversão. Observa-se que quanto 
maior a conversão, menor o fator para o efeito gel, pois quanto maior a conversão, maior a viscosidade do meio, menor a mobilidade das macrocadeias e maior a taxa de polimerização.

Figura 126 - Fator para o efeito gel em função do tempo

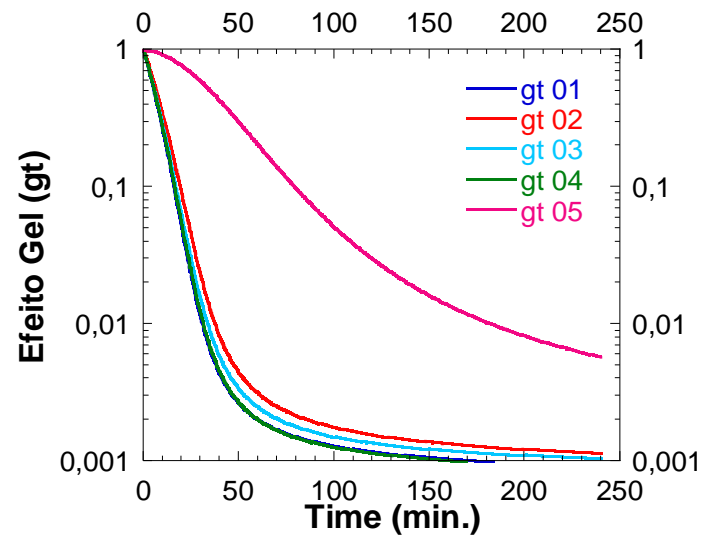

Figura 127 - Fator para o efeito gel em função da conversão

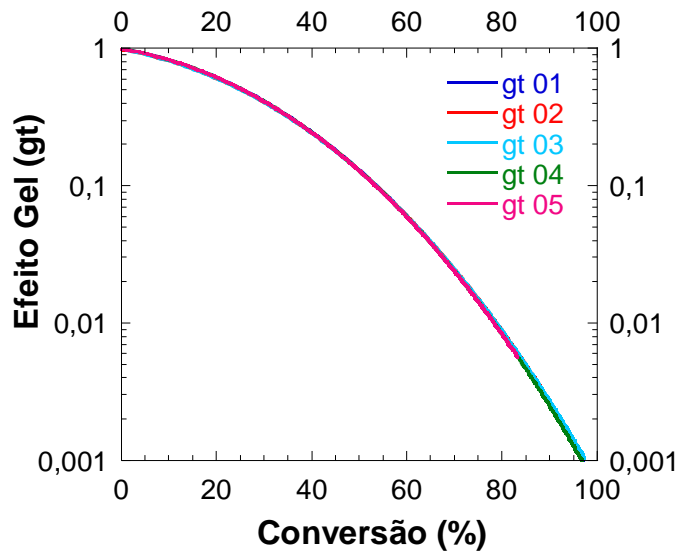

O efeito vítreo afeta diretamente a reação de propagação na fase dispersa. Assim, quanto menor o fator para o efeito vítreo, menor será a taxa de propagação. A Figura 128 mostra o fator para o efeito vítreo em função do tempo enquanto a Figura 129 mostra o fator para o efeito vítreo em função da conversão.

Figura 128- Fator para o efeito vítreo em função do tempo

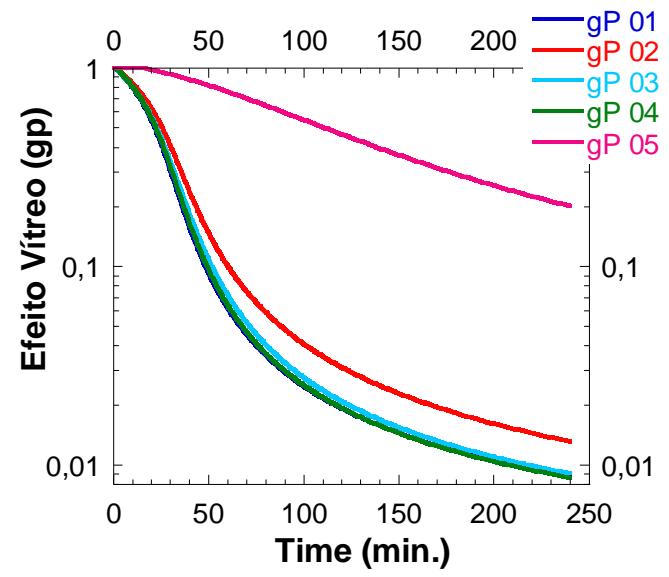

Figura 129- Fator para o efeito vítreo em função da conversão

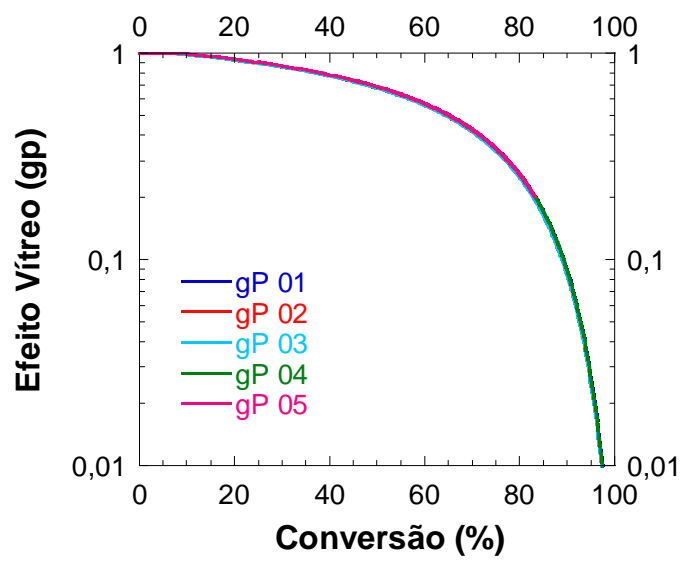




\subsubsection{Nucleação Homogênea e Nucleação Micelar}

A Figura 130 apresenta o número de partículas geradas por nucleação homogênea e comprova através do modelo matemático a existência da nucleação homogênea simultaneamente com a nucleação das gotas.

A Figura 131 apresenta o número de partículas geradas por nucleação micelar e comprova através do modelo matemático a inexistência da nucleação micelar. Essa verificação é realizada através da comparação da concentração do tensoativo utilizado, com quantidade de tensoativo necessário para realizar o recobrimento das partículas poliméricas e essa quantidade comparada com a concentração micelar crítica.

Assim, as hipóteses de presença de nucleação homogênea e ausência de nucleação micelar, adotadas inicialmente após análise dos dados experimentais, puderam ser verificadas pelo modelo matemático.

Figura 130 - Número de partículas que sofreram nucleação homogênea em função do tempo

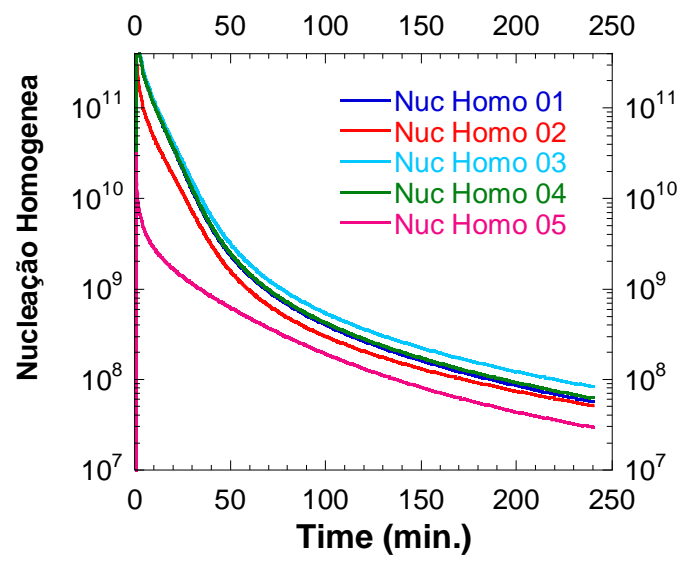

Figura 131 - Número de partículas que sofreram nucleação micelar em função do tempo

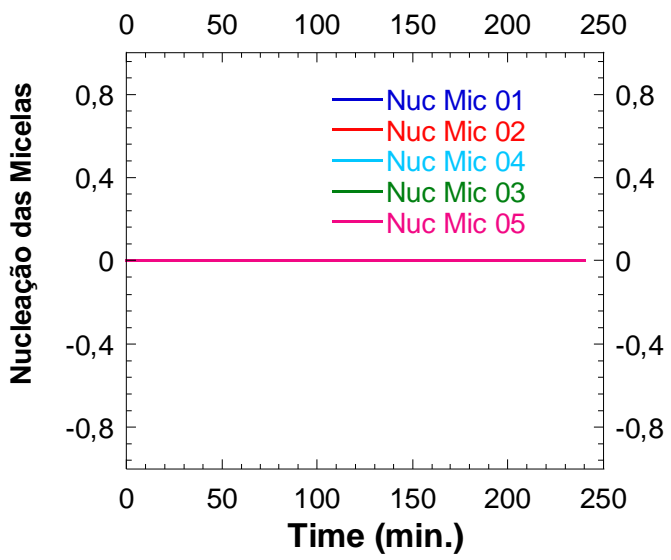

\subsection{Comparação entre os Métodos de Monitoramento \& Modelagem e Simulação}

Todas as propostas de monitoramento da conversão da reação foram eficazes e conseguiram estimar de maneira satisfatória a tendência da conversão do monômero, conforme evidencia a Figura 132 que representa a conversão da Mini_03 medida por Espectroscopia Raman (método direto), Espectroscopia NIR, Análise Gravimétrica e pelo Modelo Cinético.

Para o monitoramento do diâmetro, a Figura 133 representa os diâmetros medidos por Espalhamento de Luz- coulter, Espectroscopia Raman (método indireto), Espectroscopia NIR e pelo Modelo Cinético para a Mini_03. 
Para o início da reação, todas as propostas de monitoramento foram eficazes e conseguiram estimar de maneira satisfatória a tendência de variação do diâmetro. Desvios maiores foram observados apenas no caso de monitoramento do diâmetro com Espectroscopia Raman.

Figura 132 - Comparação entre os métodos para determinação da conversão da Mini_03

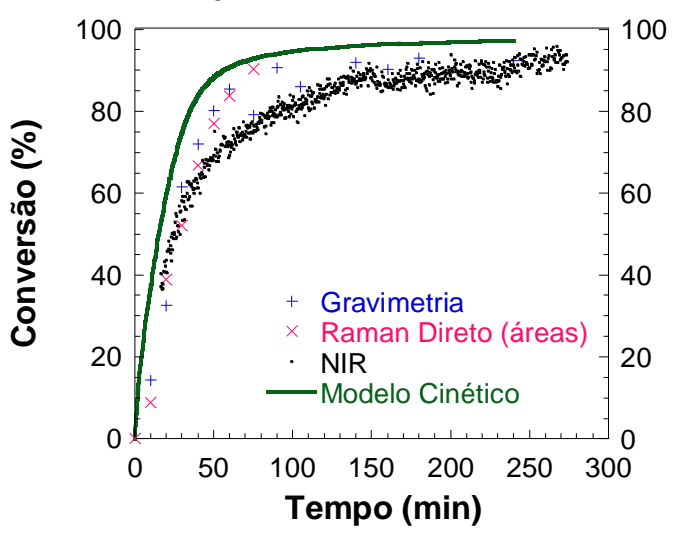

Figura 133 - Comparação entre os métodos para determinação do diâmetro da Mini_03

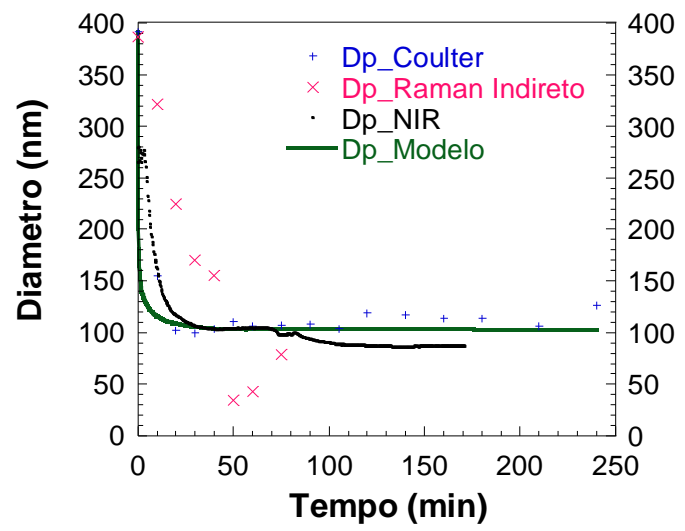




\section{CONCLUSÕES}

O presente trabalho trouxe grande contribuição para a área de polímeros, pois reuniu no mesmo trabalho: síntese, monitoramento, modelagem e simulação do processo de polimerização em miniemulsão.

O monitoramento de processo para o acompanhamento da conversão das reações foi eficaz com uso da espectroscopia NIR (in-line, com calibração multivariável) e com a espectroscopia Raman (off-line, sem calibração). O monitoramento do diâmetro médio das partículas foi satisfatório com o uso da espectroscopia NIR (in-line, com calibração multivariável) e, com a espectroscopia Raman (off-line, com calibração multivariável), o monitoramento do diâmetro das partículas foi capaz de indicar a grande redução de tamanhos que ocorreu no início do processo mas apresentou maiores desvios quantitativos em relação às medições de referência feitas por espalhamento dinâmico de luz. Dessa maneira, pode-se afirmar que o uso da espectroscopia NIR foi mais eficiente pois não exigiu preparação das amostras, forneceu respostas em tempo real, sem defasagem de tempo e também pôde ser realizada em intervalos menores de tempo, evitando a perda de informações entre uma amostra e outra.

A simulação matemática desenvolvida para o processo de polimerização em miniemulsão mostrou-se eficaz para a previsão do comportamento da reação. É uma ferramenta importante para o conhecimento do processo e permite realizar analise de sensibilidade com as variáveis de processo.

Os resultados mostraram que o modelo matemático foi satisfatório na previsão do comportamento das curvas de conversão de monômero e das variações observadas no diâmetro das partículas. O modelo considerou a possibilidade de haver nucleação micelar, nucleação homogênea e nucleação das gotas durante a reação, mas verificou-se que nos ensaios experimentais realizados, não ocorreu nucleação micelar. Além disso, contemplou a possibilidade de haver coagulação das partículas através do termo que reduz o número de partículas no meio em decorrência da coagulação.

Os resultados do modelo foram confrontados com os dados experimentos e resultaram em um ajuste coerente com os dados experimentais, representando corretamente a redução do diâmetro das partículas observada experimentalmente no início do processo de polimerização em miniemulsão. 


\section{PROPOSTAS PARA TRABALHOS FUTUROS}

A seguir citam-se algumas propostas para trabalhos futuros:

- Determinação experimental da CMC das formulações utilizadas.

- Revisão do modelo matemático considerando número de partículas e número de gotas separadamente.

- Validação dos modelos de calibração com processos industriais.

- Incluir variável teor de monômero nos estudos experimentais.

- Validação do modelo utilizando outros monômeros, iniciadores, surfactantes.

- Adaptação do modelo para miniemulsão inversa. 


\section{REFERÊNCIAS}

ALHAMAD, B.; ROMAGNOLI, J. A.; GOMES, V. G. Advanced modelling and optimal operating strategy in emulsion copolymerization: Application to styrene/MMA system. Chemical Engineering Science, v. 60, n. 10, p. 2795-2813, maio 2005.

ANALYTICS, T. H. Ultra-Mini Immersion probe. 2013.

ANTONIETTI, M.; LANDFESTER, K. Polyreactions in miniemulsions. v. 27, 2002.

ASUA, J. M. Miniemulsion polymerization. Progress in Polymer Science, v. 27, n. 7, p. 1283-1346, set. 2002.

ASUA, J. M. A new model for radical desorption in emulsion polymerization. Macromolecules, v. 36, p. 6245-6251, 2003.

BALLARD, M. J. et al. Propagation rate coefficients from electron spin resonance studies of the emulsion polymerization of methyl methacrylate. Macromolecules, v. 19, p. 1303-1308, 1986.

BARBOSA, N. B. Copolimerização em emulsão de estireno e acrilato de butila: estudo experimental em reatores batelada e semicontínuo. [s.1.] FAAP, 2014.

BEYERS, C. P. In-line monitoring of controlled radical copolymerisation reactions with near infrared spectroscopy. [s.l: s.n.].

BRANDRUP J.; IMMERGUT E. H.; GRULKE E. A.; BLOCH D. Polymer Handbook. 4th. ed. New York: [s.n.].

BRESOLIN, C. DA C. Modelagem matemática e validação experimental de reações de polimerização em miniemulsão com iniciador organossolúvel. [s.1.] Universidade Federal de Santa Catarina, 2013.

BRUKER OPTIK. OPUS, Reference Manual - Version 5. Disponível em: <http://shaker.umh.es/investigacion/OPUS_script/OPUS_5_BasePackage.pdf>. Acesso em: 4 fev. 2015.

CETESB. Ficha de Segurança do Produto Químico - Estireno. Disponível em: $<\mathrm{http}$ ://sistemasinter.cetesb.sp.gov.br/produtos/ficha_completa1.asp?consulta=ESTIRE NO>. Acesso em: 12 nov. 2014. 
CETESB. Ficha de Segurança do Produto Químico - Dodecilsulfato de Sódio. São Paulo, 2015.

CHERN, C. Principles and applications of emulsion polymerization. [s.l: s.n.].

CLAY, P. A; GILBERT, R. G. Molecular Weight Distributions in Free-Radical Polymerizations . 1 . Model Development and Implications for Data Interpretation. Macromolecules, v. 28, p. 552-569, 1995.

COEN, E. M. et al. Modelling particle size distributions and secondary particle formation in emulsion polymerisation. Polymer, v. 39, n. 26, p. 7099-7112, 2006.

COLMÁn, M. M. E. Monitoramento da Polimerização de Acrilamida em Miniemulsão Inversa por Espectroscopia Raman e NIR. [s.1.] Universidade Federal de Santa Catarina, 2013.

CORTINA, F. V. Modelagem matemática da polimerização em miniemulsão utilizando iniciador hidrossolúvel e organo-solúvel. [s.l.] Universidade Federal de Santa Catarina, 2007.

COSTA, L. A. Encapsulação de Nanopartículas de Fosfato de Alumínio pela Técnica de Polimerização em Miniemulsão. [s.1.] Universidade Federal de Santa Catarina, 2010.

DANIELS, E. S.; SUDOL, E. D.; EL-AASSER, M. S. Overview of Polymer Colloids : Preparation, Characterization, and Applications. ACS Symposium Series. Anais.Washington, 2001.

DUBE, M. A; HAMIELEC, A. E. Mathematical Modeling of Multicomponent Chain-Growth Polymerizations in Batch, Semibatch, and Continuous Reactors : A Review. Industrial \& Engineering Chemistry Research, v. 36, p. 966-1015, 1997.

Dynamic Light Scattering: An Introdution in 30 minutos. Disponível em: <http://www3.nd.edu/ rroeder/ame60647/slides/dls.pdf.>. Acesso em: 20 maio. 2013.

FITCH, R. M.; TSAI, C. H. Particle formation in Polymer Colloids. III: Predicition of the number by a Homogeneous Nucleation Theory. In: Polymer Colloids. New York: Plenum Press, 1971.

FOGLER, H. S. Elementos de engenharia das reações químicas. $3^{\text {a }}$. ed. Rio deJaneiro: LTC - Livros Técnicos e Científicos Editora SA, 2002. 
FONSECA, G. E.; DUBÉ, M. A.; PENLIDIS, A. A Critical Overview of Sensors for Monitoring Polymerizations. Macromolecular Reaction Engineering, v. 3, n. 7, p. 327-373, 14 set. 2009.

FONTENOT, K.; SCHORK, F. J. Batch Polymerization of Methyl Methacry late in Mini / Macroemulsions. Journal of Applied Polymer Science, v. 49, p. 633-655, 1993.

FORMULATION - SMART SCIENTIFIC ANALYSIS. Smart solutions for dispersions characterisation. Disponível em:

<http://www.formulaction.com/public_download/catalogue.pdf >. Acesso em: 28 out. 2013.

FORMULATION - SMART SCIENTIFIC ANALYSIS. Multiple light scattering Turbiscan Technology. Toulouse, France: Formulaction, 2015. Disponível em: <http://www.dafratec.com/images/untitled folder/Turbiscan_Tecnico.pdf >.

GAO, J.; PENLIDIS, A. Mathematical modeling and computer simulator/database for emulsion polymerizations. Progress in Polymer Science, v. 27, n. 3, p. 403-535, abr. 2002.

GILBERT, R. G. Emulsion Polymerization. A Mechanistic Approach. [s.l: s.n.].

HERGERT, W.; WRIEDT, T. The Mie Theory. [s.l: s.n.].

HUI, A. W.; HAMIELEC, A. E. Thermal Polymerization of Styrene at High Conversions and Temperatures. An experimental Study. Journal of Applied Polymer Science, v. 16, p. 749-769, 1972.

INNOVA. Ficha de Informação de Segurança de Produto Químico - Poliestireno Pellets, 2005.

LANDFESTER, K.; SCHORK, F. J.; KUSUMA, V. A. Particle size distribution in mini-emulsion polymerization. Comptes Rendus Chimie, v. 6, n. 11-12, p. 1337-1342, nov. 2003.

LI, B. G.; BROOKS, B. W. Prediction of the average number of radicals per particle for emulsion polymerization. Journal of Polymer Science, Part A: Polymer Chemistry, v. 31, p. 2397-2402, 1993.

MARINANGELO, G. Copolimerização em emulsão de estireno e acrilato de butila com alto teor de sólidos: estudo experimental e modelagem matemática do processo em reator semicontínuo. [s.l.] Universidade de São Paulo, 2010. 
MARTEN, F. L.; HAMIELEC, A. E. High-Conversion Diffusion-Controlled Polymerization of Styrene. I. Journal of Applied Polymer Science, v. 27, n. 1, p. 489$505,1982$.

MIN, K.W.; RAY, W. H. The computer simulation of batch emulsion polymerization reactors through a detailed mathematical model. Journal of Applied Polymer Sci., v. 28, p. 901-919, 1978.

OliveIRA, C.; COUTINHO, F. Reações de Polimerização em Cadeia - Mecanismo e Cinética. $1^{\text {a }}$ Edição ed.[s.l: s.n.].

PASQUINI, C. Near infrared spectroscopy: Fundamentals, practical aspects and analytical applications. Journal of the Brazilian Chemical Society, v. 14, n. 2, p. 198219, 2003.

PERRY, R. P, GREEN, D. W. Perry's Chemical Engineers' Handbook. 7th ed. ed.US: McGraw-Hill, 1999.

PINTO, J. C.; RAY, W. H. The dynamic behavior of continuous solution polymerization reactors-VII. Experimental study of a copolymerization reactor. Chemical Engineering Science, v. 50, n. 4, p. 715-736, fev. 1995.

REIS, M. M. et al. Development of calibration models for estimation of monomer concentration by Raman spectroscopy during emulsion polymerization: Facing the medium heterogeneity. Journal of Applied Polymer Science, v. 93, p. 1136-1150, 2004.

SACKS, M. E.; LEE, S.-I.; BIESENBERGER, J. A. Effect of temperature variations on molecular weight distributions: batch, chain addition polymerizations. Chemical Engineering Science, v. 28, n. 1, p. 241-257, 1973.

SCHORK, F. J. et al. Miniemulsion Polymerization. Adv Polym Sci, n. 175, p. 129$255,2005$.

SERRA, C. S. R. Controlo em linha de reações de polimerização em miniemulsão através de técnicas de espectroscopia vibracional (NIR e Raman). [s.l: s.n.].

SIESLER, H. W. et al. Near-infrared Spectroscopy: principles, instruments, applications. 3. ed. Germany: [s.n.].

SIGMA-ALDRICH. Ficha de Segurança do Produto Químico - Persulfato de Potássio, 2011.

SIGMA-ALDRICH. Ficha de Segurança do Produto Químico - Hexadecano, 2015. 
SMITH, W. V.; EWART, R. H. Kinetics of Emulsion Polymerization. JOURNAL OF CHEMICAL PHYSICS, v. 16, n. 6, p. 592-599, 1948.

Spectral Database for Organic Compounds SDBS. Disponível em: <http://riodb01.ibase.aist.go.jp/sdbs/cgi-bin/direct_frame_top.cgi>.

TEFERA, N.; WEICKERT, G.; WESTERTERP, K. R. Modeling of free radical polymerization up to high conversion. II. Development of a mathematical model. J. Appl. Polym. Sci., v. 63, p. 1663-1680, 1997.

THICKETT, S. C.; GILBERT, R. G. Emulsion polymerization: State of the art in kinetics and mechanisms. Polymer, v. 48, n. 24, p. 6965-6991, nov. 2007.

Turbiscan - Formulaction dispersion stability. Turbiscan User Guide. . [s.l.] Formulaction, [s.d.].

VICINI, L.; ADRIANO, O.; SOUZA, M. Análise multivariada da teoria à prática. 2005.

WORKMAN, J. The Handbook of Organic Compounds: NIR, IR, Raman, and UVVis Spectra Featuring Polymers and Surfactants. [s.l: s.n.]. 
APÊNDICE 


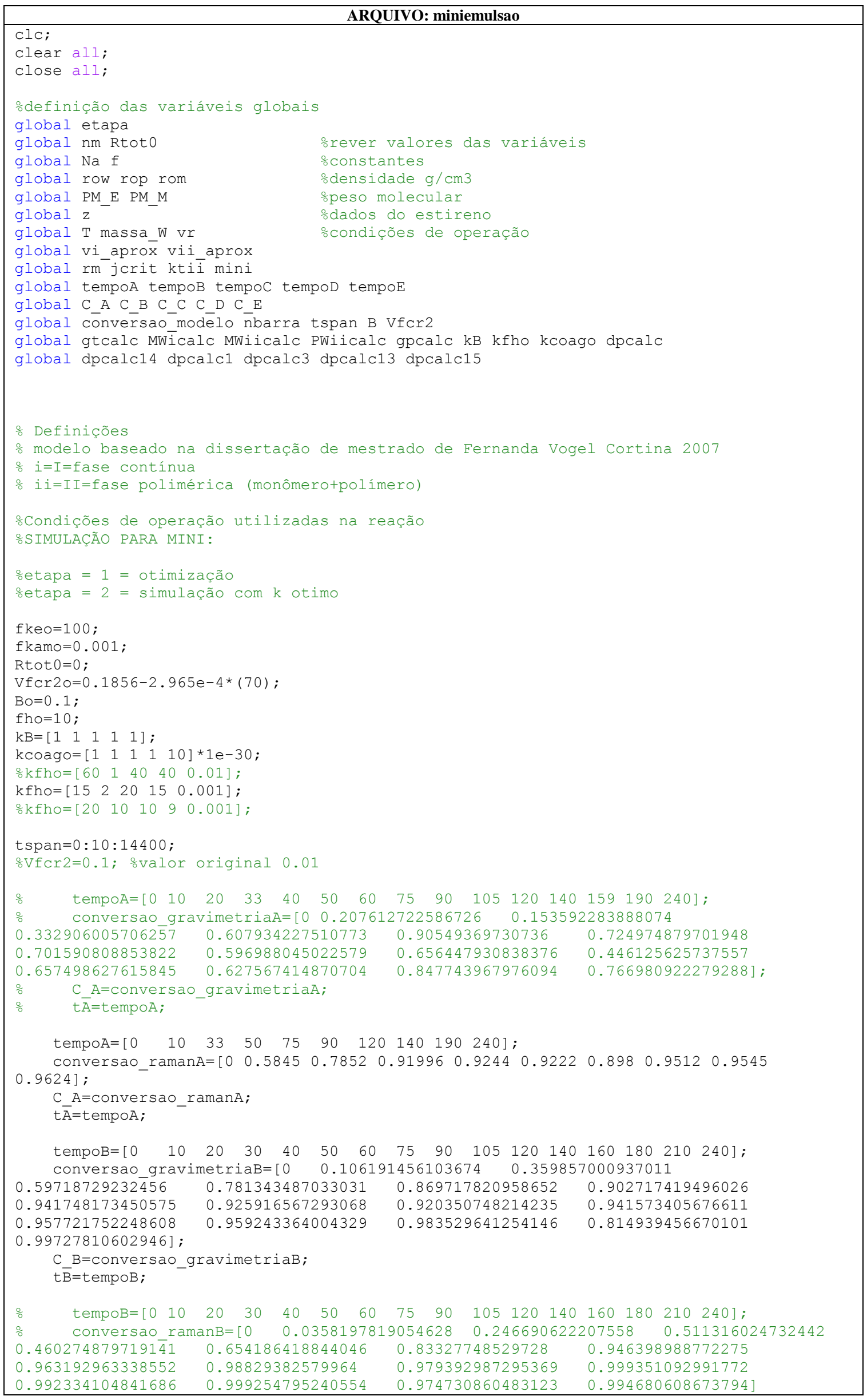




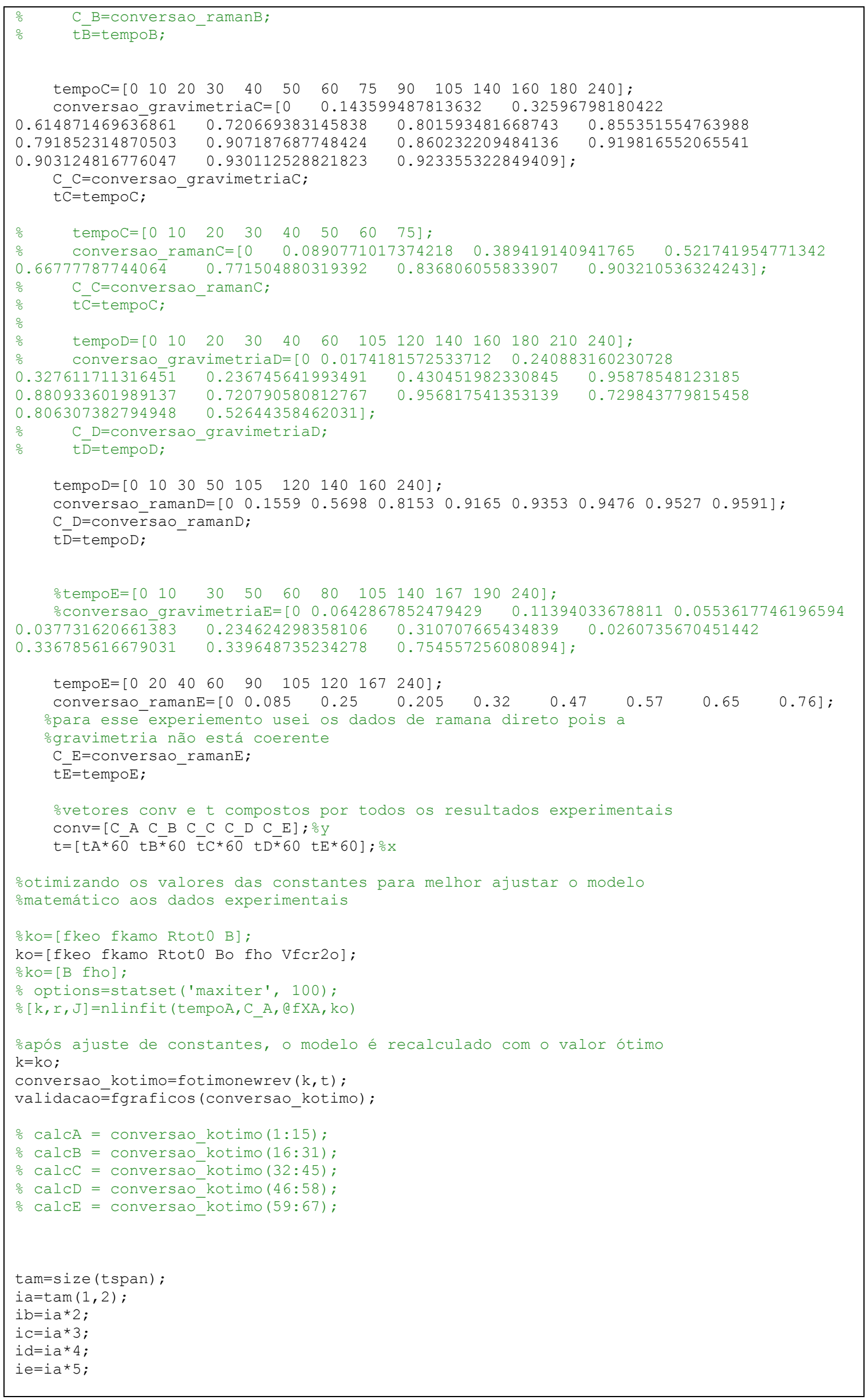



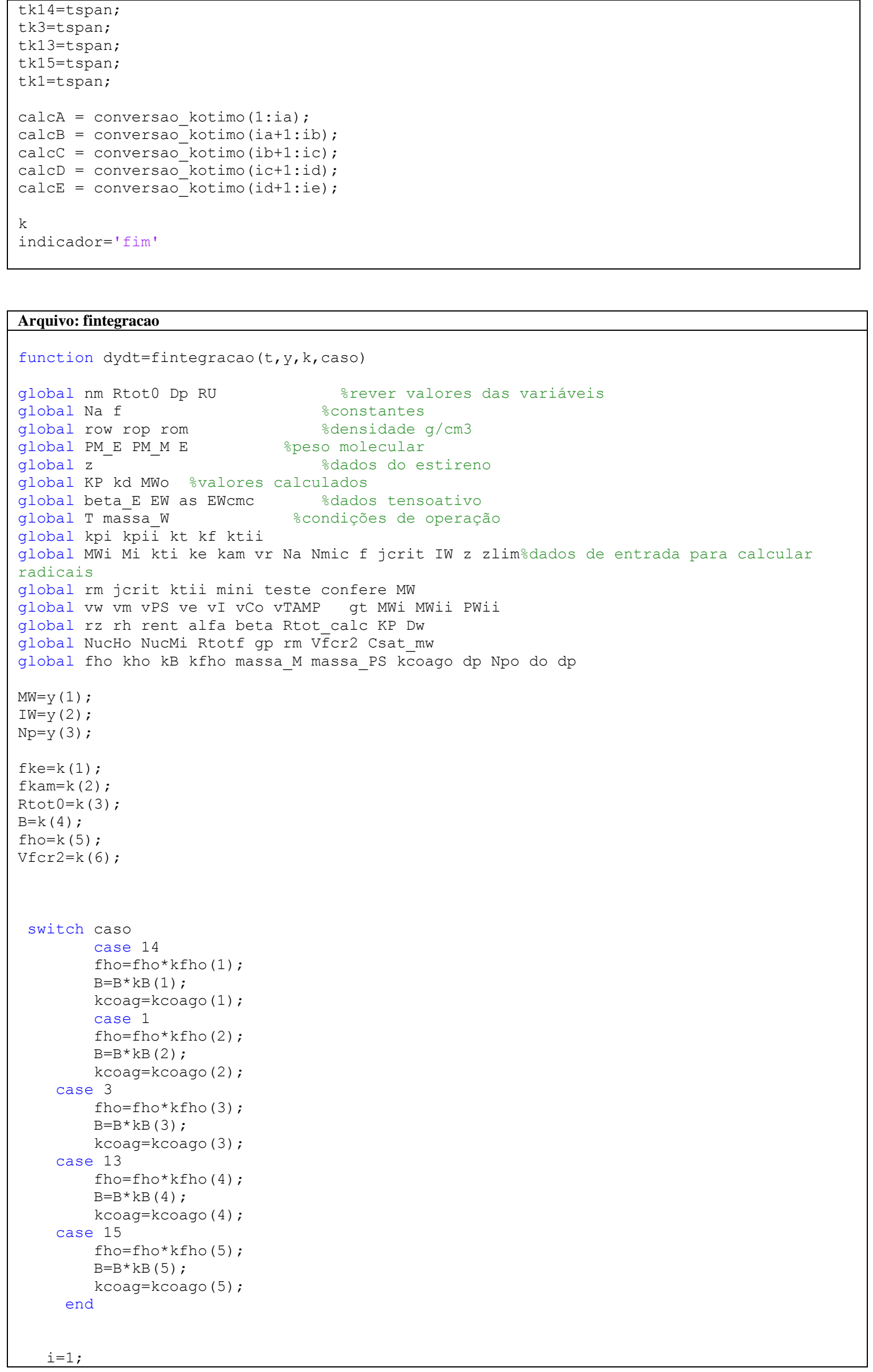
$\operatorname{vil}(1,1)=\mathrm{vw}+\mathrm{vI}+\mathrm{ve}+\mathrm{vTAMP}$

$\operatorname{viil}(1,1)=\mathrm{vm}+\mathrm{vPS}+\mathrm{vCo}$;

$\operatorname{vrl}(1,1)=\operatorname{vil}(1)+\operatorname{viil}(1)$;

somaerro2 $(1)=100$;

while somaerro2>1e-20

MWo=massa M/vrl (i) ;

$\operatorname{MWii}=\operatorname{vrl}(\overline{\mathrm{i}}) * \mathrm{MW} /((\operatorname{vil}(\mathrm{i}) / \mathrm{KP})+\operatorname{viil}(\mathrm{i}))$;

MWi=MWii/KP ;

massamonomero=MWi*Vil (i) +MWii*Viil (i) ;

WWi= massa_W/vil(i);

PWii=( (vrl $(i) *(M W o-M W))+$ massa PS) / viil(i);

$\mathrm{ma}=(\mathrm{MWi} / \mathrm{rom}+\mathrm{WWi} /$ row $+(\mathrm{vI}+\mathrm{ve}+\mathrm{vTAMP}) / \mathrm{vil}(\mathrm{i}))$;

$\operatorname{vil}(i+1)=v i l(i) * m a ;$

$\mathrm{mb}=(\mathrm{MWii} / \mathrm{rom}+\mathrm{PWii} / \mathrm{rop}+(\mathrm{vPS}+\mathrm{vCo}) / \mathrm{viil}(\mathrm{i}))$;

$\operatorname{viil}(i+1)=\operatorname{viil}(i) * m b$;

$\operatorname{vrl}(i+1)=\operatorname{vil}(1+1)+\operatorname{viil}(i+1)$;

errovi (i)=vil $(i+1)-\operatorname{vil}(i)$;

errovii(i)= viil(i+1)-viil(i);

errovi2(i)=errovi $(i)^{\wedge} 2$;

errovii2(i)=errovii (i)^2;

somaerro2 (i) =errovi2(i) $\operatorname{errovii2}(i)$;

$i=i+1$;

end

$\operatorname{vi}=\operatorname{vil}(1, i)$;

vii=viil $(1, i)$;

$\operatorname{vr}=\operatorname{vrl}(1, i)$;

oconcentração mássica de polímero na fase polimérica

$\mathrm{Mi}=\mathrm{MWi} / \mathrm{PM} \mathrm{M} * 1000$;

$\mathrm{Mi}=\mathrm{MWi}$ / $/ \overline{\mathrm{PM}} \_\mathrm{M} * 1000$;

oconstantes cinéticas

\% \%cálculo da constante cinética de propagação

alfa_p $=0.48 e-3$;

alfa $\mathrm{m}=1 \mathrm{e}-3$;

$\mathrm{Vm}=\mathrm{M} \bar{W} * \mathrm{Vr} / \mathrm{rom}$

$\mathrm{Vp}=\mathrm{PWi}{ }^{*} \mathrm{Vi}$ i/rop;

TfCe=291; $\%(K)$

$\mathrm{Tgp}=373$;

$\mathrm{Tgm}=184.95$;

vfpol $=(0.025+a l f a p *(T-T g p)) * V p / v i i$

vfmon $=\left(0.025+a l f a \_m *(T-T g m)\right) * V m / v i i$;

vfcoest $=(0.025+a l \overline{f a} m *(T-T f C e)) * v C o / v i i$;

$\mathrm{Vf}=\mathrm{vfpol}+\mathrm{vfmon}+\mathrm{vfcoest}$

$\mathrm{kpo}=(1.89 \mathrm{e} 9 * \exp (-10400 /(1.987 * \mathrm{~T}))) * 1 \mathrm{E} 3 ; \%(\mathrm{~L} / \mathrm{mol} . \mathrm{s})$ x1E3 para transformar de litro para $\mathrm{cm} 3$

$\mathrm{kpi}=\mathrm{kpo}$;

oinfluência do efeito vítreo na constante de propagação da fase polimérica if $\operatorname{Vf}<\operatorname{VfCr} 2$;

else $g p=\exp \left(-B^{*}((1 / V f)-(1 / \operatorname{Vfcr} 2))\right) ;$

end

$g \mathrm{p}=1$

kpii=kpo*gp;

\% \%cálculo da constante cinética de terminação

$\mathrm{kto}=(6.52 \mathrm{e} 13 * \exp (-8870 /(1.987 * \mathrm{~T}))) * 1 \mathrm{E} 3$;

$\mathrm{bs}=2.57-0.00505 * \mathrm{~T}$;

$\mathrm{CS}=9.56-0.0176 * \mathrm{~T}$;

$\mathrm{ds}=-3.03+0.00785 * \mathrm{~T}$;

fi p=PWii/rop;

:influência do efeito gel na constante de terminação da fase polimérica

fator_expo $=-2 *\left(b s^{*} f i \_p+c s^{*} f i \_p \wedge 2+d s * f i \_p \wedge 3\right)$;

gt=exp (fator expo); $\frac{\circ}{\mathrm{f}}$ ator para o efeito gel

kti=kto;

ktii=kto*gt;

massa Mt=MWi*Vi+MWii*Vii; $\%$ g ]

$\mathrm{Xdp}=(\overline{m a s s a} \mathrm{M}-\mathrm{massa} M \mathrm{Mt}) / \mathrm{massa} \mathrm{M}$

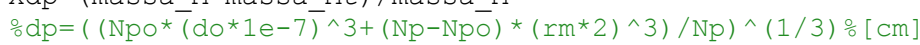

$\circ \mathrm{dp}=\left(\left(\left(\right.\right.\right.$ (massa $\mathrm{M}^{*}(1-$

$\left.\left.\mathrm{Xdp})) / \mathrm{rom})+\left(\left(\operatorname{mass} \bar{a}_{-} \mathrm{PS}+\left(\operatorname{massa} \mathrm{M}^{*} \mathrm{Xdp}\right)\right) / \mathrm{rop}\right) /(\mathrm{Np} * 3.1416 / 6)\right)^{\wedge}(1 / 3)\right) \%[\mathrm{~nm}]$ 


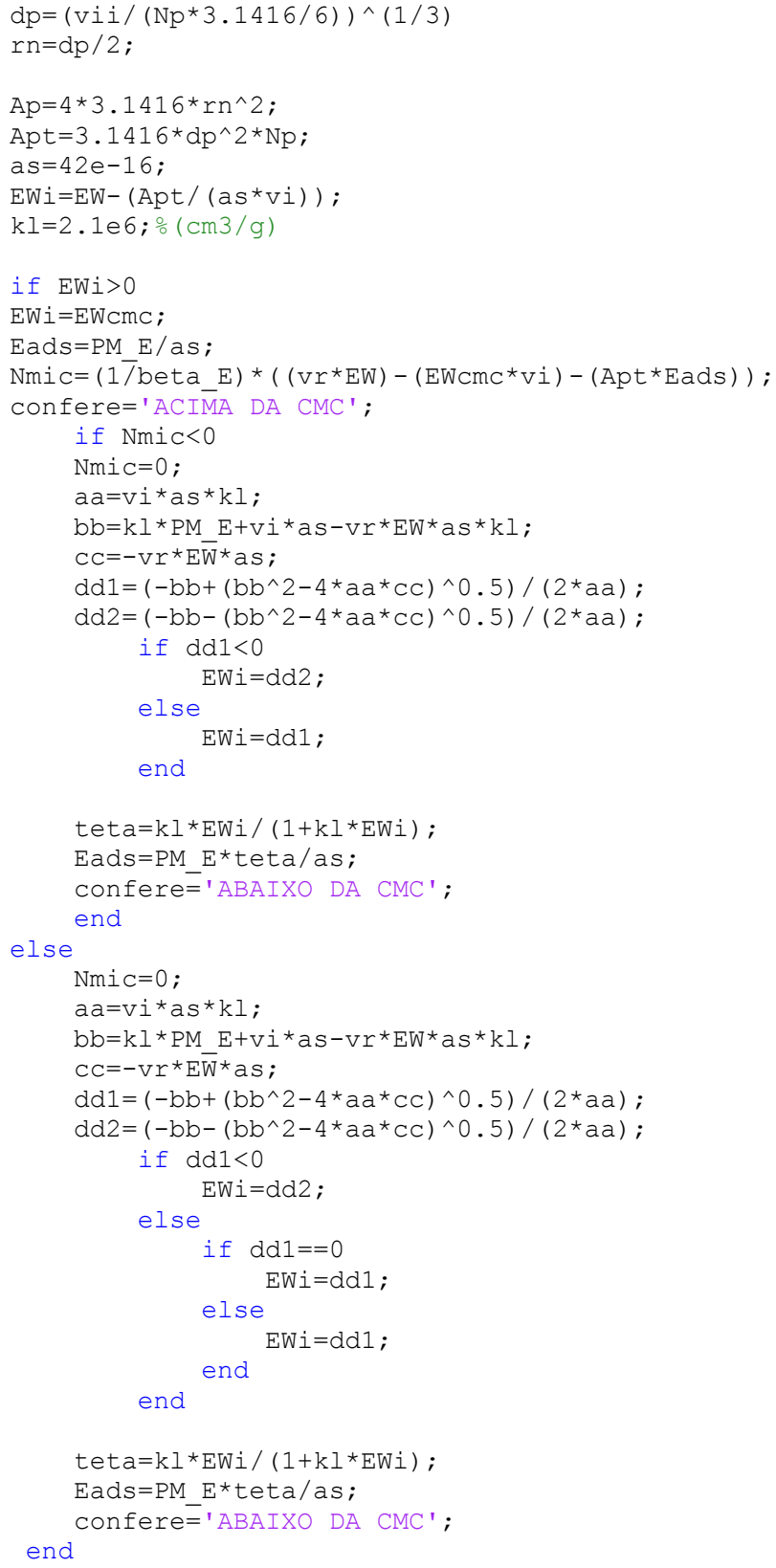

Rpinch $=r n ;$ 응io das partículas응응응응응

$\mathrm{ke}=f \mathrm{ke} * 4 * 3.1416 * \mathrm{Dw} * \mathrm{Na} *$ Rpinch; $\quad \% \mathrm{coef}$. de entrada de radicais nas partículas

poliméricas

$\mathrm{kam}=f \mathrm{kam} * 4 * 3.1416 * \mathrm{Dw}^{*} \mathrm{Na} * \mathrm{rm} ;$

Rtot $(1)=$ Rtot 0

$i=1$;

erro2 $=0.1$

$\mathrm{h}=1$;

while erro2>1e-10

oradicais com um mero RI

lambda $=\mathrm{kpi} * \mathrm{Mi}$;

fi=kpi*Mi+kti*Rtot (i)

alfa $=$ lambda/fi;

beta $=1 \mathrm{ambda} /\left(\mathrm{fi}+1 / \mathrm{vr} *\left(\mathrm{ke}{ }^{*} \mathrm{~Np} / \mathrm{Na}+\mathrm{kam} \mathrm{NmiC}^{\mathrm{Na}}\right)\right)$;

Rtot (i) ;

$R(1)=2 * f * k d * I W /((k p i * M i)+(k t i * R t o t(i)))$;

for $h=2: 1: z-1$

$\mathrm{R}(\mathrm{h})=\mathrm{R}(1) * \mathrm{alfa} \wedge(\mathrm{h}-1)$;

$\mathrm{h}=\mathrm{h}+1$;

end 

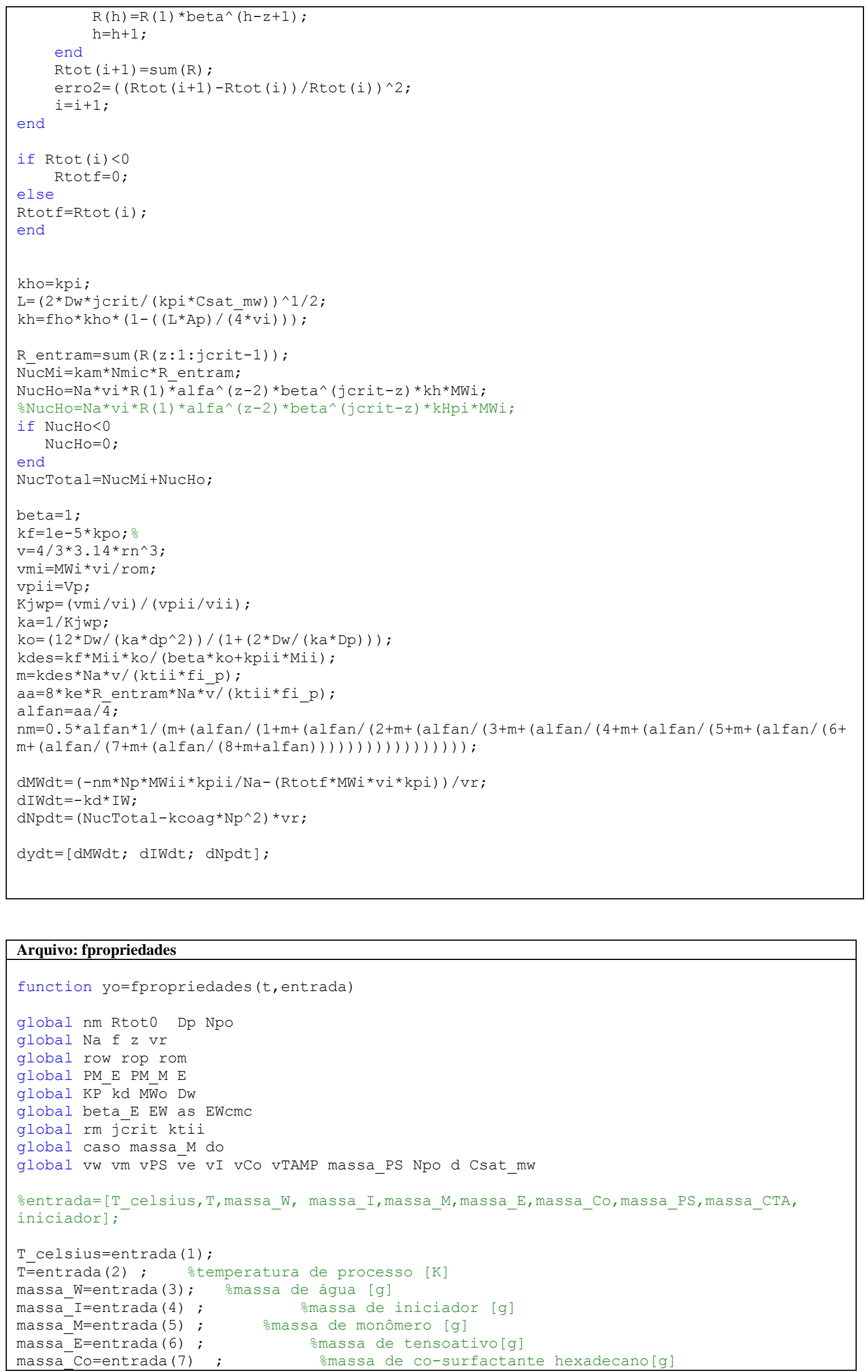


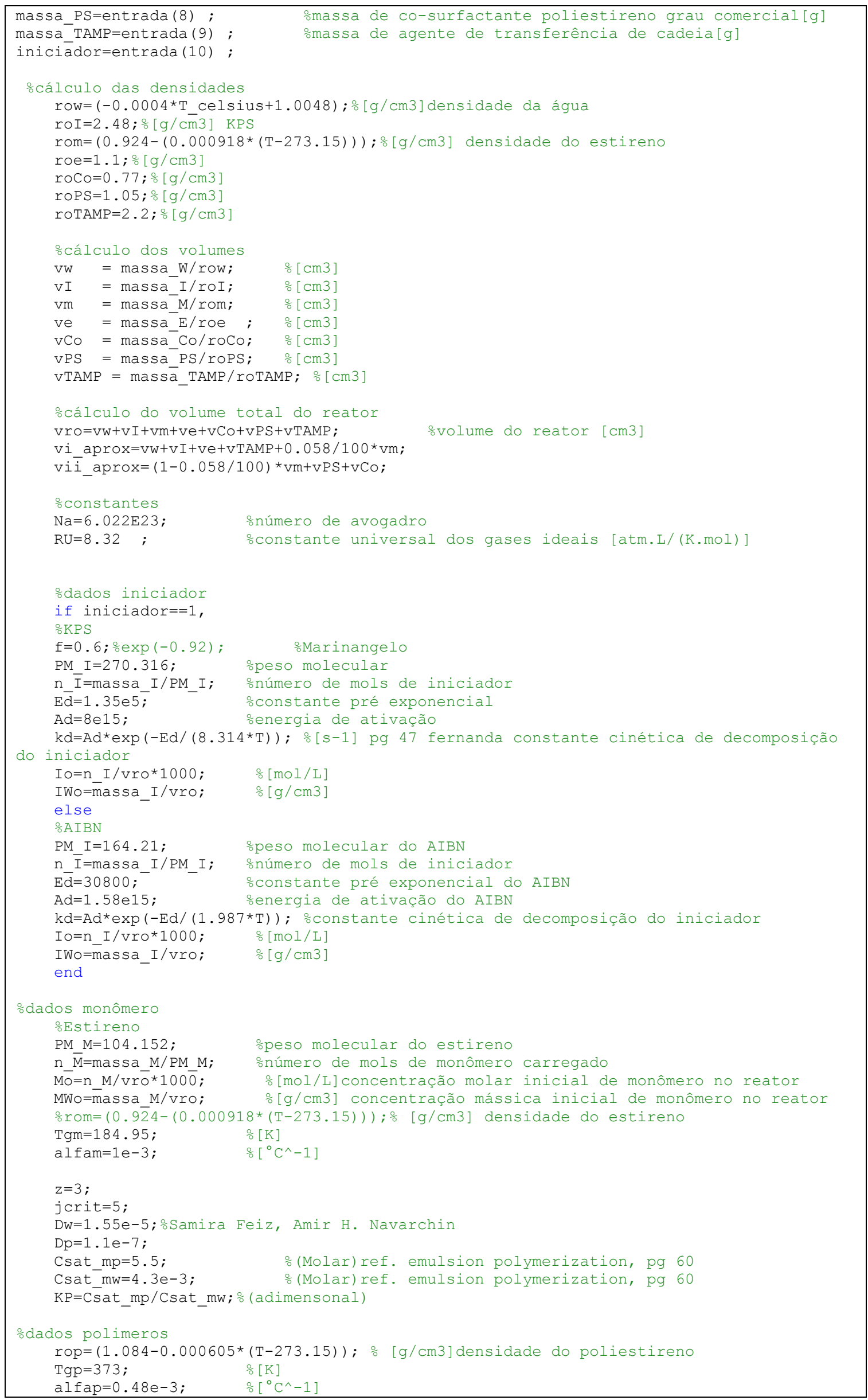



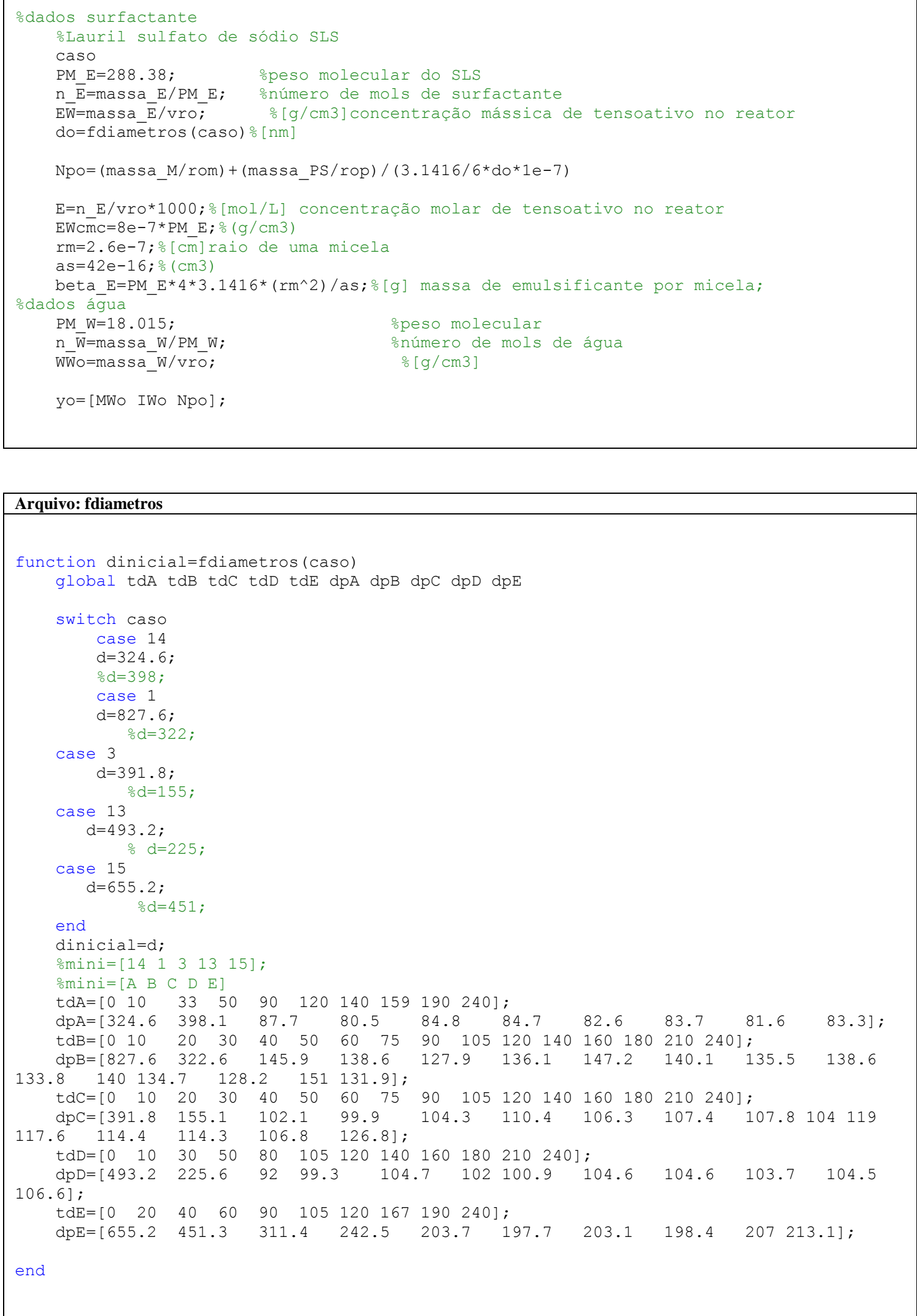


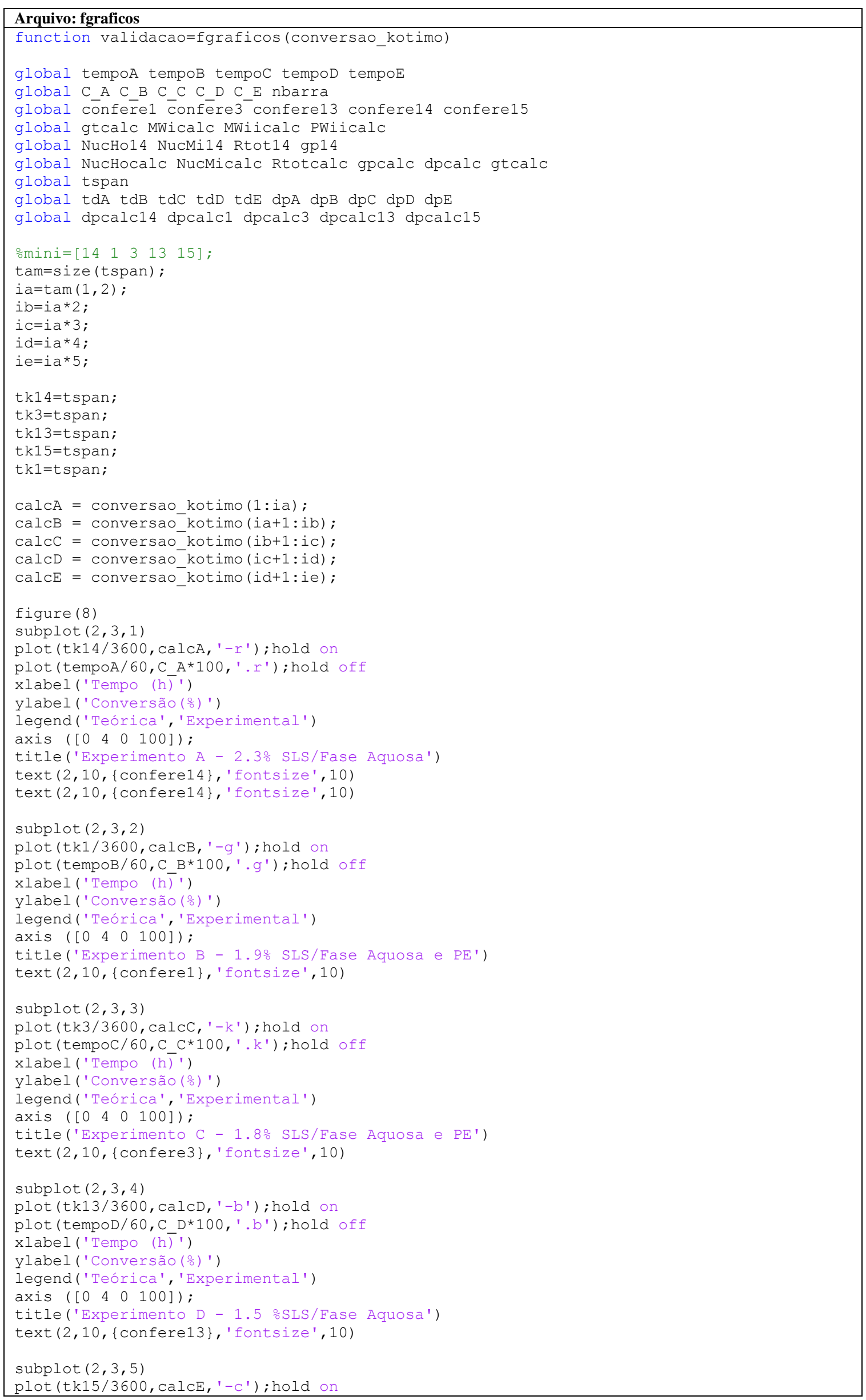


plot (tempoE/60,C $E^{\star} 100, '$. c'); hold off

xlabel ('Tempo (h)' ')

ylabel ('Conversão (\%) ')

legend ('Teórica', 'Experimental')

axis ([0 400 100]);

title('Experimento E - 0.7 \% SLS/Fase Aquosa')

text $(2,10,\{$ confere15\},'fontsize', 10)

figure (10)

plot (tk14/3600, calcA, '-r'); hold on

plot (tk1/3600, calcB,' $\left.-g^{\prime}\right)$; hold on

plot (tk3/3600, calcC, '-k'); hold on

plot (tk13/3600, calcD, '-b'); hold on

plot (tk15/3600, calcE,' '-C'); hold off

xlabel ('Tempo (h) ')

ylabel ('Conversão (\%) ')

legend('Experimento A - 2.3\% SLS/Fase Aquosa', 'Experimento B - 1.9\% SLS/Fase Aquosa e PE', 'Experimento C - 1.8\% SLS/Fase Aquosa e PE', 'Experimento D - 1.5 \% SLS/Fase Aquosa','Experimento E - 0.7 oSLS/Fase Aquosa')

axis $\left(\left[\begin{array}{llll}0 & 4 & 0 & 100\end{array}\right)\right.$;

title('Conversões Teóricas')

figure (11)

plot (tempoA/60, C A*100,'.r'); hold on

plot (tempoB/60, C B*100,' . $\mathrm{g}^{\prime}$ ) ; hold on

plot (tempoc/60, C_C*100,'. $\mathrm{k}^{-}$) ) ; hold on

plot (tempoD/60, C D*100,'.b'); hold on

plot (tempoE/60, C E*100,'.C'); hold off

xlabel ('Tempo $(\mathrm{h} \overline{)}$ ')

ylabel ('Conversão (\%) ')

legend('Experimento A - 2.3\% SLS/Fase Aquosa', 'Experimento B - 1.9\% SLS/Fase Aquosa e PE','Experimento C - 1.8\% SLS/Fase Aquosa e PE','Experimento D - 1.5 \% SLS/Fase

Aquosa', 'Experimento E - 0.7 \% SLS/Fase Aquosa')

axis ([ [ $\left.\begin{array}{llll}0 & 4 & 0 & 100\end{array}\right)$;

title('Conversões Experimentais')

figure (17)

subplot $(1,2,1)$

semilogy (tk14/3600, nbarra (1,1:1:ia), '-r'); hold on

semilogy (tk1/3600, nbarra (1,ia+1:1:ib), '-g'); hold on

semilogy (tk3/3600, nbarra (1,ib+1:1:ic), ' -k' ); hold on

semilogy (tk13/3600, nbarra (1, ict1:1:id), '-b' ); hold on

semilogy (tk15/3600, nbarra (1,id+1:1:ie), '-c'); hold off

xlabel ('Tempo (h) ')

ylabel ('nbarra')

legend('Experimento A - 2.3\% SLS/Fase Aquosa', 'Experimento B - 1.9\% SLS/Fase Aquosa e PE', 'Experimento C - 1.8\% SLS/Fase Aquosa e PE','Experimento D - $1.5 \%$ SLS/Fase Aquosa', 'Experimento E - 0.7 \%LL/Fase Aquosa')

title ('nbarra modelo')

subplot $(1,2,2)$

semilogy (calcA, nbarra (1,1:1:ia), '-r'); hold on

semilogy (calcB, nbarra (1,ia+1:1:ib), '-g'); hold on

semilogy (calcC, nbarra (1, ib+1:1:ic),'-k'); hold on

semilogy (calcD, nbarra (1, ict1:1:id), '-b'); hold on

semilogy (calcE, nbarra(1,id+1:1:ie), '-c') ; hold off

xlabel ('conversao')

ylabel ('nbarra')

legend('Experimento A - 2.3\% SLS/Fase Aquosa', 'Experimento B - 1.9\% SLS/Fase Aquosa e PE', 'Experimento C - 1.8\% SLS/Fase Aquosa e PE','Experimento D - 1.5 \% SLS/Fase

Aquosa', 'Experimento $\mathrm{E}-0.7$ \% SLS/Fase Aquosa')

title ('nbarra modeloxconversao')

figure (18)

subplot $(1,2,1)$

plot (tk14/3600, gtcalc (1,1:ia), '-r'); hold on

plot (tk1/3600, gtcalc (1,ia+1:ib), '-g'); hold on

plot (tk3/3600, gtcalc $\left.(1, i b+1: i c), '-k^{\prime}\right)$; hold on

plot (tk13/3600, gtcalc (1, ictl:id), '-b'); hold on

plot (tk15/3600, gtcalc(1,id+1:ie), '-c'); hold off

xlabel ('Tempo (h) ')

ylabel ('gt')

legend('Experimento A - 2.3\% SLS/Fase Aquosa', 'Experimento B - 1.9\% SLS/Fase Aquosa e PE', 'Experimento C - 1.8\% SLS/Fase Aquosa e PE', 'Experimento D - $1.5 \%$ SLS/Fase Aquosa', 'Experimento E - 0.7 ․ SLS/Fase Aquosa')

title('gt')

subplot $(1,2,2)$ 
plot (calcA, gtcalc $(1,1: i a),{ }^{\prime}$ r') $^{\prime}$ hold on

plot (calcB, gtcalc (1,iatl:ib), '-g'); hold on

plot (calcC, gtcalc (1, ib+1:ic), '-k'); hold on

plot (calcD, gtcalc (1,ict1:id), '-b'); hold on

plot (calcE, gtcalc (1,id+1:ie), '-c') ; hold off

xlabel ('conversao')

ylabel ('gt')

legend('Experimento A - 2.3\% SLS/Fase Aquosa', 'Experimento B - 1.9\% SLS/Fase Aquosa e PE', 'Experimento C - 1.8\% SLS/Fase Aquosa e PE', 'Experimento D - 1.5 \%SLS/Fase

Aquosa', 'Experimento E - 0.7 oLLS/Fase Aquosa')

title ('gtxconversao')

figure (19)

subplot $(1,3,1)$

plot (tk14/3600, MWicalc (1,1:ia), '-r'); hold on

plot (tk1/3600, MWicalc (1, iat1:ib), '-g'); hold on

plot (tk3/3600, MWicalc (1,ib+1:ic), '-k'); hold on

plot (tk13/3600, MWicalc(1,ic+1:id), '-b'); hold on

plot (tk15/3600, MWicalc(1,id+1:ie), '-c') ; hold off

xlabel ('Tempo (h) ')

ylabel ( 'MWi')

legend('Experimento A - 2.3\% SLS/Fase Aquosa', 'Experimento B - 1.9\% SLS/Fase Aquosa e PE', 'Experimento C - 1.8\% SLS/Fase Aquosa e PE','Experimento D - 1.5 \% SLS/Fase

Aquosa', 'Experimento E - 0.7 oSLS/Fase Aquosa')

title('MWi calc')

subplot $(1,3,2)$

plot (tk14/3600, MWiicalc (1,1:ia), '-r'); hold on

plot (tk1/3600, MWiicalc (1,ia+1:ib),' '-g'); hold on

plot (tk3/3600, MWiicalc $\left.(1, i b+1: i c), '-k^{\prime}\right)$; hold on

plot (tk13/3600, MWiicalc(1, ict1:id),'-b'); hold on

plot (tk15/3600, MWiicalc(1,id+1:ie), '-c'); hold off

xlabel ('Tempo (h) ')

ylabel ('MWii')

legend('Experimento A - 2.3\% SLS/Fase Aquosa', 'Experimento B - 1.9\% SLS/Ease Aquosa e PE', 'Experimento C - 1.8\% SLS/Fase Aquosa e PE','Experimento D - 1.5 ․SLS/Fase

Aquosa', 'Experimento E - $0.7 \%$ SLS/Fase Aquosa')

title ('MWii calc')

subplot $(1,3,3)$

plot (tk14/3600,PWiicalc(1,1:ia), '-r'); hold on

plot (tk1/3600, PWiicalc (1,ia+1:ib), '-g'); hold on

plot (tk3/3600, PWiicalc(1,ib+1:ic), '-k'); hold on

plot (tk13/3600, PWiicalc (1, ict1:id), '-b'); hold on

plot (tk15/3600, PWiicalc(1,id+1:ie), '-c') ; hold off

xlabel ('Tempo (h) ')

ylabel ('PWii')

legend('Experimento A - 2.3\% SLS/Fase Aquosa', 'Experimento B - 1.9\% SLS/Fase Aquosa e PE', 'Experimento C - 1.8\% SLS/Fase Aquosa e PE','Experimento D - $1.5 \%$ SLS/Fase

Aquosa', 'Experimento E - 0.7 \%SLS/Fase Aquosa')

title('PWii calc')

figure $(20)$

subplot $(2,2,1)$

semilogy (tk14/3600, NucHocalc(1,1:ia), '-r'); hold on

semilogy (tk1/3600, NucHocalc (1,ia+1:ib), ' $\left.-g^{\prime}\right)$; hold on

semilogy (tk3/3600, NucHocalc (1,ib+1:ic), '-k'); hold on

semilogy (tk13/3600, NucHocalc (1,ict1:id), '-b'); hold on

semilogy (tk15/3600, NucHocalc(1,id+1:ie), '-c'); hold off

legend('Experimento A - 2.3\% SLS/Fase Aquosa', 'Experimento B - 1.9\% SLS/Fase Aquosa e PE', 'Experimento C - 1.8\% SLS/Fase Aquosa e PE','Experimento D - 1.5 \%SLS/Fase

Aquosa', 'Experimento E - 0.7 oSLS/Fase Aquosa')

xlabel ('Tempo (h)')

ylabel ('Nucleação Homogênea')

subplot $(2,2,2)$

plot (tk14/3600, NucMicalc (1,1:ia), '-r'); hold on

plot (tk1/3600, NucMicalc (1,iatl:ib), '-g'); hold on

plot (tk3/3600, NucMicalc (1,ib+1:ic),' -k'); hold on

plot (tk13/3600, NucMicalc (1,ic+1:id), '-b'); hold on

plot (tk15/3600, NucMicalc (1,id+1:ie), '-c') ; hold off

xlabel ('Tempo (h) ')

ylabel ('Nucleação Micelar')

legend('Experimento A - 2.3\% SLS/Fase Aquosa', 'Experimento B - 1.9\% SLS/Fase Aquosa e

PE', 'Experimento C - 1.8\% SLS/Fase Aquosa e PE','Experimento D - $1.5 \%$ SLS/Fase

Aquosa', 'Experimento E - 0.7 \% SLS/Fase Aquosa') 
semilogy (tk14/3600, Rtotcalc(1,1:ia),'-r'); hold on

semilogy (tk1/3600, Rtotcalc (1,ia+1:ib), '-g'); hold on

semilogy (tk3/3600, Rtotcalc (1,ib+1:ic),'-k'); hold on

semilogy (tk13/3600, Rtotcalc(1,ic+1:id),' -b') ; hold on

semilogy (tk15/3600, Rtotcalc(1,id+1:ie), '-c'); hold off

xlabel ('Tempo (h)')

ylabel ('Rtot')

legend('Experimento A - 2.3\% SLS/Fase Aquosa', 'Experimento B - 1.9\% SLS/Fase Aquosa e

PE', 'Experimento C - 1.8\% SLS/Fase Aquosa e PE','Experimento D - 1.5 \%SLS/Fase

Aquosa', 'Experimento E - 0.7 ㄴ SL/Fase Aquosa')

subplot $(2,2,4)$

plot (tk14/3600, gpcalc (1,1:ia), '-r'); hold on

plot (tk1/3600, gpcalc (1,ia+1:ib),' -g'); hold on

plot (tk3/3600, gpcalc $(1, i b+1: i c), '-k ')$; hold on

plot (tk13/3600, gpcalc (1,ict1:id), '-b'); hold on

plot (tk15/3600, gpcalc(1,id+1:ie), '-c'); hold off

xlabel ('Tempo (h) ')

ylabel ('gp')

legend('Experimento A - 2.3\% SLS/Fase Aquosa', 'Experimento B - 1.9\% SLS/Fase Aquosa e

$\mathrm{PE}$ ', 'Experimento C - 1.8\% SLS/Fase Aquosa e PE', 'Experimento D - $1.5 \% \mathrm{SLS} / \mathrm{Fase}$

Aquosa', 'Experimento E - 0.7 \%SLS/Fase Aquosa')

figure (21)

plot (tk14/3600, dpcalc14*1e7,' '-r'); hold on

plot (tk1/3600, dpcalc1*1e7, '-g'); hold on

plot (tk3/3600, dpcalc3*1e7,'-k'); hold on

plot (tk13/3600, dpcalc13*1e7,' -b'); hold on

plot (tk15/3600, dpcalc15*1e7,' - c' $\left.^{\prime}\right)$; hold on

plot (tdA/60, dpA, '*r'); hold on

plot (tdB/60, dpB, '*g'); hold on

plot (tdc/60, dpc, '*k') ; hold on

plot (tdD/60, dpD, '* b') ; hold on

plot (tdE/60, dpE, ' $\left.{ }^{*} c^{\prime}\right)$; hold off

xlabel ('Tempo (h) ')

ylabel ('dp ( $\mathrm{nm}$ )')

legend('Modelo A', 'Modelo B', 'Modelo C', 'Modelo D', 'Modelo E', 'Exp A', 'Exp B', 'Exp

$\left.C^{\prime}, ' \operatorname{Exp} D^{\prime}, ' \operatorname{Exp} E^{\prime}\right)$

figure (22)

subplot $(2,3,1)$

plot (tk14/3600, dpcalc14*1e7, '-r'); hold on

plot (tdA/60, dpA, '*r'); hold off

xlabel ('Tempo (h) ')

ylabel ('Dp (nm)')

legend('Teórica', 'Experimental')

title('Experimento A - 2.3\% SLS/Fase Aquosa')

subplot $(2,3,2)$

plot (tk1/3600, dpcalc1*1e7,' -g') ; hold on

plot (tdB/60, dpB, '*g'); hold off

xlabel ('Tempo (h) ')

ylabel ('Dp ( $\mathrm{nm}$ ) ')

legend('Teórica', 'Experimental')

title('Experimento B - $1.9 \%$ SLS/Fase Aquosa e PE')

subplot $(2,3,3)$

plot (tk3/3600, dpcalc3*1e7,'-k') ; hold on

plot (tdC/60, dpC, '*k'); hold off

xlabel ('Tempo (h)')

ylabel ('Dp (nm)')

legend('Teórica', 'Experimental')

title('Experimento C - $1.8 \% \mathrm{SLS} / \mathrm{Fase}$ Aquosa e PE')

subplot $(2,3,4)$

plot (tk13/3600, dpcalc13*1e7, '-b'); hold on

plot (tdD/60, dpD, '* $\left.\mathrm{b}^{\prime}\right)$; hold off

xlabel ('Tempo (h) ')

ylabel ('Dp (nm)')

legend('Teórica', 'Experimental')

title('Experimento D - $1.5 \%$ SLS/Fase Aquosa') 
plot (tk15/3600, dpcalc15*1e7, '-c'); hold on

plot ( tdE/60, dpE, '* $\left.{ }^{\prime}{ }^{\prime}\right)$; hold off

xlabel ('Tempo (h) ')

ylabel ('Dp (nm)')

legend('Teórica', 'Experimental')

title('Experimento E - 0.7 \%LS/Fase Aquosa')

validacao=' ok' ;

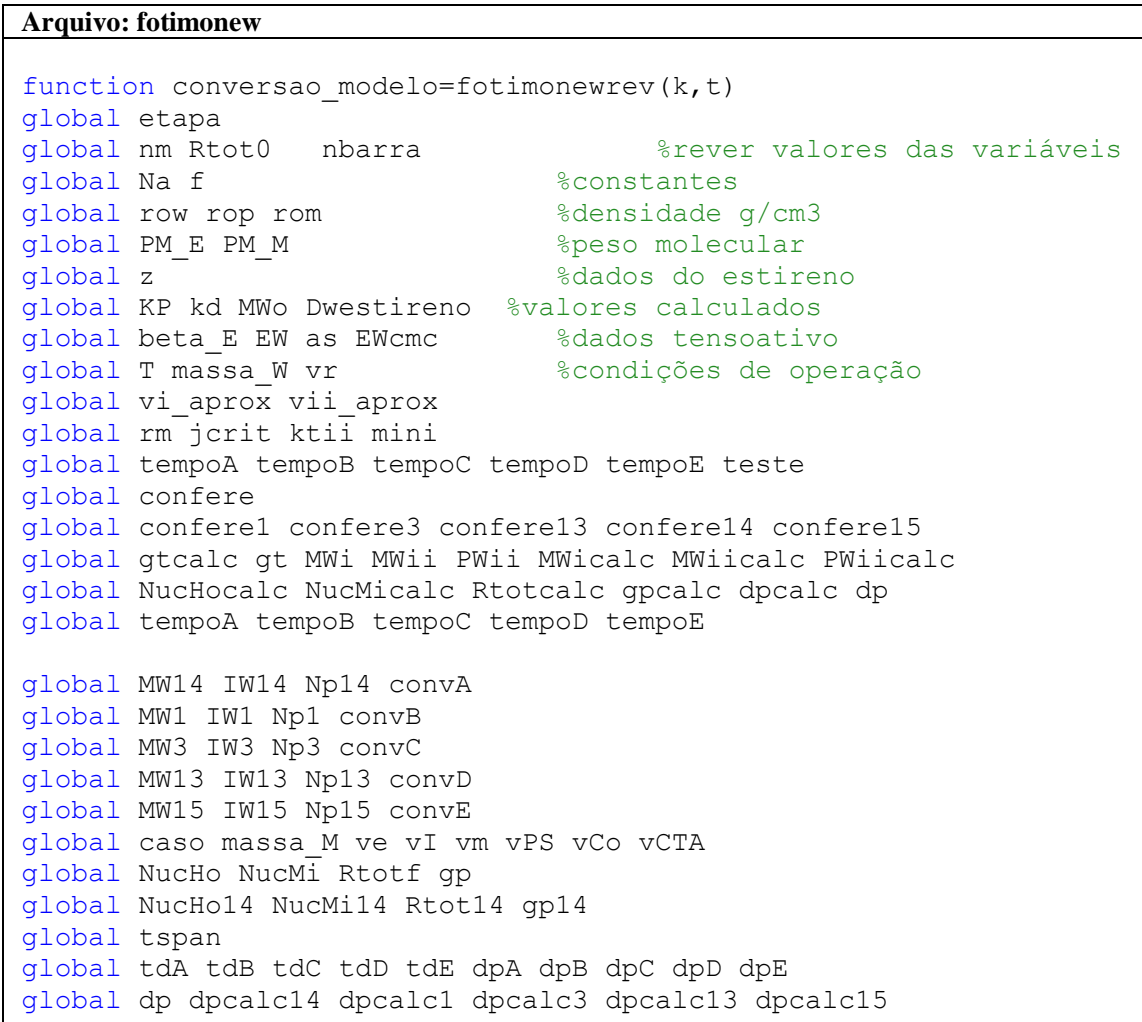

ocondições de operação utilizadas em cada batelada

$\operatorname{mini}=\left[\begin{array}{lllll}14 & 1 & 3 & 13 & 15\end{array}\right]$

mini_i=1;

ot $=0: 10: 14400 ;$ ototal de 4 horas de reação

\%Condições iniciais das Equações diferenciais

for mini_i=1:1:5

caso=mini (1,mini_i) ;

switch caso

case 14

clear vr vi vii Np massa M massa PS

-Dados da Minitur 14 ou A

T_celsius $=70 ; \quad$ otemperatura do reator $\left[{ }^{\circ} \mathrm{C}\right]$

$\mathrm{T}=\mathrm{T}$ celsius+273.15; otemperatura de processo [K]

massa $W=154.99+3.343 ; \quad$ omassa de água [g]

massa_I=0.126; omassa de iniciador [g]

massa $\mathrm{M}=36.411$; $\quad$ massa de monômero [g]

massa_E=0.86; $\quad$ omassa de tensoativo[g]

massa $\mathrm{Co}=1.5$

massa $\mathrm{PS}=0.0$;

massa_TAMP $=0.025$;

iniciādor $=1$;

teste $=$ caso;

entrada $=\left[T_{\text {_celsius, }}\right.$ T, massa_W,

massa I, massa $\bar{M}$, massa $E$, massa $\bar{C}_{\overline{0}}$, massa PS, massa TAMP, iniciador]. 
tamanho14=size (tspan);

y140=fpropriedades $(0$, entrada);

teste $=$ ' casoA'

\%integração das Equações diferenciais

[tk14,y14] =ode23 (efintegracao, tspan, y14o, [],k, caso) ;

for $i=2:$ size $(t k 14)$

dydt=fintegracao (tk14 (i),y14(i, :), k, caso) ;

nbarra14 (i) =nm;

gt14 (i) =gt :

MWi14 (i) $=$ MWi

MWii14(i)=MWii;

PWiil4(i)=PWii;

NucHo14 (i) =NucHo;

NucMi14 (i) $=$ NuCMi

Rtot14 (i) =Rtotf ;

gp14 $(i)=g p$;

dpcalc14(i) =dp;

end

$\operatorname{MW14}=\mathrm{y} 14(:, 1)$;

$\operatorname{IW1} 4=\mathrm{y} 14(:, 2)$;

$\operatorname{Np} 14=y 14(:, 3)$

$\operatorname{convA}=((1-(\operatorname{MW1} 14 . / \operatorname{MW1} 1(1,1))) * 100)$;

figure (1)

tk14=tk14/3600;

subplot $(1,3,1)$

plot (tk14,y14(:,1),'-r'); hold on;

title('Exp A - 2.3\% mSLS/mfase dispersa')

xlabel ('Tempo (h) ')

ylabel ('Concentração ( $\mathrm{g} / \mathrm{cm} 3)$ ')

legend ('Estireno')

axis ( [ $\left.\left.\begin{array}{llll}0 & 4 & 0 & 1\end{array}\right]\right)$;

subplot $(1,3,2)$

plot (tk14,y14 (:,2),'-r'); hold on;

xlabel ('Tempo (h)')

ylabel ('Concentração ( $\left.\mathrm{g} / \mathrm{cm} 3)^{\prime}\right)$ )

legend ('Iniciador')

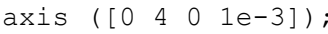

subplot $(1,3,3)$

plot (tk14,y14 (:,3),'-r'); hold on;

xlabel ('Tempo (h)')

ylabel('n' total de partículas poliméricas') $\operatorname{axis}\left(\left[\begin{array}{llll}0 & 4 & 1 e 16 & 2 e 17\end{array}\right]\right)$;

case 1

clear vr vi vii Np massa_M massa_PS

-Dados da Minitur 01 ou B

T celsius $=70$; $\quad$ omperatura do reator $\left[{ }^{\circ} \mathrm{C}\right]$

$\mathrm{T}=\mathrm{T}$ _celsius+273.15; otemperatura de processo [K]

massa $W=150.02+2.9796 ;$ omassa de água [g]

massa_I=0.1084; 前asa de iniciador [g]

massa_M=35.5608; $\quad$ omassa de monômero [g]

massa $\mathrm{E}=0.71 ; \quad$; massa de tensoativo[g]

massa_Co=1.406; omassa de co-surfactante hexadecano[g]

massa $\mathrm{PS}=0.358$;

massa ${ }^{-}$TAMP $=0.0162$;

omassa de co-surfactante poliestireno grau comercial[g]

omassa de agente de transferência de cadeia[g]

iniciādor $=1$

oniciador: $1=\operatorname{KPS} 2=\mathrm{AIBN}$

teste $=$ caso

entrada $=\left[\mathrm{T} \_\right.$celsius, $T$, massa_W,

massa I, massa $\bar{M}$, massa E, massa Co, massa PS, massa TAMP, iniciador] ;

y'o=fpropriedades $(0$, entrada $) ;$

ointegração das Equações diferenciais

teste $=$ ' casoB'

$[\mathrm{tk} 1, \mathrm{y} 1]=0 \mathrm{de} 23$ ( (afintegracao, tspan, y1o, [], k, caso);

for $i=2$ : size (tk 1$)$

dydt=fintegracao(tk1 (i), yl (i, : ), k, caso) 
nbarral (i) $=\mathrm{nm}$;

gt 1 ( $i)=g t$;

$\operatorname{MWi} 1$ ( $i)=M W i$;

MWiil $(i)=M W i i$;

PWiil (i)=PWii;

$\mathrm{NucHol}(i)=\mathrm{NucHo}$;

$\operatorname{NucMi} 1$ (i) =NucMi ;

Rtot1 (i)=Rtotf;

gpl (i) =gp;

dpcalc1 $(i)=d p$;

end

size (y1);

linhas=ans $(1)$;

$\operatorname{MW} 1=\mathrm{y} 1(:, 1)$

$\operatorname{IW} 1=\mathrm{y} 1(:, 2)$;

$\mathrm{Np} 1=\mathrm{y} 1(:, 3)$;

$\operatorname{convB}=((1-(\operatorname{MW1} . / \operatorname{MW} 1(1,1))) * 100)$;

confere $1=$ confere;

$\mathrm{tk} 1=\mathrm{tk} 1 / 3600$

subplot $(1,3,1)$;

plot (tk1, y1 $(:, 1)$, ' $^{\prime}$ ) ; hold on;

title('Exp B - 1.9\% $\mathrm{mSLS} / \mathrm{mfase}$ dispersa')

xlabel ('Tempo (h) ')

ylabel ('Concentração ( $\mathrm{g} / \mathrm{cm} 3)^{\prime}$ ')

legend('Estireno')

axis ([ [ $\left.\left.\begin{array}{llll}0 & 4 & 0 & 1\end{array}\right]\right)$;

subplot $(1,3,2)$

plot (tk1,yl $\left.(:, 2),{ }^{\prime}-g^{\prime}\right)$; hold on:

xlabel ('Tempo (h) ')

ylabel ('Concentração $(\mathrm{g} / \mathrm{cm} 3)$ ')

legend ('Iniciador')

axis ( [ $\left.\left[\begin{array}{llll}0 & 4 & 0 & 1 e-3\end{array}\right]\right)$;

subplot $(1,3,3)$

plot (tk1, y1 $\left.(:, 3),{ }^{\prime}-g^{\prime}\right)$; hold on;

xlabel ('Tempo (h)')

ylabel ('n' total de partículas poliméricas') axis ( [ $\left.\begin{array}{lllll}0 & 4 & 5 e 16 & 2 e 17\end{array}\right)$;

case 3

clear vr vi vii Np massa_M massa_PS

-Dados da Minitur 03 ou C

$\mathrm{T}$ celsius $=70 ; \quad$ omperatura do reator $\left[{ }^{\circ} \mathrm{C}\right]$

$\mathrm{T}=\mathrm{T}$ _celsius+273.15; otemperatura de processo [K]

massa $W=155.89+3.1993$; omassa de água [g]

massa_I=0.109; omassa de iniciador [g]

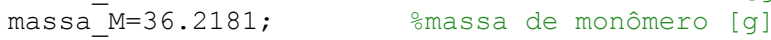

massa $\mathrm{E}=0.7 ; \quad$ omassa de tensoativo[g]

massa_Co=1.4; $\quad$ omassa de co-surfactante hexadecano[g]

massa_PS=0.438; omassa de co-surfactante poliestireno grau comercial[g]

massa TAMP $=0.0262 ; \quad$ omassa de agente de transferência de cadeia[g]

iniciādor=1; $\quad$ oiniciador: $1=\operatorname{KPS} 2=\mathrm{AIBN}$

teste $=$ caso:

entrada $=\left[\mathrm{T} \_\right.$celsius, $T$, massa_W,

massa_I, massa_M, massa_E, massa_Co,massa_PS,massa_TAMP, iniciador] ;

y $\overline{3} 0=$ fpropriedades $(0$, entrada);

:integração das Equações diferenciais

teste=' ${ }^{\prime}$ casoc'

[tk3, y3] =ode23 ( afintegracao, tspan, y3o, [ ], k, caso) ;

for $i=2:$ size (tk3)

dydt=fintegracao(tk3 (i), y3 (i, : ), k, caso) ;

nbarra3 $(i)=\mathrm{nm}$;

gt $3(i)=g t$;

$\operatorname{MWi} 3(i)=M W i$;

$\operatorname{MWi} 3(i)=\operatorname{MWi} i$

PWii3 $(i)=$ PWii

$\mathrm{NucHo} 3(i)=\mathrm{NucHo}$;

$\operatorname{NucMi} 3(i)=N u c M i$ 
Rtot3 (i) =Rtotf ;

gp3 $(i)=$ gp ;

dpcalc3 $(i)=d p$

end

$\operatorname{MW} 3=\mathrm{y} 3(:, 1) ;$

$\operatorname{IW} 3=\mathrm{y} 3(:, 2)$;

$\operatorname{Np} 3=y 3(:, 3) ;$

$\operatorname{convC}=((1-(\operatorname{MW} 3 . / \operatorname{MW} 3(1,1))) * 100)$;

confere $3=$ confere

ofigure (3)

$\operatorname{tk} 3=\mathrm{tk} 3 / 3600$

subplot $(1,3,1)$

plot (tk3,y3(:,1),'-k'); hold on;

title('Exp C - 1.8\% $\mathrm{mSLS} / \mathrm{mfase}$ dispersa')

xlabel ('Tempo (h)')

ylabel ('Concentração ( $\mathrm{g} / \mathrm{cm} 3)$ ')

legend ('Estireno')

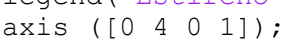

subplot $(1,3,2)$

plot (tk3,y3 $\left.(:, 2),{ }^{\prime}-k^{\prime}\right)$; hold on;

xlabel ('Tempo (h)')

ylabel ('Concentração $(\mathrm{g} / \mathrm{cm} 3)$ ')

legend ('Iniciador')

axis ([0 $\left.\left.\begin{array}{llll}0 & 4 & 0 & 1 e-3\end{array}\right]\right)$;

subplot $(1,3,3)$

plot (tk3,y3 $\left.(:, 3),{ }^{\prime}-k^{\prime}\right)$; hold on;

xlabel ('Tempo (h)')

ylabel ('nº total de partículas poliméricas')

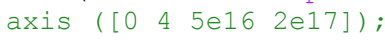

case 13

clear vr vi vii Np massa_M massa_PS

-Dados da Minitur 13 ou D

T_celsius $=70 ; \quad$ oTemperatura do reator $\left[{ }^{\circ} \mathrm{C}\right]$

$\mathrm{T}=\mathrm{T}$ celsius+273.15; $\quad$ temperatura de processo [K]

massa $W=160.12+3.3529$; omassa de água [g]

massa_I=0.1162; omassa de iniciador [g]

massa M=36.2348; Omassa de monômero [g]

massa $\mathrm{E}=0.57$

massa_Co $=1.402$;

massa $\mathrm{PS}=0.0$;

omassa de tensoativo[g]

omassa de co-surfactante hexadecano[g]

massa ${ }^{-}$TAMP $=0.0273$;

iniciāor $=1$;

-massa de co-surfactante poliestireno grau comercial[g]

omassa de agente de transferência de cadeia[g]

teste=caso;

entrada $=[\mathrm{T}$ Celsius, $T$, massa_W,

massa I, massa M, massa E, massa Co, massa PS, massa TAMP, iniciador]

y'̄ $30=$ fpropriedade $\bar{s}(0$, entrāda);

ointegração das Equações diferenciais

teste $={ }^{\prime}$ casoD ${ }^{\prime}$

$[$ tk13,y13] =ode23 ( @fintegracao, tspan, y13o, [] , k, caso) ;

for $i=2$ : size (tk13)

dydt=fintegracao (tk13 (i), y13 (i, : ), k, caso):

nbarra13 $(i)=n m$;

gt13 (i) = gt ;

$\operatorname{MWi13}(i)=\mathrm{MWi}$

$\operatorname{MWi} 13(i)=M W i$;

$\operatorname{PWii13}(i)=$ PWii;

$\mathrm{NucHo} 13$ (i) $=\mathrm{NuCHO}$

$\operatorname{NucMi13}(i)=$ NucMi;

Rtot13 (i)=Rtotf ;

gp13 (i) = gp ;

dpcalc13(i)=dp;

end

size (y13);

linhas=ans (1);

MW13=y13 $(:, 1)$;

$\operatorname{IW13}=\mathrm{y} 13(:, 2)$;

$\operatorname{Np} 13=y 13(:, 3)$; 


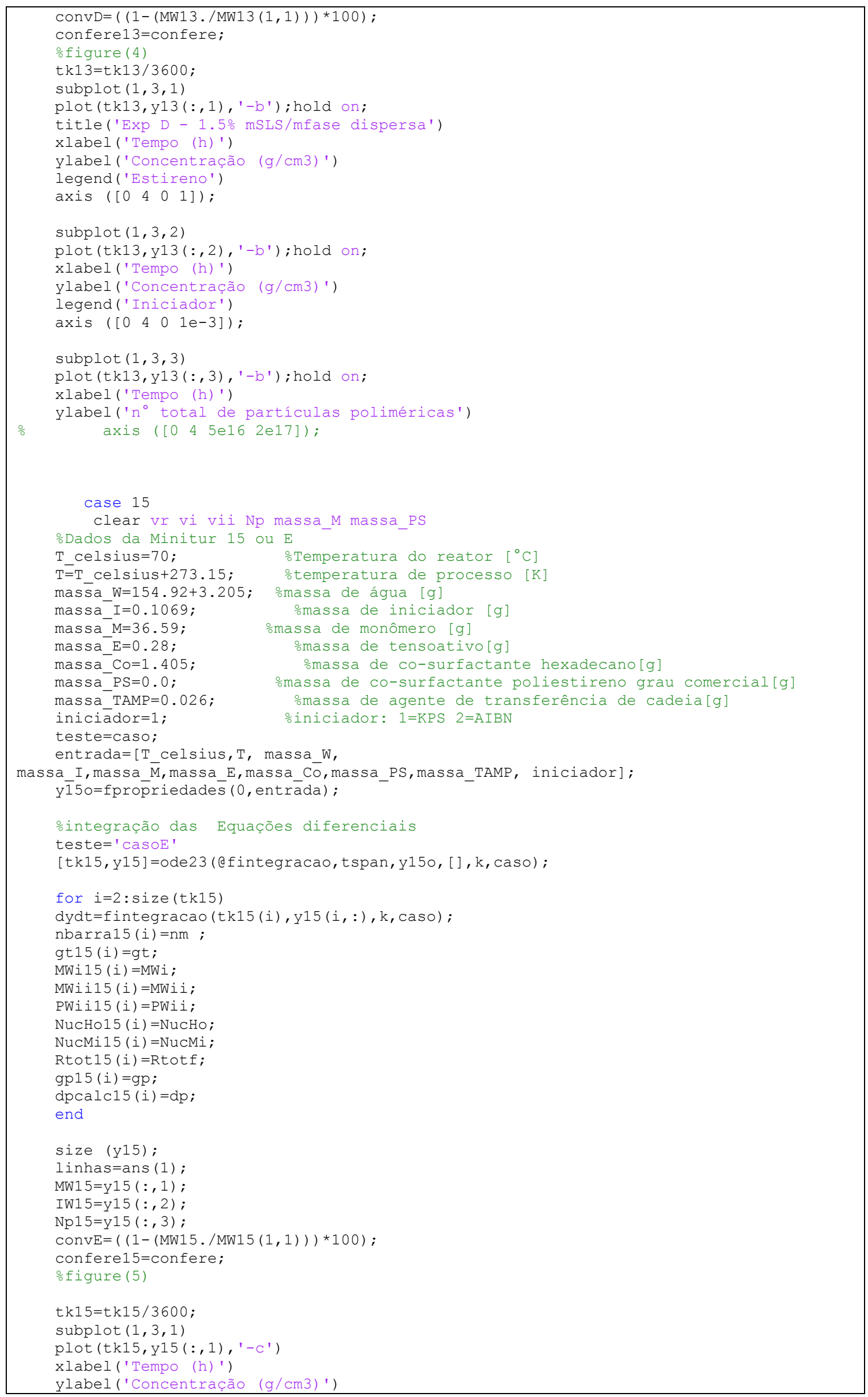




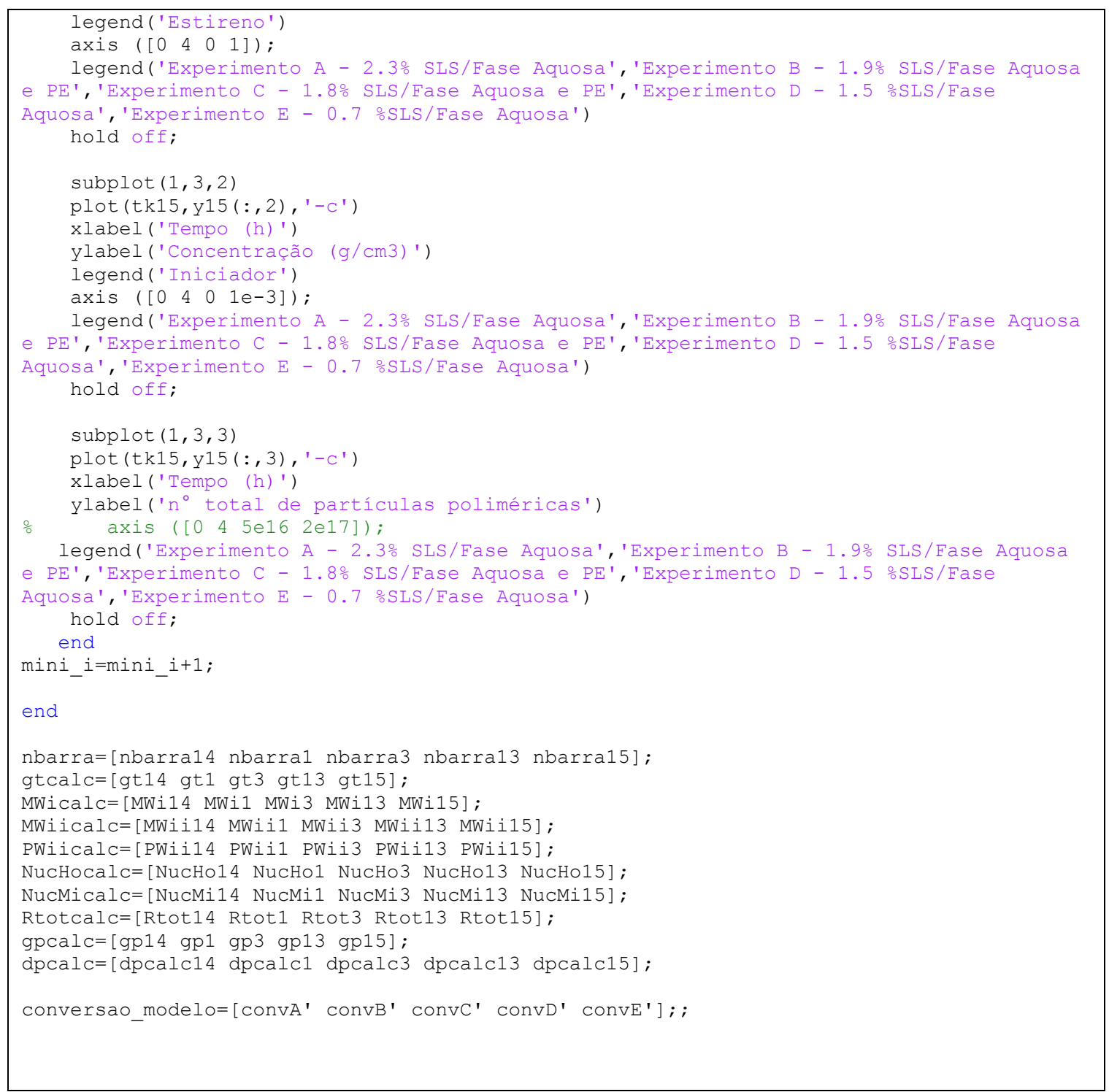

